\title{
Development of Whole-Building
}

Energy Design Targets for

Commercial Buildings

Phase 1 Planning

Volume 2: Technical Report

D. B. Crawley

J. E. Kaufman

R. S. Briggs

J. J. Deringer

J. W. Jones

E. W. Kennett

W. W. Seaton

August 1987

Prepared for the U.S. Department of Energy under Contract DE-AC06-76RLO 1830

Pacific Northwest Laboratory

Operated for the U.S. Department of Energy by Battelle Memorial Institute 


\section{DISCLAIMER}

This report was prepared as an account of work sponsored by an agency of the United States Government. Neither the United States Government nor any agency thereof, nor Battelle Memorial Institute, nor any of their employees, makes any warranty, expressed or implied, or assumes any legal liability or responsibility for the accuracy, completeness, or usefulness of any information, apparatus, product, or process disclosed, or represents that its use would not infringe privately owned rights. Reference herein to any specific commercial product, process, or service by trade name, trademark, manufacturer, or otherwise, does not necessarily constitute or imply its endorsement, recommendation, or favoring by the United States Government of any agency thereof, or Battelle Memorial Institute. The views and opinions of authors expressed herein do not necessarly state or reflect those of the United States Government or any agency thereof, or Battelle Memorial Institute.

\section{PACIFIC NORTHWEST LABORATORY operated by BATTELLE MEMORIAL INSTITUTE for the UNITED STATES DEPARTMENT OF ENERGY under Contract DE-AC06-76RLO 1830}

\begin{tabular}{|c|c|}
\hline \multicolumn{2}{|c|}{ Printed in the United States of America } \\
\hline \multicolumn{2}{|c|}{$\begin{array}{c}\text { Available from } \\
\text { Avation }\end{array}$} \\
\hline \multirow{3}{*}{\multicolumn{2}{|c|}{$\begin{array}{c}\text { National Technical Information Service } \\
\text { United States Department of Commerce } \\
5285 \text { Port Royal Road } \\
\text { Springfield, Virginia } 22161\end{array}$}} \\
\hline & \\
\hline & \\
\hline \multirow{2}{*}{\multicolumn{2}{|c|}{$\begin{array}{l}\text { NTIS Price Codes } \\
\text { Microfiche A01 }\end{array}$}} \\
\hline & \\
\hline \multicolumn{2}{|c|}{ Printed Copy } \\
\hline & Price \\
\hline Pages & Codes \\
\hline $001-025$ & $\mathrm{~A} 02$ \\
\hline $026-050$ & A03 \\
\hline $051-075$ & $\mathrm{~A} 04$ \\
\hline 076.100 & A05 \\
\hline $101-125$ & $A 06$ \\
\hline $126-150$ & A07 \\
\hline $151-175$ & $\mathrm{~A} 08$ \\
\hline $176-200$ & $\mathrm{~A} 09$ \\
\hline $201-225$ & AD10 \\
\hline $226-250$ & $\mathrm{~A} 011$ \\
\hline $251-275$ & $\mathrm{~A} 012$ \\
\hline 276.300 & $\mathrm{~A} 013$ \\
\hline
\end{tabular}


DEVELOPMENT OF WHOLE-BUILDING ENERGY DESIGN

TARGETS FOR COMMERCIAL BUILDINGS--

PHASE 1 PLANNING

VOLUME 2: TECHNICAL REPORT

D. B. Crawley

R. S. Briggs

Pacific Northwest Laboratory

J. W. Jones

W. W. Seat on American Society of Heating, Refrigerating, and Air Conditioning Engineers, Inc.

J. E. Kaufman

Illuminating Engineers Society of North America

J. J. Deringer

E. W. Kennett American Institute of Architects Foundation

August 1987

Prepared for the U.S. Department of Energy under Contract DE-AC06-76RLO 1830

Pacific Northwest Laboratory

Richland, Washington 99352 
$\because 4$ 
FOREWORD

This report is one in a series of reports describing research activities in support of the Department of Energy (DOE). Commercial Building Systems Integration Research Program. The goal of the program is to develop the scientific and technical basis for improving integrated decision making during design and construction. Improved decision making could reduce buildings" energy use $40 \%$ to $60 \%$ by the year 2010 .

The objectives of the Commercial Building Systems Integration Research Program are to

- identify and quantify the most significant energy-related interactions among building subsystens [for example, walls; roofs; windows; heating, ventilation, and air conditioning (HVAC) systems and equipment; Tighting; power; etc.]

- develop the scientific and technical basis for improving energyrelated interactions in building subsystems

- provide guidance to designers, owners, and builders for improving the integration of building subsystems for energy efficiency.

This report describes background research for preparing a plan for developing whole-building energy targets for new commercial buildings. The lead laboratory for this program is the Pacific Northwest Laboratory. A wide variety of expertise and resources from industry, academia, other government entities, and other DOE laboratories are used in planning, reviewing, and conducting research activities. Cooperative and complementary research, development, and technology transfer activities with other interested organizations are actively pursued.

Comments about the work described in this report will be appreciated by the authors or program managers. The research reports prepared for the program are in a bibliographic list at the back of this report.

Drury B. Crawley, Program Manager Building Systems Integration Pacific Northwest Laboratory
Jean J. Boulin, Group Leader Architectural and Engineering Systems Building Systems Division U.S. Department of Energy 



\section{SUMMARY}

This is the second volume of the Phase 1 report and discusses the 10 tasks performed in Phase 1. The objective of of this research is to develop a methodology for setting energy design targets to provide voluntary guidelines for the buildings industry. The whole-building energy targets project is being conducted at the Pacific Northwest Laboratory (PNL)(a) for the U.S. Department of Energy (DOE) to encourage the construction of energy-efficient buildings by informing designers and owners about cost-effective goals for energy use in new commercial buildings. The outcome of this research will be a flexible methodology for setting such targets.

The tasks are listed and discussed in this report as follows:

- Task 1--Develop Detailed Project Goals and Objectives

- Task 2--Establish Bujldings-Industry Liaison

- Task 3--Develop Approaches to the Energy Targets Mode1, Building Operations, and Climate

- Task 4--Develop an Approach for Treating Economic Considerations

- Task 5--Develop an Approach for Treating Energy Sources

- Task 6--Collect Energy-Use Data

- Task 7--Survey Energy Expert Dpinion

- Task 8--Evaluation Procedure Specification and Integration

- Task 9--Phase 1 Report Development

- Task 10--Phase 1 Review Planning.

(a) The Pacific Northwest Laboratory is operated for the U.S. Department of Energy by Battelle Memorial Institute. 



\section{ACKNONLEDGMENTS}

The authors wish to thank all of the individuals and organizations who provided assistance and guidance by responding to survey questionnaires and by providing building data and coordinating with the project team. The authors wish to recognize the many contributions of the Technical Core Team members listed below:

American Society of Heating, Refrigerating, and Air Conditioning

Engineers, Inc.

Lynn G. Bellenger, P. E.

David L. Grumman, P. E.

Neil R. Patterson, P. E.

Illuminating Engineering Society of North America

Gilbert H. Reiling

J. W. White, P. E.

American Institute of Architects Foundation

Charles Eley, AIA

Harrison Fraker, AIA

Thomas Vonier, AIA

Recognition should also be made of the efforts of the subcontractor personnel: John Holton and Judy Klein of Burt Hill Kosar Rittelmann Associates; and Bruce Hunn, John Peterson, and Scott Silver of the University of Texas Center for Energy Studies.

Appreciation is also expressed to Richard Kutina of the American Gas Association and Michael McGrath of the Edison Electric Institute for their counsel, and to Ted Kurkowsk $i$ and Jean Boulin of the U. S. Department of Energy for their support. 



\section{CONTENTS}

FOREWORD

SUMMARY

ACKNOWLEDGMENTS

1.0 PHASE 1 PLANNING

1.1 TASK 1--DEVELOP DETAILED PROJECT GOALS AND OBJECTIVES ....... 1.1

1.2 TASK 2--ESTABLISH BUILDINGS-INDUSTRY LIAISON............ 1.1

1.3 TASK 3--DEVELOPING APPROACHES TO THE ENERGY TARGETS MODEL, BUILDING OPERATIONS, AND CLIMATE

1.3.1 Task 3.1--Develop an Approach to the Energy Targets Model

1.3.2 Task 3.2--Develop an Approach for Treating

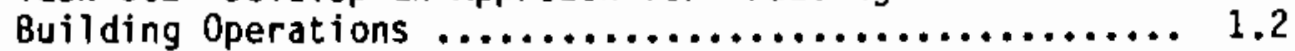

1.3.3 Task 3.3--Develop an Approach for Treating Climate ..... 1.2

1.4 TASK 4--DEVELOP AN APPROACH FOR TREATING ECONOMIC CONSIDERATIONS

1.5 TASK 5 --DEVELOP AN APPROACH FOR ENERGY SOURCES $\ldots \ldots \ldots \ldots \ldots \ldots \ldots$

1.6 TASK 6 --COLLECT ENERGY-USE DATA $\ldots \ldots \ldots \ldots \ldots \ldots \ldots \ldots \ldots \ldots \ldots \ldots$

1.7 TASK 7 --SURVEY ENERGY EXPERT OPINION $\ldots \ldots \ldots \ldots \ldots \ldots \ldots \ldots \ldots \ldots \ldots$

1.8 TASK 8--EVALUATION PROCEDURE SPECIFICATION AND INTEGRATION $\ldots . .1 .3$

1.9 TASK 9 -.PHASE 1 REPORT DEVELOPMENT $\ldots \ldots \ldots \ldots \ldots \ldots \ldots \ldots \ldots \ldots \ldots$

1.10 TASK $10-$ PHASE 1 REVIEW PLANNING $\ldots \ldots \ldots \ldots \ldots \ldots \ldots \ldots \ldots \ldots \ldots \ldots . . \ldots$

2.0 BUILDINGS-INDUSTRY LIAISON $\ldots \ldots \ldots \ldots \ldots \ldots \ldots \ldots \ldots \ldots \ldots \ldots \ldots \ldots \ldots \ldots$

3.0 DOCUMENTATION OF PHASE 1 PROOF-OF-CONCEPT TESTS OF ENERGY

3.1 BUILOING CONFIGURATION $\ldots \ldots \ldots \ldots \ldots \ldots \ldots \ldots \ldots \ldots \ldots \ldots \ldots \ldots \ldots \ldots$

3.2 AGgREGATING SPACE ENERGY USE $\ldots \ldots \ldots \ldots \ldots \ldots \ldots \ldots \ldots \ldots \ldots \ldots \ldots$ 
3.3 SPACE LOADS VERSUS ENERGY USE $\ldots \ldots \ldots \ldots \ldots \ldots \ldots \ldots \ldots \ldots \ldots \ldots \ldots \ldots$

3.4 DETERMINATION OF SYSTEM AND EQUIPMENT FACTORS $\ldots \ldots \ldots \ldots \ldots \ldots . .16$

3.5 SuMmary OF ENERgy MODEL PROOF-OF-CONCEPT RESULtS $\ldots \ldots \ldots \ldots \ldots 3.17$

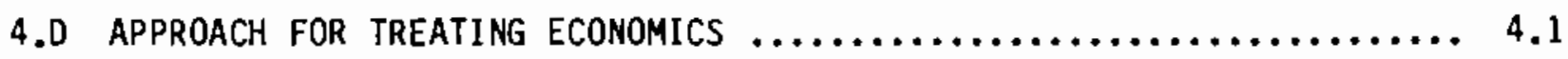

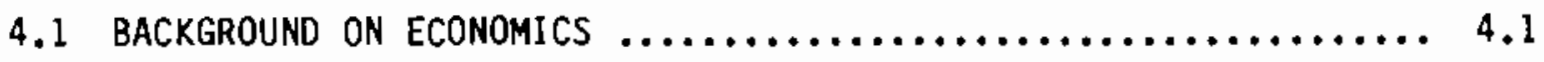

4.1.1 The Role of Economics in Developing Energy Targets ..... 4.1

4.1.2 Analysis of Performance-Based Guidelines ........... 4.2

4.1 .3 Marginal Cost Analysis $\ldots \ldots \ldots \ldots \ldots \ldots \ldots \ldots \ldots \ldots, 4.2$

4.1.4 Selecting Economic Perspectives $\ldots \ldots \ldots \ldots \ldots \ldots \ldots \ldots, 4.4$

4.1.5 Appropriate Time Horizons $\ldots \ldots \ldots \ldots \ldots \ldots \ldots \ldots \ldots, 4.5$

4.1.6 Level of Effort on Economics ................... 4.5

4.1.7 Defining Economic Parameters ................... 4.6

4.2 DESCRIPTION OF PROPOSED APPROACH $\ldots \ldots \ldots \ldots \ldots \ldots \ldots \ldots \ldots \ldots, 4.6$

4.2.1 Characteristics Set by User Inputs $\ldots \ldots \ldots \ldots \ldots \ldots \ldots . . .6$

4.2.2 Characteristics Set by Design Constraints ........... 4.9

4.2.3 Characteristics Set or Adjusted by the

Characteristics Selection Procedure ............... 4.10

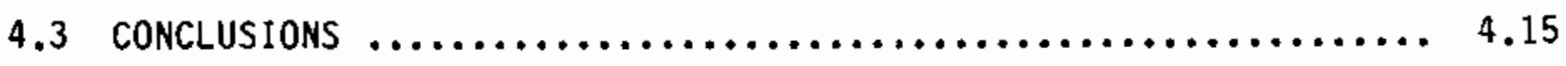

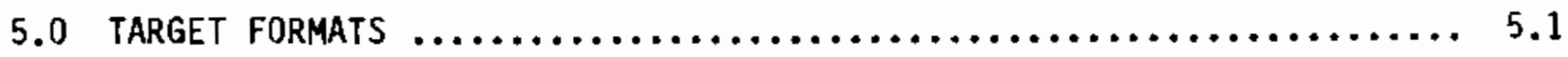

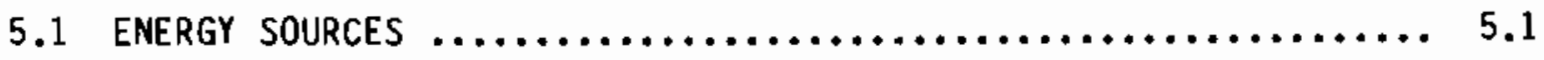

5.1 .1 Background $\ldots \ldots \ldots \ldots \ldots \ldots \ldots \ldots \ldots \ldots \ldots \ldots \ldots \ldots \ldots \ldots \ldots \ldots \ldots \ldots \ldots, 5.1$

5.1 .2 Approach $\ldots \ldots \ldots \ldots \ldots \ldots \ldots \ldots \ldots \ldots \ldots \ldots \ldots \ldots \ldots \ldots \ldots, 5.3$

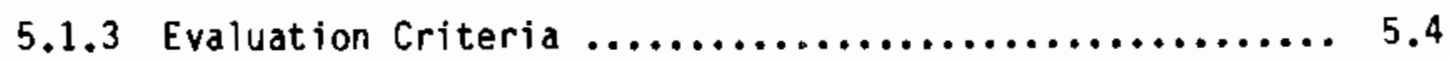

5.1 .4 Alternative Methodologies for Treating Energy
Sources $\ldots \ldots \ldots \ldots \ldots \ldots \ldots \ldots \ldots \ldots \ldots \ldots \ldots \ldots \ldots \ldots \ldots \ldots \ldots \ldots \ldots$

5.1.5 Descriptions of the Aiternative Methods $\ldots \ldots \ldots \ldots \ldots .5 .6$ 
5.1.6 Summary of Evaluation of Alternative

Methodologies .................................... 5.14

5.2 WHOLE-BUILDING ENERGY-USE METRICS $\ldots \ldots \ldots \ldots \ldots \ldots \ldots \ldots \ldots, 5.15$

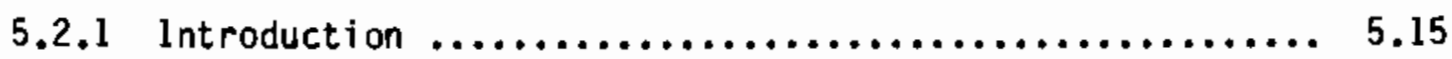

5.2.2 Issues Affecting Metric Definition ............... 5.17

5.2.3 Definition of the Energy Unit $\ldots \ldots \ldots \ldots \ldots \ldots \ldots \ldots \ldots . . \ldots .17$

5.2 .4 The Building Unit $\ldots \ldots \ldots \ldots \ldots \ldots \ldots \ldots \ldots \ldots \ldots, 5.18$

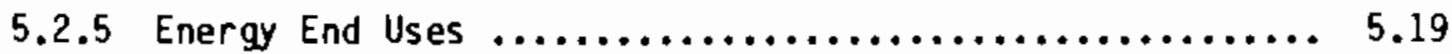

5.2 .6 Building and Space Functions $\ldots \ldots \ldots \ldots \ldots \ldots \ldots \ldots \ldots, 5.20$

5.2 .7 Building Operation/0ccupancy $\ldots \ldots \ldots \ldots \ldots \ldots \ldots \ldots \ldots, 5.21$

5.2 .8 Climate $. . . \ldots \ldots \ldots \ldots \ldots \ldots \ldots \ldots \ldots \ldots \ldots \ldots \ldots, 5.22$

5.2 .9 Economics $\ldots \ldots \ldots \ldots \ldots \ldots \ldots \ldots \ldots \ldots \ldots \ldots \ldots \ldots \ldots, 5.23$

5.2 .10 Energy Sources $\ldots \ldots \ldots \ldots \ldots \ldots \ldots \ldots \ldots \ldots \ldots \ldots \ldots \ldots, 5.23$

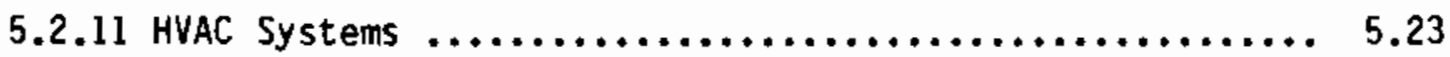

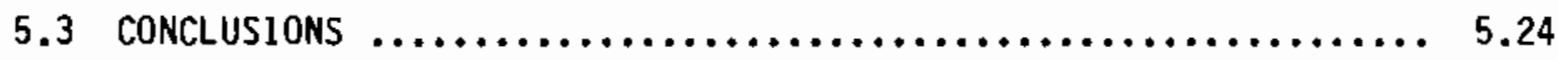

6.0 ENERGY-USE DATA COLLECTION $\ldots \ldots \ldots \ldots \ldots \ldots \ldots \ldots \ldots \ldots \ldots \ldots \ldots \ldots \ldots \ldots \ldots \ldots \ldots \ldots$

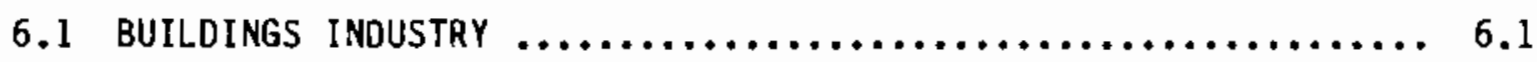

6.2 BUILOING TYPES $\ldots \ldots \ldots \ldots \ldots \ldots \ldots \ldots \ldots \ldots \ldots \ldots \ldots \ldots \ldots \ldots, 6.2$

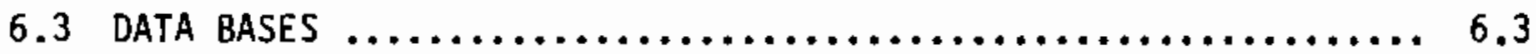

6.3 .1 Office Buildings $\ldots \ldots \ldots \ldots \ldots \ldots \ldots \ldots \ldots \ldots \ldots \ldots, 6.7$

6.3 .2 Lodging Facilities $\ldots \ldots \ldots \ldots \ldots \ldots \ldots \ldots \ldots \ldots \ldots . \ldots . . . \ldots$

6.3 .3 Educational Facilities $\ldots . \ldots \ldots \ldots \ldots \ldots \ldots \ldots \ldots \ldots . . .6 .10$

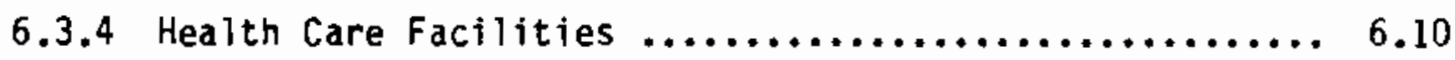

6.3.5 Warehouse and Storage Facilities $. . . \ldots \ldots \ldots \ldots \ldots . . .6 .10$

6.3 .6 Food Sales Facilities $\ldots \ldots \ldots \ldots \ldots \ldots \ldots \ldots \ldots \ldots \ldots, 6.11$

6.3 .7 Assembly Buildings $\ldots \ldots \ldots \ldots \ldots \ldots \ldots \ldots \ldots \ldots \ldots, 6.11$ 
6.3 .8 Awards Programs $\ldots \ldots \ldots \ldots \ldots \ldots \ldots \ldots \ldots \ldots \ldots \ldots \ldots \ldots, 6.12$

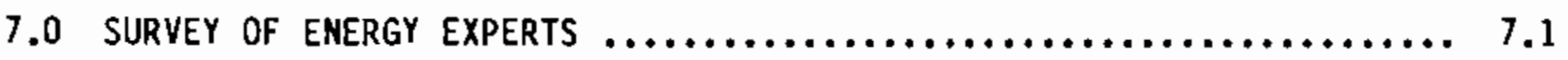

7.1 APPROACH $\ldots \ldots \ldots \ldots \ldots \ldots \ldots \ldots \ldots \ldots \ldots \ldots \ldots \ldots \ldots \ldots \ldots \ldots \ldots \ldots \ldots, 1.1$

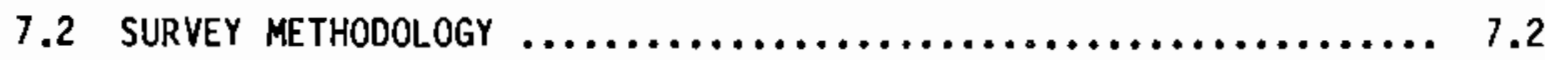

7.2.1 Selection of Energy Experts $\ldots \ldots \ldots \ldots \ldots \ldots \ldots \ldots \ldots, 7.2$

7.2.2 Developing the Survey Questionnaire $\ldots \ldots \ldots \ldots \ldots \ldots, 7.3$

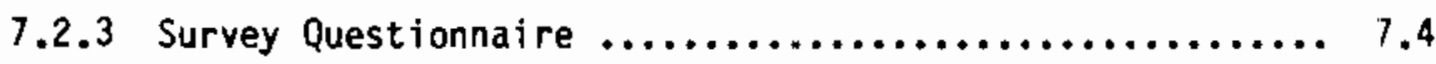

7.3 CONDUCTING THE SURVEY $\ldots \ldots \ldots \ldots \ldots \ldots \ldots \ldots \ldots \ldots \ldots \ldots \ldots, 7.4$

7.4 AMOUNT AND TYPE OF RESULTS RECEIVED $\ldots \ldots \ldots \ldots \ldots \ldots \ldots \ldots \ldots \ldots \ldots \ldots$

7.4.1 Responses by Building Type $\ldots \ldots \ldots \ldots \ldots \ldots \ldots \ldots \ldots, 7.6$

7.4.2 Regional Nature of Responses $\ldots \ldots \ldots \ldots \ldots \ldots \ldots \ldots \ldots \ldots . . .9$

7.4.3 Experience Basis for Estimates ................... 7.11

7.4.4 Design Calculations or Actual Consumption ............ 7.11

7.4 .5 Supporting Information $\ldots \ldots \ldots \ldots \ldots \ldots \ldots \ldots \ldots \ldots \ldots, 7.11$

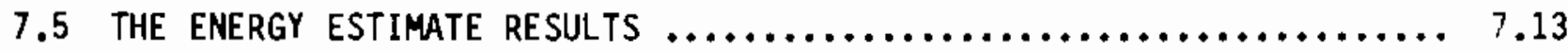

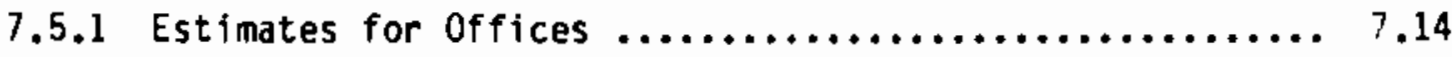

7.5.2 Estimates for Hotels/Motels $\ldots \ldots \ldots \ldots \ldots \ldots \ldots \ldots \ldots . . \ldots \ldots$

7.5.3 Estimates for Education Facilities ................ 7.20

7.5.4 Estimates for Apartments $\ldots \ldots \ldots \ldots \ldots \ldots \ldots \ldots \ldots \ldots, 7.23$

7.5.5 Estimates for Retail Facilities .................. 7.24

7.5.6 Estimates for Other 8uilding Types ............... 7.27

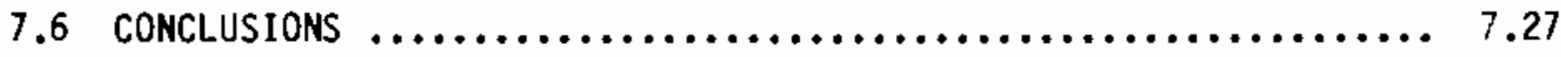

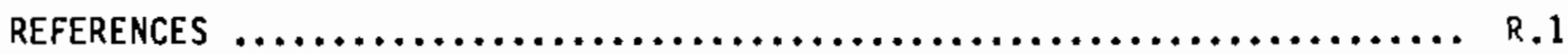

BIBLIOGRAPHIC LIST OF BUILDING SYSTEM INTEGRATION RESEARCH REPORTS ......Bib.l 
APPENDIX A - DOE-2 INPUT FILE NAME CONVENTIONS $\ldots \ldots \ldots \ldots \ldots \ldots \ldots \ldots \ldots$ A.1

APPENDIX 8 - ENERGY-COST AND BUILDING-COST MODEL AND SELECTION PROCEDURE, DOCUMENTATION OF PROOF-OF-CONCEPT

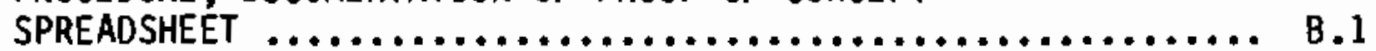

APPENDIX C - CASE STUDY: HOTEL ENERGY USE $\ldots \ldots \ldots \ldots \ldots \ldots \ldots \ldots \ldots \ldots, c .1$

APPENDIX D - SURVEY OF ENERGY EXPERTS--SUPPORTING INFORMATION $\ldots \ldots \ldots \ldots . .1$

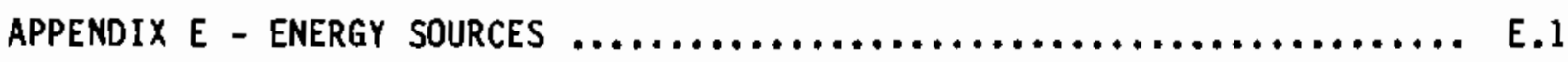




\section{FIGURES}

3.1 Floor Plan of Building $\ldots \ldots \ldots \ldots \ldots \ldots \ldots \ldots \ldots \ldots \ldots \ldots \ldots \ldots, 3.2$

3.2 Results of the Individual-Zone Sum Versus the Five-Zone Sum in

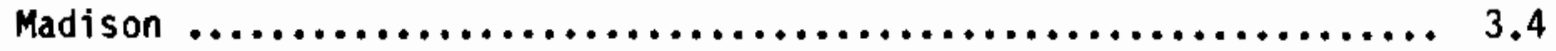

3.3 Results of the Individual-Zone Sum Versus the Five-Zone Sum in

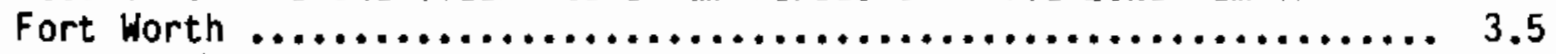

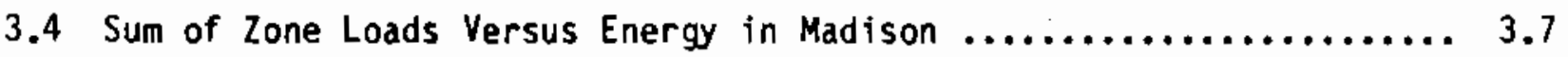

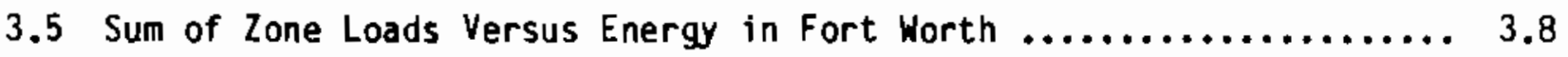

3.6 Zone Loads Versus Coil Heat Addition in Madison .................. 3.9

3.7 Zone Loads Versus Coil Heat Addition in Fort Worth $. . . \ldots \ldots \ldots \ldots . . .3$

3.8 Zone Load Versus Coil Heat Extraction in Madison ................ 3.10

3.9 Zone Load Versus Coil Heat Extraction in Fort Worth .............. 3.11

3.10 Coil Heat Addition Versus Energy Use in Madison $\ldots \ldots \ldots \ldots \ldots \ldots . . .13$

3.11 Coil Heat Addition Versus Energy Use in Fort Worth $\ldots \ldots \ldots \ldots \ldots \ldots . .13$

3.12 Coil Heat Extraction Versus Energy Use in Madison ................ 3.14

3.13 Coil Heat Extraction Versus Energy Use in Fort Worth $\ldots \ldots \ldots \ldots \ldots . . .15$

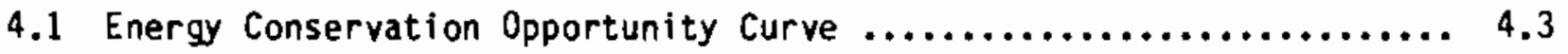

4.2 Procedure to Develop Targets for the Targets Model ............. 4.7

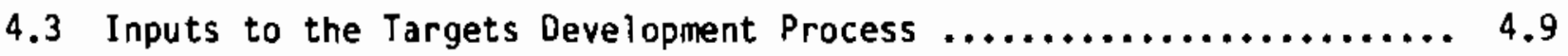

4.4 Building-Cost and Energy-Cost Model $\ldots \ldots \ldots \ldots \ldots \ldots \ldots \ldots \ldots \ldots \ldots . . \ldots \ldots$

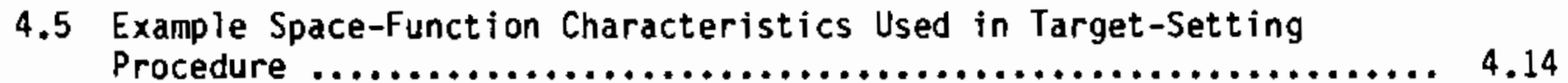

6.1 Composition of Building Stock by Numbers of Buildings $\ldots \ldots \ldots \ldots \ldots 6.3$

6.2 Composition of Building Stock by Square Footage $\ldots \ldots \ldots \ldots \ldots \ldots \ldots, 6.4$

6.3 Composition of Building Stock by Energy Use $\ldots \ldots \ldots \ldots \ldots \ldots \ldots .6 .4$

6.4 Total Energy Consumption by Building Type $\ldots \ldots \ldots \ldots \ldots \ldots \ldots \ldots .6 .5$ 
6.5 Average Energy Consumption per Building by Building Type ....... 6.5

6.6 Energy Consumption per Square Foot by Building Type ........... 6.6

6.7 Composition of Building Stock by Numbers of Buildings .......... 6.6

6.8 Composition of Building Stock by Square Footage $\ldots \ldots \ldots \ldots \ldots \ldots . \ldots .7$

6.9 Composition of Building Stock by Energy Use ................ 6.7

7.1 Flowchart of the Survey of Energy Experts $\ldots \ldots \ldots \ldots \ldots \ldots \ldots \ldots \ldots \ldots . . \ldots$

7.2 Cover Letter for Survey Questionnaire $\ldots \ldots \ldots \ldots \ldots \ldots \ldots \ldots \ldots \ldots \ldots \ldots$

7.3 Background Information on Targets Project $\ldots \ldots \ldots \ldots \ldots \ldots \ldots \ldots \ldots \ldots$

7.4 Questionnaire on Energy Targets $\ldots \ldots \ldots \ldots \ldots \ldots \ldots \ldots \ldots \ldots \ldots \ldots \ldots . \ldots . \ldots . \ldots$

7.5 Questionnaire on Assumptions $\ldots \ldots \ldots \ldots \ldots \ldots \ldots \ldots \ldots \ldots \ldots \ldots \ldots \ldots$

$7.6 \mathrm{Climate}$ Regions of the United States $\ldots \ldots \ldots \ldots \ldots \ldots \ldots \ldots \ldots \ldots \ldots$

7.7 Sumary of All Estimates for Office Buildings $\ldots \ldots \ldots \ldots \ldots \ldots \ldots \ldots . . \ldots .14$

7.8 Estimates Based on Consumption for Office Buildings ............ 7.15

7.9 Estimates Based on Design Calculations for Office Buildings ...... 7.15

7.10 Estimates Based on Design Calculations and Consumption for Office Buildings ..................................... 7.16

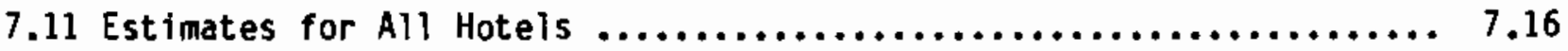

7.12 Estimates for Convention Hotels $\ldots \ldots \ldots \ldots \ldots \ldots \ldots \ldots \ldots \ldots \ldots \ldots \ldots . \ldots . \ldots$

7.13 Estimates for Roadside Hotels $\ldots \ldots \ldots \ldots \ldots \ldots \ldots \ldots \ldots \ldots \ldots \ldots \ldots \ldots . \ldots 7 . \ldots$

7.14 Hotel Energy Use Related To Food and Beverage Ratio ............ 7.20

7.15 Estimates for All Educational Facilities ................... 7.21

7.16 Estimates for Colleges and Universities $\ldots \ldots \ldots \ldots \ldots \ldots \ldots \ldots \ldots \ldots . . \ldots .22$

7.17 Estimates for Elementary and Secondary Schools ............... 7.22

7.18 Estimates for All Apartments $\ldots \ldots \ldots \ldots \ldots \ldots \ldots \ldots \ldots \ldots \ldots \ldots \ldots \ldots . \ldots \ldots$

7.19 Estimates for Apartments in Colder Climates .................. 7.24

7.20 Estimates for Apartments in All Other Climates .............. 7.25 
7.21 Estimates for Retail Facilities Without Supermarkets $\ldots \ldots \ldots \ldots \ldots .7 .26$

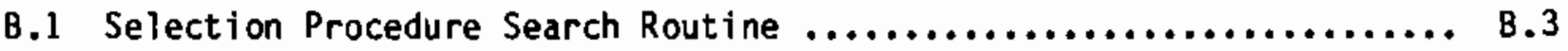

B.2 Option Limitation and Elimination Procedure $\ldots \ldots \ldots \ldots \ldots \ldots \ldots \ldots$... B.4

B.3 Example Option Elimination Table from the Spreadsheet ............. B.5

B.4 Option Comparison Procedure $\ldots \ldots \ldots \ldots \ldots \ldots \ldots \ldots \ldots \ldots \ldots \ldots \ldots \ldots \ldots . \ldots \ldots$ B.7

B.5 Example Option Comparison Table from the Spreadsheet ............. B.7

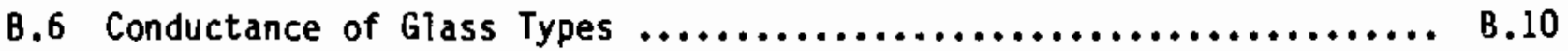

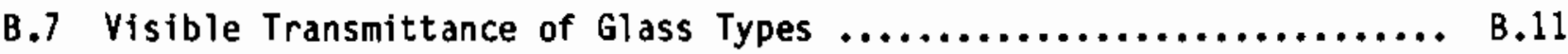

B.8 Sumary Table Generated Using Characteristics Shown in Figure $B .17 \ldots \ldots \ldots \ldots \ldots \ldots \ldots \ldots \ldots \ldots \ldots \ldots \ldots \ldots \ldots \ldots \ldots \ldots \ldots, B .12$

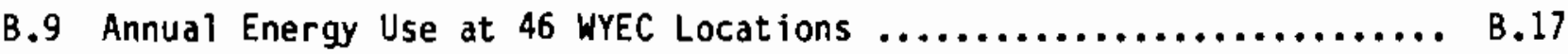

B.10 Annual Energy Use Ignoring Conversion Losses at 46 WYEC Locations ....................................... B.17

B.11 Additional First Cost at 46 WYEC Locations $\ldots \ldots \ldots \ldots \ldots \ldots \ldots \ldots$................ B

B.12 First Cost of Energy-Related Features at 46 WYEC Locations ........ B.18

B.13 Annual Energy Costs at 46 WYEC Locations ...................... B.19

B.14 Total Owning and Operating Costs (Societal) at 46 WYEC Locations ... B.19

B.15 Total Owning and Operating Costs at 46 WYC Locations ........... B.20

B.16 Annual Energy Use WYEC Locations $\ldots \ldots \ldots \ldots \ldots \ldots \ldots \ldots \ldots \ldots \ldots \ldots$. B.20

B.17 Home Screen of the Proof-of-Concept Spreadsheet $\ldots \ldots \ldots \ldots \ldots \ldots \ldots$. B.25

B.18 Spreadsheet Screen: Table of Generated Characteristics and
Target Vaiues $\ldots \ldots \ldots \ldots \ldots \ldots \ldots \ldots \ldots \ldots \ldots \ldots \ldots \ldots \ldots \ldots \ldots \ldots \ldots \ldots \ldots \ldots \ldots \ldots \ldots$

B.19 Screen: Macro Optimization Table ........................... B.27

B.20 Help Screen from Spreadsheet Program ....................... B.27

C.1 Hotel Energy Use by Year $\ldots \ldots \ldots \ldots \ldots \ldots \ldots \ldots \ldots \ldots \ldots \ldots \ldots \ldots \ldots, c .2$

C.2 Hotel Energy Use by Region in $1984 \ldots \ldots \ldots \ldots \ldots \ldots \ldots \ldots \ldots \ldots \ldots$ C.2

C.3 Hotel Energy Use Versus Number of Rooms $\ldots \ldots \ldots \ldots \ldots \ldots \ldots \ldots \ldots$, C.3 
C.4 Total Square Feet Versus Energy Use $\ldots \ldots \ldots \ldots \ldots \ldots \ldots \ldots \ldots \ldots \ldots$ C.3

C.5 Total Energy Use Versus Area $\ldots \ldots \ldots \ldots \ldots \ldots \ldots \ldots \ldots \ldots \ldots \ldots \ldots . . \ldots .4$

C.6 Average Energy Use at $10,000-\mathrm{ft}^{2}$ Intervals ................... C.4

C.7 Maximum Energy Use in Hotels ............................ C.5

C.8 Minimum Energy Use for Hotels $\ldots \ldots \ldots \ldots \ldots \ldots \ldots \ldots \ldots \ldots \ldots \ldots, c .5$

C.9 Number of Rooms Versus Energy Use $\ldots \ldots \ldots \ldots \ldots \ldots \ldots \ldots \ldots \ldots \ldots, 0.6$

C.10 Average Energy Use at 10 -Room Intervals $\ldots \ldots \ldots \ldots \ldots \ldots \ldots \ldots \ldots, 0.6$

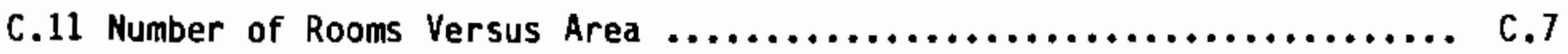

C.12 Number of Rooms Versus Energy Use $\ldots \ldots \ldots \ldots \ldots \ldots \ldots \ldots \ldots \ldots \ldots, C .7$ 


\section{TABLES}

5.1 Energy Sources Evaluation Criteria $\ldots \ldots \ldots \ldots \ldots \ldots \ldots \ldots \ldots \ldots \ldots . . \ldots . \ldots$

5.2 Methods Generated by Generic Approach ...................... 5.7

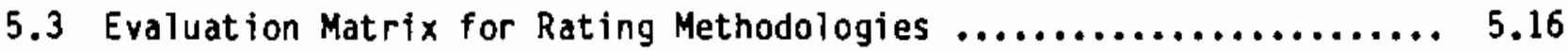

6.1 Number of Buildings Compared with Total Floor Area by Building

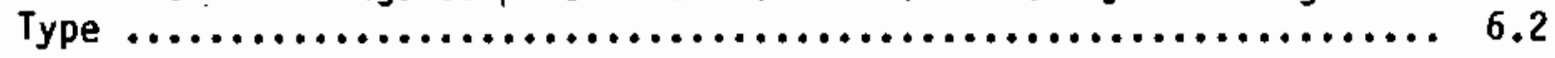

6.2 Predominant Energy Use by Building Type $\ldots \ldots \ldots \ldots \ldots \ldots \ldots \ldots \ldots .6 .3$

7.1 Estimates by Building Type $\ldots \ldots \ldots \ldots \ldots \ldots \ldots \ldots \ldots \ldots \ldots \ldots \ldots, 7.9$

7.2 Number of Estimates by National Climate Regions $\ldots \ldots \ldots \ldots \ldots \ldots \ldots .7 .10$

7.3 Estimates by Experience Basis $\ldots \ldots \ldots \ldots \ldots \ldots \ldots \ldots \ldots \ldots \ldots \ldots, 7.11$

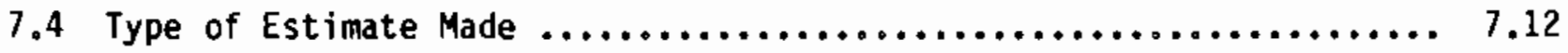

7.5 Estimates for Five Building Types $\ldots \ldots \ldots \ldots \ldots \ldots \ldots \ldots \ldots \ldots \ldots, 7.13$

7.6 Survey Results for Other Bufiding Types $\ldots \ldots \ldots \ldots \ldots \ldots \ldots \ldots \ldots, 7.27$

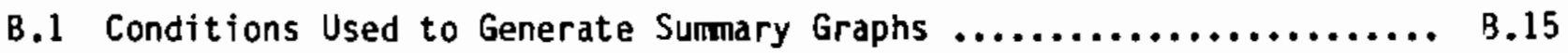

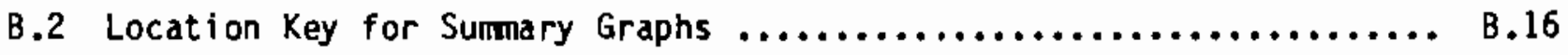

D.1 Energy Estimates Obtained from Respondents $\ldots \ldots \ldots \ldots \ldots \ldots \ldots \ldots \ldots . .2$

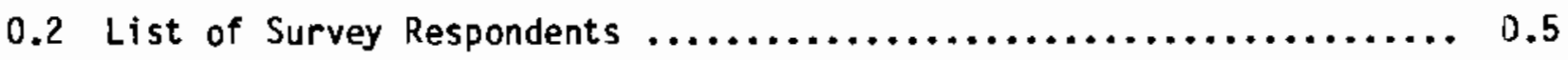




\subsection{PHASE 1 PLANNING}

The objective of the buildings targets project is to encourage the design of energy-efficient buildings by developing voluntary, performance-based guidelines for energy use in new commercial buildings. These guidelines are referred to as whole-building energy design targets, and the intent of setting these targets is to inform new building designers and owners about energy-use goals that can be achieved cost-effectively without interfering with other design goals. The Volume 1: Final Report (Crawley et al. 1987) presents the planning effort completed in Phase 1 of the research on a proposed methodology for setting such targets. This Volume 2: Technical Report describes the technical results of the 10 tasks in Phase 1. The Phase 1 tasks are summarized in this section.

\subsection{TASK 1--DEVELOP DETAILED PROJECT GOALS AND OBJECTIVES}

This task involved the expansion of the project objective into a clearly defined set of goals. These goals, as well as a set of desirable attributes for whole-bullding targets, which are also developed in this task, are described in Section 1 of the Volume 1: Final Report (Crawley et al. 1987).

\subsection{TASK 2--ESTABLISH BUILDINGS-INDUSTRY LIAISDN}

Task 2 involved establishing liaisons with a variety of building-owner and building-operator firms and associations. The liaison activities are discussed in Section 2. In Phase 2, the liaisons established during this task will contribute to the procedures for target development.

\subsection{TASK 3--DEVELOP APPROACHES TO THE ENERGY TARGETS MODEL, BUILOING} OPERATIONS, AND CLIMATE

This task comprises three subtasks, which are described below. The elements of Task 3 are discussed in Section 3. 


\subsubsection{Task 3.1--Develop an Approach to the Energy Targets Mode?}

This subtask involves establishing and testing a proof-of-concept methodology to develop an energy model for using building-space function as a primary approach to target deveiopment. Various functional areas were defined and quantified. Major heating, ventilation, and air conditioning (HVAC) system types were defined and used in DOE-2.1C (LBL 1984) to simulate energy in several example functional spaces.

\subsubsection{Task 3.2--Develop an Approach for Treating Building Operations}

In this subtask, the effects of building operating schedules on building energy use were examined. Various types of energy loads were defined, and the effects of utilization hours, climate, and system control strategies on these loads were reviewed.

\subsubsection{Task 3.3--Oevelop an Approach for Treating Climate}

In this subtask, the effect of climate was considered in the same manner as developed in the American Society of Heating, Refrigerating, and Air Conditioning Engineers, Inc. (ASHRAE) Special Project 41 (SP 41) (PNL 1983) and expanded in ASHRAE Standard 90.1P (ANSI/ASHRAE/IES 1986). During Phase 2, climate values and variables will be refined. In particular, the climate ranges should be extended to include Alaska, Hawaij, and locations other than the continentar United States.

\subsection{TASK 4--DEVELOP AN APPROACH FOR TREATING ECONOMIC CONSIOERATIONS}

In Task 4, the economic effects of numerous variables in the building process were examined. These variables and their effects were integrated into a proof-of-concept energy-cost and building-cost model tested in Phase 1 for potential in the development of energy targets. The results of this task are discussed in Section 4 of this report.

\subsection{TASK 5--DEVELOP AN APPROACH FOR TREATING ENERGY SOURCES}

Under Task 5, a study of various methods to address energy sources was conducted, and the advantages and disadvantages of each method studied were evaluated and ranked. Of the 14 methods studied, the highest ranked method was 
selected for the primary focus of further development in Phase 2; the secondand third-ranked methods will also be examined for further development in Phase 2, but at a lower priority. The background and approach of dealing with the methods to address energy sources are discussed in Section 5 of this report.

\subsection{TASK 6--COLLECT ENERGY-USE DATA}

Through the liaisons described under Task 2, sources of energy-use data were identified. Data-collection activities are discussed in Section 6 of this report.

\subsection{TASK 7--SURVEY ENERGY EXPERT OPINION}

Under Task 7, the expert opinion of design professionals was surveyed to determine anticipated levels of building energy use for various types of buildings with differing energy performance levels. These opinions were used as background information for the proof-of-concept analyses conducted in Phase 1. The results of this task are discussed in Section 7 of this report.

\subsection{TASK 8--EVALUATION PROCEDURE SPECIFICATION AND INTEGRATION}

As part of Task 8, procedures to evaluate whether building designs met the proposed energy targets were addressed. A plan for the integrating of evaluation procedures with the target development process was also developed. These procedures include a simplified spreadsheet-based model, simplified energy analysis-based model such as the modified bin method, and an hourly energy analysis-based model such as DOE-2 or BLAST-3.0. These topics are discussed in Section 4 of the Volume 1: Final Report.

\subsection{TASK 9--PHASE 1 REPORT DEVELOPMENT}

This task integrates the results of research conducted in Tasks 1 through 8 into the Phase 1 reports Volume 1: Final Report and Volume 2: Technical Report. The Phase 1 reports document the results, including proof-of-concept research for the space-function energy model, the energy-cost and building-cost model, and the characteristic selection procedure. An approach is recormended 
to develop an energy targets procedure in Phase 2. The Phase 1 reports also contain the preliminary Statement of Work for Phase 2 target development.

\subsection{TASK 10--PHASE 1 REVIEW PLANNING}

The Phase 1 reports developed in Task 9 will be given wide distribution to various groups with an interest in whole-building energy targets: design professional societies, and building owners, developers, and operators. After an appropriate review period, a workshop will be conducted to obtain the input from potential users of the targets. These coments will be used to modify the Phase 2 Statement of Work as necessary to address issues relating to the different user groups. Task 10 was discussed in Volume 1: Final Report at the review meeting that took place in March 1987. 


\subsection{BUILDINGS-INDUSTRY LIAISON}

A liaison has been established with major buildings-industry groups to keep then informed about the targets project and to incorporate their expectations and knowledge about specific building and owner types into the project. During Phase 2, the buildings-industry groups will be asked to participate in a number of workshops in order to provide input on the progress of the targets development research.

The following building-owner organizations were identified and contacted to initiate liaison activities during Phase 1. Other associations will be contacted in Phase 2 to cover other building types, including nursing homes and service stations/repair shops.

American Association of Museums 1055 Thomas Jefferson Street, NW Washington, DC 20007

American Hospital Association 840 N. Lake Shore Drive

Chicago, IL 60611

American Hotel and Motel

Association

888 Seventh Avenue

New York, NY 10019

American Library Association

$50 \mathrm{E}$. Huron Street

Chicago, $1 \mathrm{~L} 60611$

Association of Physical

Plant Administrators

1446 Duke Street

Alexandria, VA 22314

Building Owners and Managers

Association

1250 Eye Street, NW

Washington, DC 20005
Council of Educational

Facility Planners

29 W. Woodruff Avenue

Columbus, $\mathrm{OH} 43210$

Federation of American Hospitals

1111 19th Street NW, Suite 402

Washington, DC 20036

Institute of Real Estate

Managenent

430 N. Michigan

Chicago, IL 60611

International Council of Shopping Centers

665 Fifth Avenue

New York, NY 10022

National Apartment

As sociation

1101 14th Street NW

Washington, DC 20005

National Association of

Home Builders

15th and $M$ Streets, NW

Washington, DC 20005 
National Association of

Theatre Owners

1560 Broadway, Suite 714

New York, NY 10036

Nationa1 Restaurant Association

311 First Street MN

Washington, DC 20001

National Retail Merchants

Association

$100 \mathrm{~W} 31$ st Street

New York, NY 10001
Warehousing Education and Research Council

1100 Jorie Boulevard, Suite 118

0ak Brook, IL 60521

Urban Land Institute 1090 Vermont Avenue NW

Washington, DC 20005 


\subsection{DOCUMENTATION OF PHASE 1 PROOF-OF-CONCEPT TESTS OF ENERGY ANALYSIS MODEL}

This section presents a more detailed technical description of the proofof-concept tests briefly described in Volume 1: Final Report (Crawley et a). 1987). Several key questions related to the space-function concept had to be resolved in Phase 1 before the proposed procedure could be recommended for developing energy performance targets in Phase 2. These key questions were:

- What are the implications of estimating annual building energy use as the sum of energy use for independent functions (spaces) served by individual systems versus estimating energy use for a building made up of the same function spaces but served by a single system?

- How does annual energy use for heating and cooling vary as the annual space loads vary both in magnitude and in distribution over time?

- How does the relationship between the annual space loads and annual energy use for heating and cooling vary for differing HVAC systems?

The answers to these questions were explored through a series of DOE-2.1C (LBL 1984) simulations of the energy performance of a test building considered as the sum of five individual zones and as a single five-zone system.

\subsection{BUILOING CONFIGURATION}

The first task in setting up the DOE-2.1C simulations in Phase 1 was to select a building configuration for the tests. After some discussion and consultation with the project team, the base building configuration used in the SP 41 work (PNL 1983) was selected. This configuration is a simple five-zone model of an intermediate floor of a building, comprised of four perimeter zones and one core zone as shown in Figure 3.1. The zones were defined to have only a single exterior exposure oriented in one of the cardinal directions (north, south, east, or west). Variations in the simulated space heating and sensible cooling loads were affected by changing the glazing from single-pane to doublepane, and then to triple-pane glass with varying shading coefficients. For the initial series of tests at all three load levels, the occupancy, schedules, and 


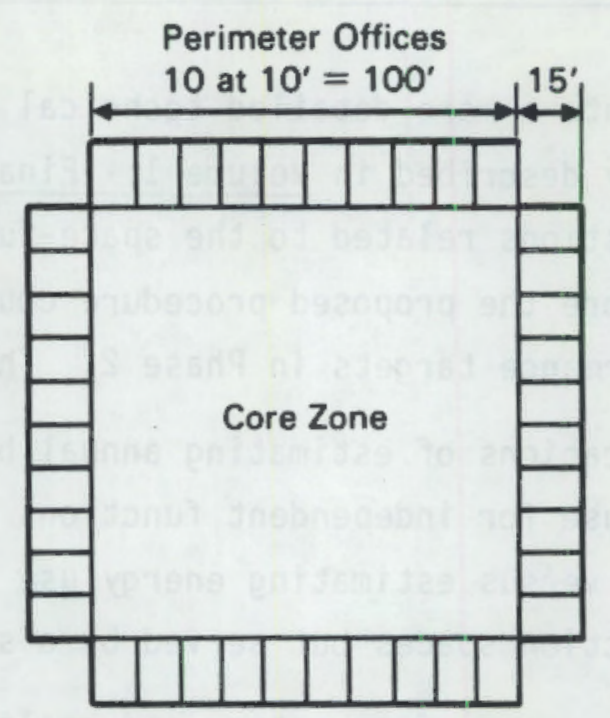

FIGURE 3.1. Floor Plan of Building (PNL 1983)

latent loads assumed were typical for an office building. A second series of tests at a single sensible load level modified the schedules to reflect extended hours of operation.

Three generic HVAC system types were selected for examination:

- a variable-air-volume system (VAV) with a water-cooled centrifugal chiller, a zone reheat, and an electric boiler

- a constant volume-packaged-single-zone (PSZ) system with air-cooled direct expansion cooling and electric resistance subzone reheat

- a package-terminal air-conditioning (PTAC) system with electric resistance heating which cycled as needed to maintain space conditions.

The VAV system is typical of the systems used in large buildings with site-assembled, centralized equipment and an extensive distribution system. The PSZ system is a factory-assembled unit typical of systems selected for smaller buildings with much shorter distribution system runs. The PTAC, a through-the-wall unit, is typically used for air conditioning small spaces with independent schedules; it has no associated distribution system. 
A wide variety of individual HVAC systems may be encountered in the design of commercial buildings. The intent in selecting these three systems for study was to cover a reasonable range of system configurations and identify the major variations in operating characteristics without examining all possible HVAC systems. Each of the selected HVAC systems were simulated for the building with both a multiple-zone (five-zone) and an independent-zone system configuration.

Systems $\left(F_{\text {system }}\right)$ and equipment ( $\left.F_{\text {equipment }}\right)$ factors were determined for each of the three systems in the two Phase 1 locations. The two locations chosen for the proof-of-concept tests were Fort Worth, Texas, a predominant cooling climate, and Madison, Wisconsin, a predominant heating climate. The results of the analyses provided the following responses on each of the issues raised regarding the adequacy of the proposed space-function energy model.

\subsection{AGGREGATING SPACE ENERGY USE}

The first question addressed in Phase 1 was the extent of the difference in energy use predicted for a building simulated as a collection of zones, a building where the individual zones were simulated separately, and a building where energy use was defined as the sum of individual-zone energy use. A comparison of the energy use for each of the three HVAC systems for a simultaneous analysis (five-zone simulation with interzone heat transfer and system diversity) with the results of the sum of the separate zone analyses (individual zone simulations without any interzone heat transfer or consideration of system or equipment diversity) for Madison and Fort Worth indicates that the differences between the total annual energy use for heating, cooling, and fans for the five-zone and individual-zone simulations are small. These results are illustrated by Figures 3.2 and 3.3. Results were not obtained for the intermediate, sensible load case for the PTAC system simulated as individual zones.

\subsection{SPACE LOADS VERSUS ENERGY USE}

The second question addressed in Phase 1 was the effect of varying loads on the relationship between loads and energy use. It was anticipated that the 


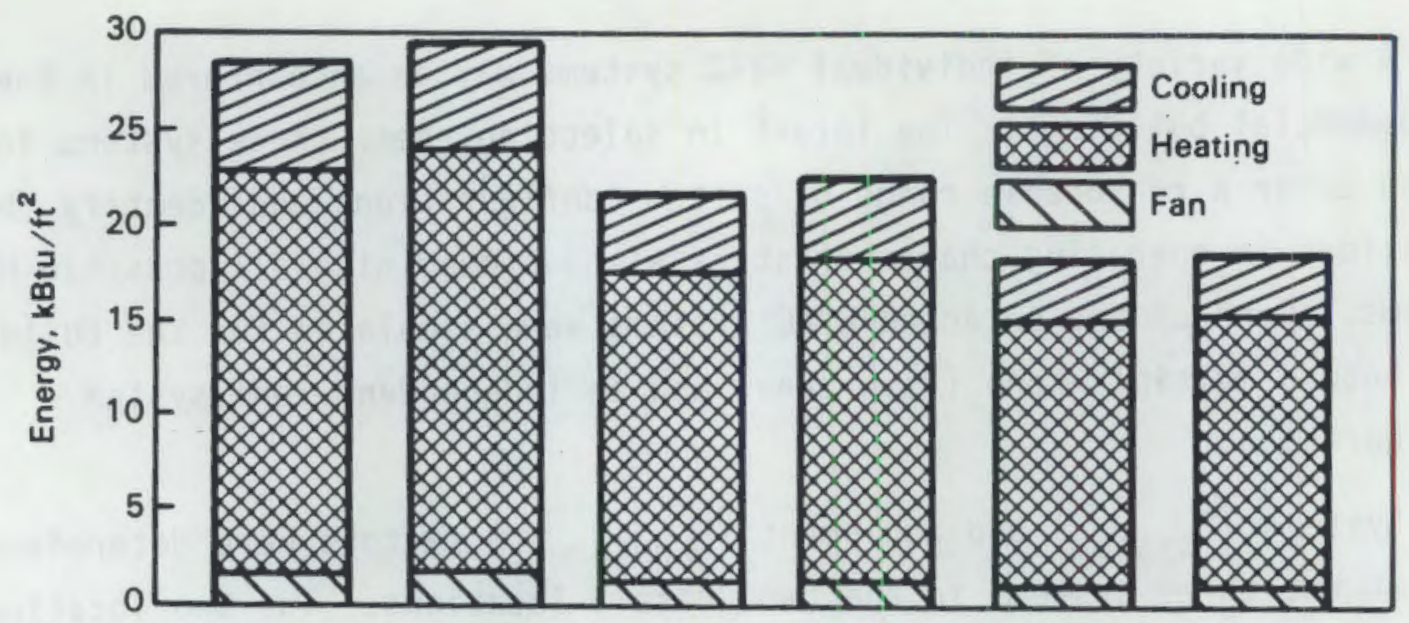

(a)

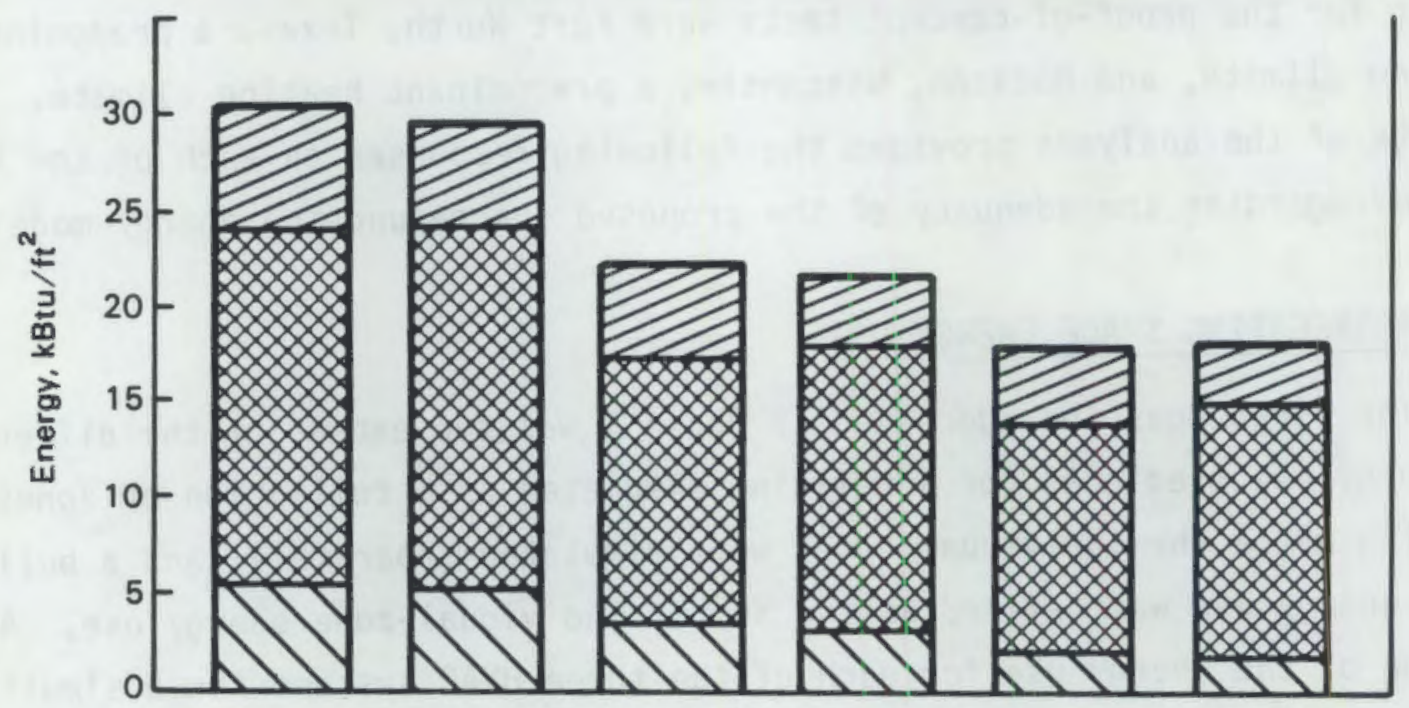

(b)

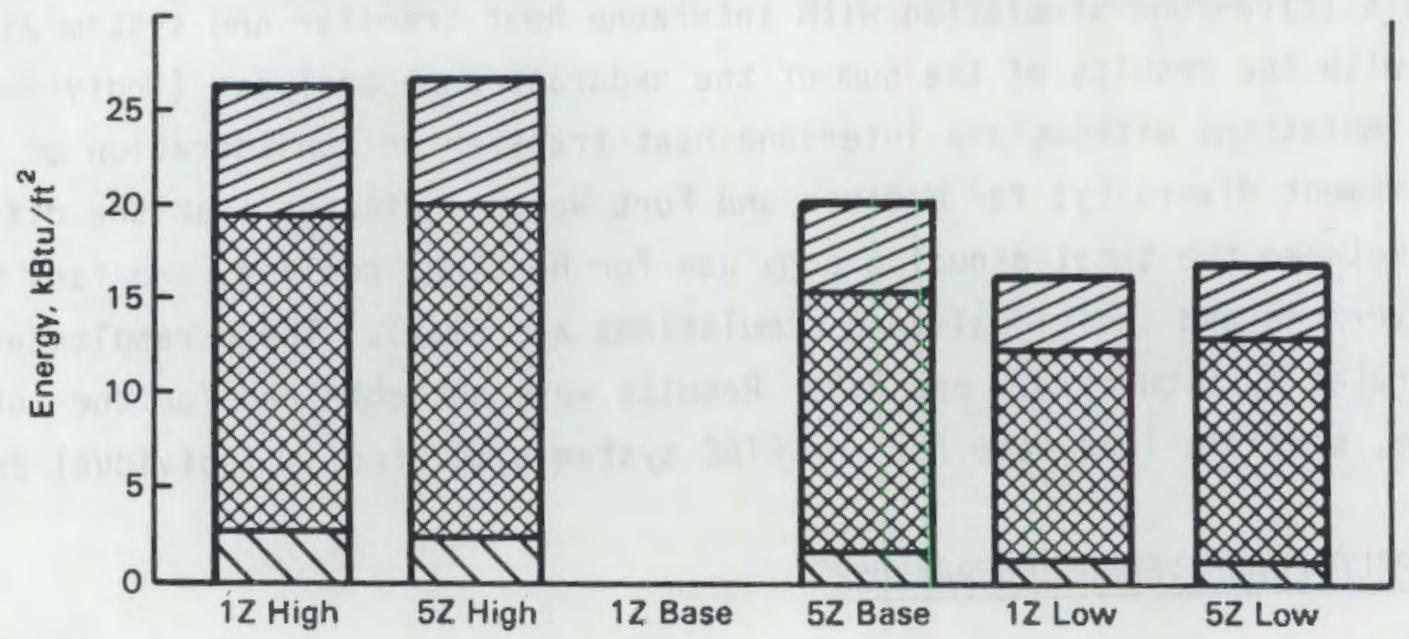

(c)

FIGURE 3.2. Results of the Individual-Zone Sum Versus the Five-Zone Sum in Madison: a) VAV Five-Zone System, b) PSZ Five-Zone System, and c) PTAC Five-Zone System 


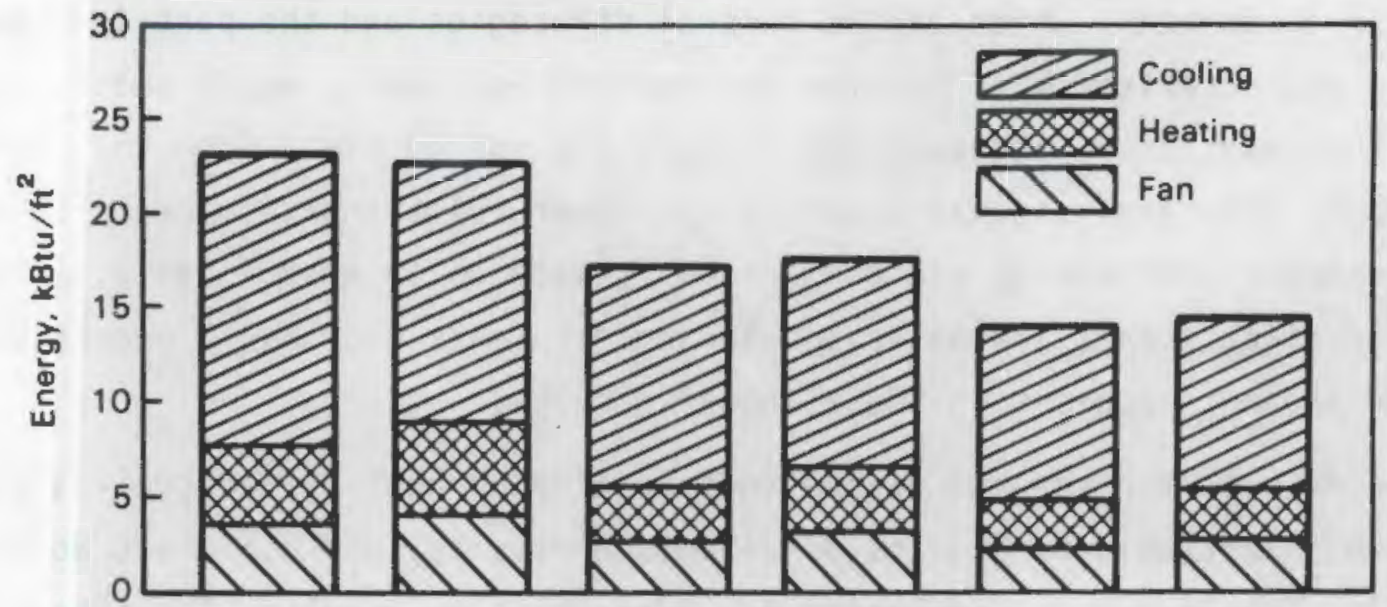

(a)

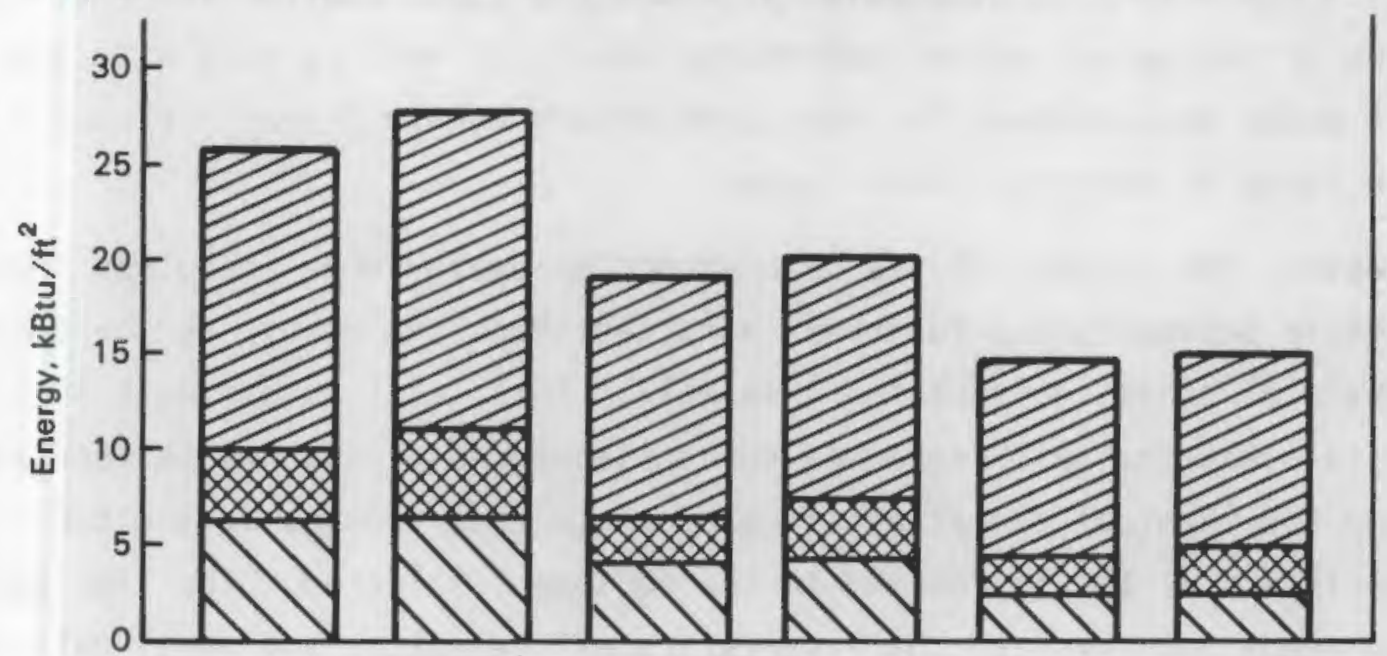

(b)

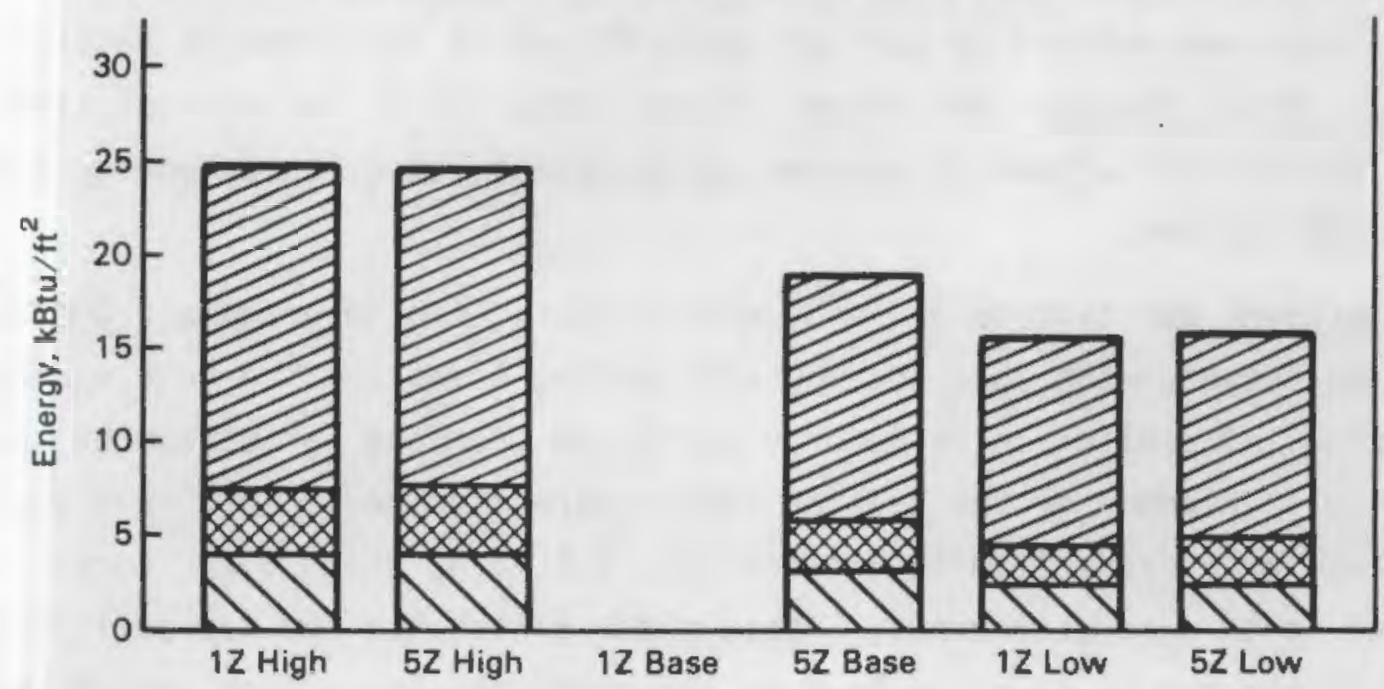

(c)

FIGURE 3.3. Results of the Individual-Zone Sum Versus the Five-Zone Sum in Fort Worth: a) VAV Five-Zone System, b) PSZ Five-Zone System, and c) PTAC Five-Zone System 
use of an economizer, which varied control strategies and the part-load performance characteristics of heating and cooling equipment, would substantially affect the relationship between space loads and energy use. From the results obtained in this analysis, an essentially linear relationship appears to exist when the space load/energy use comparison is made on an annual basis. The nonlinear effects that are observed when hourly loads and hourly energy use are examined are not apparent in these annual results.

The results for the sum of the individual zone heating and cooling simulations are illustrated by Figures 3.4 (Madison results) and 3.5 (Fort Worth results). The five-zone simulation provided the same result. The intercept and slope of the annual space-load-energy-use relationships vary with system type, as would be expected, but the correlations remain linear for each system over the range of sensible loads tested.

However, the success of the space-function energy model requires that the relationship between space-function characteristics and energy use be defined for individual zones (orientations) as well. This relationship must also be defined in a way that will separate the consequences of changes in function needs and the physical characteristics of space from changes in the operation characteristics of the system and in the equipment selected. The link between function needs and physical characteristics of the space, and zone heating and cooling loads was defined by earlier research and is described in Section 2 of Volume 1: Final Report. The intent of the present proof-of-concept tests has been to explore the effect of system and equipment selection on energy use for heating and cooling.

To account for systems and equipment effects, two intermediate DOE-2.1C simulation outputs--the zone heating and cooling loads and the heat exchange at the heating and cooling coils (energy extracted from the air stream by the cooling coil or added by the heating coil)--were examined. Coil heat exchange is plotted versus zone load in Figures $3.6,3.7,3.8$, and 3.9 for north, east, west, and south perimeter zones. These plots illustrate the way coil loads respond to changes in sensible load on the space resulting from variations in 


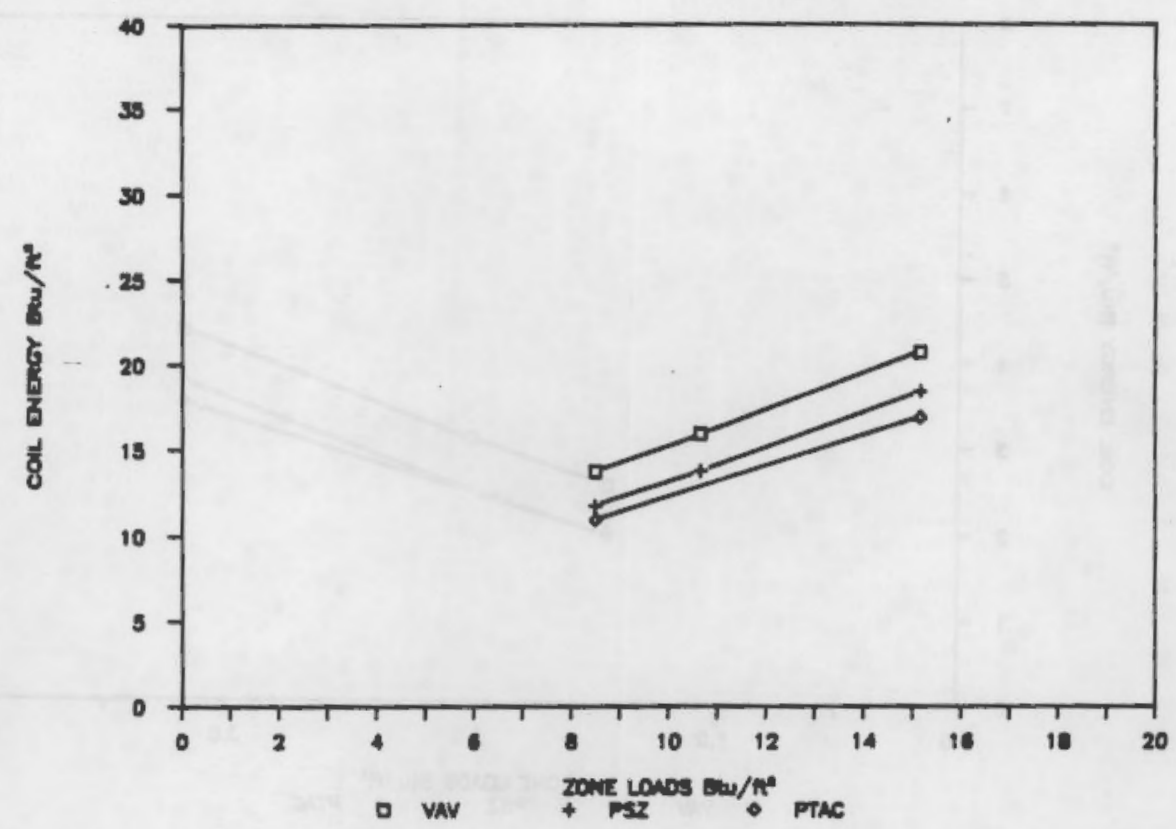

(a)

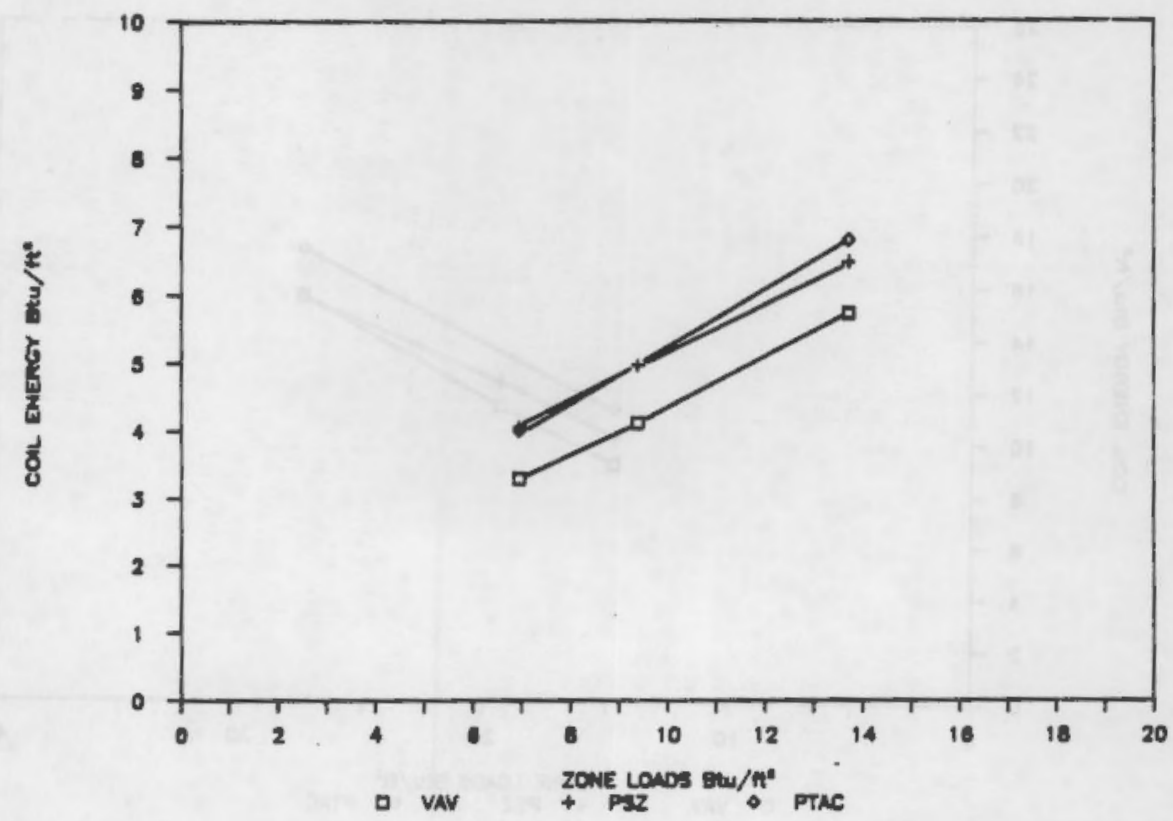

(b)

FIGURE 3.4. Sum of Zone Loads Versus Energy in Madison: a) Heating and b) Cooling 


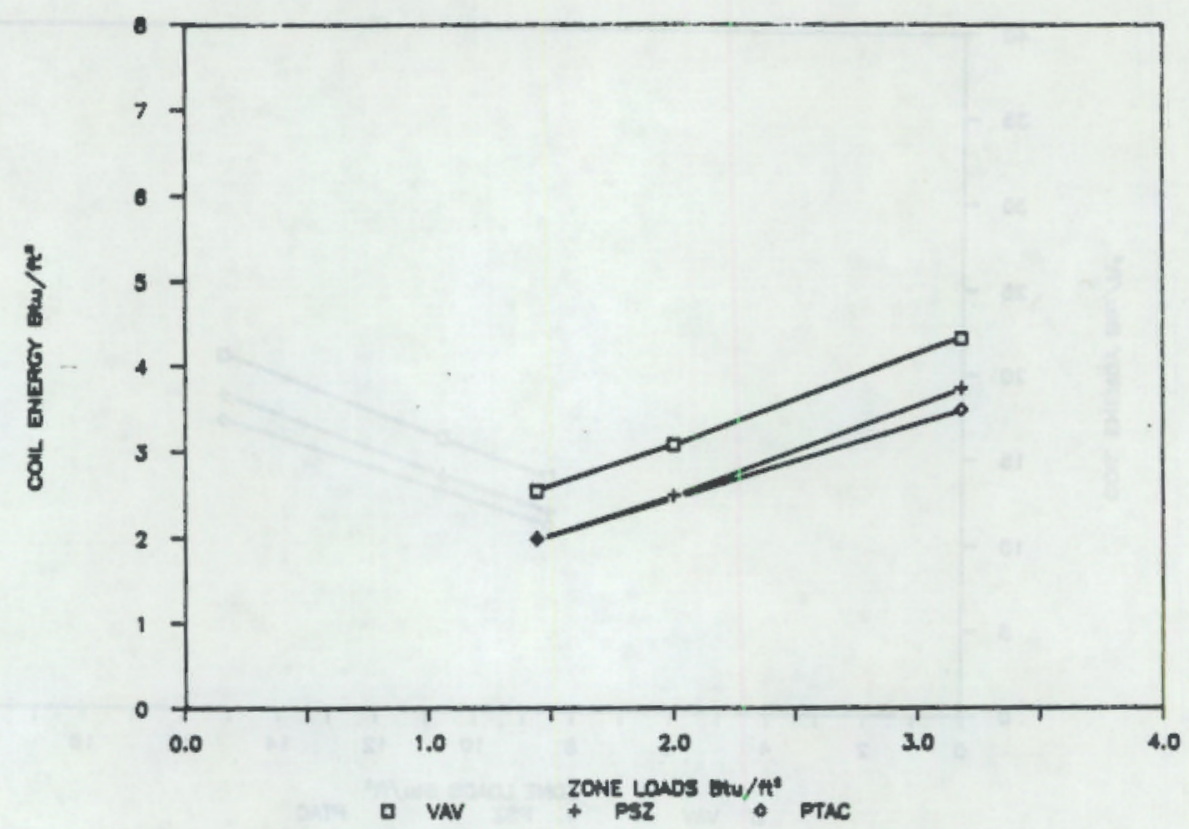

(a)

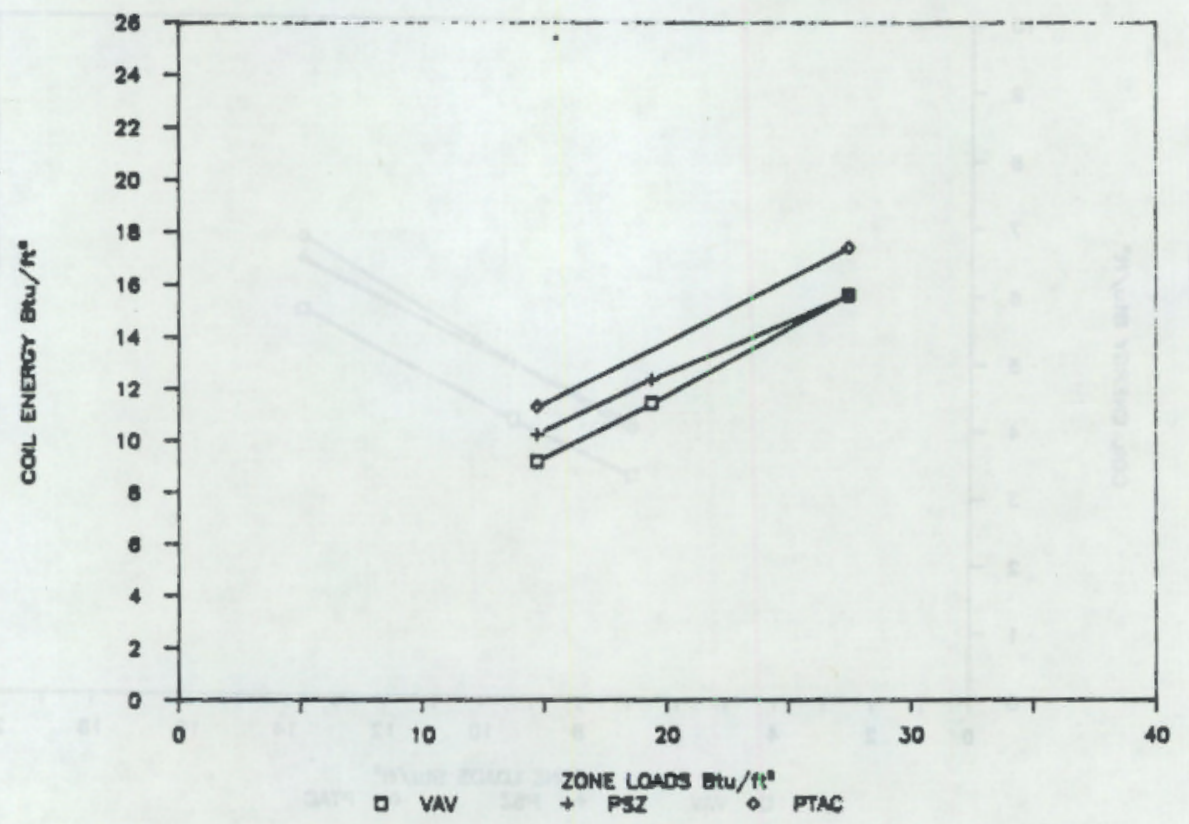

(b)

FIGURE 3.5. Sum of Zone Loads Versus Energy in Fort Worth: a) Heating and b) Cooling 


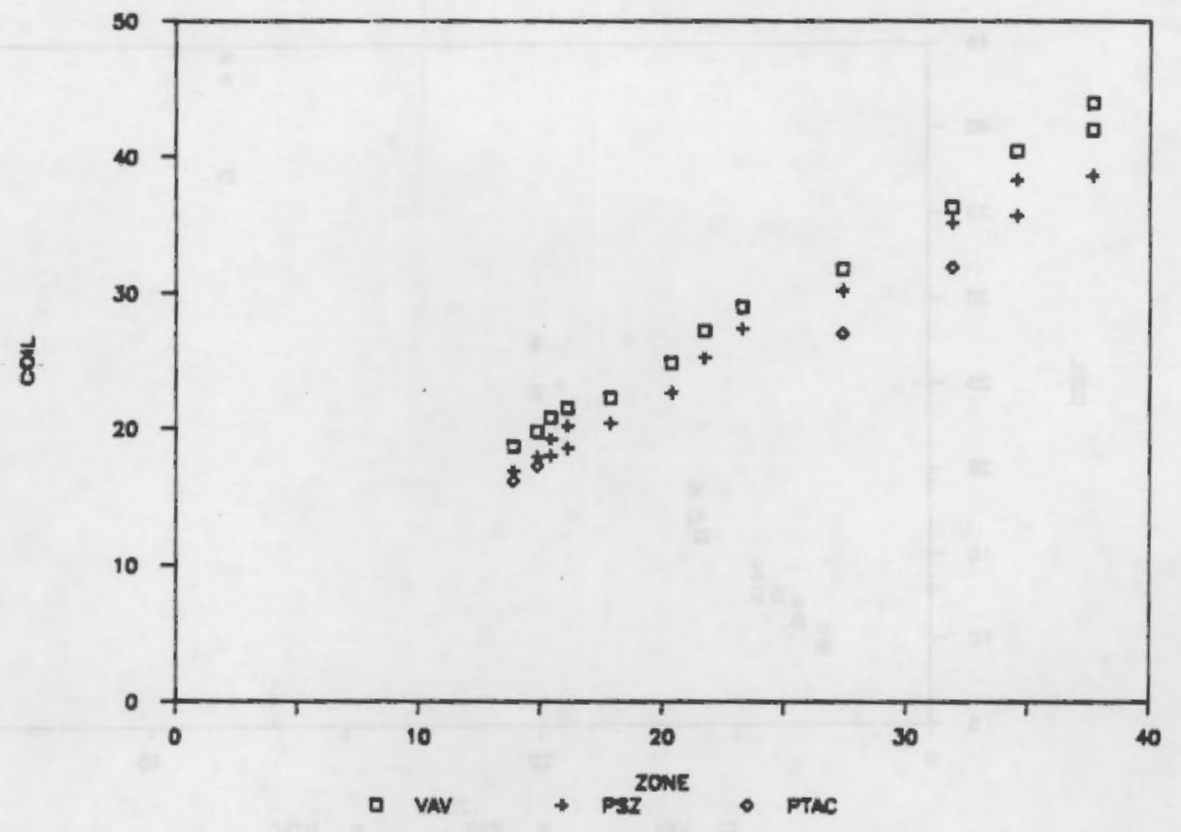

FIGURE 3.6. Zone Loads Versus Coil Heat Addition in Madison

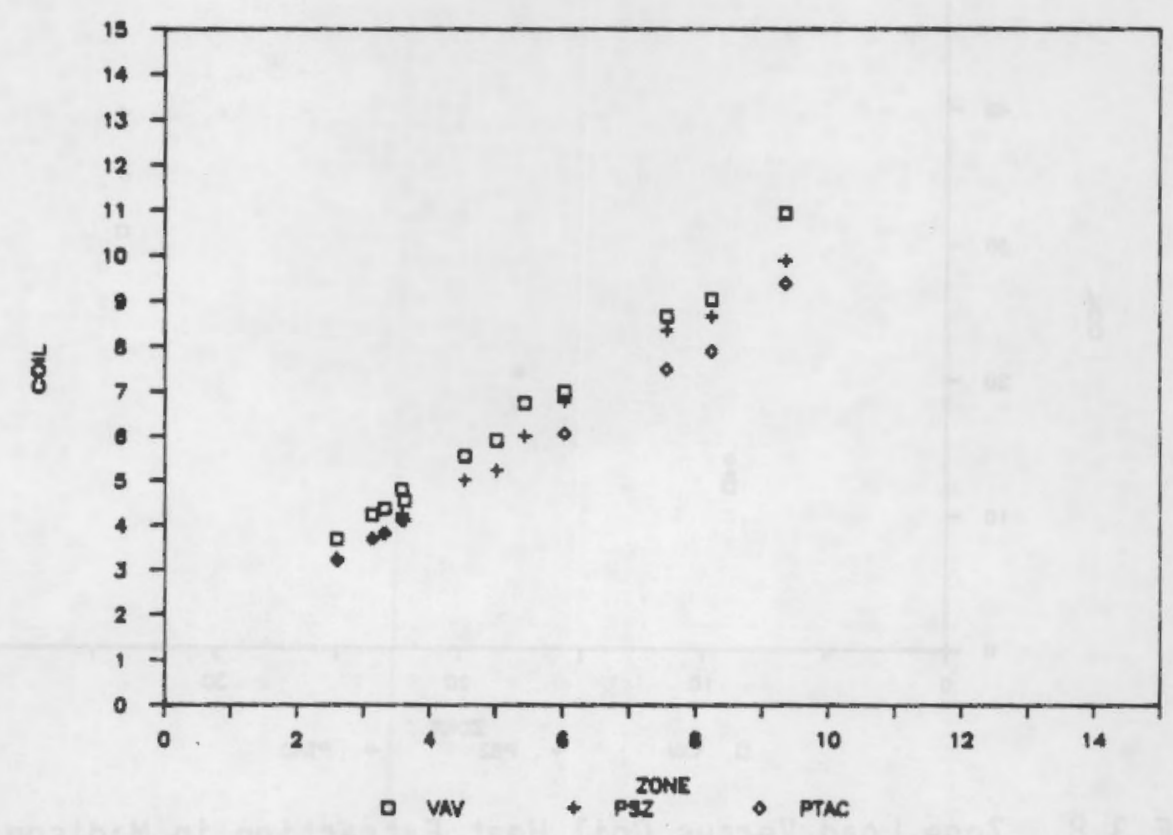

FIGURE 3.7. Zone Loads Versus Coil Heat Addition in Fort Worth 


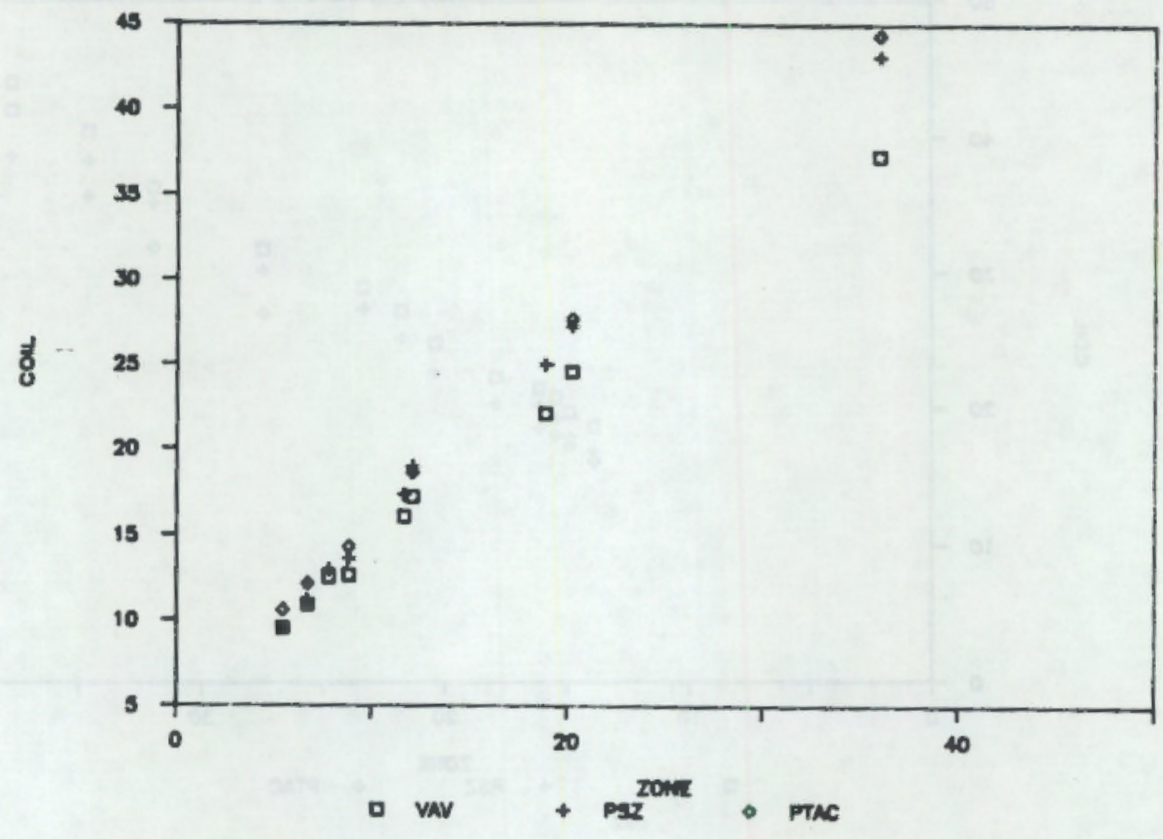

(a)

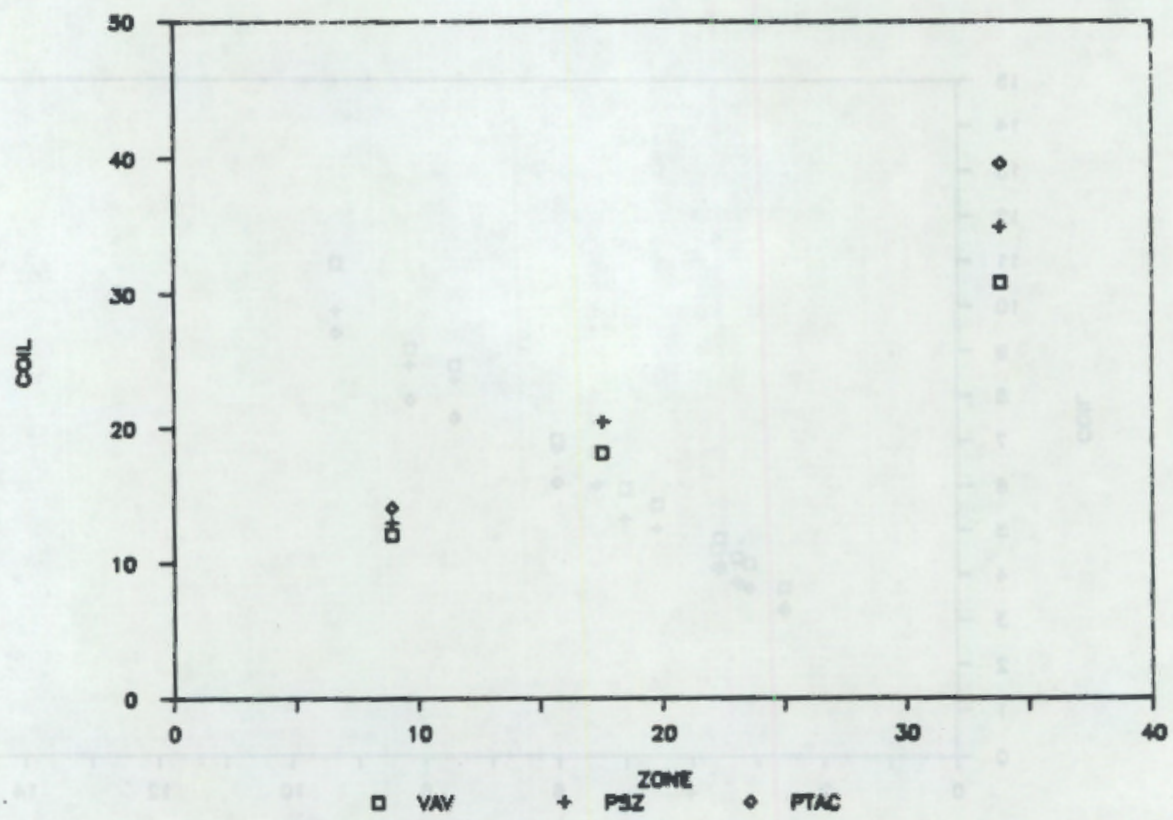

(b)

FIGURE 3.8. Zone Load Versus Coil Heat Extraction in Madison a) for the North, East, and West Zones, and b) for the South Zone 


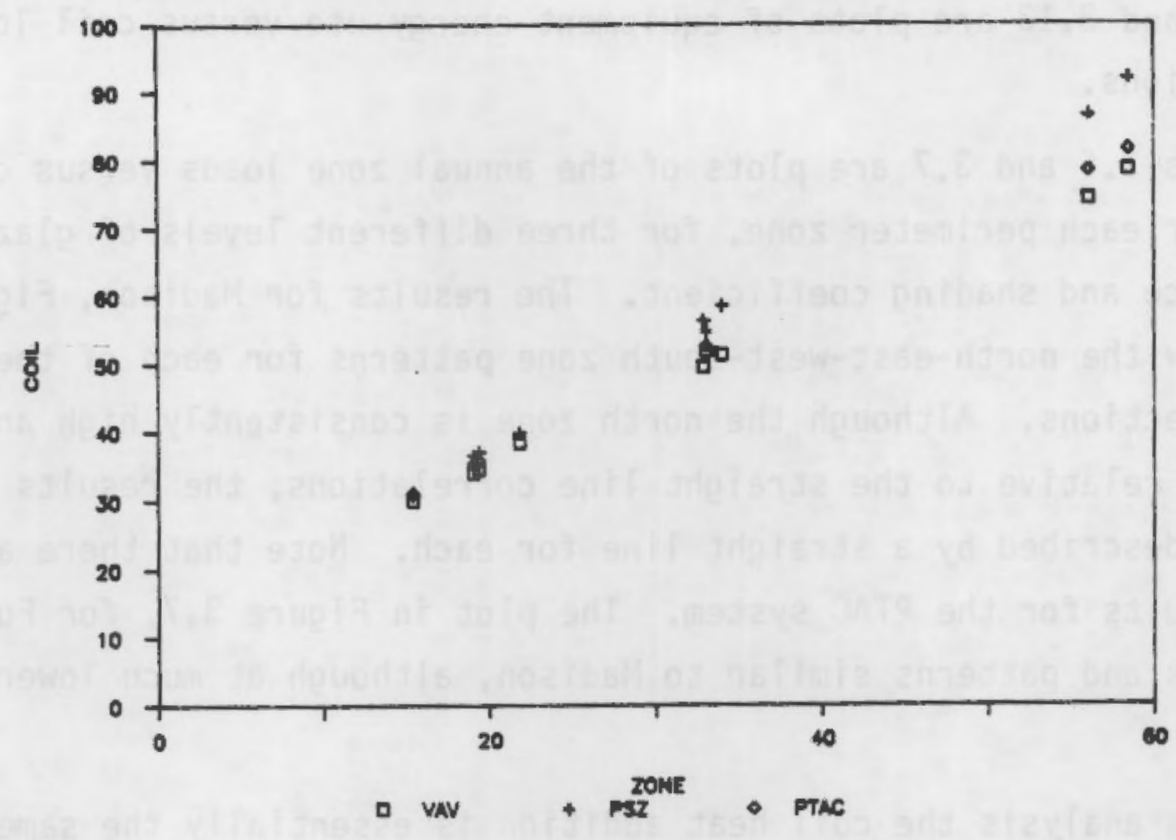

(a)

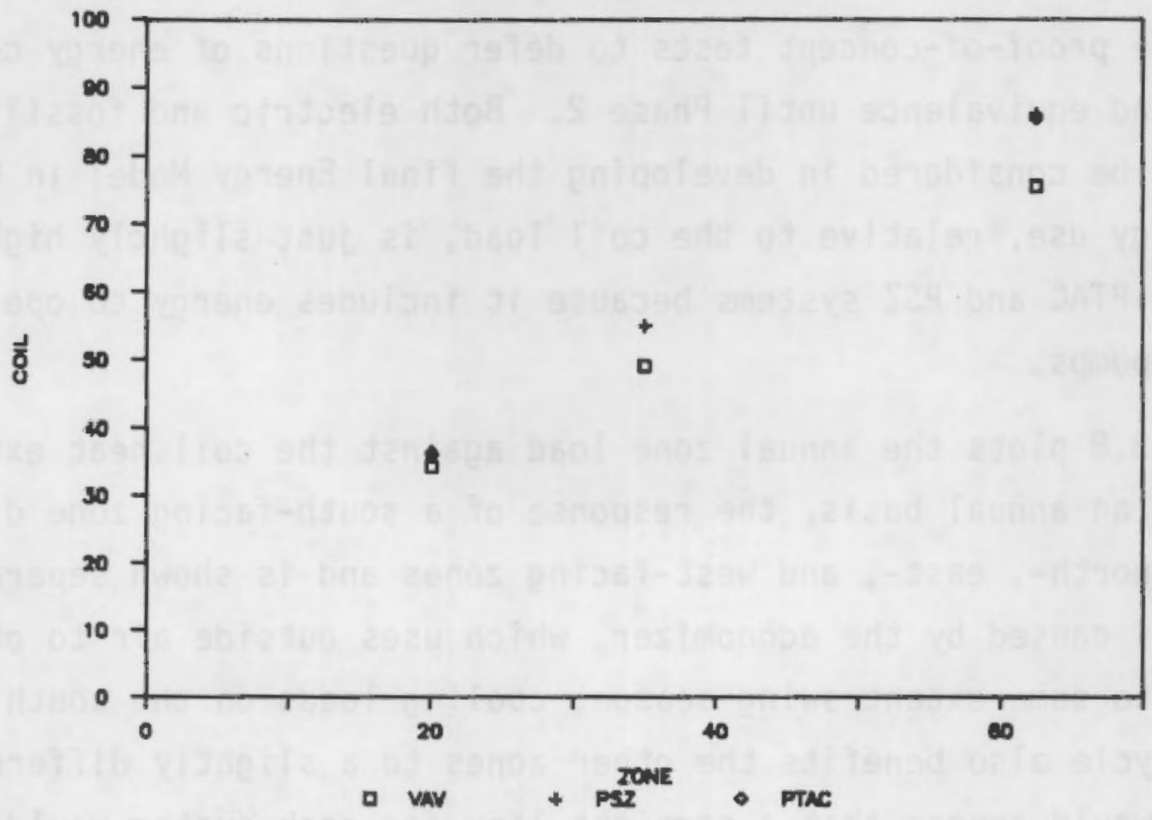

(b)

FIGURE 3.9. Zone Load Versus Coil Heat Extraction in Fort Worth a) for the North, East, and West Zones, and b) for the Soutn Lone 
the transmission and solar gain characteristics of the glazing. Figures 3.10 , $3.11,3.12$ and 3.13 are plots of equipment energy use versus coil loads for the same variations.

Figures 3.6 and 3.7 are plots of the annual zone loads versus coil heat addition for each perimeter zone, for three different levels of glazing thermal transmittance and shading coefficient. The results for Madison, Figure 3.6, clearly show the north-east-west-south zone patterns for each of the three glazing selections. Although the north zone is consistently high and the south zone is low relative to the straight line correlations, the results can be reasonably described by a straight line for each. Note that there are only two sets of results for the PTAC system. The plot in Figure 3.7, for Fort Worth, shows trends and patterns similar to Madison, although at much lower heating loads.

In this analysis the coil heat addition is essentially the same as the energy use, as is shown by the $45^{\circ}$ correlation lines in Figures 3.10 and 3.11 . This similarity exists because electricity was selected as the heating energy source in the proof-of-concept tests to defer questions of energy conversion efficiency and equivalence until Phase 2. Both electric and fossil fuel heat sources will be considered in developing the final Energy Model in Phase 2. The VAV energy use, relative to the coil load, is just slightly higher than that for the PTAC and PSZ systems because it includes energy to operate circulating pumps.

Figure 3.8 plots the annual zone load against the coil heat extraction for Madison. On an annual basis, the response of a south-facing zone differs from that of the north-, east-, and west-facing zones and is shown separately. This difference is caused by the economizer, which uses outside air to offset the winter, and to some extent swing season, cooling loads on the south zone. The economizer cycle also benefits the other zones to a slightly different extent. However, it would appear that a straight line for each system would provide a reasonable $f$ it of the simulation results for the north, east, and west zones. Figure 3.9 shows the same results for Fort Worth, which has considerably higher cooling loads than Madison, but still shows the same linear increase in zone load with an increase in coil heat extraction. In each of these figures the 


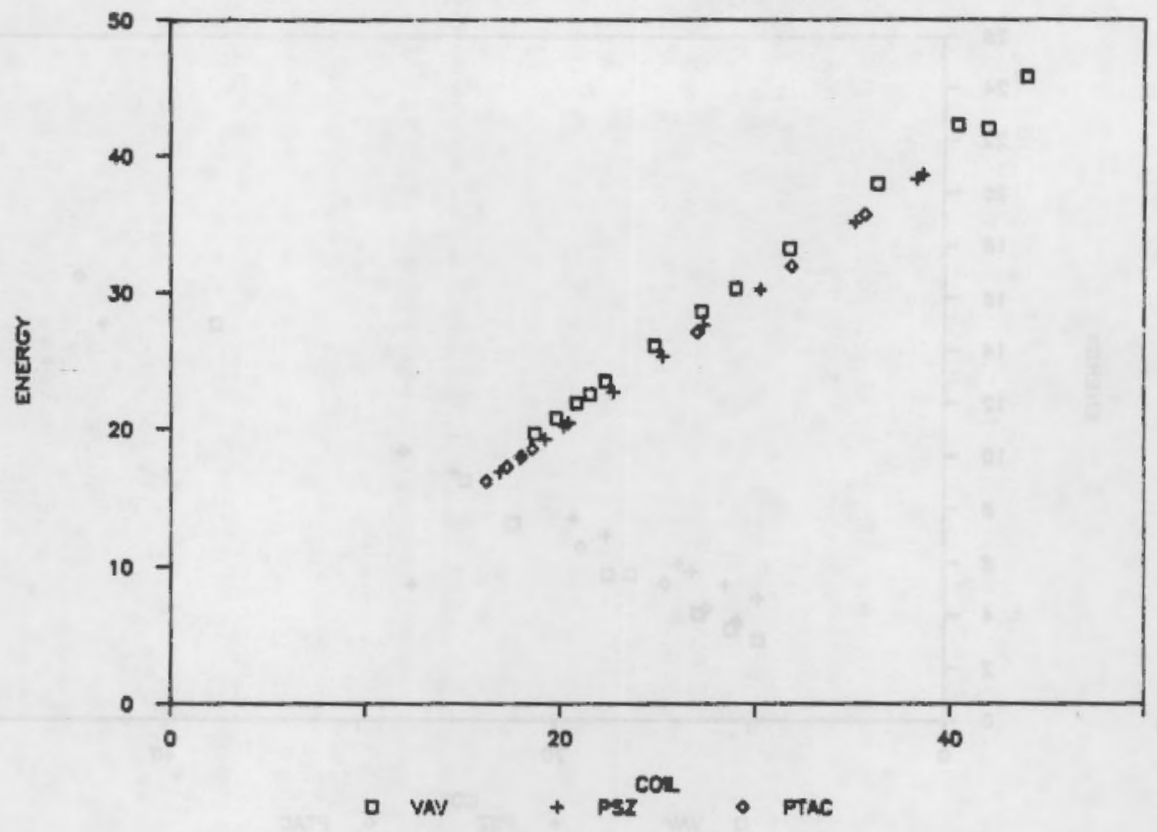

FIGURE 3.10. Coil Heat Addition Versus Energy Use in Madison

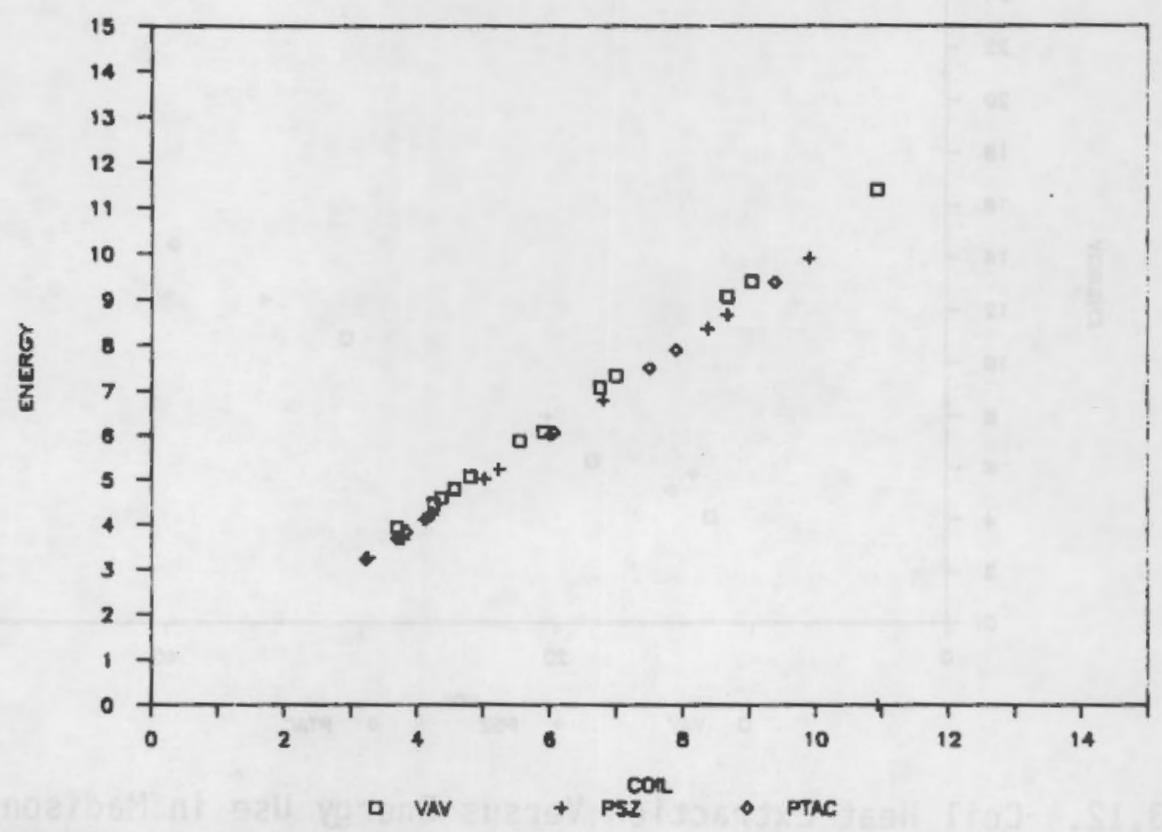

FIGURE 3.11. Coil Heat Addition Versus Energy Use in Fort Worth 


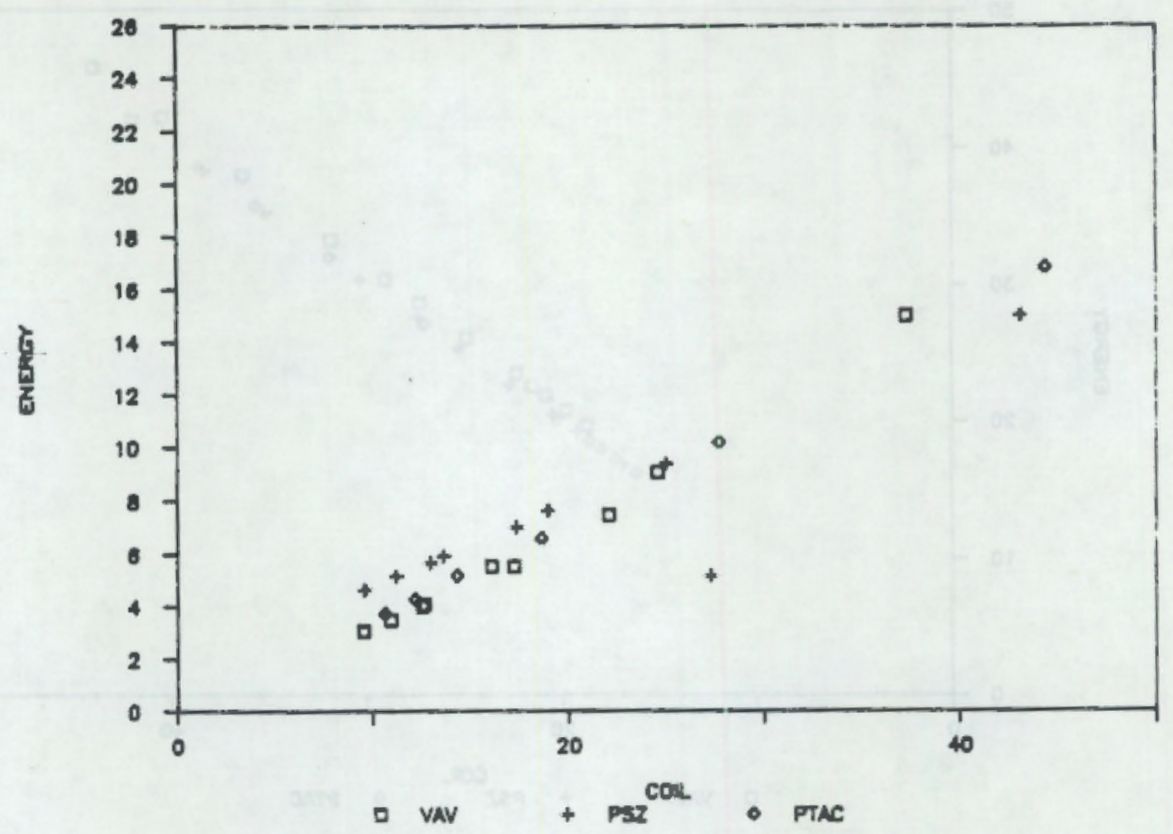

(a)

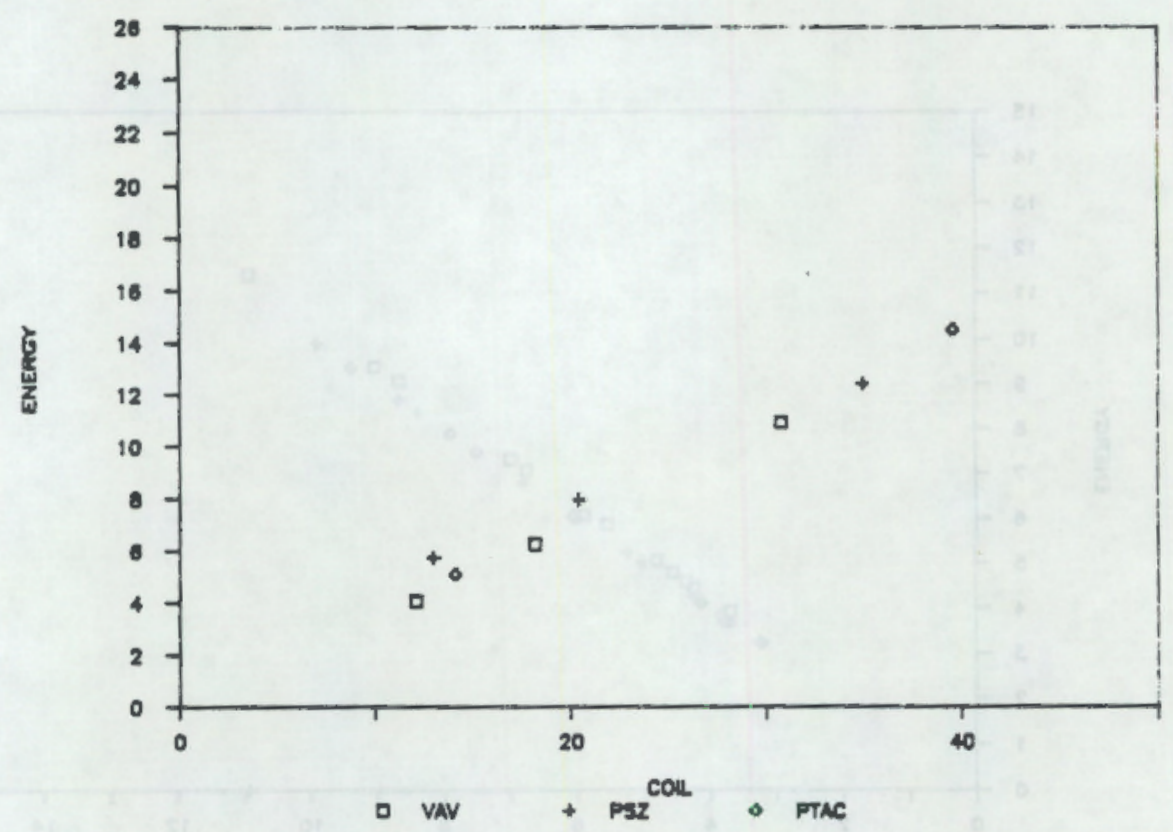

(b)

FIGURE 3.12. Coil Heat Extraction Versus Energy Use in Madison a) for the North, East, and West Zones, and b) for the South Zone 


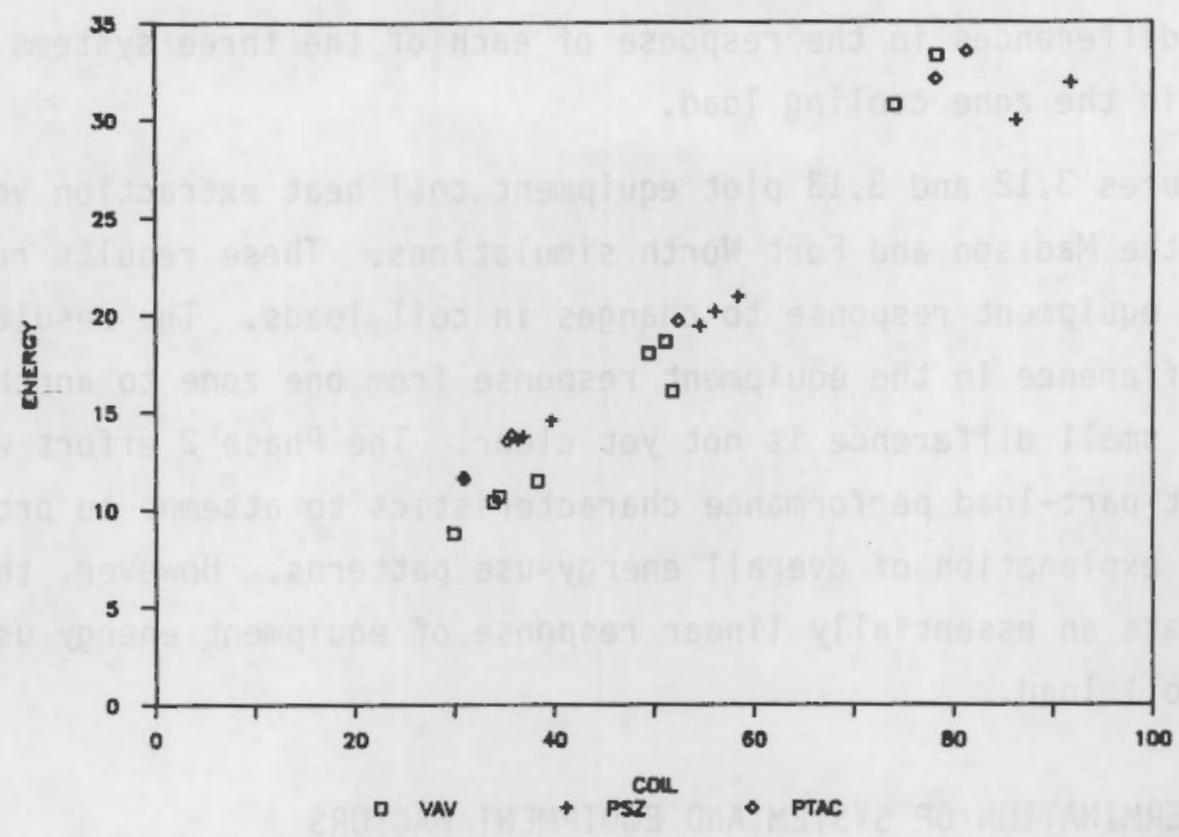

(a)

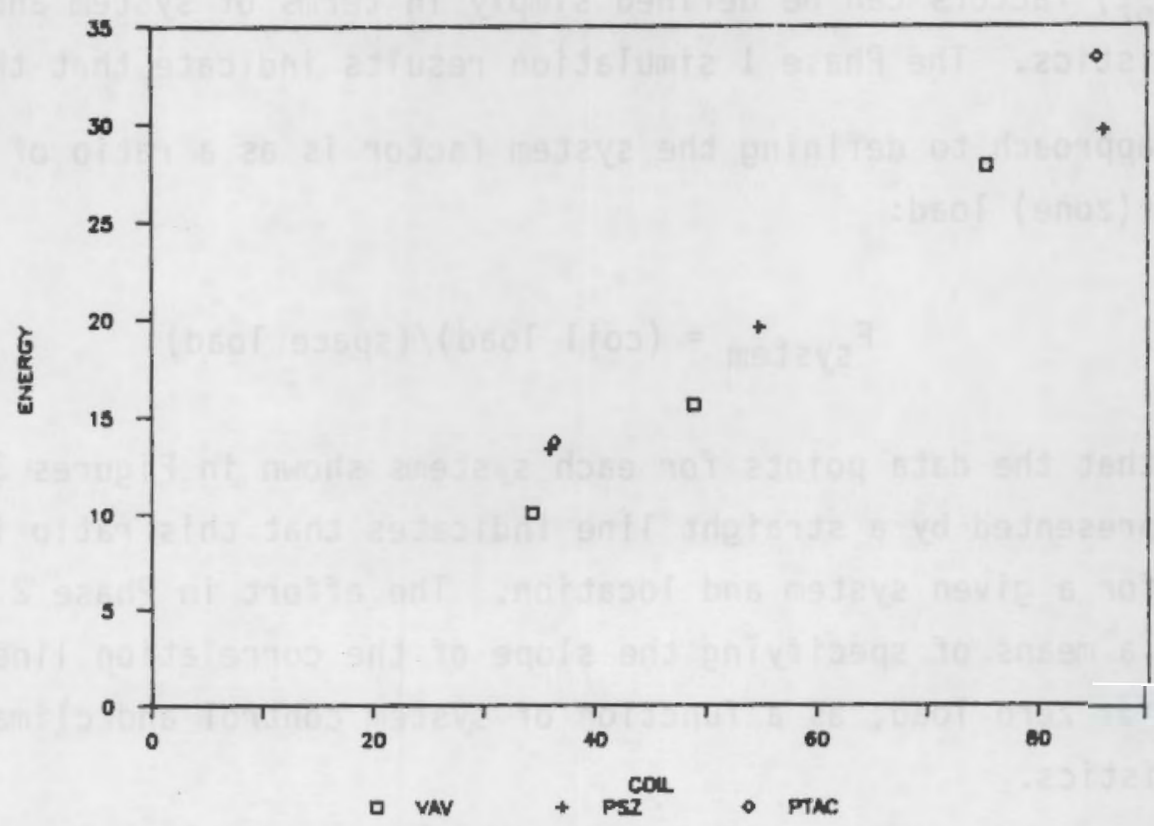

(b)

FIGURE 3.13. Coil Heat Extraction Versus Energy Use in Fort Worth a) for the North, East, and West Zones, and b) for the South Zone 
differences between the zone load versus coil heat extraction correlations reflect differences in the response of each of the three systems examined to changes in the zone cooling load.

Figures 3.12 and 3.13 plot equipment coil heat extraction versus energy use for the Madison and Fort Worth simulations. These results reflect differences in equipment response to changes in coil loads. The results also show a small difference in the equipment response from one zone to another; the reason for this small difference is not yet clear. The Phase 2 effort will examine equipment part-load performance characteristics to attempt to provide a more complete explanation of overall energy-use patterns. However, the results demonstrate an essentially linear response of equipment energy use to a change in the coit load.

\subsection{DETERMINATION OF SYSTEM AND EQUIPMENT FACTORS}

The final question is whether or not the system ( $\left.F_{\text {system }}\right)$ and equipment ( $\left.F_{\text {equipment }}\right)$ factors can be defined simply in terms of system and equipment characteristics. The Phase 1 simulation results indicate that they can.

One approach to defining the system factor is as a ratio of coil loads to the space (zone) load:

$$
F_{\text {system }}=(\text { coil load }) /(\text { space load })
$$

The fact that the data points for each systems shown in Figures 3.6 through 3.9 can be represented by a straight line indicates that this ratio is reasonably constant for a given system and location. The effort in Phase 2 will be to determine a means of specifying the slope of the correlation line, and the intercept at zero load, as a function of system control and climate characteristics.

A similar procedure can be applied to determine the annual equipment factor as a ratio of the energy use to the coil loads:

$$
\left.F_{\text {equipment }}=\text { (energy use }\right) /(\text { coil load })
$$


Figures 3.12 and 3.13, which present plots of coil heat extraction versus energy use for Madison and Fort Worth, also indicate that the equipment factor, an annual coefficient of performance (COP) in this case, can be defined for a particular selection of equipment. Again, the slope and intercept vary with equipment type and climate. The Phase 2 effort will define these relationships in terms of basic characteristics.

\subsection{SUMMARY OF ENERGY MODEL PROOF-OF-CONCEPT RESULTS}

This preliminary proof-of-concept analysis has indicated that the spacefunction approach is a viable alternative to the Building Energy Performance Standard, also known as BEPS (DOE 1979), and ANSI/ASHRAE/IES Standard $90 \mathrm{Sec}-$ tion 10 (ANSI/ASHRAE/IES 1975) approaches. The BEPS developed energy budgets for 16 commercial building classifications. The ANSI/ASHRAE/IES Standard 90 Section 10 required development and simulation of building design and a separate building that complies with the requirements of Section 1 through 9 of the Standard. The space-function approach has the distinct advantage of being more flexible than the BEPS procedures and easier to use than Standard 90. The results obtained in Phase 1 show that it is possible to consider individual functions and that a linear relationship exists between annual space loads and annual energy use for three basic and inherently different HVAC systems. This linear relationship exists even when energy use differs markedly from one system to another. A number of factors must still be considered, but the present research provides clear rationale for continuing the development of this concept in Phase 2. 



\subsection{APPROACH FOR TREATING ECONOMICS}

This section describes the methods that have been proposed to deal with economic considerations in Phase 2 and explains the underlying rationale for this approach.

The section consists of two major parts: the first part discusses background issues, and in general terms, how these issues will be addressed; the second part gives a detailed description of the approach. Much of the work on economics that was done during Phase 1 involved the development of a proof-ofconcept computer spreadsheet. This work is described in detail in Appendix $B$ of this report.

\subsection{BACKGROUND ON ECONOMICS}

Economic analysis will serve two distinct functions in the Targets Project: to provide guidance in targets development and to assess the economic performance of the resulting targets. This section discusses the role of economics, the analysis of performance-based guidelines, the marginal cost analysis, the economic perspectives, the appropriate time horizons, and the definition of economic parameters related to the Targets Project.

\subsubsection{The Role of Economics in Developing Energy Targets}

Professional judgment has been the primary basis for building standards in the past. Economics has always been a factor in the development of these standards because generalized knowledge about the economics of building design is embedded in professional judgment. Economic assessments of standards, when conducted in the past, have usually been done after the fact, intending to assess the impact of the result rather than guiding the effort.

The general emphasis of the whole-building energy Targets Project has been to employ thorough and technically rigorous approaches to each aspect of the methodology for developing targets. In this context, a methodology has been developed for using building construction costs, energy costs, and economic methods to guide the target setting process in a direct and systematic way. This approach has been designed to yield targets that have a rigorous technical 
basis and also a sound economic basis. Economic evaluations will be conducted as part of Phase 2 of the project to characterize the economic performance of the target levels.

\subsubsection{Analysis of Performance-Based Guidelines}

The economic analysis of performance-based guidelines is difficult because of the variety of materials and methods (all with different associated costs) that can be employed to achieve a specified performance level. In addition, because of the complex and interactive effects that building features have on energy use, one feature will have varying energy and economic performance depending on other features that are present in the building. Each designer may have the incentive to select and apply measures efficiently, but there can be no guarantee that the measures employed to achieve a target level will result in an appropriate level of economic performance.

The targets development procedure will rely on a simplified energy model and sets of space characteristics to define achievable levels of energy performance. The energy targets will be based on sound selections of space characteristics. The proposed approach will base target selection on the performance resulting from the use of readily available materials and methods that are appropriate and cost-effective in their particular application.

\subsubsection{Marginal Cost Analysis}

Marginal productivity is a concept that is important to the proposed approach to economics for use in the Targets Project. Figure 4.1 shows the energy-cost savings resulting from improvements in energy efficiency versus the changes in building first cost that are necessary to achieve improvements. The graph represents the cumulative costs and performance impacts of collections of measures. While the graph is hypothetical, it reflects relationships that are often observed: initial declining first costs resulting from mechanical system first-cost reductions as efficiency is improved in very inefficient buildings; and continuously diminishing returns from additional investments in energy efficiency. 


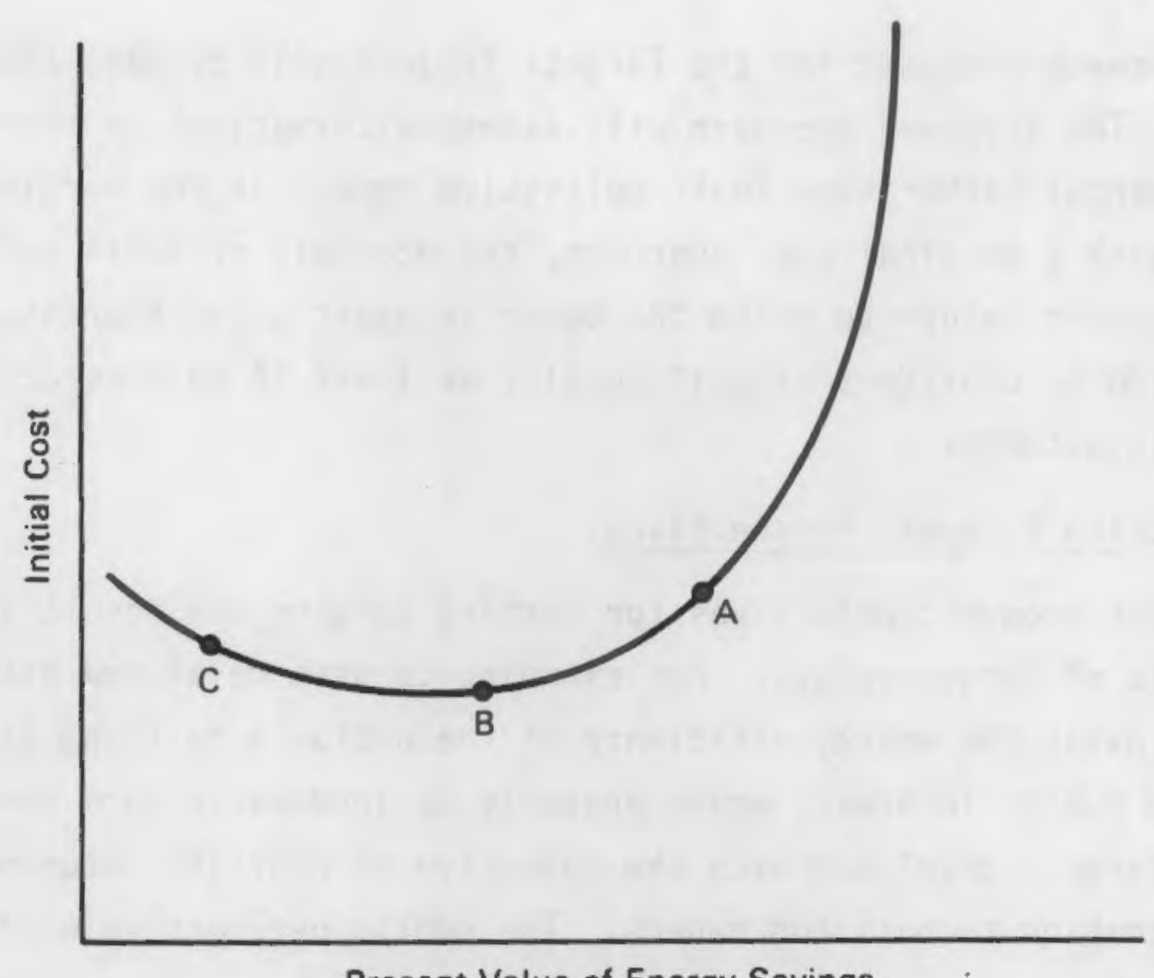

Present Value of Energy Savings

FIGURE 4.1. Energy Conservation Opportunity Curve

The curve describes the best available opportunities for energy cost savings and their corresponding initial costs; the slope of the curve at any point represents the marginal (or incremental) productivity of these energy-saving opportunities. When economics is used as the basis to determine appropriate levels of energy efficiency, there is a critical slope above which the investment is considered insufficiently productive to warrant the expense. This critical slope might be termed the investment threshold, the minimum attractive rate of return, or target payback ratio. In the example, the slope of the line segment through point $A$ represents this critical slope.

The most desirable level of energy efficiency is found by including all measures that are as or more productive than this threshold. This level is found by examining the marginal productivity of investments in efficiency rather than the average productivity of the full set of measures relative to a base case. In the example, point $A$ represents the most desirable level of performance where the slope is positive and the incremental first cost equals the energy-cost savings. 
The approach proposed for the Targets Project will by-pass the need to use base cases. The proposed approach will assess alternatives on the basis of their incremental rather than their collective impact at the margin as defined above. In such a marginal cost approach, the economic criteria reflect the level of economic return to which the owner is exactly indifferent, i.e., the level at which he considers himself equally well off if he does or does not accept the investment.

\subsubsection{Selecting Economic Perspectives}

Different economic objectives for setting targets can result in very different levels of target values. For example, targets developed with the objective of improving the energy efficiency of the nation's building stock, based upon a broad public interest, would probably be inherently more energy efficient than targets developed with the objective of providing economically beneficial information to building owners. The public perspective would place a higher value on energy efficiency than the private perspective because many of the costs associated with energy use (national security implications, impacts on world energy markets, resource depletion, pollution, and macroeconomic impact) are external costs to a building owner (i.e., the individual building owner does not pay for them).

The proposed approach of producing multiple target levels allows such diverse economic perspectives to be addressed directly. One level of targets might reflect typical public interest in economic considerations. Another level might reflect the economic perspectives of the typical long-term enlightened owner. Still another target level might reflect typical shorter term owner economic perspectives. The multiple target level approach has the advantage of not attempting to squeeze such diverse economic perspectives into a single compromise that satisfies few. In addressing the building owner's economic perspective, it is important that the owner's economic perspective be examined carefully. Legitimate concerns related to risk, liquidity, return on investment, tax impacts, and the owner's reasonable expectations for cost escalation and ultimate disposal of the asset can be considered as appropriate by an owner in developing his own targets. 


\subsubsection{Appropriate Time Horizons}

Selecting the appropriate time horizons to define economic perspectives is tied to the definition of the several target levels (e.g. minimum acceptable practice, good practice, technical and economic limit) that have been proposed. Although the final decision on the number of levels (probably from two to four) that will be developed will not be made until Phase 2, economics is a natural and appropriate basis for distinguishing between target levels. Regardless of how many target levels are ultimately specified, all perspectives cannot be accurately represented with a fixed set of targets.

The outlook of building owners who have long-term interests in their buildings will be used in defining the economic perspectives corresponding with the most energy-conserving performance levels. The time horizon may vary with building type. This approach will focus on the needs of owners having interest in the inherent value of buildings for their intended purposes as opposed to those whose interest in buildings are primarily for speculative gain. Shortterm and speculative owners are assumed to be reluctant to invest in energy efficiency that is not consistent with their economic perspective. Most likely these owners would opt for buildings designed to the minimum acceptable practice level defined by code.

\subsubsection{Level of Effort on Economics}

The large costs involved in conducting economic evaluations on similar projects in the past appear to have been primarily associated with the development of building cost data rather than with the economic analyses. For example, in the ASHRAE SP 41 research, the economic evaluation involved the selection and estimation of the cost of materials for each building in each location tested. Because judgment was involved in many of the selections, selected materials and performance levels sometimes appeared inconsistent.

Such problems will be minimized by using an approach that uses generalized costs based on significant samples of building materials, rather than the selection of specific materials and their associated costs. In a sense, this approach will increase the level of abstraction of the study, but will enhance its validity from a statistical point of view while lowering research and 
development costs and improving the consistency of results. Rather than expending time to modify and estimate the costs of specific building designs, time will be spent to build or manipulate a data base of building construction costs to yield arithmetic expressions relating the energy performance of building components to component costs. These expressions will, in turn, be used in conjunction with the space-function energy model to help define economical space characteristics and to guide the development of the targets.

\subsubsection{Defining Economic Parameters}

Much of the extreme disparity in economic parameters that has been observed among some economic studies in the past has resulted from the use of values that are inconsistent with long-term trends. Extremely high long-term energy-cost escalation rates in studies done during the mid-1970s are prime examples. Estimates for most economic parameters can be generated with reasonable confidence when these parameters are seen in the appropriate context and in view of long-term trends. Since a number of the economic parameters that need to be defined will depend on the perception of the intended user as much as the opinion of experts, it is appropriate that procedures be established to include those perceptions in the process of defining the economic perspectives. A process emphasizing target-audience input and review will be employed to establish economic parameters for the project. The economic perspective provided by this information will constitute one of several sources of input to determine appropriate targets performance levels.

\subsection{OESCRIPTION OF PROPOSED APPROACH}

The whole-building energy targets will be generated using the spacefunction energy model and descriptions of spaces that have been appropriately configured for energy efficiency. Figure 4.2 illustrates the basic procedure to develop energy targets, the Targets Mode1. The proposed approach for treating economic issues makes economics an integral part of the methodology for developing targets.

The need for the targets to be responsive to wide ranges of design constraints and operating conditions among commercial buildings has led to an 


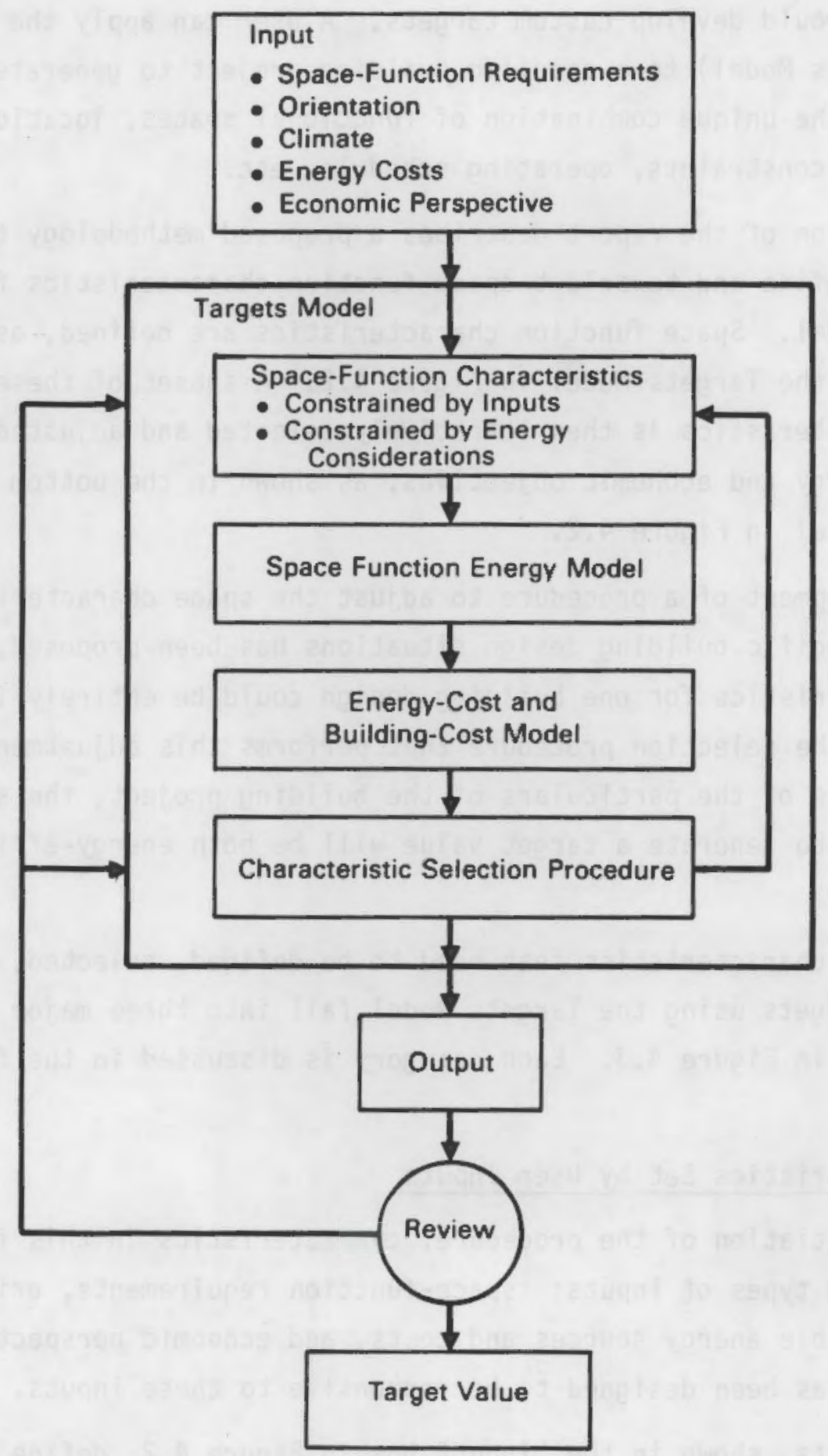

FIGURE 4.2. Procedure to Develop Targets for the Targets Model 
approach that would develop custom targets. A user can apply the targets procedures (Targets Model) to a specific building project to generate a target that reflects the unique combination of functional spaces, location, energy prices, design constraints, operating schedule, etc.

This section of the report describes a proposed methodology that has been developed to define and to select space-function characteristics for use with the Targets Model. Space function characteristics are defined, as shown in the top box within the Targets Model in Figure 4.2. A subset of these spacefunction characteristics is then iteratively selected and adjusted to achieve a balance of energy and economic objectives, as shown in the bottom box within the Targets Model in Figure 4.2.

The development of a procedure to adjust the space characteristics to accomnodate specific building design situations has been proposed, since appropriate characteristics for one building design could be entirely inappropriate for another. The selection procedure that performs this adjustment must ensure that, regardless of the particulars of the building project, the space characteristics used to generate a target value will be both energy-efficient and cost-effective.

The space characteristics that need to be defined, selected, or adjusted to generate targets using the Targets Model fall into three major categories, as illustrated in Figure 4.3. Each category is discussed in the following sections.

\subsubsection{Characteristics Set by User Inputs}

At the initiation of the procedure, characteristics in this first category are set by five types of inputs: space-function requirements, orientation, climate, available energy sources and costs, and economic perspective. The Targets Model has been designed to be responsive to these inputs.

These inputs, shown in the "Input" box in Figure 4.2, define specific values for a variety of physical characteristics of the functional space and the pattern of its use. The physical characteristics set by these inputs are shown in the top section of Figure 4.3. Once set at the beginning of the Targets 


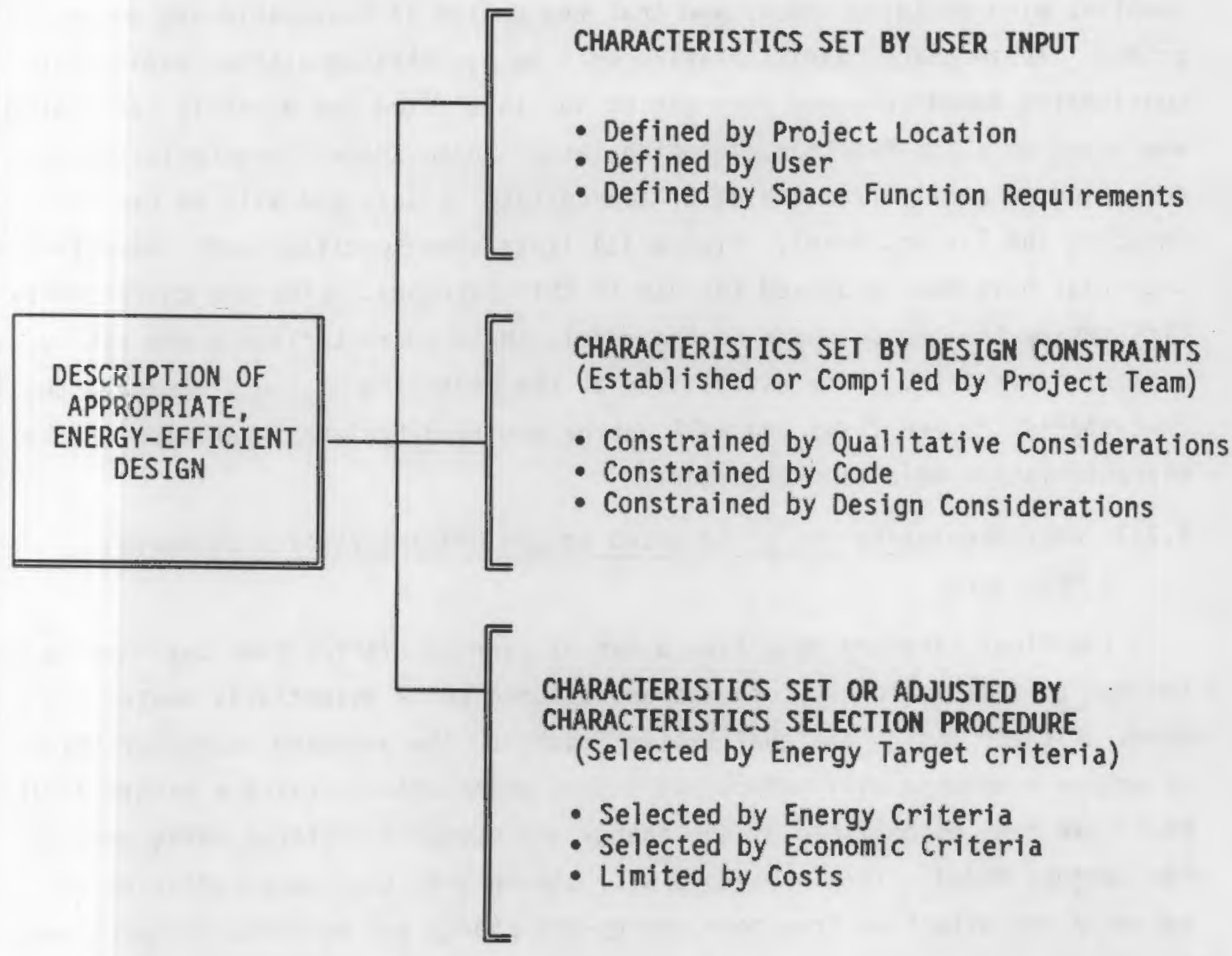

FIGURE 4.3. Inputs to the Targets Development Process

Model procedure, these space function characteristics are fixed; they are not modified by later operation of the characteristics selection procedure.

\subsubsection{Characteristics Set by Design Constraints}

These characteristics are also set at the initiation of the procedure to ensure that a target value determined for a particular design project accommodates the specific design constraints of that project (e.g. site constraints, occupancy schedule, environmental quality objectives, internal loads in response to special process requirements, etc). Characteristics in this category are constrained to ensure that the quality of the interior environment 
complies with building codes, and that the design is reasonable and appropriate. These space characteristics will be established without explicitly considering economics, and they can be set in a fixed (or directly calculated) way based on space function, location, etc. These space characteristics will be copied primarily from tables of appropriate values, and will be used as input to the Targets Model. Figure 4.4 lists some specific space characteristics that have been proposed for use in this category. Like the characteristics set by the basic inputs to the model, these characteristics are set by design constraints. Once established at the beginning of the procedure, the characteristics are fixed and will not be modified by later operation of the characteristics selection procedure.

\subsubsection{Characteristics Set or Adjusted by the Characteristics Selection Procedure}

The final category comprises a set of characteristics that can have major impacts on building energy use and are assumed to be essentially neutral in terms of their design and qualitative impacts. The proposed characteristics selection procedure will select and adjust these characteristics within limits that have been established by the energy and economic criteria being used by the Targets Model. This procedure will ensure that the characteristics are balanced and effective from both energy-efficiency and economic perspectives. Building and energy costs will be used in the selection procedure. Available options for these characteristics are viewed as potential investments in building energy efficiency, and the selection procedure serves to optimize the performance of the investment.

This selection process, like the design process it is intended to reflect, is complicated by the interactive nature of many of the characteristics in this third category. For example, heating system type and lighting loads affect what insulation levels will be cost-effective. Likewise, fenestration selection affects whether automatic daylighting controls can be cost-justified, and automatic daylighting controls affect appropriate fenestration and electric lighting selections. One consequence of these interactions is that the selection of these physical space characteristics would be extremely difficult by simply solving an equation. Instead, an iterative procedure is proposed. 


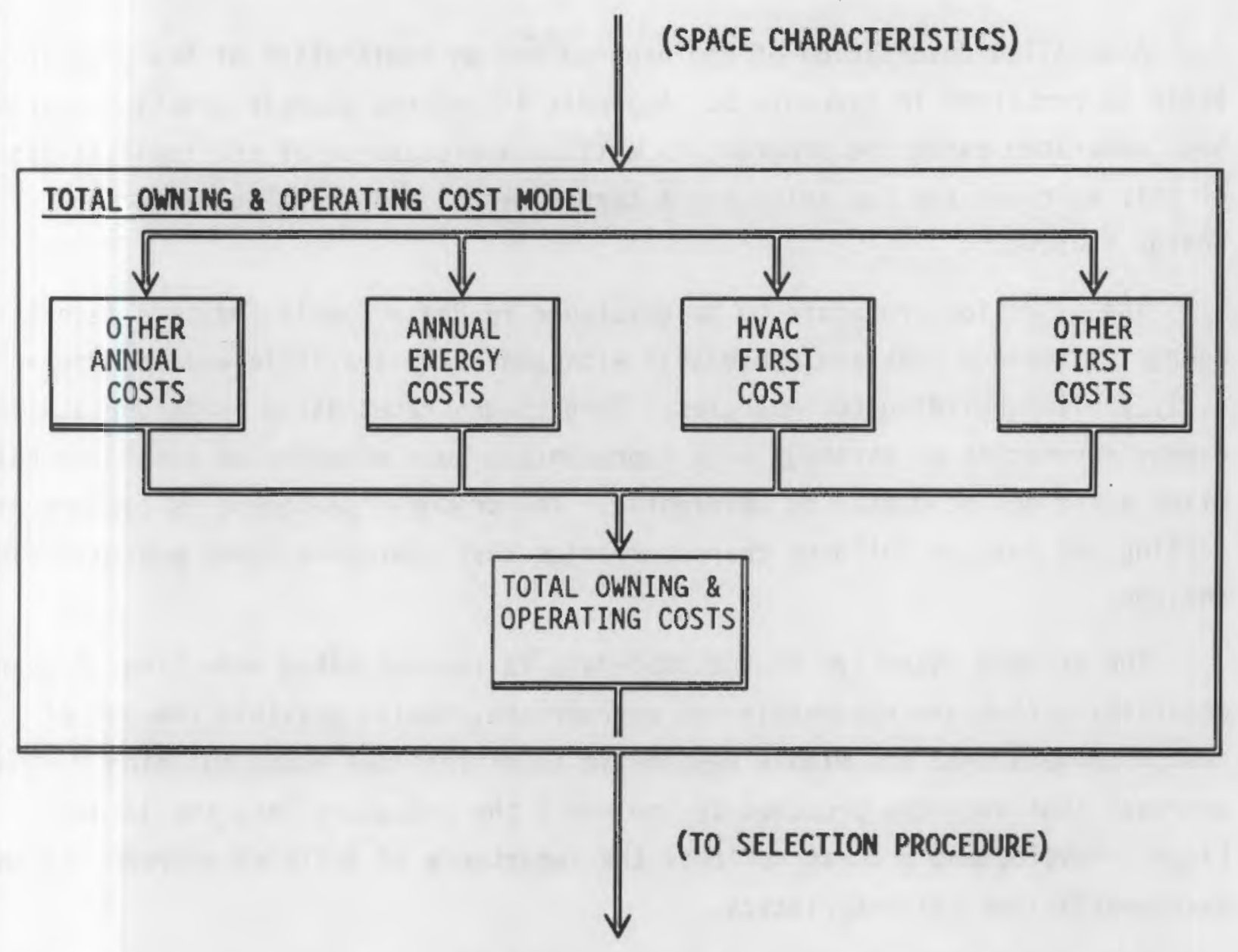

FIGURE 4.4. Building-Cost and Energy-Cost Model

A computer program has been proposed to make the automatic selections of physical space characteristics. A proof-of-concept version of such a program was developed during Phase 1 using a spreadsheet program and its keyboard macro facilities. The program was written to select the most cost-effective type of heating system, cooling system, and glazing. Values for electric lighting power density, window shading coefficients, and wall conductance are also determined by the program. In addition, the program determines whether automatic daylighting controls should be employed. Total owning and operating costs (TOOC, as calculated by the regression-based space-function energy model and the energy-cost and building-cost model) are minimized by the selection process. 
A detailed description of the program and an explanation of the program logic is contained in Appendix B. Appendix B contains example graphs that have been generated using the program, as well as a discussion of the implications of this approach for the selecting a target metric and treating different energy sources.

The selection procedure to be developed in Phase 2 will indicate levels of energy efficiency that are achievable with generally available and appropriately applied building technologies. Targets generated using inappropriate energy strategies or strategy sets representing poor economic or technological mixes would not be useful or meaningful. The proposed procedure is capable of sorting out sets of building characteristics that represent sound energy design choices.

The primary objective of the procedure is the automated selection of characteristics that are reasonable and appropriate, making possible the use of custom targets that are highly responsive to differences among buildings. The approach that has been proposed to implement the procedure into the larger targets-development process reflects the importance of defining appropriate and energy-efficient characteristics.

Figure 4.2 illustrates how the characteristics selection procedure will be integrated with the other parts of the Targets Model to yield a single procedure. The arrows within the box entitled "Targets Model" illustrate the iterative nature of the procedure; the characteristics selection procedure operates by means of multiple recalculations of the space-function energy model and the building-cost and energy-cost model. The review loop illustrates that the target-generating procedure will be subject to adjustment based on information sources external to the model, including metered data from existing buildings and the judgments of knowledgeable professionals representing various buildings disciplines.

Figure 4.4 shows the building-cost and energy-cost model, which is intended to provide a comprehensive accounting of energy-related costs. Costs that are incurred at the time of construction, as well as the major recurring costs for energy and for maintenance, are included. Cost variations by project 
location are determined from the basic input to the Targets Mode1. This component of the Targets Model will employ standard analysis methods used in engineering economics. The final selection of these methods, which may include cash-flow analysis and life-cycle costing, will depend on the definitions of target performance levels, which will be developed during Phase 2. The Phase 1 proof-of-concept test employed economic parameters representing five different perspectives; these perspectives sought to minimize initial costs, minimize net initial year cash flow, and minimize three different measures of TOOC.

Figure 4.5 is an enlargement of Figure 4.3 and shows more detail of the proposed categories of space function characteristics. Some of the characteristics listed in the figure were used in the selection procedure model developed during Phase 1 as a proof-of-concept. These characteristics will probabiy change as a result of further development work in Phase 2.

The parameters in the top box ("Space Function Characteristics") of Figure 4.5 describe the project, while those in the second box ensure appropriateness, acceptable building quality, and energy efficiency. The lowest box represents the output from the characteristics selection procedure, the characteristics of an appropriate, energy-efficient design.

If the proposed procedure is employed in the process to develop targets, it will be possible to characterize the economic performance of each target level without further analysis. The technique used in the selection procedure will incorporate additional energy-related features until their marginal economic productivity declines to a predefined level. This predefined level of marginal economic productivity can be translated to an easily understood measure of economic performance within the context of the assumptions used in the model. For example, one could characterize the economic performance of a target level by indicating that it represents the level of energy use obtainable where only measures paying back in 5 years or less were employed. This characterization is somewhat different from past economic assessments of similar work where buildings that were configured to meet the performance level, were 


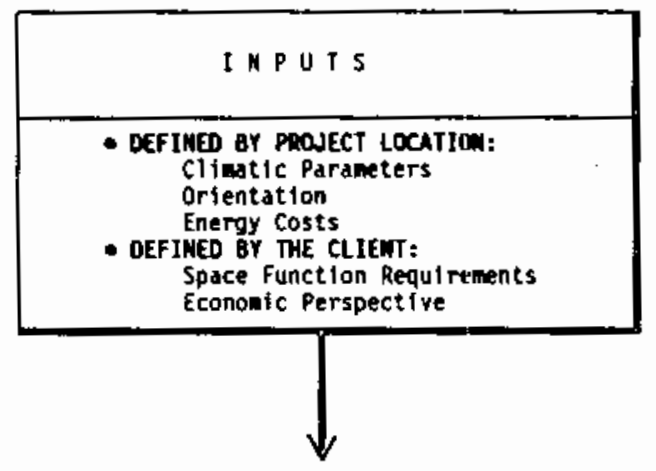

\section{TARGETS}

MODEL

SPACE FUNCTIOA

CHARACTERISTICS

(Examoles)

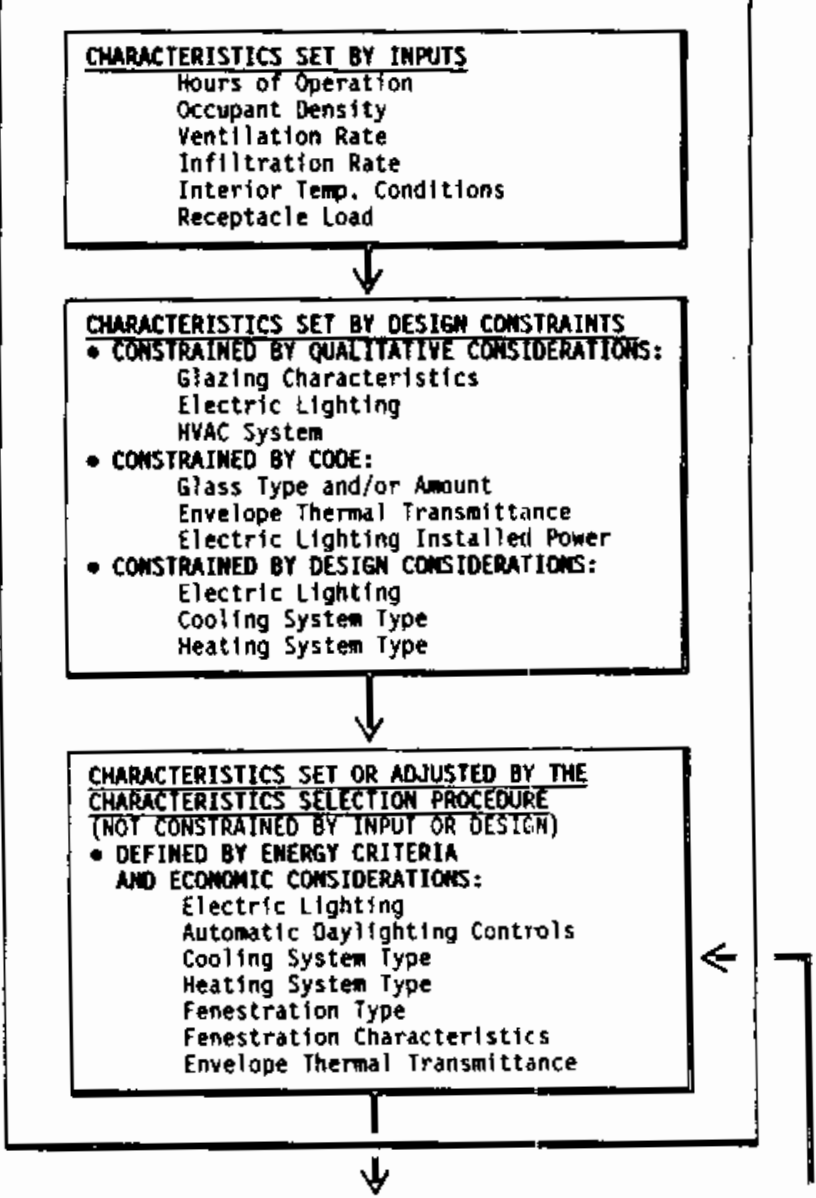

(TO SPACE FUMCTION EMERGY MOOEL)

(FAM)

CHARACTERISTIC

SELECTIOH

PROCEDURE)

FIGURE 4.5. Example Space-Function Characteristics Used in Target-Setting Procedure 
compared to base-case configurations, and economic comparisons were made essentially on a case-study basis. The economic assessment using this approach should yield more meaningful results while dramatically diminishing the cost and effort required.

\subsection{CONCLUSIONS}

The approach that has been proposed for treating economic considerations would make economics an integral part of the process for developing targets. The proof-of-concept testing (described in Appendix B) demonstrated the initial technical feasibility of the approach. Subsequent analysis examined the nature of the resulting targets and revealed the following implications:

- If the proposed approach is employed, targets would be based on the application of specific building technologies in specific building projects and on the costs of implementing those technologies.

- Inherent in the generation of each target would be at least one set of building characteristics that would meet the target. Assuming this information is made available to the user, it would serve the educational and demonstration goals of the project and would of fer the user a way to check the reasonableness of target values.

- Updating the targets could be very straightforward and would only involve updating performance coefficients to reflect the availability and performance of new energy-related building technologies. Updating energy costs would be automatic if local utility costs were used, and construction costs could be keyed to published construction cost indices to keep them current.

- The approach should minimize any conflict between the targets as voluntary, good-practice guidelines and the client's own selfinterest, because that self-interest would be built directly into the procedure.

- The approach would eliminate the need to perform external or afterthe-fact economic analysis on the cost-effectiveness of target performance levels. Parameters that can be used to characterize 
economic performance will be contained within the Targets Model any time it is used to generate targets.

- The optimization capability of the targets selection procedure may be suitable as a preliminary design tool, thereby encouraging use and acceptance of the targets. The routines designed for target definition could be used by the designer early in the design process to help in the selection of cost-effective design approaches and strategy combinations.

- The approach would provide an economic basis for neutrality and equity among energy sources, space functions, hours of operation, location, etc.; all targets at the same target level would be based on the same objective criteria. The differential treatment of competing energy sources, for example, would be based not on equivalence among fuels based on resource energy or energy costs but by the economic productivity with which the energy could be conserved. Equal economic pressure to conserve would be exerted on users of natural gas and users of electricity. In addition to benefits in terms of equity, the approach would lead to an efficient allocation of capital and the greatest possible energy savings for any given level of additional building costs expended to achieve the targets.

- The approach has the potential to make the technical basis for the targets more open and accessible because the targets would be based more firmly on analytical procedures and explicit assumptions than past efforts.

- Another benefit is that professional judgment, always a key ingredient in establishing target levels, would tend to be applied more explicitly. Professional judgment would be a key source of the energy and economic criteria that would be used in the exercise of the Targets Model to generate any given set of energy target values. 


\subsection{TARGET FORMATS}

This section describes the previous approaches to whole-building energy targets that formed the basis for proceeding with current work and for identifying the potential approaches that can be used in the context of this project. Alternative approaches that were examined for the specific formats to present the targets and for the content and structure of supporting information are discussed in this section.

The examination of target format involves a discussion of the following two elements:

- the development of an approach to deal with differences among various energy sources

- a survey of the issues related to energy target metrics.

\subsection{ENERGY SOURCES}

This section describes the Phase 1 work that was conducted to develop an approach for treating energy sources that is consistent with the project goal of promoting economical levels of building energy efficiency. The approach also had to be acceptable to the energy-supply and buildings industries. The intent of this work was to use an approach to energy sources that was free from artificial bias regarding competing energy sources and building systems, and that did not introduce distortions that would undermine the economic appropriateness of the targets.

\section{1 .1 Background}

The treatment of energy sources has proven to be difficult in similar building-energy-guideline projects. Different forms of energy used in buildings vary in the thermal efficiency of their production and end-use conversion, in their market prices, and in the social and environmental costs associated with their production and use. There is no simple or obvious common basis upon which all energy sources can be compared. Moreover, it is technically difficult to devise a procedure to deal with different energy sources that does not 
inadvertently introduce distortions and biases that artificially favor certain energy sources or building systems over others.

Two issues are particularly important in considering the approach for treating different energy sources: the method for measuring energy and the treatment of energy costs.

\section{Energy Measurement}

Energy use can be measured as a raw resource at a building's site boundary, at the heating and cooling coils, or at a number of points in between. Energy targets, based on each of these methods of measuring energy, would result in significantly different incentives for the end user.

Targets that measure energy use at the raw resource level would place electricity at a great competitive disadvantage versus fossil fuels, because of the inherent inefficiencies involved in generating electricity from thermal sources. The user of these targets would not have an incentive to use electricity. If the targets measured energy use at the site boundary, fossil fuels would be put at a disadvantage because the conversion losses occur after delivery to the site rather than before. Either of these approaches would result in artificial biases that would create incentives for the user to switch fuel types in order to more easily meet the target. Providing incentives to switch fuel is a serious bias or distortion that the energy-sources approach employed in the project will attempt to eliminate.

The problem of measuring energy is complicated further when certain energy sources are considered, e.g., steam, low-temperature hot water, and fuels used in the cogeneration of heat and electricity. Heat is the one common denominator for all forms of energy--chemical, potential, and electrical--because any form of energy can be converted into thermal energy. Whereas using the thermal value of different energy sources does permit comparison of all energy sources, it completely fails to reflect the value of those energy sources for specific applications within a building. For example, compare electricity with lowtemperature hot water. Electricity is an expensive but highly versatile form of energy, while low-temperature hot water, which in some cases may be available at very low cost, has far fewer productive uses within a building. 


\section{Energy Costs}

Most performance-based building energy standards and guidelines in the past have been energy-based rather than cost-based; that is, they have not integrated energy costs into the methodology. The cost of utility-supplied energy varies by as much as a factor of 10 across the United States. Targets that ignore these differences would promote inadequate levels of performance in high-energy-cost areas while promoting unwarranted expenditures on energy efficiency in areas having low-cost energy resources.

The original impetus for building-energy efficiency standards grew out of the energy shortages that occurred during the 1970s. At that time, the United States became acutely aware that a high level of dependency on imported oil would be costly for the nation, in terms of economic health and stability and national security. Many of these costs were understood to be intangible and some largely speculative.

Simitarly, there are costs to the nation associated with the depletion of domestic energy resources, with pollution resulting from energy production and use, and with the water-resource and land-use impacts resulting from the development of certain energy resources. These costs, however real, are very difficult to quantify.

Some efforts at developing building energy guidelines have attempted to incorporate these costs into the procedures, and these attempts have proven to be highly controversial. Furthermore, the approaches have been inextricably tied to political issues that would make the issues controversial even if a consensus were achieved on a technical level. For these reasons, and for this project, procedures on energy costs, as reflected by local market prices, have received high evaluation ratings.

\subsubsection{Approach}

The Phase 1 work on energy sources consisted of two major tasks. The first task was to develop a set of evaluation criteria to assess the various methods to treat energy sources. The second task was to compile a list of possible methods to treat energy sources and to assess these methods in light of 
the evaluation criteria. A detailed discussion of the advantages and disadvantages and the ranking for each method is contained in Appendix $E$.

The approach was designed to ensure that the consideration of options to deal with the energy sources issue would be done in an open, thorough, and objective way. The use of explicit criteria and a methodical approach to assessing alternative methods was intended to facilitate review by clearly communicating the basis for decisions to interested reviewers. Technical representatives of the gas and electric industries have contributed to all project team discussions and decisions regarding the treatment of energy sources. Extensive review of this work will take place before further development of the selected approach is begun during Phase 2.

\subsubsection{Evaluation Criteria}

This section describes the criteria that were developed to assess the suitability of the different methods to treat energy sources for the targets project. The evaluation criteria grew directly out of the statement of project goals and desirable attributes for the targets, described in Section 1 of the Volume 1: Final Report. These criteria are shown in Table 5.1. Included in the table are the relative weights assigned by the project team to each of the four major evaluation areas. The weights assigned are subjective, and represent the team's consensus of the relative importance of each criterion to the ultimate success of the project in achieving its basic goal. These evaluation criteria and weights were used to rate each of the alternative methods.

\subsubsection{Alternative Methodologies for Treating Energy Sources}

By considering the range of options available to treat different energy sources, the project team ensured that important alternatives were not overlooked, and the basis upon which the project team selected approaches for further consideration was documented. The experience gained in previous examinations of the energy sources issue will be useful in the development of a final energy sources methodology.

The following four generic approaches for treating different energy sources have been identified: 


\section{TABLE 5.1. Energy Sources Evaluation Criteria}

Major Criteria

1. USER ISSUES (Weight: 10)
Supporting Criteria

Easy to understand

Easy to use
Details

Meaningful units Familiar

Manageable computation

Manageable information

requirements

2. DEVELDPMENT AND MAINTENANCE Economical to develop

ISSUES (Weight: 5) Easy to update

Quick to develop

3. TECHNICAL ISSUES/SCOPE Technically sound

(Weight: 10)

\begin{tabular}{|c|c|}
\hline Technically sound & $\begin{array}{l}\text { Procedures suitable for } \\
\text { multiple disciplines } \\
\text { Accurate } \\
\text { Repeatable }\end{array}$ \\
\hline Comprehensive & $\begin{array}{l}\text { Contains key variables } \\
\text { to be considered } \\
\text { Addresses climate/ } \\
\text { regional differences } \\
\text { Allows use of all } \\
\text { energy sources } \\
\text { Accounts for energy, } \\
\text { demand, time-of-day } \\
\text { Social \& environmental } \\
\text { factors considered }\end{array}$ \\
\hline
\end{tabular}

4. NEUTRALITY (Weight: 10) Reflective of market forces

Free from artificial biases

- Convert to thermal energy at the site boundary. This method uses the heat value of energy sources at the building site boundary to measure total energy use.

- Convert to thermal energy at the site boundary, but ignore fossil fuel conversion losses. This method uses the heat value of energy sources at the building site boundary but treats all conversions of fossil fuels to thermal energy as if they were thermally $100 \%$ efficient processes. The intent of this approach is to put all energy forms on a postconversion basis. 
- Convert energy resources to thermal energy. This approach converts energy resources into their equivalent heat value. The term "energy resource" refers to the raw form of the resource prior to its conversion to a form in which it can be transported to the building site and used. The intent of this approach is to put all energy forms on a preconversion basis.

- Convert to energy cost. This approach uses cost instead of heat value as the basis for relating different different energy sources.

\subsubsection{Descriptions of the Alternative Methods}

Within the four generic approaches, 14 distinct methods have been identified. Some methods are simply variations on others. Table 5.2 shows the relationship among the 14 different methods and the four generic approaches to the energy source issues listed above. This listing does not include all the methodologies that have ever been suggested or used. However, it does cover virtually all of the methods that have received widespread consideration and review.

In the sumary descriptions that follow, each distinct method is briefly described, the rationale behind the method is presented, and a brief history of its use is given. For some methods, key strengths and weaknesses are discussed. More detailed descriptions of the alternative methods, including listing of their strengths and weakness, are provided in Appendix $E$. The strengths and weaknesses are organized according to the evaluation criteria presented in Table 5.1 .

Convert to Thermal Energy at the Site Boundary

The following subsections describe the possible methods within this first generic approach to treat different energy sources.

Site Boundary Conversion to Thermal Energy Method. This method has recefived the most widespread use. The annual energy use for each energy source is converted to thermal energy (e.g., $3413 \mathrm{Btu} / \mathrm{kWh}$ for electricity). These values are then added to yield a total annual energy use value, usually expressed in $B t u /\left(y r \cdot f t^{2}\right)$. This method was not really developed; it has evolved as a simple way to measure building energy use. 
TABLE 5.2. Methods Generated by Generic Approach

A. MEASURE THERMAL ENERGY AT THE SITE BOUNDARY

1. Site Boundary Conversion to Thermal Energy

2. ASHRAE/IES Standard 90B-1975 (Section 10) Method

B. MEASURE THERMAL ENERGY AT SITE BOUNDARY, COIL FOR FOSSIL FUELS

3. Apply On-Site Post-Conversion Factor

4. Omit On-Site Conversion Energy Losses

C. MEASURE ENERGY AT THE RESOURCES LEVEL

5. DOE's Institutional Grant Program (IGP) Factor

6. QN Index

7. ASHRAE 90C-1977R -- RUFs/RIFs(a)

D. USE ENERGY COST AS BASIS FOR COMPARISON

8. Building Energy Performance Standards (BEPS) -Weighting Factors

9. National Average Unit Cost Per Energy Source

10. Regional Average Unit Cost Per Energy Source

11. Local cost (ASHRAE/IES Standard 90B-1975R)

12. Local Energy Source Cost (per Published Rate Schedule)

13. Marginal Cost

14. Total Owning and Operating Cost

(a) This method, Resource Utilization Factor/Resource Impact Factor (RUF/RIF), actually goes beyond resource energy; it is the only one that explicitly attempts to address societal and environmental impacts.

ASHRAE/IES Standard 90B-1975 (Section 10) Method. This method calls for the conversion of each energy source to a value that is "equivalent for purposes of comparing ... total energy used," but does not specify how that equivalence is to be established. The implication was that a site-boundary equivalence, would be used, probably employing the method entitled "Site Boundary Conversion to Thermal Energy."

Section 10 was a response to those who desired a more flexible way to comply with Standard 90 than the prescriptive component path. The method was to be used in testing for compliance by comparing the annual energy use of two building designs (a reference design complying with the prescriptive portions of Standard 90, and the design in question). By employing this method, a 
designer is required to use the same energy forms for similar functions in both the reference and the design being checked; thus, it is not possible to meet a target simply by switching energy sources.

This method is used in the current version of Standard 90; the method is also used in the Model Code for Energy Conservation administered by code groups, and thus is in effect in well over 40 states.

Convert to Thermal Energy at the Site Boundary, but Ignore Fossil Fue 1 Conversion Losses

The following subsections describe the possible methods within the second generic approach to treating different energy sources.

Onsite Postconversion Adjustment Factor Method. This method applies a predefined adjustment factor to the energy use of fossil fuels, thus putting it on a postconversion basis. The adjustment factor is designed to offset the fossil fuel combustion losses, which occur onsite. Fossil energy is combined with the onsite heat equivalent of electrical energy use, calculated using $3413 \mathrm{Btu} / \mathrm{kWh}$. The final result is expressed in $B t u /\left(y r \cdot \mathrm{ft}^{2}\right)$. This method has been used privately but has not, to the authors' knowledge, been used by any public entities.

Omit Onsite Conversion Energy Losses Method. This method is very similar to the previous method; it differs however, when calculated annual load data are available. In that case, the loads to be served using fossil fuels (e.g., heating boilers and service water heaters) are used in place of estimated energy use, adjusted to offset combustion losses. As with the previous method, the result is expressed in $\mathrm{Btu} /\left(\mathrm{yr} \cdot \mathrm{ft}^{2}\right)$. This method was considered for inclusion in the systems analysis portion, Section 10, of ASHRAE Standard 90, but was not adopted.

If energy used for space conditioning were measured at the bujlding's heating and cooling coils (after onsite conversion losses), then the resulting incentive to reduce these loads would be identical for fossil fuels and electricity. While this would at first appear evenhanded, when the typical difference in the cost of delivered energy from fossil fuels and electricity is 
considered, some subtle but significant distortions may occur. Where electricity is used for heating, higher levels of energy performance in the building envelope are of ten sought because of the high productivity of such improvements in the face of high unit energy costs. If the targets were to employ this approach of ignoring onsite conversion losses, target levels that were costjustified for electrically heated buildings would be too stringent for gasheated buildings.

Convert Energy Resources to Thermal Energy at the Resources Level

The following subsections describe the possible methods within the third generic approach to treating different energy sources.

The U.S. Department of Energy's Institutional Grant Program Factor Method. The Institutional Grant Program (IGP) Factor method converts energy measured at the site boundary into its equivalent heat value as a raw resource. Like the two methods that follow, the intent of the IGP method is to express all energy sources on a preconversion basis. The method differs from them primarily in the conversion factor that is used for electricity, which is $11,600 \mathrm{Btu} / \mathrm{kWh}$. As with the other the methods, the final result is expressed in Btu/(yr.ft $\left.{ }^{2}\right)$.

Use of this method began in late 1970 s when DOE prescribed it for evaluating energy conservation measures in the Institutional Buildings Grant Program (IBGP), which covered existing buildings only. The conversion procedure just described is used only for reporting IGP program results to Congress. Decisions on implementing specific energy conservation measures for specific building projects are determined using federal life-cycle-costing procedures. A few other entities (e.g., state codes) have used this method, although with somewhat different conversion values.

QW 1ndex. This method differs from the previous method in two ways: a conversion value of $11,000 \mathrm{Btu} / \mathrm{kWh}$ is used for electricity; and the resulting annual energy-use value is normalized by dividing by two additional parameters, the sum of heating and cooling degree days (HDD and CDD) and the number of operating hours/year of building systems' air handling systems. Both the 
target and the energy estimate of the building design are then expressed in thousands of Btu/(yr.ft $\left.{ }^{2} \mathrm{DDh}\right)$.

The intent of this method is to factor out. two parameters that can have a significant impact on a building's annual energy use, but are beyond the control of the designer. By removing the effect of these two sources of variation, a single target becomes useful for a wider range of buildings. This method was developed in the early years of the energy crisis, but it is doubtful that its use was ever widespread.

ASHRAE 90C-1977R -- Resource Utilization Factor/Resource Impact Factor. Impact. This method is similar to the IGP Factor and the QW methods because offsite conversion losses are explicitly included; however, the Resource Utilization Factor/Resource Impact Factor (RUF/RIF) is considerably more comprehensive. In this method, the quantity of each energy source, measured at the site boundary, is multiplied by an RUF, which adjusts the energy use to an equivalent unconverted level. This value is then multiplied by an RIF, which adjusts for the relative impact of development and consumption of that form of energy on the nation's well-being, taking a range of social, economic, and environmental considerations into account. The method yields a comprehensive measure, although not completely subjective, of the impact or burden posed by the energy needs of a project.

The method was developed in response to numerous comments, which recommended a more comprehensive approach, received during public review of ASHRAE 90C-1977 during the period from 1978 to 1980. The latest version of this method was sent out for public review in 1980, as a proposed revision to ASHRAE 90C-1977 (Section 12). A consensus was not achieved on this revision, and thus, it was never issued as part of the standard.

\section{Convert to Energy Cost}

A11 of the energy cost methods are based on the assumption that cost is a reasonable common denominator for all forms of energy. While a free market might, in theory, reflect the true value of different forms of energy, many factors serve to distort their market prices. Government subsidies, utility marketing and pricing strategies, and various costs that are external to the 
market, all severely limit the extent to which energy costs accurately reflect the full costs associated with energy development and use. In some cases, government policies may serve to mitigate price distortions, as when the cost of scrubbers is embedded in rates for electrical power generated from coal.

Although they are not the perfect mechanism to compare the true cost of different forms of energy, energy costs are important to the user. Virtually all building owners are acutely interested in the bills that they must pay, so cost-based comparisons have a relevance and importance to the user that other approaches cannot match.

For the project, the use of cost rather than energy units has important implications related to information requirements, calculation methods, and added complexity. These implications are reviewed in Appendix $E$. The following subsections describe cost comparison methods.

Building Energy Performance Standards Weighting Factors. In this method, proposed in the BEPS project (DOE 1979) energy use measured at the site boundary is modified by a set of weighting factors designed to account for differences in the national average market prices of the different energy sources. The proposed weighting factors were 1.0 for natural gas, 1.2 for oil, and 3.08 for electricity. The weighting factors were to be applied to simulated design energy consumption by fuel type, and the total compared to the energy budget for the location and builing type.

The weighting-factor approach to energy sources was part of a proposed, mandatory energy performance standard for buildings (DOE 1979), the development of which was mandated by Congress. The BEPS energy budgets were established for 80 locations and 16 building type classifications. Following its release for public comment, the proposed standard became extremely controversial and was abandoned because of public and industry opposition.

National Average Unit Cost Method. This method would use the ratio of national average unit costs to convert different energy sources to common units. A calculation to determine the kilowatt-hour equivalent energy use for a building that uses both electricity and natural gas is presented in Section E.4.2. No known method of this type has been put forth for public use. 


$$
\text { kWh } \left.h_{\text {equivalent }}=k h_{\text {actual }}+\mathrm{Mft}^{3} \text { actual (Unit Energy Cost electricity }\right)
$$

Regional Average Unit Cost Method. This method would use the same procedure as the National Average Unit Cost method but would employ average regional costs as the basis for the conversions. Regional energy cost information, published regularly by the DOE Energy Information Administration (EIA), would be used. These data are compiled for 10 different regions of the country.

While regional costs would better reflect the actual energy costs seen by building owners than national costs, cost varies considerably within these regions. This variation would significantly undermine the importance of the targets to users in some locations and overemphasize the importance of the targets to users in other locations. No known method of this type has been put forth for public use.

ASHRAE/IES Standard 90B-1975R (Local Cost) Method. This method is similar in most respects the ASHRAE/IES Standard 90B-1975, Section 10, Method (ASHRAE/ IES 1975). A building design is checked against a version of the same design that has been brought into compliance with the prescriptive path of the standard. In cases where the use of each source of energy, measured at the site boundary, is lower for the design being checked than the reference design, the method is the same as in the Section 10 method. In cases where the use of one energy source is higher, and the other lower, the current local cost for each form of energy is used to determine if total energy cost is lower than in the reference design.

The intent of the method is to have local energy cost be the medium of exchange between electricity and fossil fuels. The method, as developed, does not specify whether demand charges or time-of-day rates are to be included in the current local cost. This method was proposed as a replacement for the existing version of $90 \mathrm{~B}$, but the reviewers of this standard did not reach a consensus. 
Local Energy Cost (per Published Rate Schedule) Method. This method enlarges upon the previous method, ASHRAE/IES Standard 90B-1975R, local cost, (ASHRAE/IES 1975) by explicitly including all energy and related charges as they appear in the rate schedules of the local utility. If the utility rate schedule includes demand charges or time-of-day rates, the building energy-use pattern must be determined before costs can be compared. An advantage of this method is that to determine compliance it uses the same parameters that actually drive the energy-related decisions of designers and building owners. A major disadvantage is its potential complexity.

This method contains greater detail and addresses objections raised to ASHRAE/IES Standard 90B-1975. A version of this method (Local Energy Cost per Published Rate Schedule) is included in Section 9 of ANSI/ASHRAE/IES Standard $90.1 P 1986$.

Marginal Cost Method. This method uses the local or regional marginal costs for each energy source as the basis for comparison. Marginal costs are the estimated costs that will be experienced by the utility system in providing an additional unit of energy. Though utility costs and end-user costs are obviously related, marginal cost is the cost experienced by the utility, not the immediate cost experienced by the end user. Estimates of marginal cost are generally developed assuming specific time periods and energy quantities. For example, marginal costs may be estimated for a short (1- to 3-year) or long (10- to 15-year) time interval, and marginal costs will depend upon aggregate energy demands placed upon the utility system over the specified time horizon. The rationale behind using marginal costs for new building design is that they more accurately describe the true costs associated with pursuing alternative courses of action.

A total-life-cycle-cost (TLCC) methodology using regional marginal costs was developed for (and is required by) the Federal Energy Management Program (FEMP). In late 1981, the EIA forecasted and published regional average costs for use in FEMP. Although the FEMP requires regional marginal costs to be used in the TLCC methodology, these have never been developed. Marginal energy costs are sometimes developed internally by utilities to determine costeffectiveness of utility conservation programs. 
Total Owning and Operating Cost Methods. The TOOC methods measure averall cost to the owner to acquire a building and operate it over time. These methods permit detailed assessment of costs and benefits, including first costs, interest, taxes, utility costs, maintenance, the value of building space, and the users' expected financial return. This method also allows simultaneous examination of energy sources and conservation options. Specific TOOC methods include (but are not limited to) TLCC, cash flow, savings-toinvestment ratio, net present value, internal rate of return, and discounted payback. Nearly all TOOC methods recognize the time value of money.

The rationale for using TOOC methods is that they measure the true cost of different courses of action to the building owner. These methods specifically address tradeoffs between first cost and ongoing energy and operating costs, issues that are central to most energy design decisions. In addition, TOOC methods are capable of responding to owner needs, because the owner's financial outlook can be incorporated directly in the analysis.

The use of TOOC decision methods is highly developed and well known in the financial community. In the buildings and design communities there is varied acceptance, although one simplistic TOOC methoit, the simple payback, is frequent ly used.

The TOOC methods in various forms are being used by the federal government. The FEMP and other federal programs require the use of TLCC. Net present value and other methodologies are used to gauge the effectiveness of, and to set conservation levels for, DOE building and appliance standards. At least one state, California, has an operative building energy standard that allows use of TOOC methods as an alternative compliance path. The American Society for Testing and Materials (ASTM) has developed, and continues to develop, standardized TOOC methodologies.

\section{1 .6 Sumary of Evaluation of Alternative Methodologies}

All of the methods that have been reviewed are imperfect, none fully meet all of the evaluation criteria. Selecting methods for further consideration and use in Phase 2 has been a matter of determining those methods that best match project objectives and desired attributes. 
An evaluation matrix that sumarizes the performance of each of the 14 methods with respect to the evaluation criteria has been developed and is shown in Table 5.3. Using their professional judgment, the project team developed the ratings in the evaluation matrix. These ratings were combined, using the relative weights for each of the four major categories of evaluation criteria. The ratings within each category were averaged, then multiplied by the weight for that category. The sum of the results for each category yielded an overall numerical score for each method.

Based upon the evaluation, the TOOC method was selected for primary development in Phase 2 of the project. The methods which rated second and third will also be considered, but at a lower priority than the TOOC method. Despite its first-place rank, the $T O O C$ method received a low evaluation score because it is complicated to use. During Phase 2 simplified techniques to use and implement TOOC methods must be developed.

\subsection{WHOLE-BUILDING ENERGY-USE METRICS}

The results of examining issues related to metrics of energy use for the Targets Project are discussed in this section. The three elements of this examination are:

- review of approaches used for whole-building energy-use metrics in similar past efforts

- examination of issues related to metrics

- development of recommendations for a set of metrics for further consideration during Phase 2 of the project.

\section{2 .1 Introduction}

A number of approaches to whole-building energy targets have been developed in the past by the federal government, state governments, and other organizations. A number of these methods are referenced in the sections that discuss methods of treating energy sources. While these approaches have varied greatly in detail, most are remarkably consistent in their general approach to a whole-building format, with Btu/(yr.ft $\left.{ }^{2}\right)$ as the unit of measurenent. 
TABLE 5.3. Evaluation Matrix for Rating Methodolgies

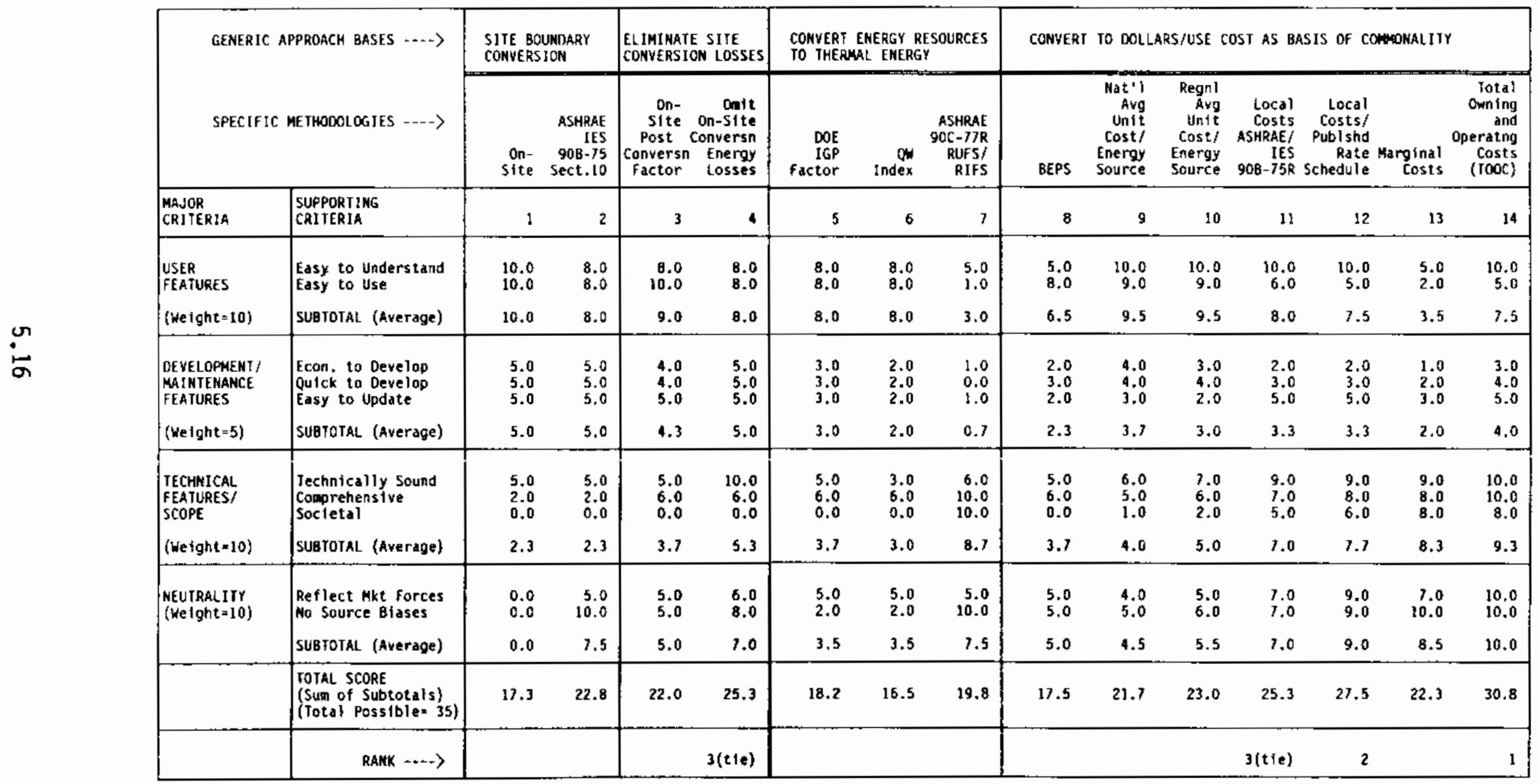


In addition to developing energy targets, at least two previous approaches (originated by the state of California and the Northwest Power Planning Council) have developed supporting information and examples of ways to achieve the specified targets, often called Alternative Component Packages (ACPs). The ACPs are easy to use. For example, a potential user learns little about what needs to done to achieve a target simply by being given an energy target of

$45,000 \mathrm{Btu} /\left(\mathrm{yr} \cdot \mathrm{ft}^{2}\right)$ for an office building. The ACPs describe sets of measures that would produce energy performance levels comparable to the target.

\subsubsection{Issues Affecting Metric Definition}

There are a number of tssues that need to be addressed in defining a system to measure and compare building energy performance. The response to these issues will determine the scope, incentives, comprehensiveness, and neutrality of the resulting targets. These issues include defining

- the energy unit

- the building unit

- energy end uses

- building and space functions

- building operating conditions

- climate variations

- economics

- energy sources

- HVAC systems.

\subsubsection{Definition of the Energy Unit}

By definition, an energy target must specify an index for energy performance relative to some building or functional unit. The energy index, $B t u /\left(y r \cdot \mathrm{ft}^{2}\right)$ has been used most commonly in the past. If a Btu/(yr.ft $\left.{ }^{2}\right)$ metric is employed, it must be specified where this Btu is measured: at the power plant, at the building line, or at the space conditioning coils. This question is addressed in detail in the energy sources portions of this section. The question of how the procedure treats different energy sources involves both the metric that is used for measuring performance relative to the targets and the basis that is used for setting the targets. 
Although most previous whole-building energy target metrics have dealt strictly with annual energy use, a few approaches have considered setting targets or limits on the power or demand of a building. No known efforts have combined both an annual energy target and a power or demand target, although this seems to be a promising approach.

Annual energy cost or life-cycle energy cost could be used as a measure of building energy performance. While the resulting values would not strictly be energy targets, they would be generaliy useful and well understood measures of building energy performance. Such targets would bear a strong relationship to the economic considerations that of ten drive most design decisions and make them relevant to potential users. Letting the energy marketplace establish the basis for comparison would lessen the problem of treating different energy sources. As indicated in Section 2 of the Volume 1: Final Report and in Section 4.0 of this report, the intent of this project is to directly consider these energy costs in formulating the energy target format.

\subsubsection{The Building Unit}

In the past, the building unit that has been most commonly used has been square feet of floor area, usually the gross fluor area, although some measures have used building net conditioned space or net rentable space.

Some complications exist in using a floor area unit; the treatment of enclosed parking is an example of a complication. Including or excluding enclosed parking can radically change a whole-building target. Another complication arises because different building disciplines calculate the area in different manners. Three or four different estimates of total area for the same building can of ten result. Clear definitions of area are required for this approach. These have been developed for BEPS and other projects, a1though they differ from the definitions used by some groups in the buildings industry.

In addition to square feet of floor area, there are alternative ways to define a building unit:

- Use $B t u /\left(y r \cdot \mathrm{ft}^{3}\right)$. This unit measures enclosed volume rather than square footage. 
- Use Btu/living unit for apartments. Many energy uses, such as appliances and cooking, are largely independent of square footage and depend more on the number and the age of apartment occupants.

- Use Btu/(yr.room) for hotels and motels. Possibly include a factor that adjusts for the relationship of total annual sales for rooms divided by total annual sales for food and beverages.

- Use Btu/thousand pieces of mail shipped for post offices.

- Use Btu/burger, or some similar measure for restaurants. This type of measure does not always work and depends greatly upon the type of food and type of cooking process.

It may be desirable for some building functions or types to have alternative units of measurement, one of which would be $B t u /\left(y r \cdot \mathrm{ft}^{2}\right)$, while the other might relate to the space function.

\section{2 .5 Energy End Uses}

Most previous efforts have included the following end uses in commercial whole-building energy targets:

- heating

- cooling

- fans and pumps (air and water distribution)

- lighting

- service hot water

- zone equipment (receptacle loads)

- special equipment.

Three options exist for dealing with process energy components: they can be excluded; they can be included as internal loads in the calculation procedure, though not in the definition of the metric; or they can be included in both the calculation procedure and the metric.

The first option avoids any constraint on energy used by the component and introduces distortions into calculating and accounting for internal heat gains. The second option, including the load in the calculation procedure but not in the metric, avoids the distortion but also avoids any constraint on energy used 
by that component. This may be an appropriate approach for example, for buildings in which large quantities of process energy are used. Use of the second option would significantly increase the scope of the project in the attempt to define appropriate levels of energy use for such processes. Including the process energy component in both the calculation procedure and the metric, the third option, allows tradeoffs between energy used by the process and that used by the bullding. These tradeoffs may or may not be desirable, depending on the nature of the process load.

Given the negative experience in the BEPS program that resulted from ignoring process energy in building types such as hotels/motels, hospitals, and restaurants, dealing with process energy appears to be imperative.

\subsubsection{Building and Space Functions}

There are three general approaches to making the targets metric responsive to differences in building functions and operation. Separate targets can be developed on the following bases:

- building types (schools, office buildings, warehouses, etc.)

- building functions (classrooms, corridors, storage rooms, etc.)

- bujlding parts (floors, elevation versus interior zones, etc.).

Building Types

This approach has often been taken in the past. Typically, a number of building types have been identified, and separate whole-building energy targets have been specified for each major building type.

A number of difficulties occur with this approach. Considerable variation in building function exists within any major building type. For example, retail stores might include drugstores, hardware stores, strip shopping centers, department stores, and supermarkets. Many of these subtypes may have significantiy different energy uses from one another because of differences in proportions of functional spaces and in internal heat gain for refrigeration equipment, as well as different occupant densities, hours of operation, and different HVAC and ifghting requirements. 
Such differences occur within virtually every major building type. Past efforts at identifying building types have produced varied results. For example, 10 building types were identified by Oak Ridge National Laboratory, 16 by BEPS, and 60 to 70 by the state of Ohio. For a simple basis, a relatively small number of building types are required; for an accurate basis, a large number of different building types, probably we11 over 30 and approaching the number used by Ohio, are required. Developing targets for a large number of different building types is extremely time-consuming and expensive.

Space Functions

This approach develops annual energy-use targets for specific space functions. The advantage to this approach is that if, for example, a designer had an office building that contained retail space and a restaurant, he would have the flexibility to build up a whole-building target as a composite of the targets for each of the functions. The development of energy targets for approximately 30 different space functions would be sufficient to cover the vast majority of buildings constructed.

\section{Building Parts}

This approach recognizes that in a typical floor of an office building there may be five zones, four exterior zones (north, east, south, and west), and an interior zone. The energy requirements for each zone is likely to be somewhat different. Typically an interior zone will use less energy, in the range of $70 \%$ to $80 \%$ of an equivalent exterior zone. This project will examine the exterior versus interior and orientation building-part differences as part of the space-function mode 1 being developed.

\subsubsection{Building Operation/0ccupancy.}

The number of hours a building is operated per day and per year and the density of its occupancy have a major impact on its energy use. The following list indicates the variations in occupancy patterns that are routinely seen in office buildings:

- 8 hours per day

- 10 hours per day 
- 12 hours per day

- no weekend occupancy

- half occupancy on Saturday, partial occupancy on Sunday

- 24 hours per day

- extended occupancy for retail or restaurant facilities within office buildings.

Variations in hours of occupancy such as these have major impacts both on the amount of energy that a building will use over a year and on the peak demand required for the building. Likewise, large variations in the density of occupancy are common. A corporate office facility might have a very low density with $400 \mathrm{ft}^{2}$ per person. On the other hand, a speculative office building with a high density might have an occupancy of $100 \mathrm{ft}^{2}$ per person. These changes in density can result in substantially different energy requirements and energy use. Phase 2 will examine the variations in occupancy patterns for space functions rather than attenpt to define sets of standard conditions.

\section{2 .8 Climate}

Most previous attempts to develop whole-bujlding energy targets have explicitly varied the target in response to changes in climatic conditions. However, a number of energy experts have developed single energy targets for the nation, with the assumption that heating and cooling energy requirements generally offset each other. Climate needs to be viewed in light of the level of accuracy that is required. The considerable variation in the approach to climate is evident in the following examples:

- The BEPS (DOE 1979) used 78 locations throughout the country with a specific energy target for each building type in each location.

- California used 16 climate zones with specific energy targets for each building type in each climate zone within the state.

- The approach proposed in ASHRAE SP 41 (PNL 1983) has demonstrated that a limited number of aggregated climate variables (in the range of 5 to 9 variables) can be used to describe a full range of climates. 
Typically, changes in climate will strongly affect the requirements for heating energy and cooling energy but not the requirements for other energy end uses. In this context, several important issues need to be considered:

- How important is variation in climate to a whole-building energy target?

- Are different treatments of climate required for buildings that are heavily internally loaded?

- Which is the most appropriate approach to variations in climate-climate zones or climate variables?

- Which are the important climate variables to use [HDD, CDD, cooling degree hours (CDh), solar, wind, or others]?

This project will expand upon the approach taken in ASHRAE SP 4I (PNL 1983) by examining ranges of a limited number of aggregated climate variables to describe climate differences.

\subsubsection{Economics}

Variations in building construction costs and energy costs from location to location are significant in the identification and selection of cost-effective energy solutions. In different regions of the country, energy cost vary by as much as a factor of 10 , while construction costs may vary by nearly a factor of 2. In general, these variations have much more impact on energyrelated design decisions than do variations in climate.

The economic motivation of different building owners vary. The development of targets representing more than a single level of performance is currently planned. Economic objectives provide a natural basis for defining these a)terative levels of performance.

\subsubsection{Energy Sources}

Refer to Section 5.1 of this report for a discussion of energy sources.

\subsubsection{HVAC Systems}

As a result of HVAC system type, annual energy use can vary widely, even among appropriate and reasonably efficient systems. There are important 
nonenergy design constraints that dictate HVAC system selection in many cases, and for this reason it might be appropriate to base targets on the particular system that the designer has selected. This basis would, in a sense, remove any constraint from the target on the choice of mechanical system type. However, if the targets are set on the basis of systems that are reasonable and appropriate for the given space use, the designer should not be unduly con.* strained by a target based on a system type that is different from the one that he is using. In this case, if he chose a less efficient system type he would need to make up for the lost efficiency elsewhere in the design. Phase 2 will examine the impacts of generic levels of HVAC system efficiency on the levels of space function energy performance.

\subsection{CONCLUSIONS}

Some of the issues involved with the selection of a suitable metric (or metrics) for the whole-building energy targets have been covered in this section. The approach to energy metrics proposed for use in Phase 2 includes the following concepts:

- The energy unit, Btu/(yr.ft $\left.{ }^{2}\right)$, at the building site is the favored energy unit. Demand or demand costs, energy cost, and total lifecycle cost will also receive further consideration as part of the metric.

- The favored building unit is gross square footage. Because unconditioned spaces will have their own space-function-based targets, they should not pose a problem to this approach.

- The targets procedure will consider the range of energy end uses listed in the bottom row of Figure 2.3 in the Volume 1: Final Report. The targets will not constrain the use of process energy, but will consider the impacts of process energy on internal loads.

- Targets will be developed for different space functions, and these targets will be aggregated in a limited number of cases to yield demonstration whole-building energy targets. 
- Targets will be responsive to specific variations in building operation and occupancy conditions.

- Climate variation will be considered by means of a limited set of climate parameters.

- Variations in economic parameters and objectives will be part of the basis on which multiple target performance levels will be developed. The methodology will account for local energy costs, defined by utility rate schedules and local building costs.

- The issue of different energy sources will be addressed by a procedure that establishes a cost-based equivalency between energy sources. Case study examples of energy source-specific targets will be developed for reference purposes.

- Target levels will be set on the basis of appropriate HVAC system efficiencies, but separate targets will not be developed to account for the varying efficiencies of different HVAC system types. 



\subsection{ENERGY-USE DATA COLLECTION}

The energy-use data that were identified during Phase 1 and that will be collected during Phase 2 will be used as background information to develop the targets procedures and the demonstration energy targets. Another reason for collecting data on existing building energy use is to identify any metrics other than $8 t u /\left(y r \cdot f^{2}\right)$ that correlate more closely to actual energy performance for particular space functions or building types. The following sections describe the sources of information that were identified during Phase 1.

\subsection{BUILDINGS INDUSTRY}

The buildings industry in the United States is characterized by diversity and decentralization. Within the U.S. buildings industry, there are almost 1 million general and specialty contractors involved in construction, over 50,000 architecture and engineering firms, over 25,000 building materials suppliers, 15 major building and construction unions, at least 180 buildings industry-related trade associations, and more than 10,000 building code jurisdictions that are members of the 3 model code organizations.

Despite the diversity and complexity of the buildings industry, some of its discrete segments are more important than others. For example, of the approximately $\$ 200$ billion of nonresidential construction in 1983, almost half was built by the nation's 400 largest contractors and almost $80 \%$ of the total volume was completed by the 200 largest members of the 17,000-member Associated Builders and Contractors.

Presently, there are 4 million buildings totaling 52,000 million $\mathrm{ft}^{2}$ in the United States. Approximately 33\% of the building stock and floor area was constructed before 1945; approximately 40\% was built between 1945 and 1970; and the remaining approximately $25 \%$ was built since 1970 . For the years 1980 to 1983, the average area per building rose to $40,000 \mathrm{ft}^{2}$ from $12,000 \mathrm{ft}^{2}$ for previous years. If this trend continues for the remainder of the decade, new buildings constructed during the 1980s will make up $23 \%$ of the total floor area but only $11 \%$ of the total number of buildings (EIA 1983a). 


\subsection{BUILDING TYPES}

Within the building stock, several building types offer the largest opportunity for energy savings, as shown in Table 6.1. Schools, health care facilities, hotels/motels, offices, and warehouses of fer the greatest opportunity, accounting for a third of the total number of buildings but half the total floor area.

The EIA's 1979 Nonresidential Buildings Energy Consumption Survey (EIA 1983a; EIA 1983b) identified 8 building types representing $80 \%$ of the total energy consumed by the nonresidential building stock in the United States, as shown in Table 6.2. Office buildings, warehouses, educational facilities, health care facilities and lodging facilities account for $34 \%$ of the total number of buildings while composing $50 \%$ of total floor area and almost $54 \%$ of total annual energy use.

If assembly buildings are added, $46 \%$ of the total number of buildings are represented with $60 \%$ of the total floor area and $61 \%$ of the total energy use. By adding food sales, 55\% of the total number of buildings are accounted for with $64 \%$ of the total floor area and $67 \%$ of the total energy use. By adding retail stores, the total number of buildings is increased to $82 \%$, the total floor areas are increased to $83 \%$, and the total annual energy usage is increased to $80 \%$.

Figures 6.1 through 6.9 present a number of comparisons of building types.

TABLE 6.1. Number of Buildings Compared with Total Floor Area by Building Type

$\begin{array}{lccc}\text { Building Type } & & \begin{array}{c}\text { Percentage of Total } \\ \text { Number of Buildings }\end{array} & \begin{array}{c}\text { Percentage of } \\ \text { Floor Area }\end{array} \\ \text { Educational } & 4 & 12 \\ \text { Health care } & 1 & 5 \\ \text { Lodging (hotels/motels) } & 2 & 4 \\ \text { Office } & 14 & 16 \\ \text { Warehouse/storage } & 11 & 13 \\ \text { Assembly } & 12 & 10 \\ \text { Retail } & 27 & 20 \\ \text { Food Sales } & 10 & 3\end{array}$


TABLE 6.2. Predominant Energy Use by Building Type

\begin{tabular}{lcr}
\multicolumn{1}{c}{ Building Type } & $\begin{array}{c}\text { Percentage of Total } \\
\text { Energy Consumption }\end{array}$ & $\begin{array}{c}\text { Percentage of } \\
\text { Buildings }\end{array}$ \\
\cline { 1 - 1 } Office & 19 & 600,000 \\
Retail & 12.5 & $1,000,000$ \\
Warehouse/storage & 12 & 450,000 \\
Educational & 9.5 & 180,000 \\
Health care & 8 & 60,000 \\
Assembly & 7.5 & 450,000 \\
Food sales & 6.5 & 400,000 \\
Lodging & $5 \quad 100,000$ & \\
$\quad$ Total & $803,240,000$ & \\
& \multicolumn{2}{c}{}
\end{tabular}

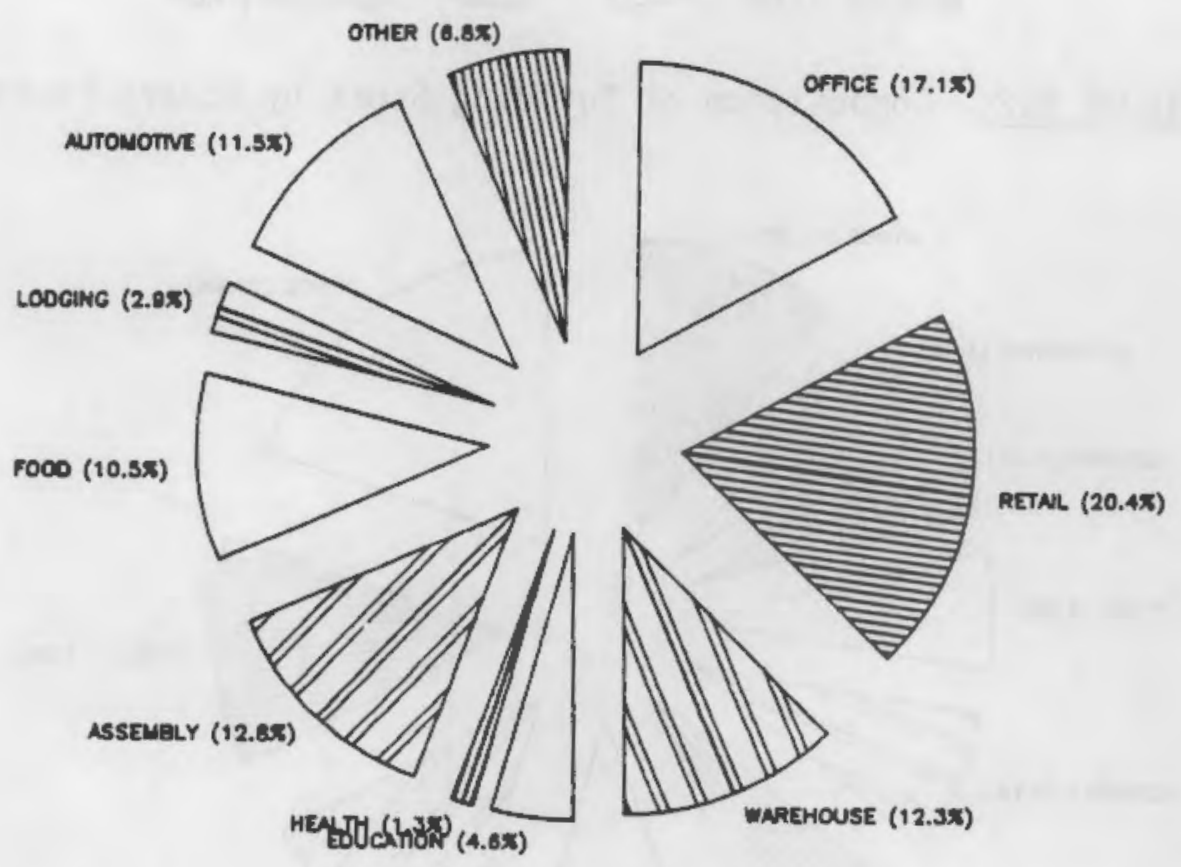

FIGURE 6.1. Composition of Building Stock by Numbers of Buildings

\subsection{DATA BASES}

Various organizations, including building owner associations, private building owners and corporations, state agencies, universities, awards programs, utility companies, and architectural and engineering firms, were identified and contacted to determine if they held any energy-use data that could be 

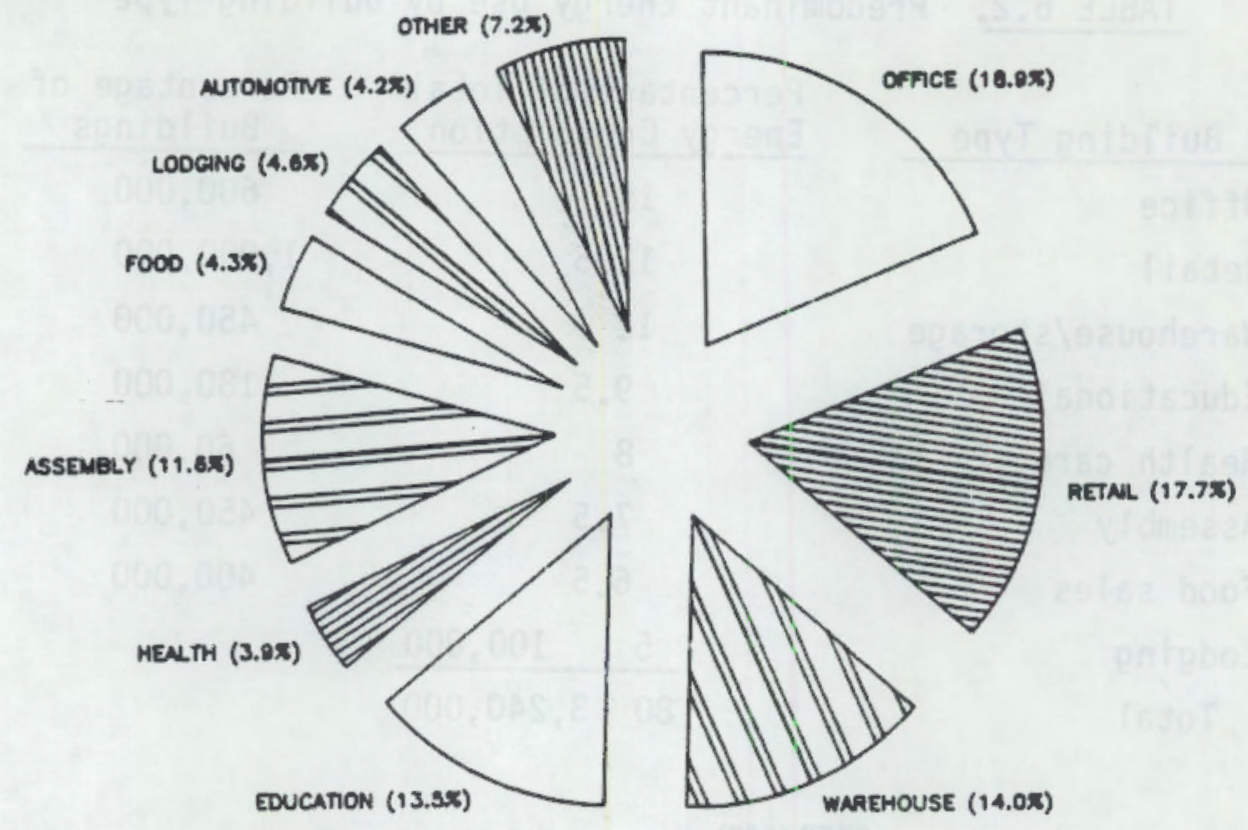

FIGURE 6.2. Composition of Building Stock by Square Footage

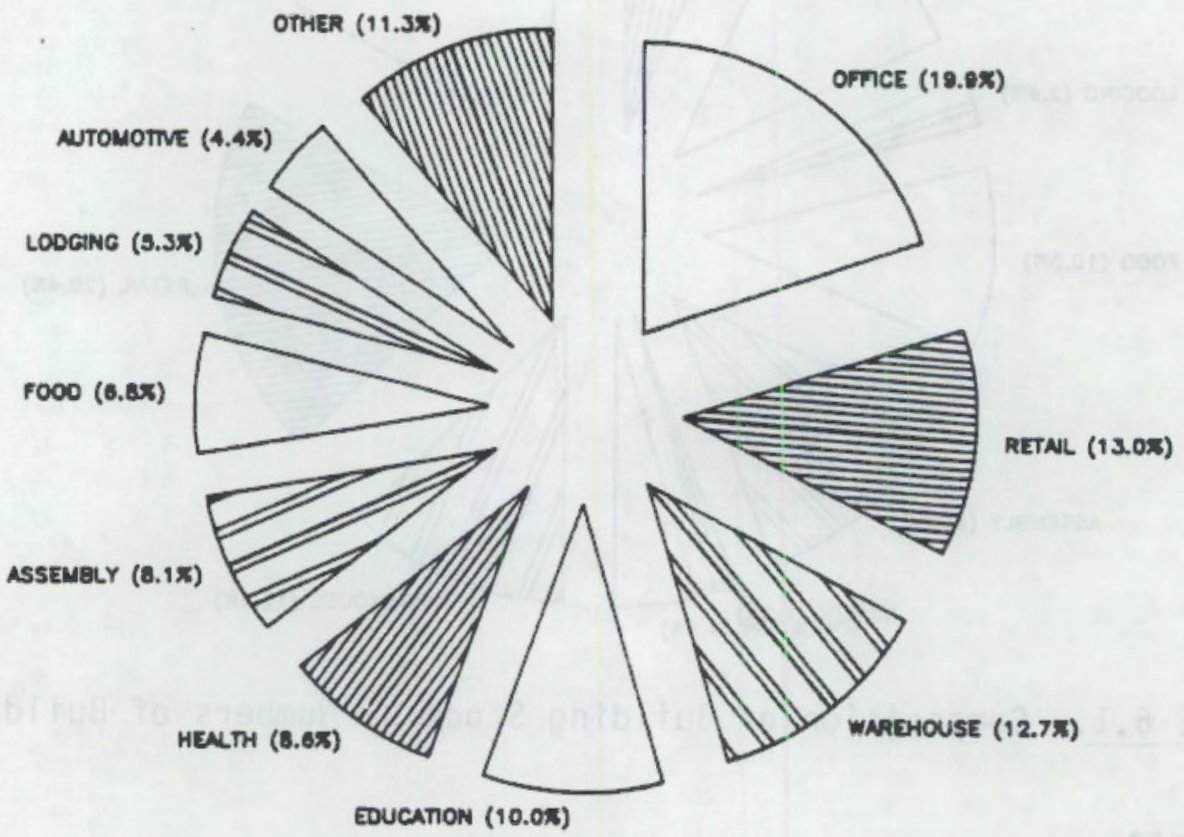

FIGURE 6.3. Composition of Building Stock by Energy Use 


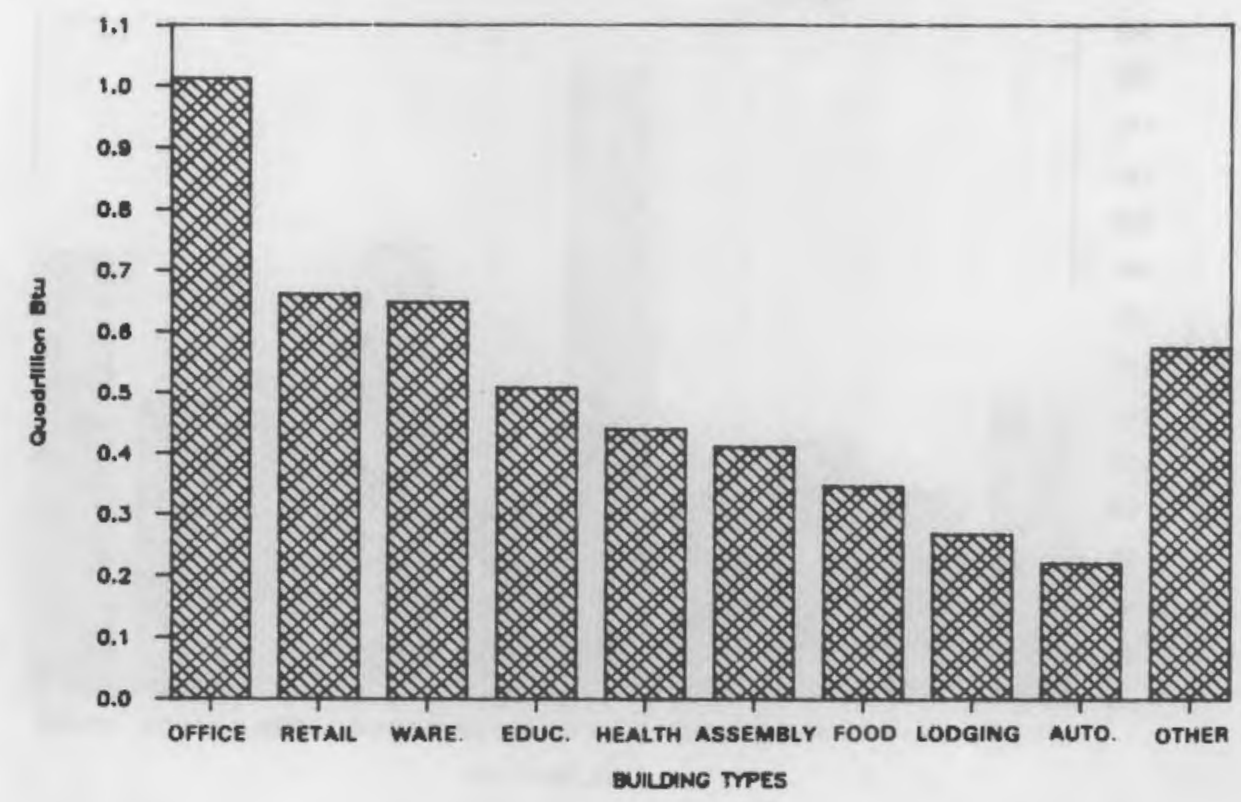

FIGURE 6.4. Total Energy Consumption by Building Type

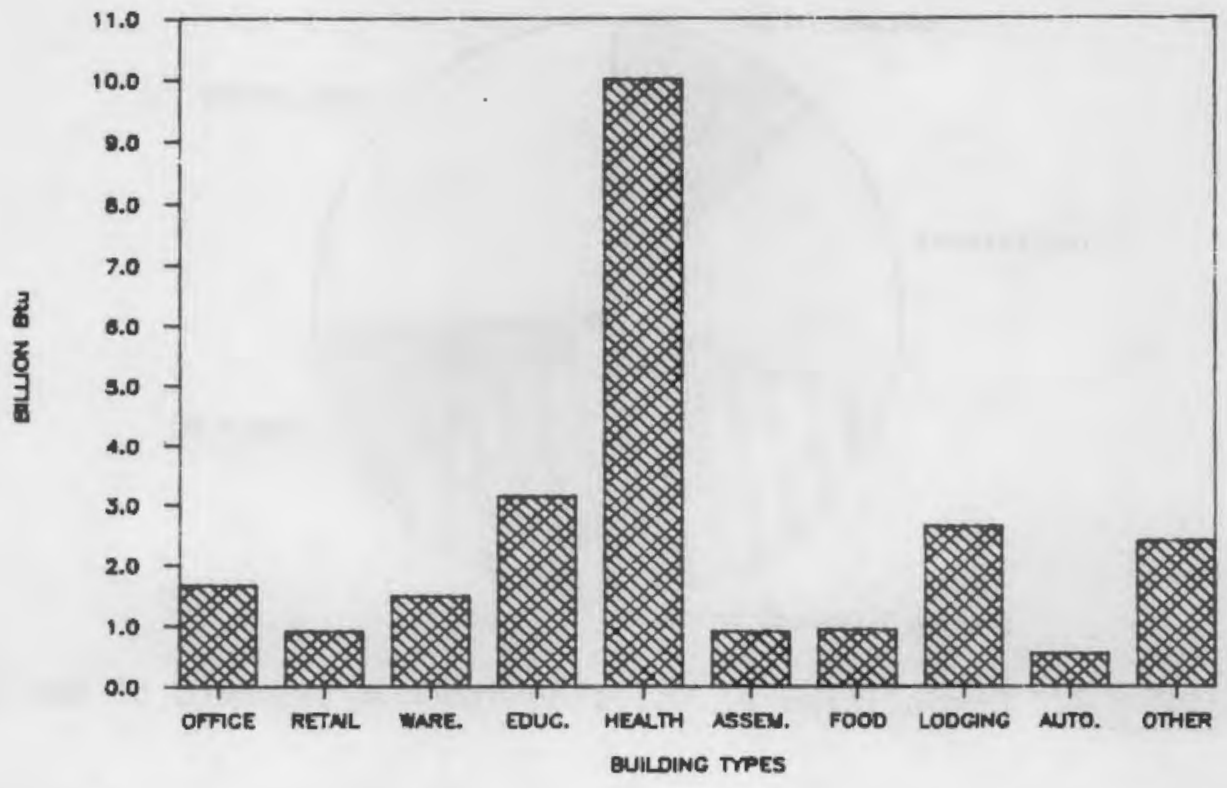

FIGURE 6.5. Average Energy Consumption per Building by Building Type 


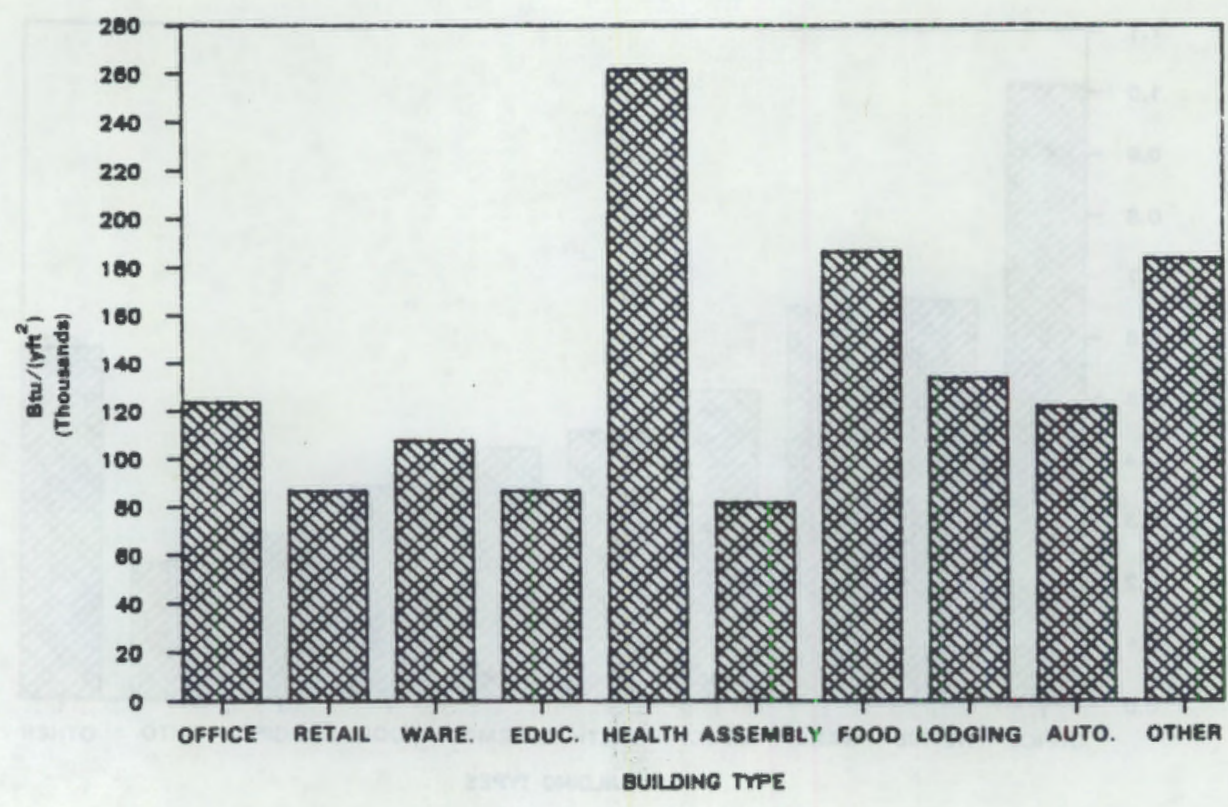

FIGURE 6.6. Energy Consumption per Square Foot by Building Type

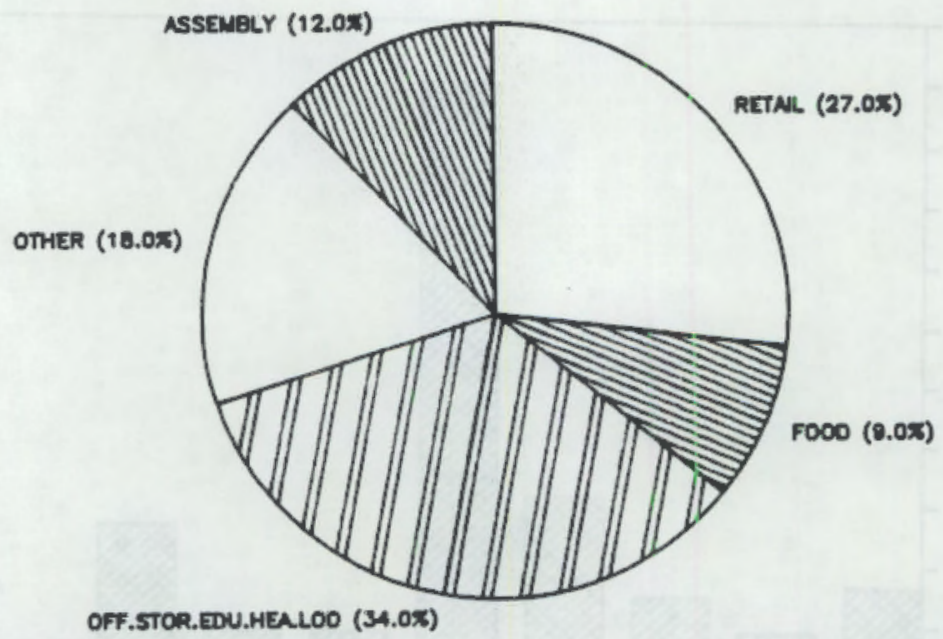

FIGURE 6.7. Composition of Building Stock by Numbers of Buildings

collected during Phase 2. The following sections are arranged by building type, and identify the organizations, their addresses, and the type of energyuse data collected by each organization. 


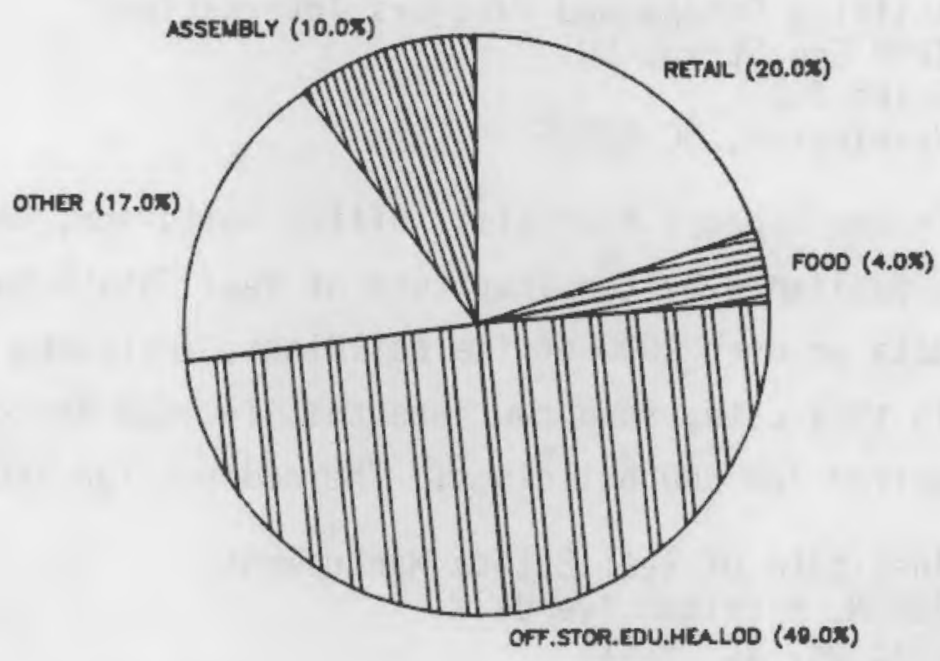

FIGURE 6.8. Composition of Building Stock by Square Footage

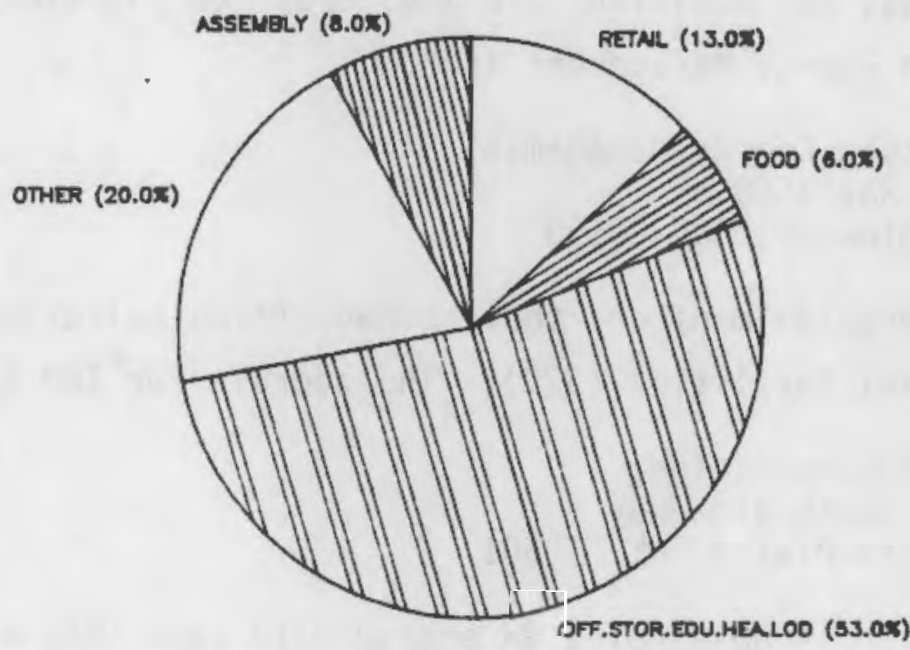

FIGURE 6.9. Composition of Building Stock by Energy Use

\subsubsection{Office Buildings}

The 1984 BOMA Experience Exchange Report, published by the Building Owners and Managers International (BOMA 1984), includes data on over 3000 office buildings. The energy data are aggregated by cost and are not displayed by Btu or kWh per building. However, BOMA does have raw data for energy use for about 500 office buildings. Various physical characteristics for the buildings are aggregated. The address for BOMA is 


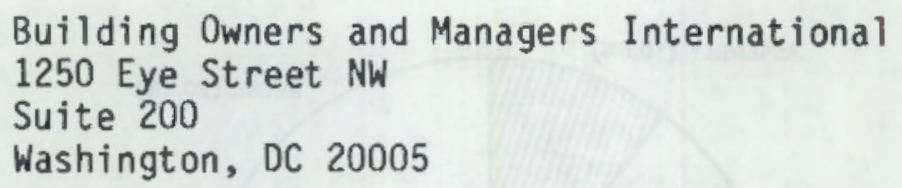

The 1986 "Income/Expense Analysis: Office Buildings, Downtown and Suburban" report published by the Institute of Real Estate Management (IREM 1986) includes data on over 2000 office buildings, including fuel costs in dollars. Also in this case, some raw data that include energy use in Btu or kWh could be acquired for 500 buildings. The address for IREM is

\section{Institute of Real Estate Management 430 N. Michigan Avenue \\ Chicago, IL 60611}

Natkin Energy Management monitors a number of office buildings (350 to 4D0) for individual clients, including Northwestern Mutual Life and Prudential Realty Group. About 225 buildings are monitored for individual clients. The address for Natkin Energy Management is

\section{Natk in Energy Management \\ PO Box 1598 \\ Englewood, CO 80150}

The IBM Corporation monitors their owned of fice buildings ( 80 ) and a large number of industrial facilities (320). The address for IBM is

IBM Corporation

44 South Broadway

White Plains, NY 10601

Coldwell Banker is developing an energy data base that will everitually include 130 office buildings. The address for Coldwell Banker is

Coldwell Banker

533 Fremont

Los Angeles, CA 90071

Property Management Systems is developing an energy data base for 150 office buildings. The address for Property Management Systems is

Property Management Systems

2900 N. Loop West

Suite 600

Houston, TX 77092 


\subsubsection{Lodging Facilities}

The American Hotel and Motel Association (AHMA) conducts an annual energy data survey to compile total energy consumption. The 1984 data are based on 300 hotels and motels and include information on number of rooms and water usage. A discussion and display of this data are included in the Appendix $C$. A discussion of the energy estimates provided for hotels and motels may be found in Section 7 of this report. The address for the AHMA is

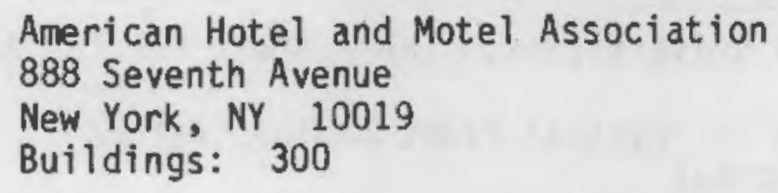

Hyatt Hotels has monitored their hotels since 1982 and has over 24 months of data for each of their 80 buildings. The address for Hyatt Hotels is

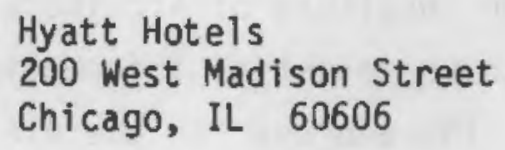

The Sheraton Corporation monitors energy use on their 60 hotels. The address for the Sheraton Corporation is

\section{Sheraton Corporation \\ 60 State Street \\ Boston, MA 02109}

Several of the 30 Radison Hotels have been submetered in a DOE project. The address for the Carlson Company, which operates the Radison Hotels, is

Carlson Company (Radison Hotels)

12755 State Highway \#55

Plymouth, MN 55441

For the last 2 years, an outside contractor has monitored the 40 Westin Hotel buildings. The address for the Westin Hotels is

Westin Hotels

The Westin Building

Seattle, WA 98121

Hilton Hotels have monitored their 50 buildings since 1977 . The address for Hilton Hotels is 
Hilton Hotels

9336 Santa Monica Boulevard

Beverly Hills, CA 90210

\subsubsection{Educational Facilities}

The Association of Physical Plant Administrators of Universities and Colleges (APPA) collects energy-use data in higher education institutions every other year. The latest edition of Comparative Costs and Staffing Report for College and University Facilities (APPA 1986) includes data in both Btu and costs for 800 colleges and universities. The address for the APPA is

Association of Physical Plant Administrators 1446 Duke Street Alexandria, VA 22314

With energy-use data from DOE's Institutional Conservation Program and the Tennessee Valley Authority, the American Institute of Architects (AIA) developed end-use energy data and physical characteristics information from over 2000 elementary and secondary schools. The address for the AIA is

\section{AIA}

1735 New York Avenue, NW

Washington, DC 20006

\subsubsection{Health Care Facilities}

The American Hospital Association (AHA) conducted a hospital-wide energy survey in 1980 and the results were published in a series of reports entitled Hospital Energy Strategies. Various physical and functional characteristics were gathered as part of the survey. The address for the AHA is

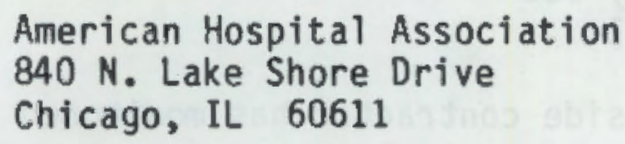

\subsubsection{Warehouse and Storage Facilities}

The Warehousing Education and Research Council (WERC) indicated that they would assist in contacting their larger members to solicit energy-use data bases. They believe that their individual members keep records of energy use and operational costs. The address for the WERC is 
Warehousing Education and Research Council

1100 Jorie Boulevard

Suite 118

Dak Brook, IL 60521

\subsubsection{Food Sales Facilities}

A one-time survey of supermarket energy use was conducted by the Food Marketing Institute (FMI). The sample includes 300 of the newest supermarkets owned by over 150 companies in the year 1981. Various other characteristics were also collected. The address for FMI is

Food Marketing Institute

$1750 \mathrm{~K}$ Street, NW

Washington, OC 20006

During a one-year period in 1983 and 1984 , seven restaurants were metered in detail at the energy end-use level in a joint project conducted by Pacific Northwest Laboratory (PNL) and the National Restaurant Association (NRA). The address for the NRA is

\section{National Restaurant Association}

311 First Street, NW

Washington, DC 20001

Marriott Corporation monitors the energy use of the food services facilities in each of its approximately 100 properties. The address for the Marriott Corporation is

Marriott Corporation

1 Marriott Drive

Washington, OC 20058

The Kroger Company has manitored energy use of its buildings (1,200 supermarkets and 500 drugstores) since 1976. The address of the Kroger Company is

The Kroger Company

1014 Vine Street

Cincinnati, $\mathrm{OH} 45201$

\subsubsection{Assembly Buildings}

Loews Theaters has monitored 65 theaters since 1978 for energy use. The address for Loews Theaters is 
Loews Theaters

666 5th Street, 16th Floor

New York, NY 10103

Walter Communications, an energy management firm, monitors energy use in 450 theaters for several large theater owners. The address for Walter Communications is

\section{Walter Communications \\ 195 Lake Avenue \\ Worcester, MA 01604}

\subsubsection{Awards Programs}

The Owens-Corning Fiberglass Corporation (OCF) holds the submission forms for their Energy Efficient Design Awards showing basic characteristics and estimated annual energy use for hundreds of buildings. Detailed documentation and analysis exist for 65 projects that received awards from 1972 through 1983. The address for OFC is

Owens-Corning Fiberglas Corporation

Toledo, $\mathrm{OH} 45232$

Progressive Architecture (PA) holds the nomination and submission forms for their annual Progressive Architecture Design Awards. These forms contain detailed information on a wide variety of building types, and many include analysis of estimated annual energy use. The address for PA is

Progressive Architecture

600 Summer Street

Box 1361

Stamford, CT 06904 


\subsection{SURVEY OF ENERGY EXPERTS}

The main objective of this task is to develop estimates of several levels of whole-building energy performance based on the combined professional judgment of a number of building energy experts in two areas: average energy design practice and good design practice for energy efficiency. These two areas were bounded by asking energy experts for their opinions on four aspects of energy design practice: technical limit, good practice, average practice, and energy-intensive design practice. Qualitatively determining the current extent of expert agreement on different levels of whole-building energy performance is another objective.

The information obtained from this survey is intended to provide guidance to the project team in the development of other project activities, and provide a useful qualitative reference for building designers and owners. The results of this survey are not intended to be used as a direct source of energy targets to be developed by this project.

This task is one of the Phase 1 proof-of-concept activities. For the proof-of-concept effort, Phase 1 has focused on obtaining estimates for two building types, offices and motels/hotels. Estimates for other building types have also been recorded if obtained during the survey.

\subsection{APPROACH}

The approach consisted of surveying building energy experts throughout the country to obtain their professional judgment about levels of energy performance. The emphasis is on the judgment of the experts, not on collecting data. The main steps in the approach used are shown in Figure 7.1.

The objective of the survey was to obtain a consensus of expert opinion and judgment. A consensus among the participating experts was not sought via one or more feedback loops. Rather, the effort was limited to simply gathering the professional estimates ahout energy performance levels and documenting the combined results obtained. 


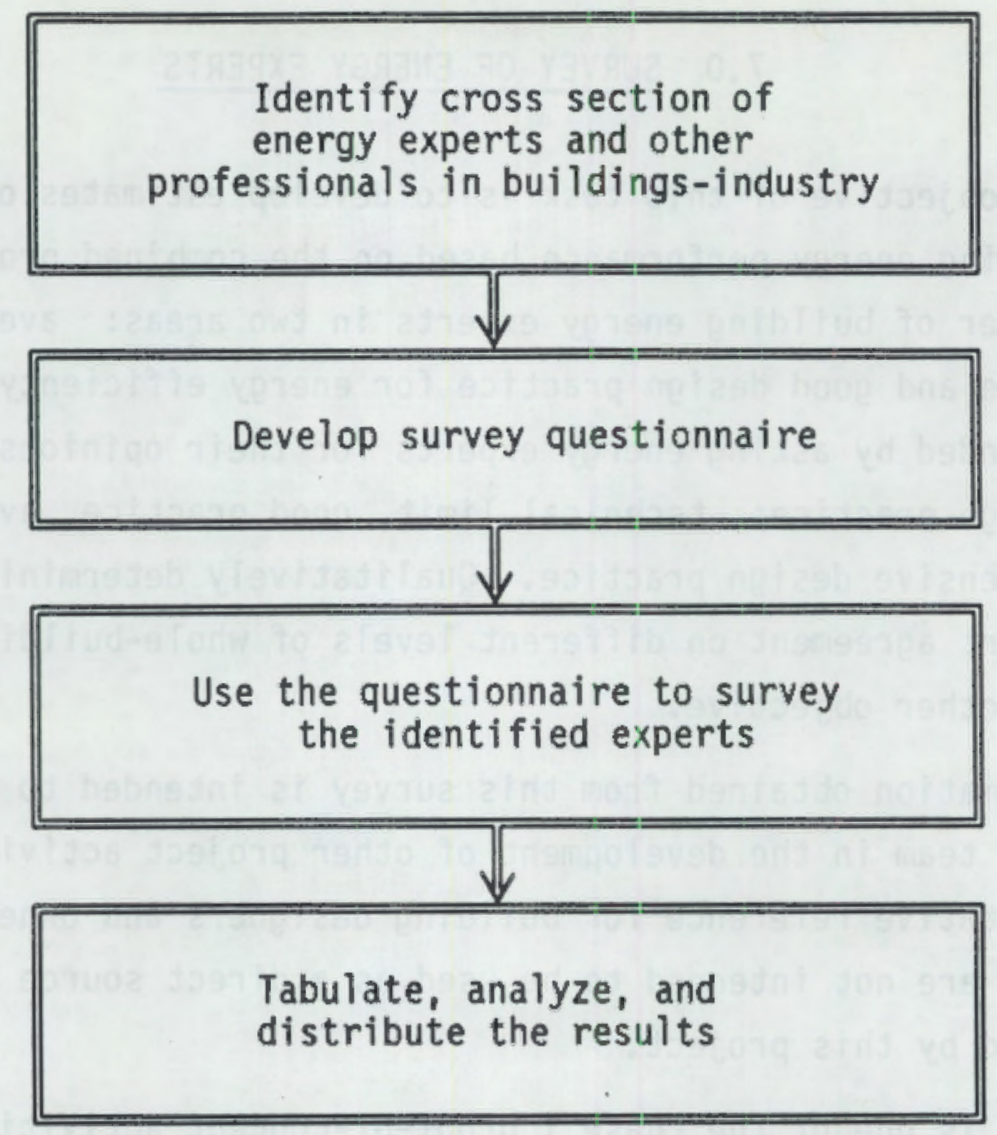

FIGURE 7.1. Flowchart of the Survey of Energy Experts

\subsection{SURVEY METHODOLOGY}

Once the general survey methodology was developed and agreed upon by the task team, selection of the energy experts to be polled and the development of a survey questionnaire were carried on simultaneously. Once these two tasks were accomplished, the survey was conducted.

\subsubsection{Selection of Energy Experts}

The task team identified a number of criteria for selecting the energy experts. The experts should have

- been located in the range of climate conditions experienced in the continental United States

- been experienced with a variety of building types, especially offices and hotels/motels 
- represented a range of buildings industry groups such as designers (architects, mechanical engineers, electrical engineers/lighting designers), owners, managers, energy consultants.

Given this set of requirements and expected partial responses to the survey, the task team estimated that 100 to 150 energy experts would be a reasonable number to contact. The list was developed using the knowledge and judgment of the project team, supplemented by contacts within ASHRAE, I1luminating Engineers Society of North America (IESNA), and AIA. No attempt was made to develop a statistically meaningful sample. The final list of individuals to be contacted included approximately 125 names.

\subsubsection{Developing the Survey Questionnaire}

In developing the survey questionnaire, a number of considerations were addressed. The time involvement of the energy experts was kept to a minimum, because they were not paid to participate. The questionnaire was designed to accommodate a wide range of answers because some experts were expected to provide answers based on broad experience with a building type, while other experts were expected to use a few selected case studies as a basis for their estimates. The energy experts were not required to provide estimates for all four levels of energy design practice requested (these levels were identified earlier in this section); estimates could be provided for any one or more of the four levels. The energy expert was also asked to provide any important assumptions used in providing his estimates of energy performance levels.

To accommodate these considerations in developing the survey questionnaire, a number of features were incorporated into the survey process. To reduce the time involved and to improve the response rate, telephone follow-up calls were made after the questionnaires were distributed. This feature allowed the energy experts to respond to the survey questions either in writing or through a telephone interview. A page of questions was developed to define relevant assumptions used and/or to insert comments about any special qualifications or features that might affect the interpretation of the respondents' estimates and responses. 


\subsubsection{Survey Questionnaire}

The six-page package containing the questionnaire is shown in Figures 7.2 . through 7.5. The six pages were on a single foldout and arranged as follows:

- Figure 7.2 cover letter (page 1)

- Figure 7.3 background information on project (page 2)

- Figure 7.4 questionnaire on energy targets (pages 3 and 4 )

- Figure 7.5 questionnaire on assumptions (pages 5 and 6 ).

The questionnaire was designed to be photocopied to complete additional building types or subtypes. Insofar as possible, the project team took care not to prejudge or pre-identify building types and subtypes.

\subsection{CONDUCTING THE SURVEY}

Once the list of energy experts to be polled was completed, and the questionnaire and associated materials were developed, the questionnaire package was mailed to each identified expert. Each of the task team members was designated as a contact person for a set of the identified respondents. The appropriate task team member name had been included on the questionnaire that was sent to each respondent. The task team members then telephoned the experts to determine if the questionnaires had been received and if they wished to complete a questionnaire in writing or via a telephone interview.

The time required to obtain responses was longer than anticipated. The usual difficulty with incorrect or incomplete addresses was compounded with the timing of the survey. The questionnaires were sent to the list of experts right after Thanksgiving and before the Christmas holiday. Because of this timing, establishing contact with many of the respondents was difficult.

Once the responses were received, a spreadsheet program was used to tabulate the information from the Targets Questionnaire (Figure 7.4). The information on the Assumptions Questionnaire (Figure 7.5) was only partially completed by the entire set of respondents. This information was generally included as notes to the information contained on the spreadsheet. 


\section{ASIMRAR/ARA/RE}

22 November 1985

TO:

Joe Deringer, AIA

RE: REQUEST FOR YOUR JUDGMENT ABOUT BUILDING ENERGY PERFORMANCE LEVELS.

BASED ON YOUR EXPERTISE AND EXPERIENCE, YOU ARE BEING ASKED TO PROVIDE YOUR BEST ESTIMATES ABOUT VARIOUS RANGES OF ENERGY PERFORMANCE ACHIEVABLE TOOAY.

You are one of approximately 100 people throughout the country selected for your experfence in this area. The information compiled will help guide our project to develop energy performance targets for new comerctal buildings.

This entire effort should take only a small anount of your time. We are asking you to:

1. Read this package and reflect on it.

2. Answer the questions asked elther by completing the questionnaire or by responding to the questions during a telephone interview.

3. Review the result's once we have complled them, and comment on them, including revising your own input if you think it is appropriate.

Your contact for this Survey of Experts will call you shortly to see if your are interested in participating. For background information on this project, see the back of this page. We thank you in advance for your interest.

Sincerely,

ASHRAE

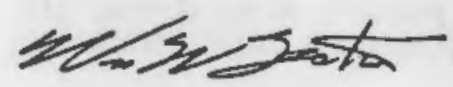

Willian Seaton
AIA

Canew 0 Conner

Earle Kennett
IES

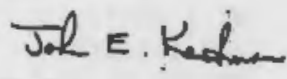

John Kaufman

Note: Your contact for this Survey of Experts is:

If you complete the questionnaire by hand, please mail it to:

$$
\begin{gathered}
\text { HHOLE-BUILDING DESIGN TARGETS PROJECT } \\
\text { c/O BHKRA }
\end{gathered}
$$

440 First Street, N.W., Suite 500

Washington, DC 20001

FIGURE 7.2. Cover Letter for Survey Questionnaire 
The American Society of Heating, Refrigerating and Air-Conditioning Engineers, Inc. (ASHRAE), the American Institute of Architects (AIA) and the Illuminating Engineering Society of North America (IES) are conducting a joint research project to determine energy performance targets for new commercial building designs. Funding for the project. is being provided by the U. S. Department of Energy (DOE) through the Battelle, Pacific Northwest Laboratories (PNL).

The objective of the project is to develop voluntary whole building energy targets. Design of bulldings for energy efficiency has reached a level of maturity nationwide wich lends support to the development of threshold performance targets at this time. The targets are intended for design use. The targets are not intended to dictate the levels of energy use wich are required, but rather to inform butlding designers and owners what levels of energy use are feasible and practical.

It is the intent of the project to develop at least two levels of targets. One level would be comparable to component performance requirements, such as those in ANSI/ASHRAE/IES 90A-1980 or in ANSI/ASHRAE/IES 90.1P, yet offer greater flexibility in the use of varlous systems, materials and designs. A second level would represent a high level of Energy Excellence to be used as goal by aspiring designers.

The approach taken in the project recognizes a wide diversity of building types, sizes, and functions. The design targets will include guidelines showing alternative design approaches and bullding features that $c$ an be considered in order to achieve the targets. The guidelines will cover standard design concepts as well as more innovative approaches.

The first phase of the project involves developing a process and methodology to perform detailed analysis of possible energy target levels, and to conduct an industry review. The second phase will utilize that methodology to actually develop the targets.

The energy design targets which result must be acceptable to those wo will be affected by them. In an effort to gain that acceptance, we will actively involve building owner groups, industry associations, gas and electric utflities, code-writing organizations and other affected groups in the development process.

\section{FIGURE 7.3. Background Information on Targets Project}

\subsection{AMOUNT AND TYPE OF RESULTS RECEIVED}

Energy estimates were obtained from 57 respondents, representing about $45 \%$ of the questionnaires. Some respondents gave estimates for more than one building type or region, yielding a total of 141 separate estimates.

\subsubsection{Responses by Building Type}

Five building types accounted for $87 \%$ of the energy estimates provided. In Table 7.1 , the number of estimates received was tabulated by building 


\section{INSTRUCTIONS FOR WOLE-BUIDING DESIGN - TARGETS}

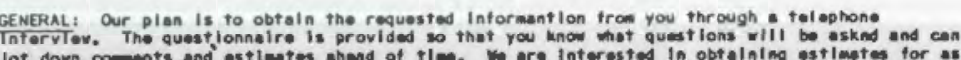

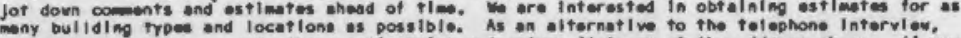

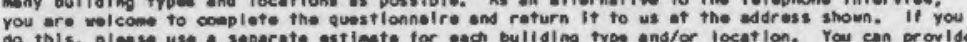

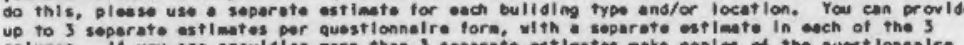

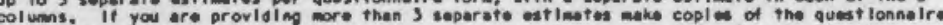

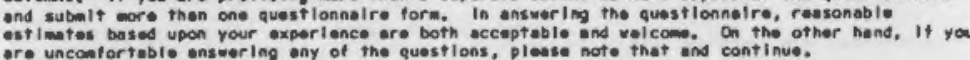

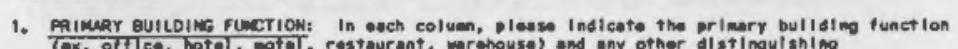

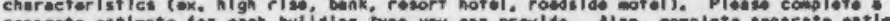

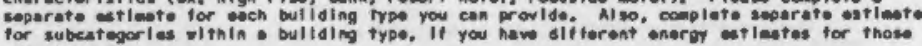
subcatagorles.

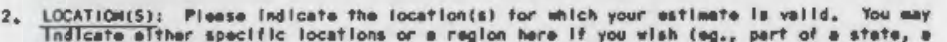

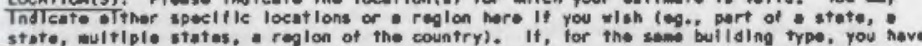

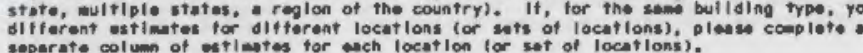

3. EXPERIENCE MITM BUILOING TMPE: Plase check the one category that best watchas your

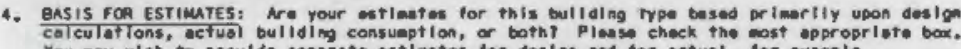

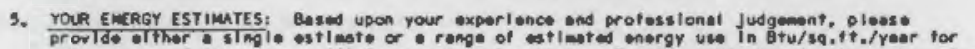

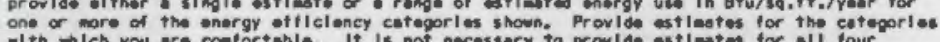

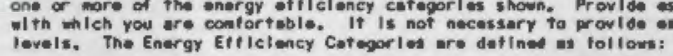

\begin{tabular}{|c|c|}
\hline 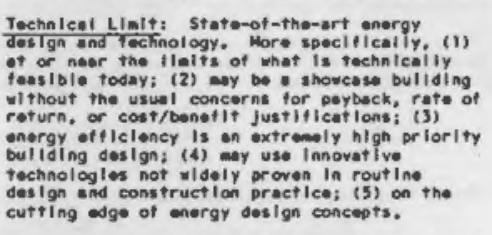 & 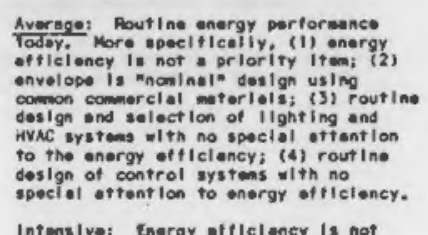 \\
\hline 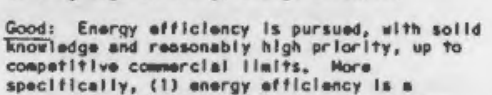 & 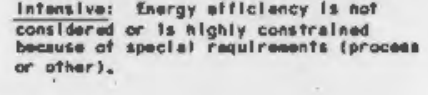 \\
\hline
\end{tabular}
speciticaliy, (1) energy ofticiency is

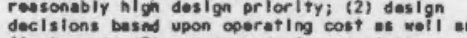

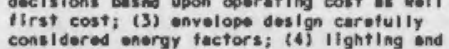

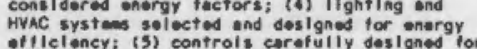
ipecitic buliding components.

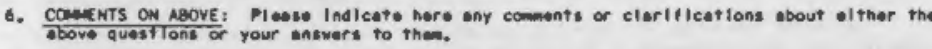

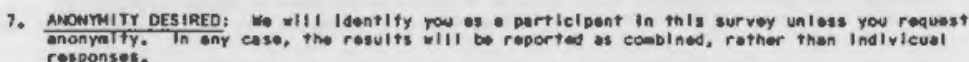

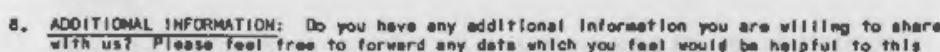

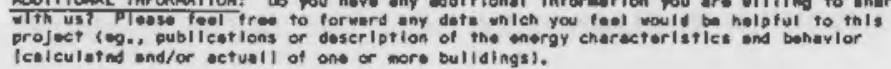

QUESTUONNAURE - TARGETS MOL-BUILING DESIGN

1. Primert Building Function:

$$
\text { Subtype, It necessory: }
$$

2. LOCATION'S:

3. EXPERIENCE WITH BUILDING TTPE:

A. Broes exper lence with mergy

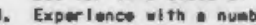

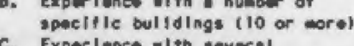

c. Experlences ith severel

0. Expertlencos with one

4. BASIS foR ESTIMATES:

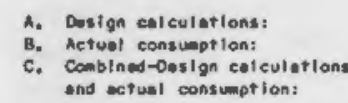

A. Dasign eslculations:

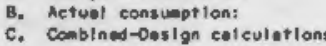

end ectual consumption:

Rospondent:

Tolophone Contiect:

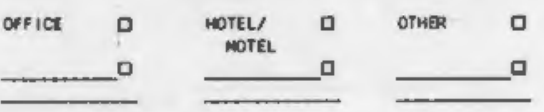

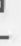

YOLR ENERGY ESTIMATES: In Btu/st/roor, or other messure

TECHAICAL LIWIT

GEOERAC

AVERAEE

on

TECHNICAL LIMIT

areorace

INTENS IVE

$\begin{array}{lll}\text { Single } & \text { Single } & \text { Single } \\ \text { Estingite } & \text { Estimote } & \text { Estimete }\end{array}$

7. MOMmitr OESIRED: Yas a Doos Not Matter D

- acoitiome inforeurion:

9. dranization co gipus sizo

PLEASE RETRR TO: Molo-Bullaling Dosign Targots PTolect

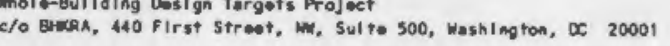

FIGURE 7.4. Questionnaire on Energy Targets 
INSTRUCTIONS FOR WHOLE-BUILING DESIGN - ASSUMPTIONS (OptionaI)

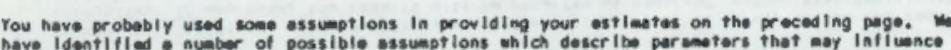
bullising emergy pertormence. Would you ecomplote the folloring to the extent possibie?

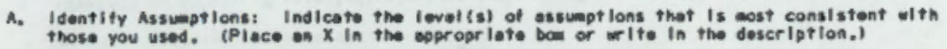

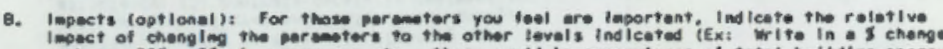

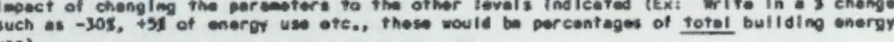

The tollowing notes describe the werlous har essumptions.

1. BUILDING SIZE: Self-axplenatory

2. MUMER OF STORIES: Lait-explenetory

3. AMERSHIP MPE (cost approor late to offlico catogary): = speculotive bullalng

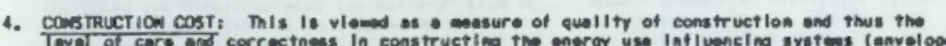
insulation, glazing, HYNC, Otc.)

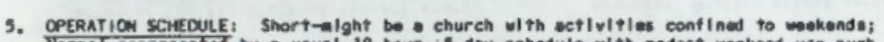

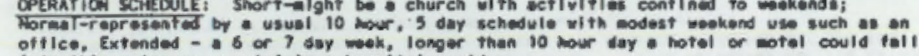

6. OCCUPACC OENSITY (most appropr lets to offlices estegory):

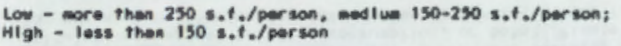

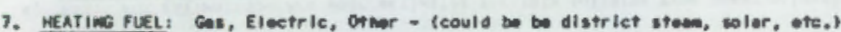

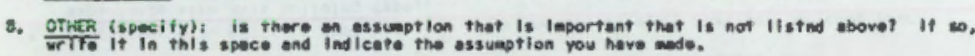

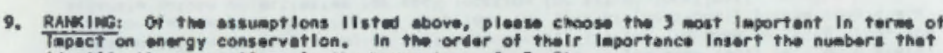

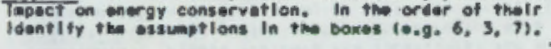

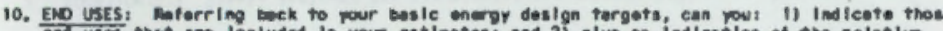

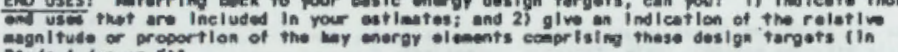
biu/s.t. $/ 4$ or 31$)$ encresoun coptionsi)

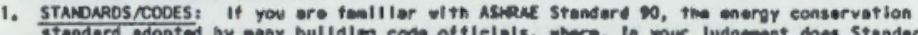

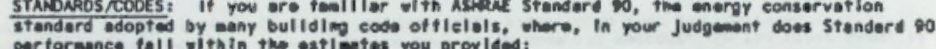

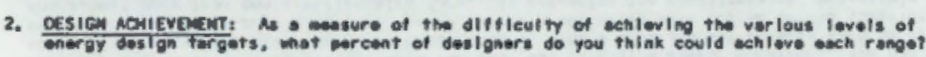

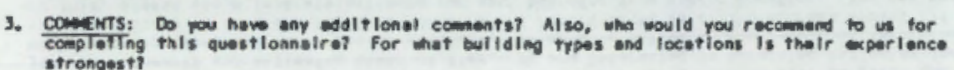

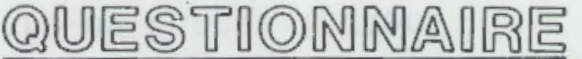

MOLE-BUILDING DESIEN

OFFICE

1. BUILOHG SIZE

2. MEBBer Of STORIES

3. OUMGeship type

4. Construction cost

9. aperating scheoule

6. cocupancr detisitr

7. metiting fuel

0. OTrER (apociter)

$$
\text { Sm Mod }
$$$$
{ }_{2}^{2-4}, 3
$$

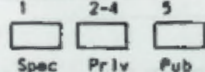$$
\square
$$
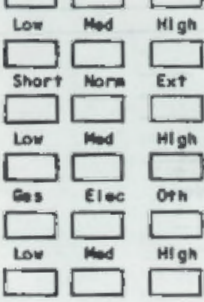

9. runak 3 nost inportant FACTOas LISTED neove

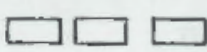

10. EMERGY ENO USE

\section{Cooling \\ ventiLTion}

LIGTING

conestic hot mater

FOCO PREP/DISTHASH

Luncar

OTHER :

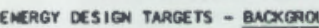

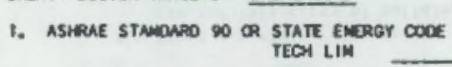

$$
{ }_{6000}=
$$

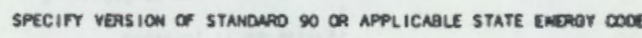

2. XESIOH MOHIEVERENT

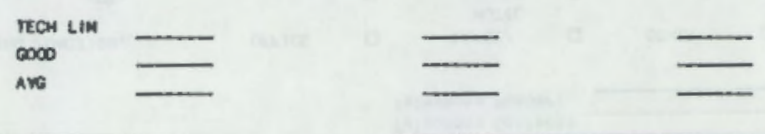

or

Lon Nigh
ASSUMPTIONS

\section{(Optional)}

$\square$

$\square_{5000}^{2-1} \sum_{p=15}^{3}$

Spoc Priv Pub

$\square_{\text {Smart }} \square_{\text {nore }}$

$\square \square \square$

$\square \square$

Cos Elec orn

$\square \square \square$

$\square \square$

otwer

or

$\square$

$\square_{\text {spoce }}^{1} \prod_{\text {Priv }}^{2-4}$

$\square \square$

$\square \square$

Ext

$\square$

eas $\sum_{\text {Eloe }}$

$\square \square$

$\square^{\text {loot }}$

$\square \square \square$

$\square \square \square$
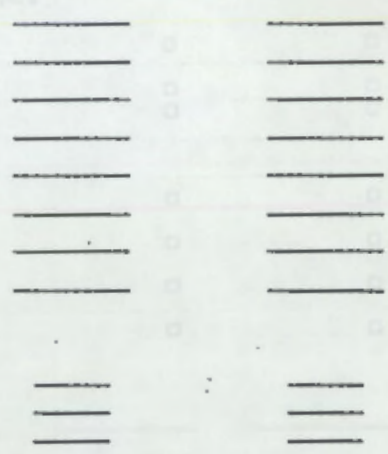

FIGURE 7.5. Questionnaire on Assumptions 
TABLE 7.1. Estimates by Building Type

\begin{tabular}{lcccc} 
Building Type & & $\begin{array}{c}\text { Number of } \\
\text { Estimates }\end{array}$ & $\begin{array}{c}\text { Percent of } \\
\text { Estimates }\end{array}$ & $\begin{array}{c}\text { Aggregate } \\
\text { Percentage }\end{array}$ \\
\cline { 2 - 3 } Offices & 60 & & 43 & 43 \\
Education & 24 & 17 & 60 \\
Hotel/motel & 19 & 13 & 73 \\
Apartments & 11 & 8 & 81 \\
Retail & 8 & 6 & 87 \\
Other & 19 & $\underline{13}$ & 100 \\
$\quad$ Total & 141 & 100 &
\end{tabular}

type. Separate tabulations are included in Section 7.5 for each of these five building types. Almost half of the responses were for office buildings ( 60 responses, or $43 \%$ ). Education and hotel/motel building types came next with 24 and 19 responses, respectively. There were 11 responses for apartments, and $B$ responses for retail facilities.

\subsubsection{Regional Nature of Responses}

Most respondents either indicated that their estimates were good for the entire country for a region of the country (e.g., west coast, coastal area, Rocky Mountains high plains area, areas above 4000 HDD, etc.), or for specific locations (state or city). Because of the limited number of responses, summaries of the responses are grouped geographically as follows:

- national

- cold

- hot/cold

- hot/humid

- hot/arid

- temperate.

A map of the suggested regions used is shown in Figure 7.6. The actual locations for the specific estimates are shown in Table $D .1$ in Appendix $D$ of this report.

A summary of the regional composition of respondents and estimates in shown in Table 7.2. As can be seen from this table, a greater proportion of 


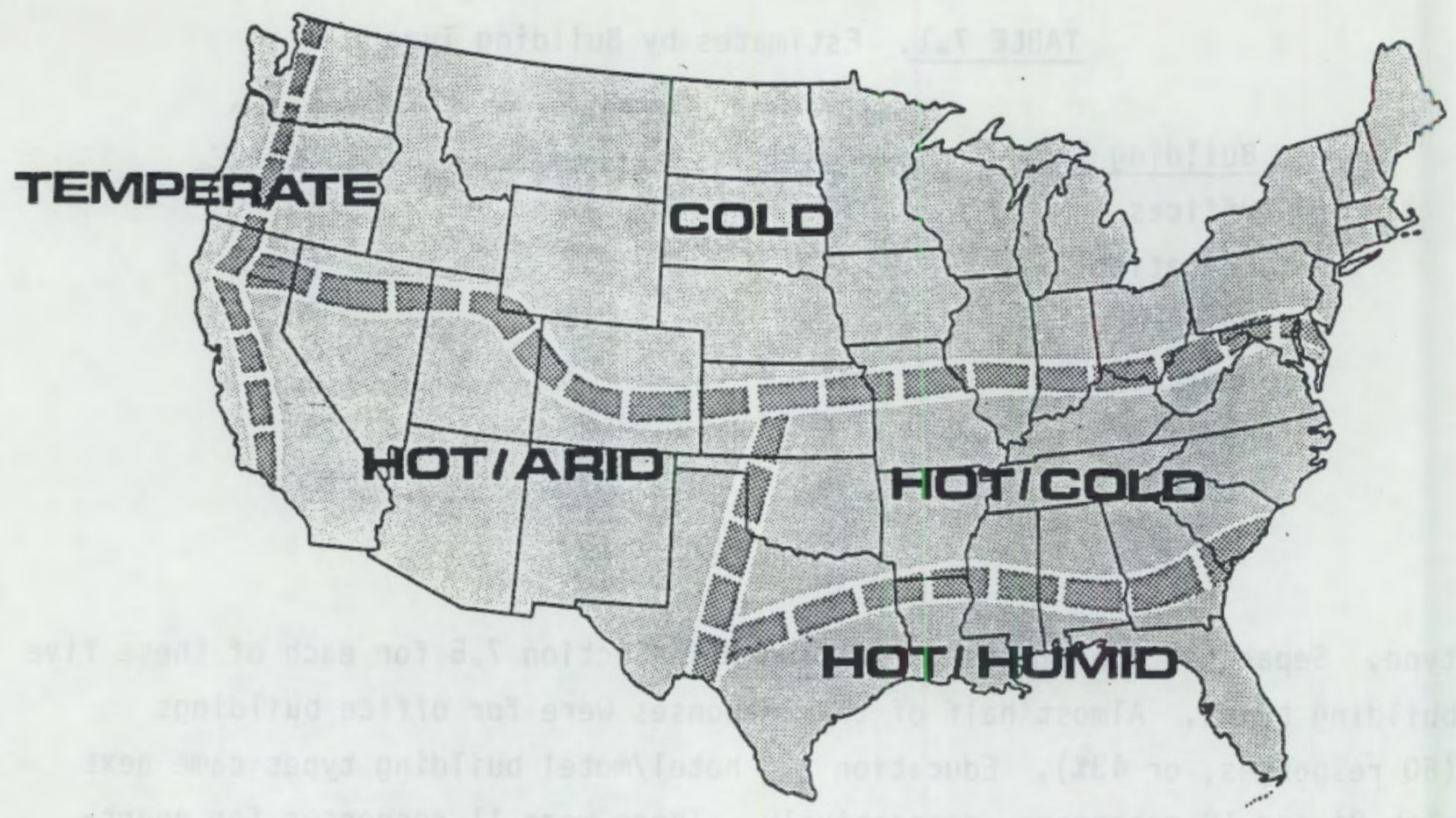

FIGURE 7.6. Climate Regions of the United States

TABLE 7.2. Number of Estimates by National Climate Regions

\begin{tabular}{|c|c|c|}
\hline Region & $\begin{array}{l}\text { Number of } \\
\text { Estimates }\end{array}$ & $\begin{array}{l}\text { Percentage } \\
\text { of Total }\end{array}$ \\
\hline National & 16 & 12 \\
\hline Cold & 45 & 34 \\
\hline Hot/cold & 40 & 31 \\
\hline Hot/humid & 9 & 7 \\
\hline Hot/arid & 8 & 6 \\
\hline Temperate & 13 & 10 \\
\hline Total & 131 & 100 \\
\hline
\end{tabular}

responses was received from the more heavily populated regions of the country, and the responses from the hot/humid and hot/arid areas appear to be underrepresented. It is important to note when reviewing the responses for each building type that most responses came from the northern and eastern parts of the country. 
Relative to the national estimates provided, several respondents indicated that the reduction in heating was compensated by increase in cooling and that a number of factors tended to compensate from region to region. For example, one respondent indicated that his national estimate might have a $\pm 10 \%$ fluctuation throughout the country.

\subsubsection{Experience Basis for Estimates}

The participants were asked to indicate the experience basis of their estimates. Table 7.3 summarizes the total responses according to this factor. 7.4.4 Design Calculations or Actual Consumption

The participants were also asked to indicate whether their estimates were based on design calculations, actual consumption, or a combination of the two. Table 7.4 indicates the combined responses for this factor. In some cases, respondents provided separate estimates for design calculation estimates and for actual consumption estimates.

\subsubsection{Supporting Information}

The answers to question number 5, "Energy Estimates" of the Targets Questionnaire, compose the major results of this survey. All other responses

\section{TABLE 7.3. Estimates by Experience Basis}

Experience in
Building Type
Broad experience
with building
type
Experience with
10 or more
buildings
Experience
with 2 to 9
buildings
Experience
with a single
building
Total

Number of Percentage Estimates of Estimates with 2 to 9

wilding 
TABLE 7.4. Type of Estimate Made

\begin{tabular}{|c|c|c|}
\hline Type of Estimate & $\begin{array}{l}\text { Number of } \\
\text { Estimates }\end{array}$ & $\begin{array}{c}\text { Percentage } \\
\text { of Estimates }\end{array}$ \\
\hline Design calculation & 42 & 29.8 \\
\hline Actual consumption & 53 & 37.6 \\
\hline $\begin{array}{l}\text { Calculations and } \\
\text { actual consumption } \\
\text { combined }\end{array}$ & 46 & 32.6 \\
\hline Total & 141 & 100.0 \\
\hline
\end{tabular}

may be considered as assumptions about, comments on, or qualifications to the energy estimates. Additional responses included comments on estimates, requests for anonymity, and backup information or supporting data for estimates.

Some respondents completed all of the questions about supporting assumptions while others made a generic comment such as building estimates were based upon typical design practice. In a few cases, respondents indicated in comments or assumptions that their estimates were special cases. Such special cases are indicated in the results tabulations. Many respondents provided information about their estimates that qualified those estimates or that indicated some special features of the buildings that influenced the estimates.

Virtually all responses were in terms of $B t u /\left(y r^{\cdot} \mathrm{ft}^{2}\right)$ or $\mathrm{kBtu} /\left(\mathrm{yr} \cdot \mathrm{ft}^{2}\right)$ at the building site. In a few cases, another unit of measure was used. But in these cases, two sets of estimates were provided, one in Btu/(yr·ft $\left.{ }^{2}\right)$ and another in a second unit of measurement.

\section{Nonresponses}

A number of people did not respond because they felt they did not have the proper experience base to make such estimates. In some cases, these individuals could provide partial estimates (e.g., for the lighting system) but not for the building as a whole. The reasons for such partial or nonresponses were not tabulated. 
Several people did not respond because they thought there was too much variation in building energy to provide meaningful estimates, and suggested that energy targets were meaningless for this reason. Several ASHRAE members, including two ASHRAE Fellows, and one AIA member, wrote letters expressing their concerns about the variations. These letters are included in Appendix D but are not attributed to the writers. This practice preserves the survey policy of anonymity.

\subsection{THE ENERGY ESTIMATE RESULTS}

A complete listing of the survey energy estimate results, sorted by building type, is contained in Table 0.1 of Appendix $D$. This table is from the spreadsheet file used to generate all summary information from the survey. In keeping with the agreement established as part of the survey, individual respondents are not identified with respect to the individual estimates. The list of individuals who provided energy estimates is contained in Table 0.2 in Appendix $D$. This list excludes the names of the respondents who requested anonymity.

For the five building types having more than a few responses, Table 7.5 provides an overall summary of the average energy estimates produced by the survey. The averages are calculated results. Some respondents provided estimates as ranges, while other provided estimates as average values. All estimates supplied as ranges were calculated as the average of the extremes of the ranges provided.

TABLE 7.5. Average Energy Estimates for Five Building Types (in Btu/yr.ft ${ }^{2}$ )

\begin{tabular}{|c|c|c|c|c|c|c|c|c|}
\hline & \multicolumn{4}{|c|}{ Office } & \multirow{2}{*}{$\begin{array}{l}\text { Hotel/ } \\
\text { Motel } \\
\end{array}$} & \multirow{2}{*}{ Educ. } & \multirow[b]{2}{*}{ Apts } & \multirow[b]{2}{*}{ Retail } \\
\hline & Design & Actual & Combined & A11 & & & & \\
\hline Technical Limit & 33 & 43 & 44 & 39 & 70 & 36 & 42 & 92 \\
\hline Good Practice & 46 & 61 & 66 & 57 & 90 & 55 & 58 & 105 \\
\hline Average Practice & 62 & 82 & 102 & 80 & 117 & 81 & 74 & 157 \\
\hline Energy Intensive & 103 & 122 & 127 & 116 & 166 & 99 & 117 & 265 \\
\hline
\end{tabular}


In each case, these averages are for the total number of responses received, without regard to differences in experience basis, estimate basis (design calculation or actual consumption), region of the country, etc. Therefore, any use of these averages needs to be treated with great caution.

Figures 7.7 through 7.13 contain more statistics about the estimates, specifically the maximum and minimum estimates, the mean (indicated by a thick black line) and the standard deviation, organized by building type. These figures also show the wide range of variation that occurred in each set of estimates.

\subsubsection{Estimates for Offices}

Table 7.5 shows the average results for all of fice buildings combined. Because a substantial number of responses were received for offices, the data were sorted several times. These tabulations need to be qualified, for in each case the data were sorted only for the item of interest. For example, there was an insufficient number of responses to simultaneously sort for regional

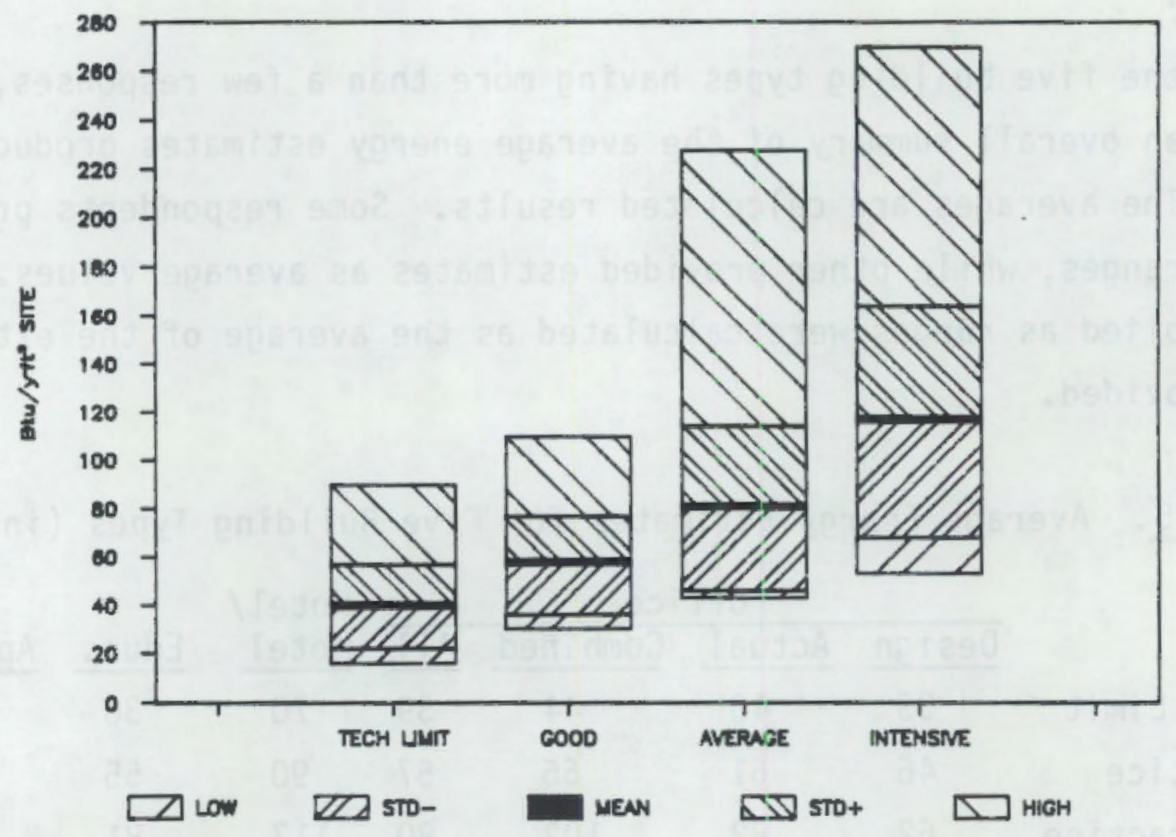

FIGURE 7.7. Summary of All Estimates for Office Buildings 


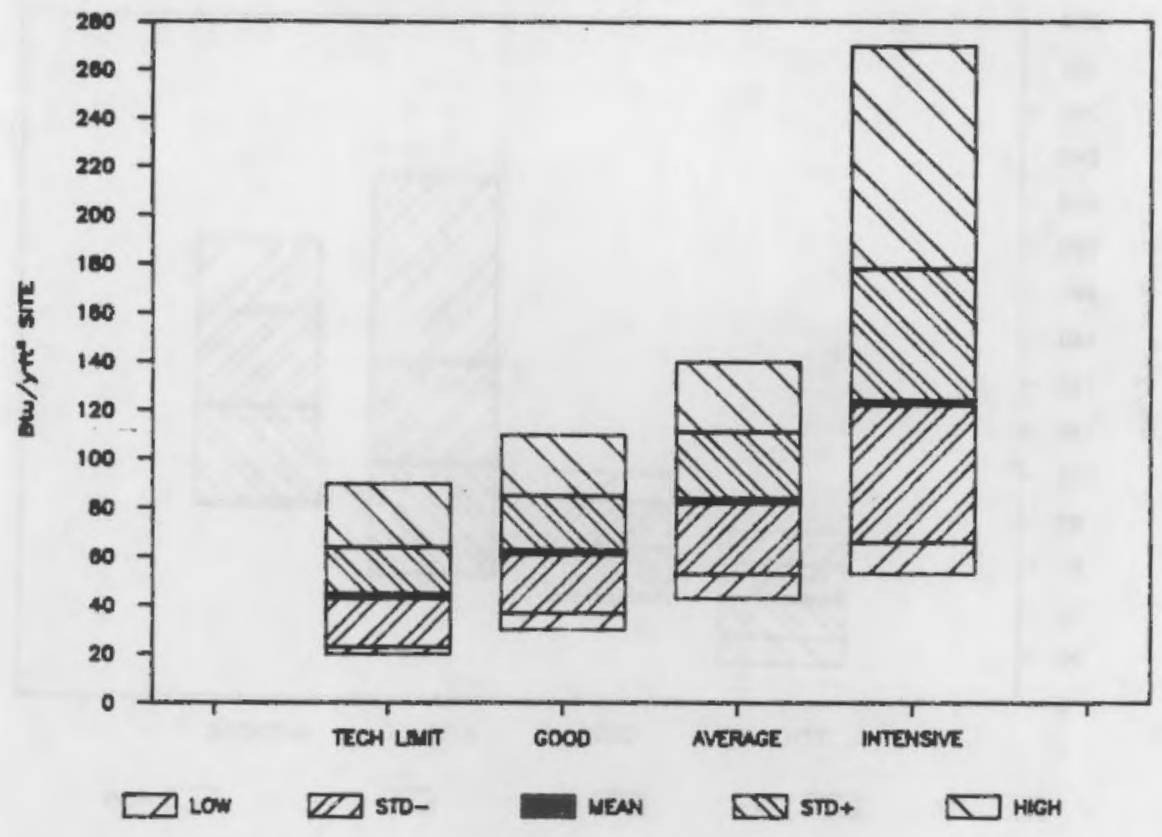

\section{FIGURE 7.8. Estimates Based on Consumption for Office Buildings}

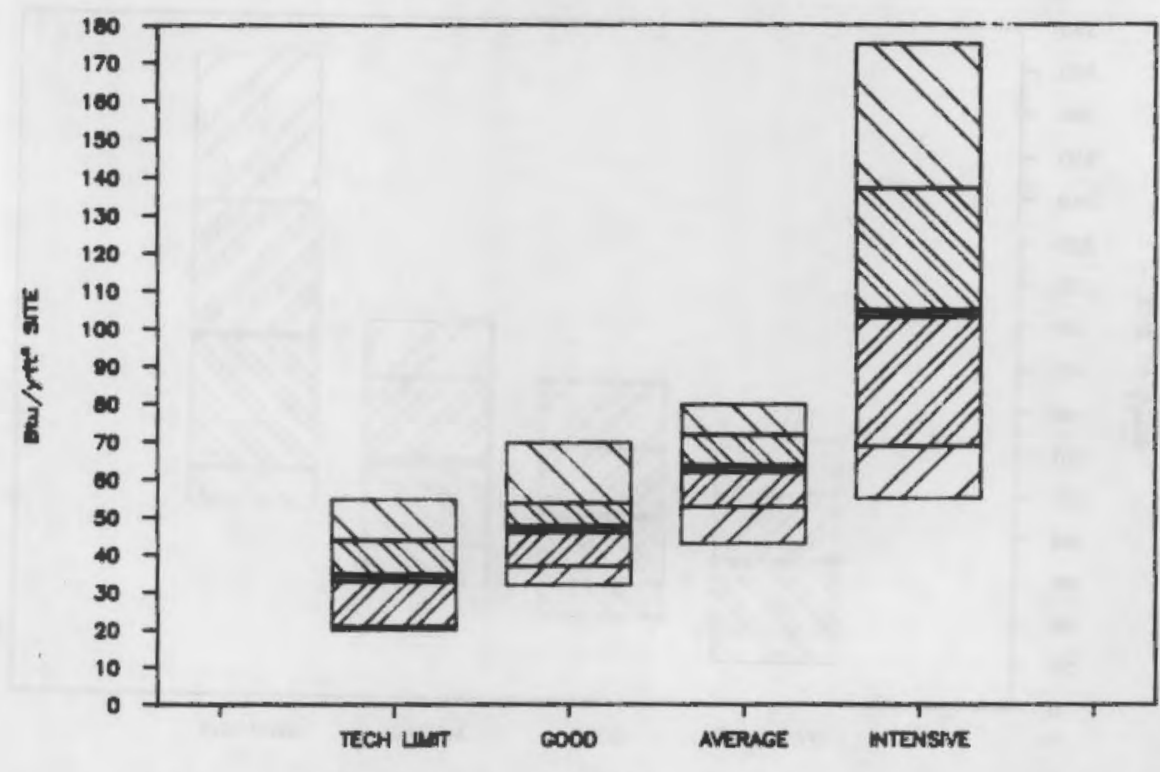

DLOW MEN

FIGURE 7.9. Estimates Based on Design Calculations for Office Buildings 


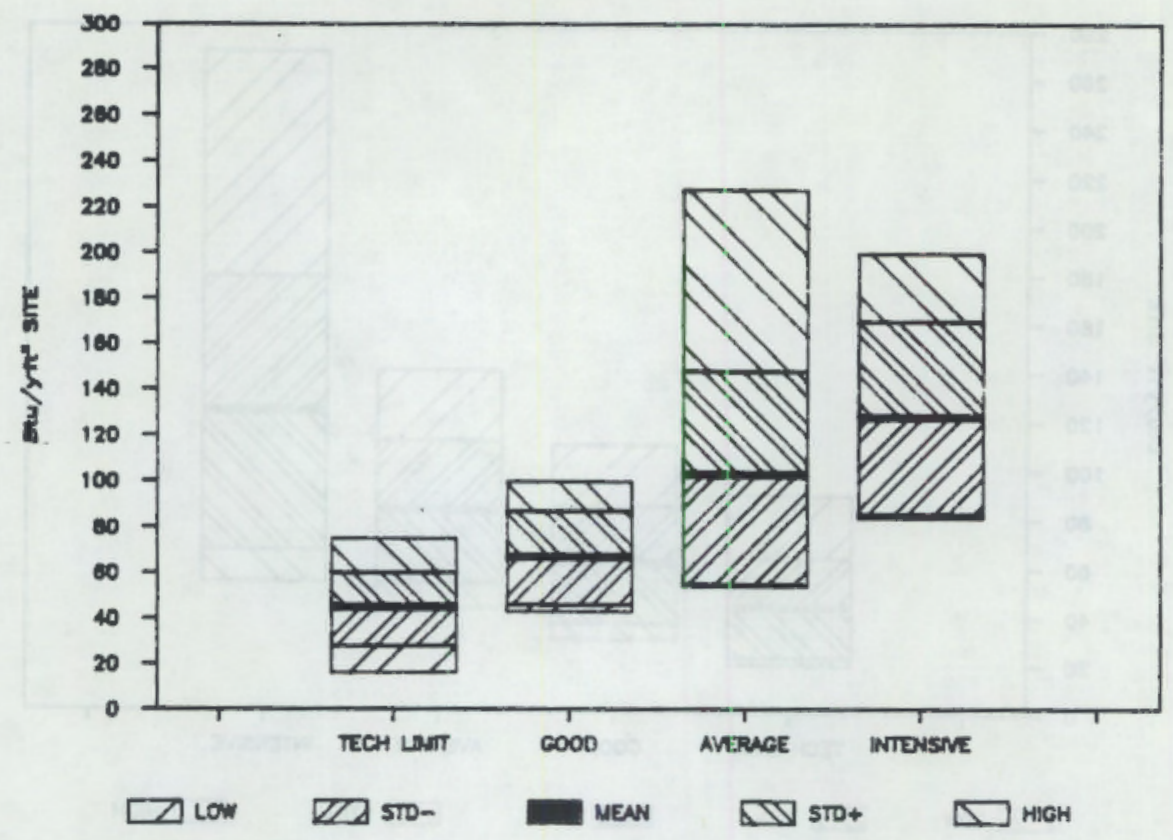

FIGURE 7.10. Estimates Based on Design Calculations and Consumption for Office Buildings

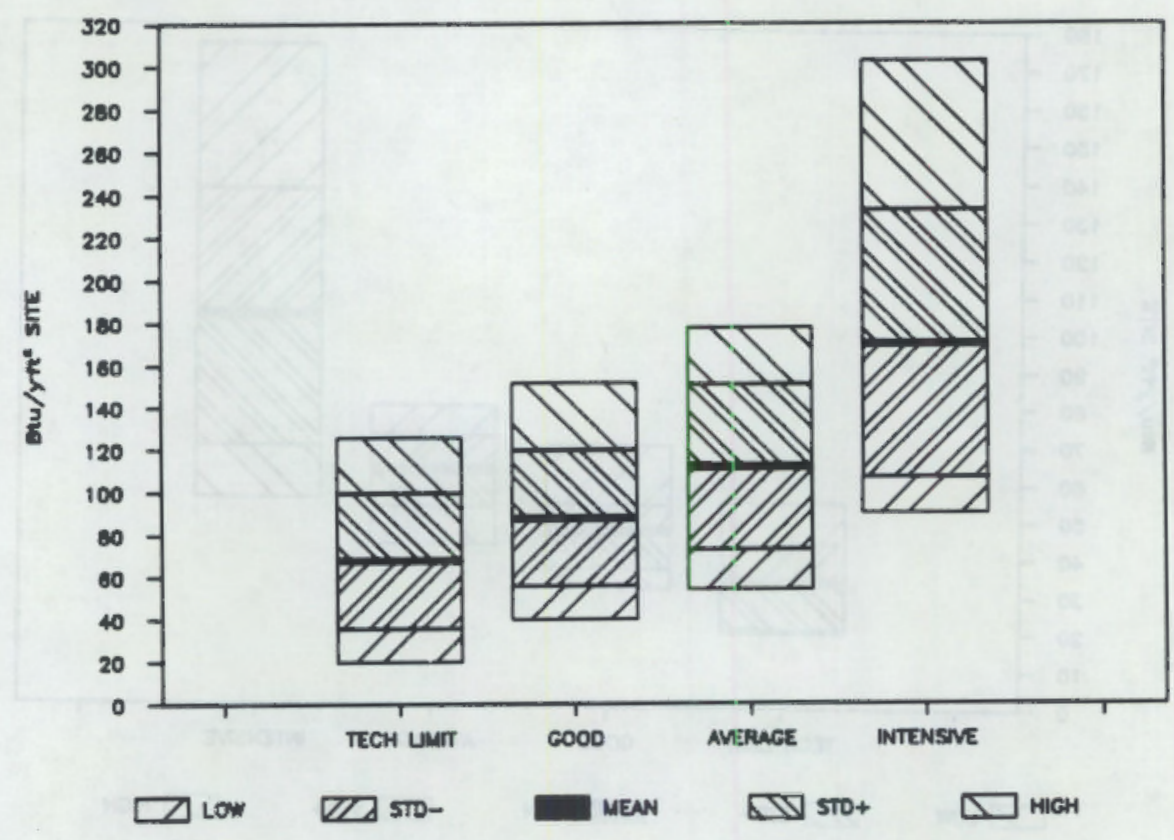

FIGURE 7.11. Estimates for All Hotels 


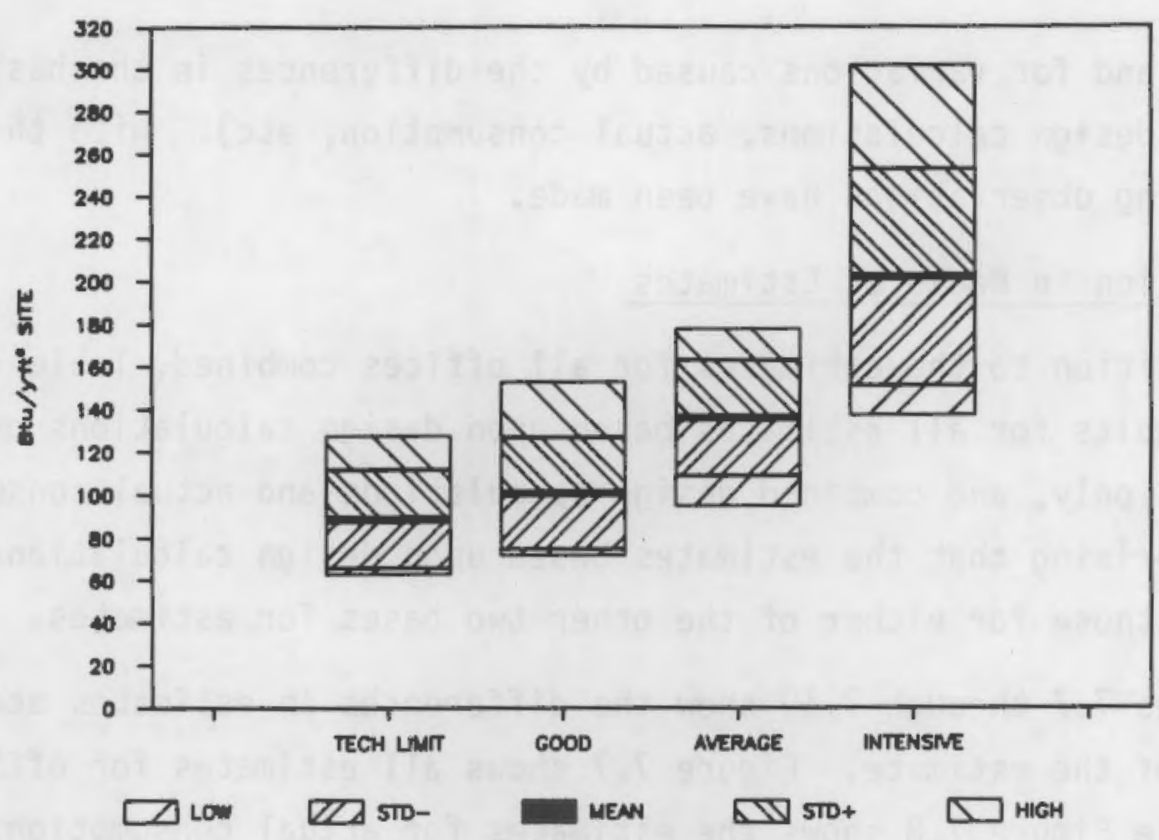

\section{FIGURE 7.12. Estimates for Convention Hotels}

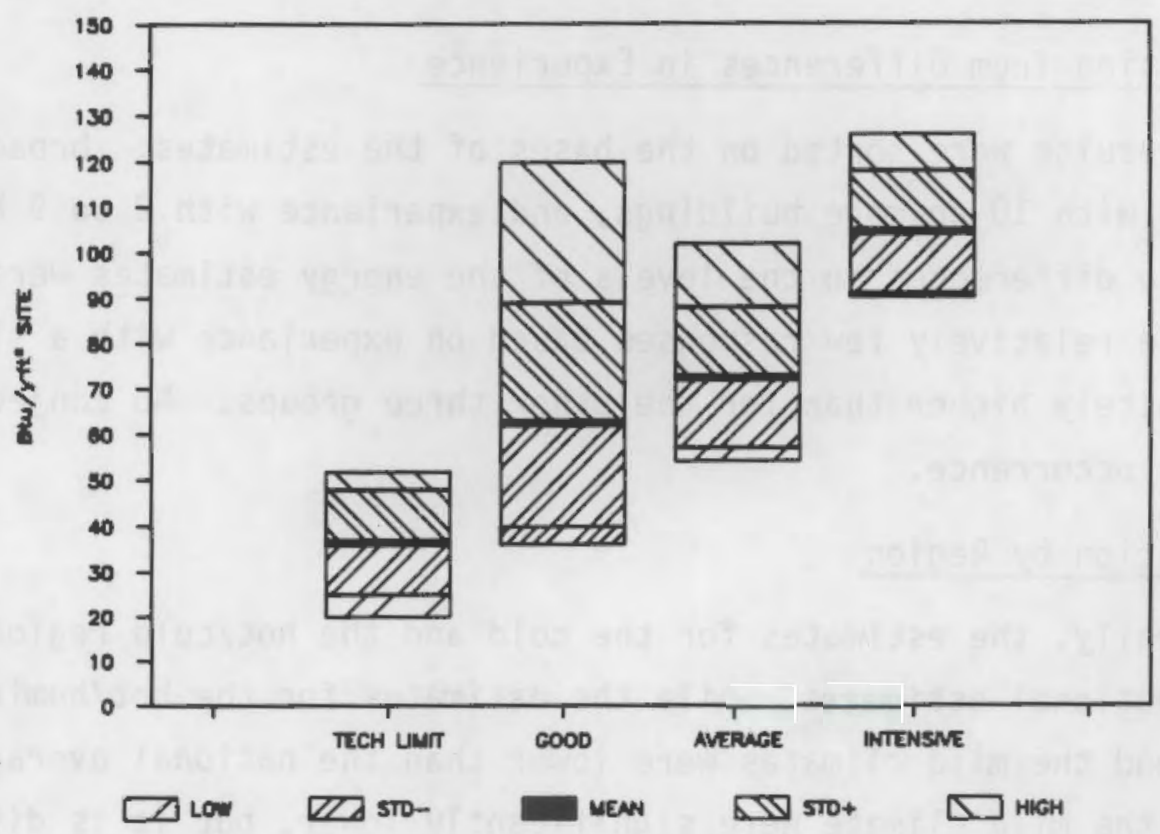

FIGURE 7.13. Estimates for Roadside Hotels 
variations and for variations caused by the differences in the basis of the estimates (design calculations, actual consumption, etc). With this provision, the following observations have been made.

\section{Variation in Basis of Estimates}

In addition to the estimates for all offices combined, Table 7.5 shows the average results for all estimates based upon design calculations only, actual consumption only, and combined design calculations and actual consumption. It is not surprising that the estimates based upon design calculations only are lower than those for either of the other two bases for estimates.

Figures 7.7 through 7.10 show the differences in estimates according to the basis of the estimate. Figure 7.7 shows all estimates for offices combined, while Figure 7.8 shows the estimates for actual consumption, Figure 7.9 shows design calculations, and Figure 7.10 shows combined consumption/design calculations.

\section{Variation from Differences in Experience}

The results were sorted on the bases of the estimates: broad experience, experience with 10 or more buildings, and experience with 2 to 9 buildings. No discernible differences in the levels of the energy estimates were found. However, those relatively few responses based on experience with a single building were definitely higher than for the other three groups. No conjecture is made about this occurrence.

\section{Variation by Region}

Generally, the estimates for the cold and the hot/cold regions were higher than the national estimates, while the estimates for the hot/humid, the hot/arid and the mild climates were lower than the national average. The estimates for the mild climate were significantly lower, but it is difficult to isolate this occurrence as climate-related or related to active codes and standards of California and the Northwest Power Planning Council. 


\subsubsection{Estimates for Hotels/Motels}

The combined estimates for hotels and motels are shown in Figure 7.11. The estimates for convention hotels and for roadside hotels/motels were markedly different, as can be seen by comparing Figures 7.12 and 7.13. As might be expected, energy use in convention hotels is much greater than in roadside hotels/motels. Some causes for these differences are discussed below.

\section{Estimates for Hotel Chains}

Several of the estimates represent considerable knowledge about hotel energy behavior, based upon data bases for hotel chains such as Mariott Hotel, Hyatt Hotels, and Holiday Inn.

\section{Some Causes of Variation}

During a telephone interview, one of the respondents discussed some of the major causes of variation in energy use among hotels. A major cause is the food and beverage ratio, expressed as:

$$
\text { Food and Beverage Ratio }=\frac{\text { Annual Food and Beverage Sales }}{\text { Annual Room Sales }}
$$

This ratio is usually in the range of 0 to 1.5. Generally, the higher the ratio of food and beverage sales to room sales, the higher the energy use per hotel room or per square foot of hotel space. This relationship is shown in Figure 7.14, based upon the information provided.

Other causes of variation include the number of rooms, the room rate (the food and beverage ratio is implicit in this cost), the room occupancy rate (higher the rate, the higher the energy use per room), and presence of laundries (it takes more energy to do the linen than to heat the rooms). For roadside hotels, this respondent included laundries, and indicated the estimate would be $25 \%$ lower without the laundries.

\section{Estimates by Region}

The estimates for convention hotels were fairly well distributed by region. However, the estimates for roadside hotels were predominantly from the 


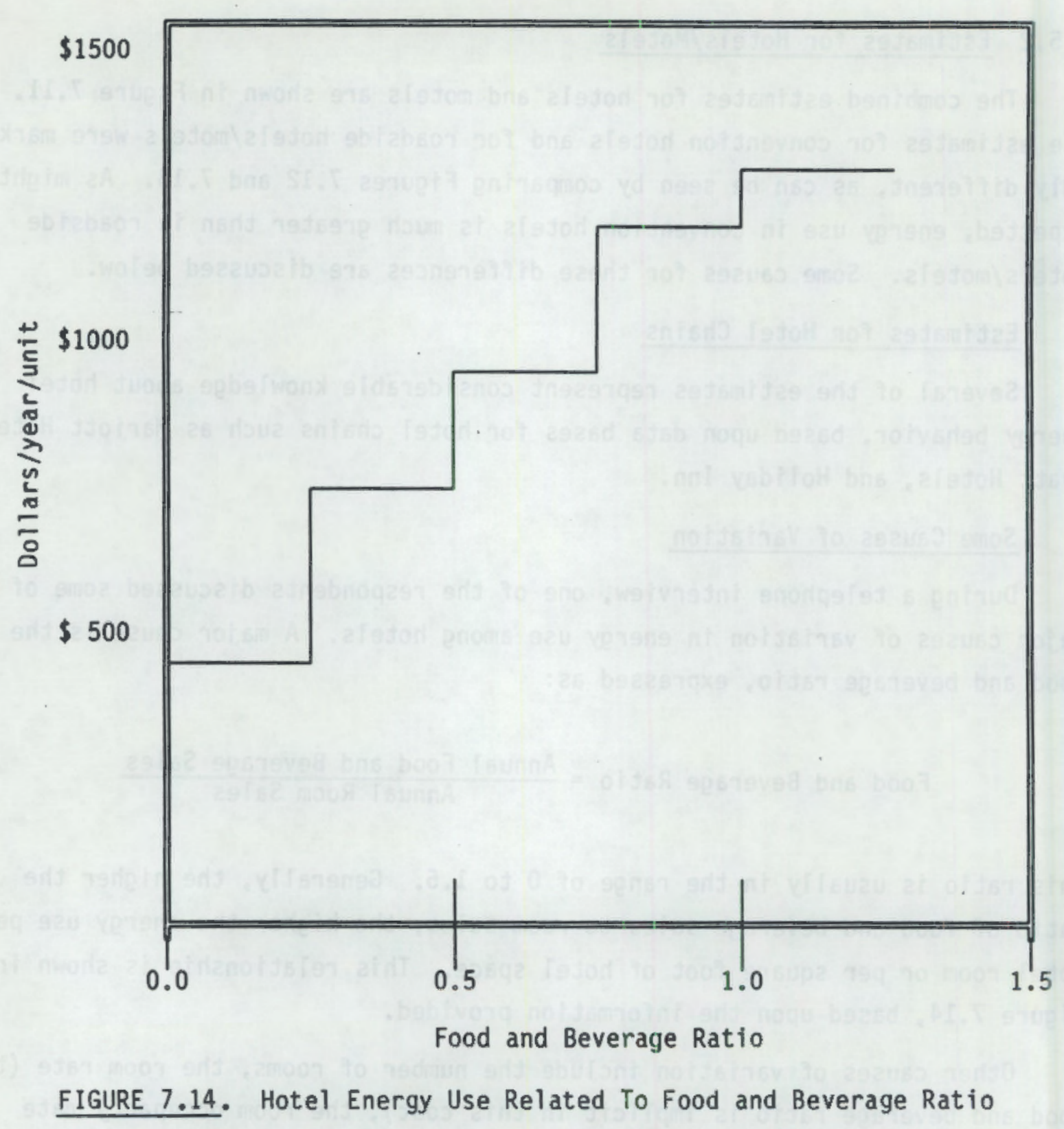

cold and hot/cold regions. Only one national estimate and one estimate for the mild region were received. Because of the limited number of responses, no attempts have been made to distinguish levels of energy estimates by region. 7.5.3 Estimates for Education Facilities

The energy estimates for all education facilities combined are shown in Figure 7.15. Over two-thirds of the estimates provided were for elementary or secondary schools (17), 6 estimates were for colleges and universities, and 


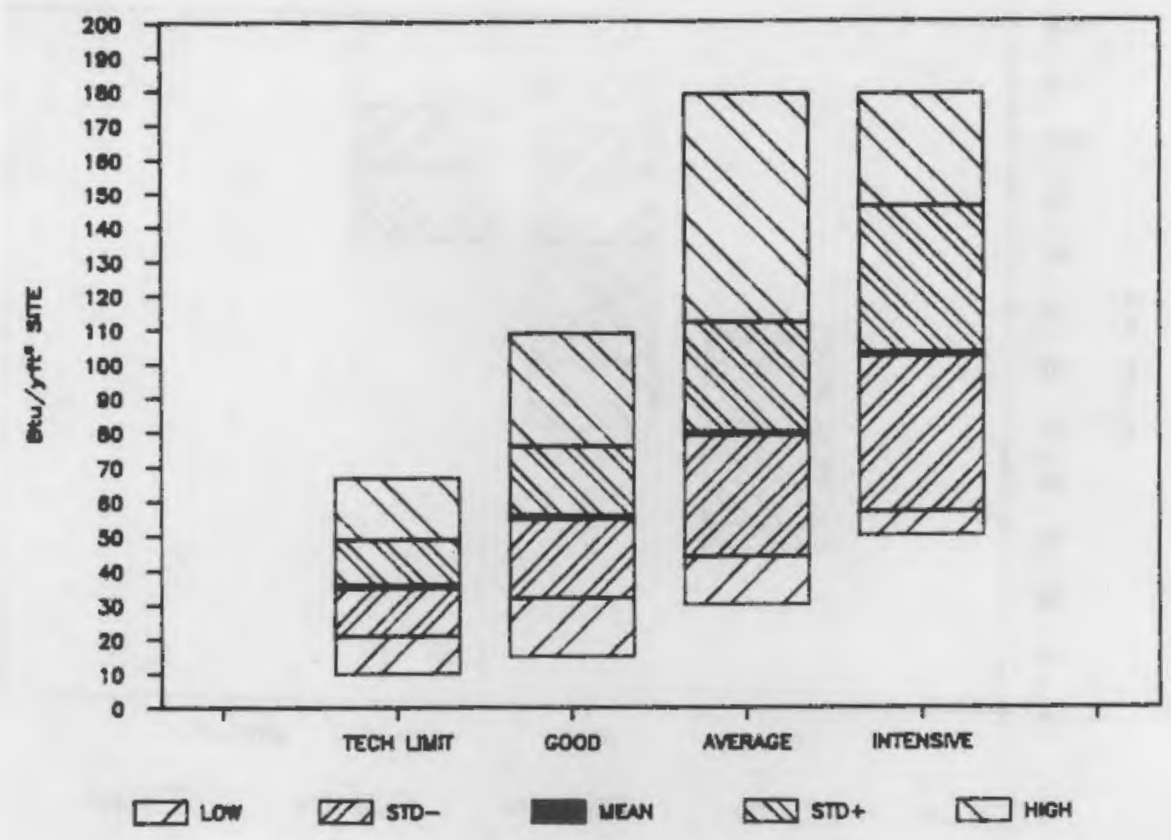

FIGURE 7.15. Estimates for All Educational Facilities

1 estimate was given for community colleges. Significant differences exist among the estimates by education subtype.

\section{Estimates by Education Subtype}

The energy estimates for colleges and universities were higher than those for elementary and secondary schools. This difference is shown in Figures 7.16 and 7.17. Too little information was provided in the estimates for colleges and universities to distinguish among building subtypes. Also, the data were insufficient to show information about the energy intensive level for colleges and universities. Many respondents simply indicated school as building type designation for their estimates. In those cases, "Elem/Scnd?" with a question mark indicates that no specific subtype was given.

\section{Community Colleges}

The single estimate provided for community colleges was based upon general knowledge of the building type. The estimate for community colleges is:

Est imate

$\frac{\text { Technical Limit }}{60} \quad \frac{\text { Good }}{70} \quad \frac{\text { Average }}{85} \quad \frac{\text { Energy Intensive }}{100}$




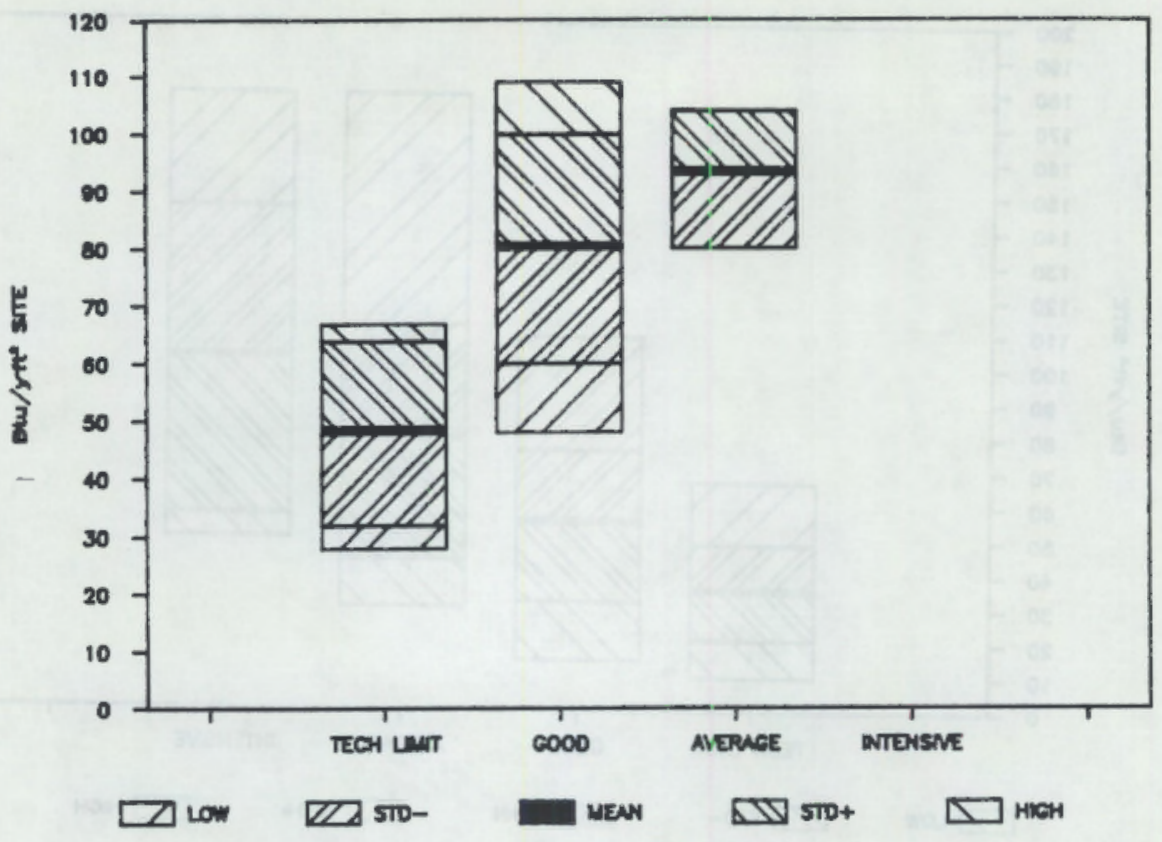

FIGURE 7.16. Estimates for Colleges and Universities

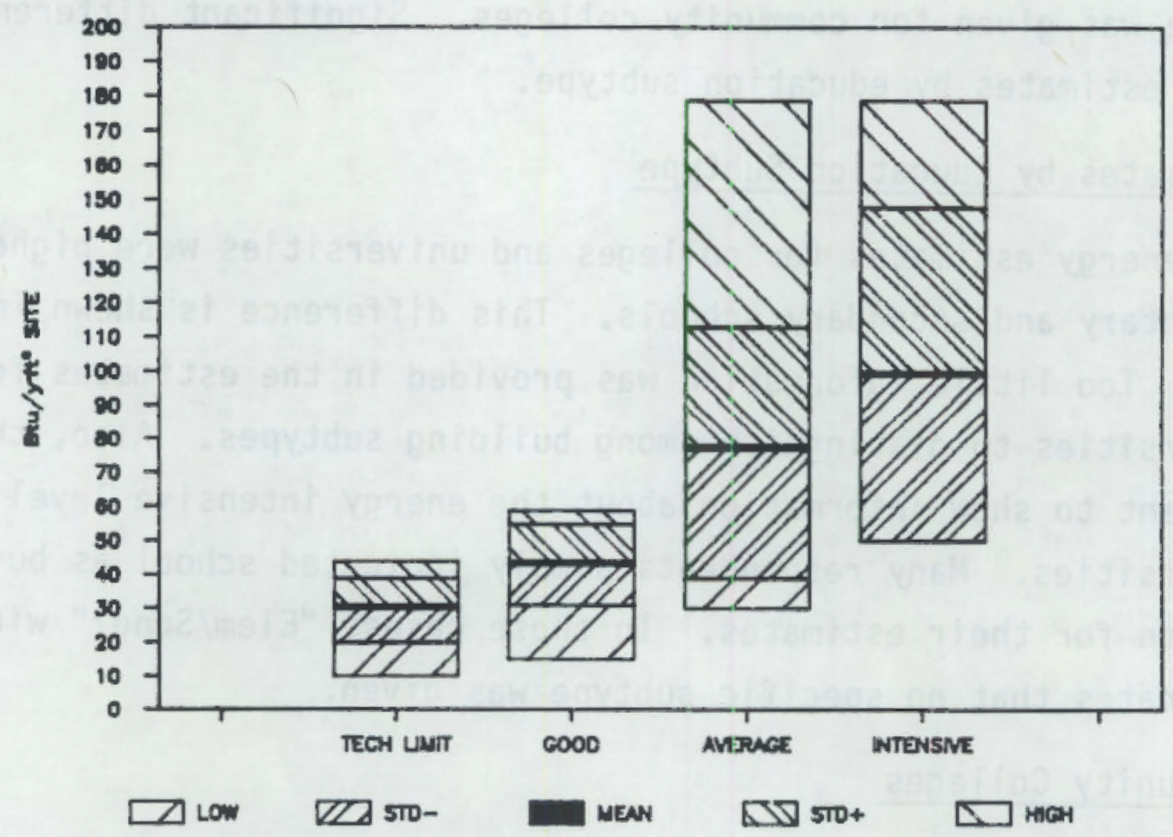

FIGURE 7.17. Estimates for Elementary and Secondary Schools 
This estimate assumes that such facilities tend to be newer than traditional 4-year colleges. The estimate also assumes a single building or facility with an ordinary mix of functions (classrooms, library, science lab, recreation facility, cafeteria, bookstore, auditorium, gymnasium, and offices).

\section{Estimates by Region}

Over three-fourths of the education responses were for the cold and hot/cold regions. Thus, the education estimates should be considered most applicable to these two regions. Only 3 responses were for the nation as a whole. Only one response was received for each of the other climate regions, hot/humid, hot/arid, and mild.

The energy estimates for the cold region were compared with the estimates for the hot/cold region. The estimates for the cold region are lower than those for the hot/cold region. This lower estimate may be a result of less use of HVAC for cooling in the cold region than in the hot/cold region.

\subsubsection{Estimates for Apartments}

The combined energy estimates for apartments are shown in Figure 7.18. Because of the limited number of responses for this building type, only one

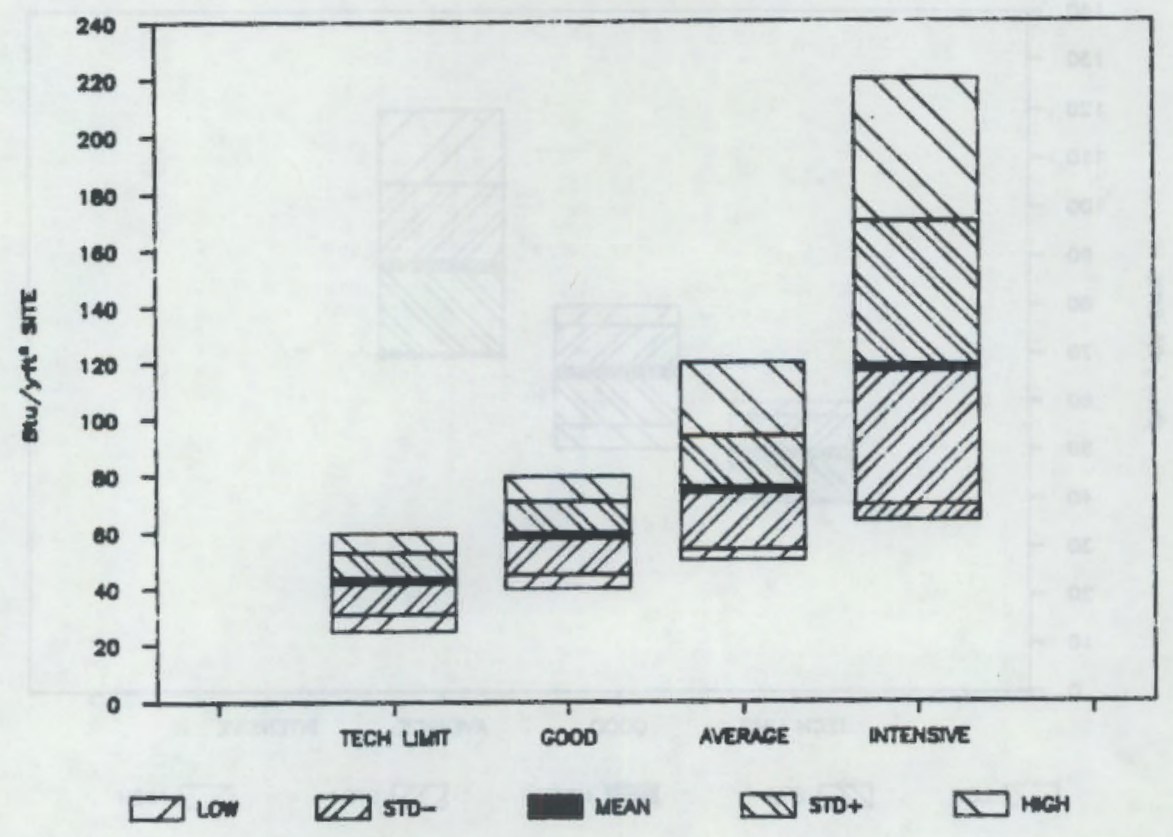

FIGURE 7.18. Estimates for All Apartments 
subset of the estimates was analyzed, and is discussed below. One respondent indicated that low-rise apartments had more surface area, but high-rise apartments had more ventilation, and in colder climates those effects tended to cancel each other.

About half of the responses were based upon design calculations and half were based upon actual consumption or a mix of consumption and design calculations. Most of the responses were based upon broad experience with the building type. Two responses were based upon experience with 10 or more buildings, and two responses were based upon experience with 2 to 9 buildings.

\section{Estimates by Region}

Six of the 11 responses were for the cold region. As one might expect for this building type, the estimates for the cold region tended to be somewhat higher than for all the other regions, as shown in Figures 7.19 and 7.20.

\subsubsection{Estimates for Retail Facilities}

Only eight estimates were provided for retail facilities of all kinds, including small (1) versus large facilities (1), supermarkets (1), drugstores

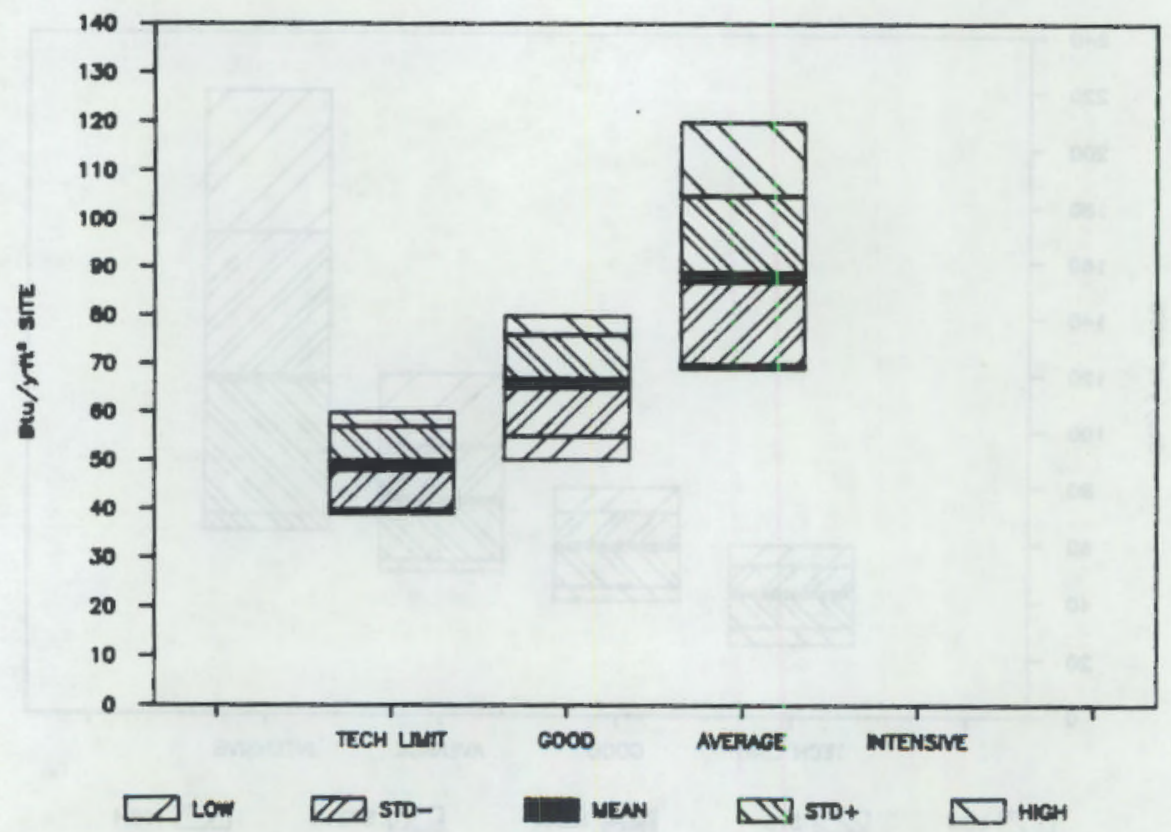

FIGURE 7.19. Estimates for Apartments in Colder Climates 


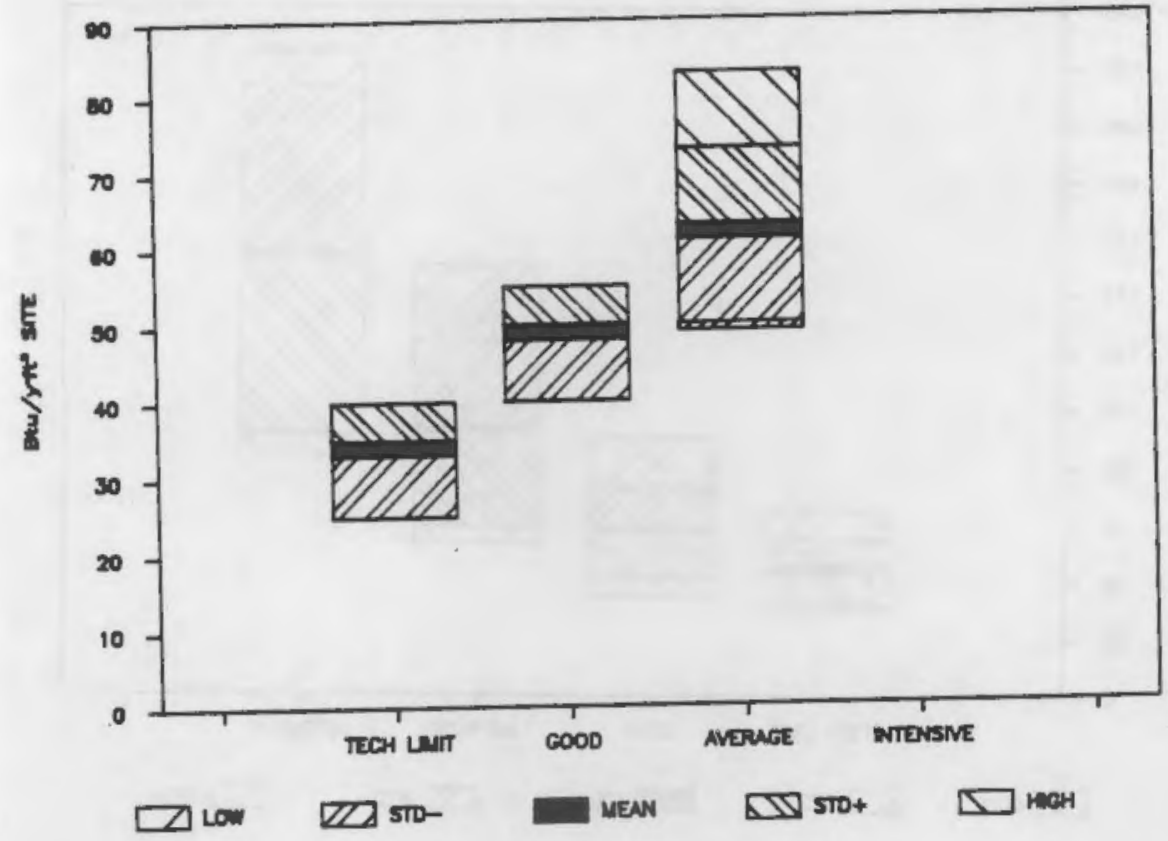

FIGURE 7.20. Estimates for Apartments in All Other Climates

(1), department stores (2), and undesignated (2). Given this small sample, Figure 7.21 shows the results for the estimates combined (excluding the supermarket). These estimates should be used for very general reference only because of the dissimilarities of energy requirements among the retail building subtypes involved.

\section{Drugstores}

The estimates are typical of chain stores that are usually carefully and centrally designed and controlled. These chain stores reflect a trend toward larger facilities like minidepartment stores (e.g., 10,000 $\mathrm{ft}^{2}$ ). The large jump in the "intensive" estimate includes such items as frozen food, food service, and bakeries. Nonchain stores would tend to have lower energy use, because they are generally smaller and contain fewer energy-intensive functions. 


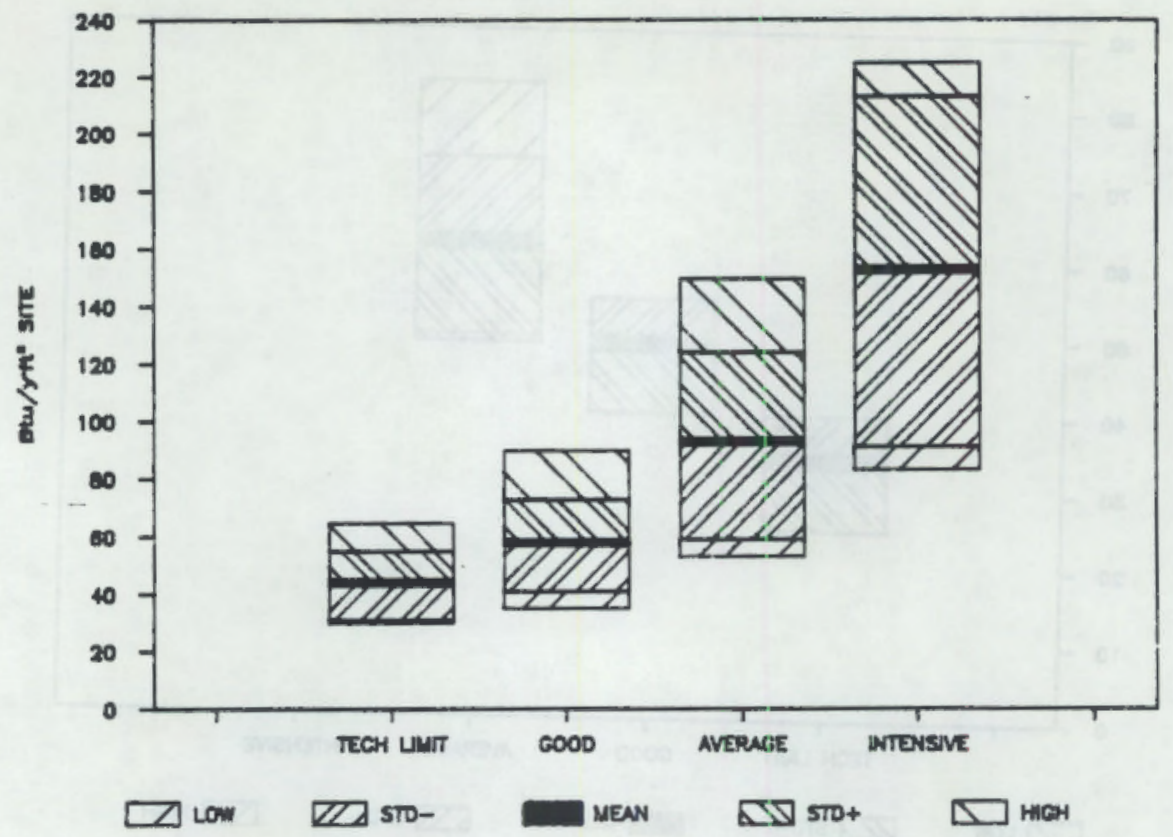

FIGURE 7.21. Estimates for Retail Facilities Without Supermarkets

\section{Supermarkets}

The high loads for supermarket refrigeration set this building type apart. The single estimate for this building type is shown below:

$\begin{array}{lllll}\text { Estimate } & \text { Technical Limit } & \frac{\text { Good }}{275} & \frac{\text { Average }}{300} & \frac{\text { Energy Intensive }}{350}\end{array}$

This energy estimate was based upon knowledge of buildings in the Pennsylvania and New Jersey area; therefore, the estimate may not apply very well to different climates. Also, the estimate is based upon general knowledge of the type, but not extensive knowledge of a number of specific buildings. Thus, the estimates for this building type probably should be considered to have a lower level of confidence than estimates for other building types.

\section{Estimates by Region}

The regional basis for the estimates was fairly broad, with a one or two estimates for each of the regions, except the hot/humid region, which was not represented. 


\subsubsection{Estimates For Other Building Types}

Table 7.6 lists calculated estimates of average energy use at each of the four energy levels where estimates were requested for other building types. Because so few estimates were provided for each building type, Table 7.6 simply lists those individual estimates.

\section{Churches}

The estimates for churches are based on data for some 500 buildings. The estimates assume sanctuary-type buildings with meeting rooms and Sunday schools. The operations assume weeknight, not weekday, classes. Most churches are in the range of 40 to $60 \mathrm{kBtu} /\left(\mathrm{yr} \cdot \mathrm{ft}^{2}\right)$.

\subsection{CONCLUSIONS}

This survey produced valuable information about estimates of commercial building energy use, based upon the combined professional judgment of a number

TABLE 7.6. Survey Results for Other Building Types

\begin{tabular}{|c|c|c|c|c|c|c|c|}
\hline \multirow[b]{2}{*}{ Bullding Type } & \multirow[b]{2}{*}{ Reglon } & \multirow[b]{2}{*}{$\begin{array}{c}\text { Exper. } \\
\text { Base } \\
\end{array}$} & \multirow[b]{2}{*}{$\begin{array}{c}\text { Estime } \\
\text { Bose }\end{array}$} & \multicolumn{4}{|c|}{$\begin{array}{l}\text { Averages } \\
\text { sands of } \mathrm{g}+\mathrm{u} /\left(\mathrm{yr} \cdot \mathrm{ft}^{2}\right)\end{array}$} \\
\hline & & & & $\begin{array}{c}\text { Technteat } \\
\text { LImit } \\
\end{array}$ & $\begin{array}{c}\text { Good } \\
\text { Practice }\end{array}$ & $\begin{array}{l}\text { Average } \\
\text { Practice }\end{array}$ & $\begin{array}{c}\text { Energy } \\
\text { Intensive } \\
\end{array}$ \\
\hline Church & $\mathrm{Na}+1$ & aroad & $\operatorname{Cons}^{(0)}$ & 20 & 25 & 40 & 100 \\
\hline Community Center & $\mathrm{H} / \mathrm{C}$ & $10+$ & $\operatorname{comb}{ }^{(b)}$ & 28 & 43 & - & - \\
\hline Computer Center & Not I & Brood & Calce $c^{(c)}$ & 200 & 250 & 260 & 350 \\
\hline Laboratory & cold & 2 to 9 & Colc & 60 & 80 & 120 & - \\
\hline Library & $H / C$ & 2 to 9 & Comb & 20 & 45 & 100 & 135 \\
\hline Nursing Home & $H / H$ & Broad & Cons & 75 & 100 & 120 & -- \\
\hline Nursing Home & $\mathrm{H} / \mathrm{C}$ & Arood & Cons & -- & - & 142 & -- \\
\hline Recreation Center & $\mathrm{H} / \mathrm{C}$ & One & Calc & $\cdots$ & - & - & 306 \\
\hline USPS took $\mathrm{ft}^{2+}$ & $\mathrm{NatI}$ & Broad & Cons & - & - & 85 & - \\
\hline USPS $25 K-100 K \mathrm{ft}^{2}$ & $\mathrm{Nat1}$ & Brood & Cons & - & $\rightarrow$ & 70 & - \\
\hline USPS $<25 K t^{2}$ & $\mathrm{Nati}$ & Broad & Cons & - & $\rightarrow$ & 50 & - \\
\hline
\end{tabular}

(a) Consumption.

(b) Combined.

(c) Calculated. 
of knowledgeable people throughout the country. The information proved valuable not only for the average estimates produced, but also for 1) the variations in the estimates, 2) the respondents' extensive comments about qualifications on their estimates, and 3) proving difficulties of collecting, tabulating, and interpreting the estimates.

The results of this survey will be used by the project team as one point of reference in the further development of energy target methodologies and leve1s. The results should also prove useful to building owners and designers as general reference information about the professional judgment concerning various levels of energy use for some building types.

However, because of numerous limitations in the survey and the results, the energy estimates obtained should be used with considerable care and judgment. This is especially important considering the consistently wide variation in the estimates provided. Phase 2 of this project will directly address many of the causes of variation in commercial building energy use that have surfaced in this survey and elsewhere. 


\section{REFERENCES}

ANSI/ASHRAE/IES 90.1P. 1986. Public Review Draft of Energy Efficient Design of New Buildings Except Low-Rise Residential Buildings. Cosponsored by the American Society of Heating, Refrigerating, and Air Conditioning Engineers and the Illuminating Engineering Society, Atlanta, Georgia.

ASHRAE 90C-1977. Energy Conservation in New Building Design, Section 12. Cosponsored by the American Society of heating, Refrigerating and Air Conditioning Engineers and the Illuminating Engineering Society of North America, Atlanta, Georgia.

ASHRAE/IES 90-75. Energy Conservation in New Building Design, Sections 10 and 11, ASHRAE/IES 90B-1975. Cosponsored by the American Society of Heating, Refrigerating, and Air Conditioning Engineers and the Illuminating Engineering Society, New York.

Association of Physical Plant Administrators of Universities and Colleges (APPA). 1986. Comparative Costs and Staffing Report for College and University Facilities. Association of Physical Plant Administrators of Universities and Colleges, Alexandria, Virginia.

Building Owners and Managers Association lnternational (BOMA). 1984. 1984 BOMA Experience Exchange Report. Building Owners and Managers Association International, Washington, D.C.

Crawley, D. B., R. S. Briggs, J. W. Jones, W. W. Seaton, J. E. Kaufman, J. J. Oeringer, and E. W. Kennett. 1987. Development of Whole-Building Energy Design Targets for Commercial Buildings--Phase 1 Planning, Volume 1: Final Report. PNL-5854, Vol. 1, Pacific Northwest Laboratory, Richland, Washington.

Energy Conservation Production Act. Pub. L. No. 94-385.

Energy Information Administration (EIA). 1983a. Nonresidential Buildings Energy Consumption Survey: 1979 Consumption and Expenditures, Part 1: Natural Gas and Electricity. DOE/EIA-0318/1, U. S. Department of Energy, Energy Information Administration, Washington, 0.C.

Energy Information Administration (EIA). 1983b. Nonresidential Buildings Energy Consumption Survey: 1979 Consumption and Expenditures, Part 2: Steam, 0i1, $[P G$, and A 11 Fuels. D0E/EIA-0318(79)/2, U. S. Department of Energy, Energy Information Administration, Washington, D.C.

Institute of Real Estate Management (IREM). 1986. Income Expense Analysis: Office Buildings, Downt own and Suburban, 1986 edition. Institute of Real Estate Management, Chicago, 11linois.

Lawrence Berkeley Laboratory (LBL). 1984. D0E-2 Supplement Version 2.1C, LBLB706 Rev. 4. Supp1., Lawrence Berkeley Laboratory, BerkeTey, California. 
Pacific Northwest Laboratory (PNL). 1983. Recommendations for Energy Conservation Standard and Guidelines for New Commercial Buildings. PNL-4870, Volumes 1-40, Pacific Northwest Laboratory, Richland, Washington.

U.S. Department of Energy (DOE). 1979. Notice of Proposed Rulemaking Energy Performance Standards for New Buildings. DOE/CS/0112, U. S. Department of Energy, Washington D.C. 
BIBL IOGRAPIC LIST OF BUILDING SYSTEM INTEGRATION RESEARCH REPORTS

\begin{tabular}{|c|c|}
\hline PNL -4358 & $\begin{array}{l}\text { Project Plan, Development of Recommendations to Upgrade } \\
\text { ASHRAE/IES Standard 90A-1980 Energy Conservation in New } \\
\text { BSilding Design, Pacific Northwest Laboratory, Richland, } \\
\text { WA. June 1982. }\end{array}$ \\
\hline NL -4435 & $\begin{array}{l}\text { W. M. Bowen, S. Moreno, A. R. } 01 \text { sen, Climate Selection and } \\
\text { Development of Climate Indicators, Pacific Northwest } \\
\text { Laboratory, Richiand, WA. September } 1982 \text {. }\end{array}$ \\
\hline PNL $=5123$ & $\begin{array}{l}\text { J. L. Stoops, J. J. Deringer, S. Moreno, H. P. Misuriello, } \\
\text { Summary Report: The BEPS Redesign of } 168 \text { Commercial } \\
\text { Buildings, Pacific Northwest Laboratory, Richland, WA. } \\
\text { May 1984. }\end{array}$ \\
\hline PNL-5143 Vol. I & $\begin{array}{l}\text { Weather Data for Simplified Energy Calculation Volume I. } \\
\text { Eastern United States: TRY Data, Pacific Northwest } \\
\text { Laboratory, Richland, WA. August 1984. }\end{array}$ \\
\hline PNL-5143 Vol. II & $\begin{array}{l}\text { Weather Data for Simplified Energy Calculation Volume II. } \\
\text { Middle United States: TRY Data, Pacific Northwest } \\
\text { Laboratory, Richland, WA. August 1984. }\end{array}$ \\
\hline PNL-5143 Vol. III & $\begin{array}{l}\text { Weather Data for Simplified Energy Calculation Volume III. } \\
\text { Western United States: TRY Data, Pacific Northwest } \\
\text { Laboratory, Richland, WA. August } 1984 .\end{array}$ \\
\hline IL-5143 Vol. IV & $\begin{array}{l}\text { Weather Data for Simplified Energy Calculation Volume IV. } \\
\text { United States: WYEC Data, Pacific Northwest Laboratory, } \\
\text { Richland, WA. August 1984. }\end{array}$ \\
\hline $\begin{array}{l}\text { PNL }-4870-1 \\
\text { through } 40\end{array}$ & $\begin{array}{l}\text { R. W. Reilly, Recommendations for Energy Conservations } \\
\text { Standards and Guldelines for New Commercial Buildings, } \\
\text { Pacific Northwest Laboratory, Richland, WA. October } 1984 .\end{array}$ \\
\hline PNL $=5027$ & $\begin{array}{l}\text { J. A. Heidell, Commercial Building End-Use Energy Metering } \\
\text { Inventory, Pacific Northwest Laboratory, Richland, WA. } \\
\text { April } 1985 \text {. }\end{array}$ \\
\hline PNL -5462 & $\begin{array}{l}\text { C. Claar, R. P. Mazzucchi, J. A. Heide 11, Project on } \\
\text { Restaurant Energy Performance End-Use Monitoring, Pacific } \\
\text { Northwest Laboratory, Richiand, WA. June } 1985 .\end{array}$ \\
\hline $\begin{array}{l}-5462 \\
\text { pendi ces }\end{array}$ & $\begin{array}{l}\text { C. Claar, R. P. Mazzucchi, J. A. Heidell, Project on } \\
\text { Restaurant Energy Performance End-Use Monitoring, Pacific } \\
\text { Northwest Laboratory, Richland, WA. June 1985. }\end{array}$ \\
\hline
\end{tabular}


PNL -5709

J. A. Heidell, J. J. Deringer, Fifth Generation Design

Process Tools: Phase I Planning Report, Pacific

Northwest Laboratory, Richtand, WA. November 1985.

PNL -5696

R. W. Reilly, Recommendations for a Multi-Year Plan for

Building Systems Integration Research, Pacific Northwest

Laboratory, Richland, WA. January 1986.

PNL -5966

National Association of Home Builders, Cutting Energy Costs

in Mulitfamily Housing: Practical Case Studies for the

Builder and Developer, Pacific Northwest Laboratory,

Richland, WA. August 1986.

DOE $/ C E-0166$

Volume 1 of 4. G. L. Wilfert, J. W. Callaway, Environmental Assessment: Proposed Interim Energy Conservation Standard

for Design of New Federal Commercial Buildings. U.S.

Department of Energy, Washington, DC. November 1986.

Volume 2 of 4. J. M. Roop, Economic Analysis: Proposed

Interim Energy Conservation Standard for Design of New

Federal Commercial Buildings. U.S. Department of Energy, Washington, OC. November 1986.

Volume 3 of 4. D. B. Crawley, P. D. Gilbride, Envelope

System Performance Compliance Calculation Program

Documentation - Version 1.0. U.S. Department of Energy, Washington, $\mathrm{DC}$. November 1986.

Volume 4 of 4. D. B. Crawley, E. G. Stephan, Lighting

Prescription and System Performance Compliance Calculation

Program Documentation - Version 1.0. U.5. Department of

Energy, Washington, OC. November 1986.

PNL-5854-1 D. B. Crawley, R. S. Briggs, J. W. Jones, W. W. Seaton,

J. E. Kaufman, J. J. Deringer, E. W. Kennett, Development of Whole-Building Energy Design Targets for Comercial

Buildings - Phase 1 Planning, Volume 1: Final Report, Pacific Northwest Laboratory, Richland, WA. Apri1 1987.

PNL-5854-2 D. B. Crawley, R. S. Briggs, J. W. Jones, W. W. Seaton, J. E. Kaufman, J. J. Deringer, E. W. Kennett, Development of Whole-Building Energy Design Targets for Commercial Buildings - Phase 1 Planning, Volume 2 : Technical Report, Pacific Northwest Laboratory, Richland, WA. July 1987.

Research reports are available from:

National Technical Information Service

U.S. Department of Commerce

5285 Port Royal Road

Springfield, VA 22161

Bib.2 
APPENDIX A

DOE-2 INPUT FILE NAME CONVENTIONS 


\section{DOE-2 INPUT FILE NAME CONVENTIONS}

Modifications of original SP41 DOE-2 file appear in four sets:

- design day runs for establishing design zone flowrates

- parametric runs with systems serving all five zones (two parametrics per systen plus base case, simulated in order of decreasing sensible loads)

- parametric runs with separate systems serving each zone two runs required per system type (a11 perimeter zones $=1$, core $=2$ ) because of the limit of 4 plant assignments per run (VAV system only)

- additional parametric runs for schedule variations.

\begin{tabular}{|c|c|c|}
\hline Fllename & & Simulation Description \\
\hline $\begin{array}{l}\text { <CS SET } 1 \\
\text { FVAVOI } \\
\text { MVAVOI }\end{array}$ & $\begin{array}{l}\text { PD } \\
\text { YAY } \\
\text { YAV }\end{array}$ & $\begin{array}{l}\text { design day sizling } \\
\text { design day sizing }\end{array}$ \\
\hline $\begin{array}{l}\text { <\& SET } 2 \\
\text { FYAVI } \\
\text { MVAVI } \\
\text { FPSZI } \\
\text { MPSZ! } \\
\text { FPTAI } \\
\text { MPTAI }\end{array}$ & $\begin{array}{l}\text { VAV } \\
\text { VAY } \\
\text { PSZ } \\
\text { PSZ } \\
\text { PTAC } \\
\text { PTAC }\end{array}$ & $\begin{array}{l}\text { paranatrlcs, } 5 \text { zones } \\
\text { parametrlcs, } 5 \text { zones } \\
\text { parametrlcs, } 5 \text { zones } \\
\text { parametrles, } 5 \text { zones } \\
\text { parametrics, } 5 \text { zones } \\
\text { parametrlics, } 5 \text { zones }\end{array}$ \\
\hline $\begin{array}{l}\text { <C SET } 3 \\
\text { FVAVRAP } \\
\text { FVAVRAC } \\
\text { MVAYRAP } \\
\text { AVAVRAC } \\
\text { FPSZA1 } \\
\text { MPSZAI } \\
\text { FPTAAI } \\
\text { MPTAAI }\end{array}$ & $\begin{array}{l}\text { PS } \\
\text { VAY } \\
\text { VAY } \\
\text { VAY } \\
\text { VAY } \\
\text { PSZ } \\
\text { PSZ } \\
\text { PTAC } \\
\text { PTAC }\end{array}$ & 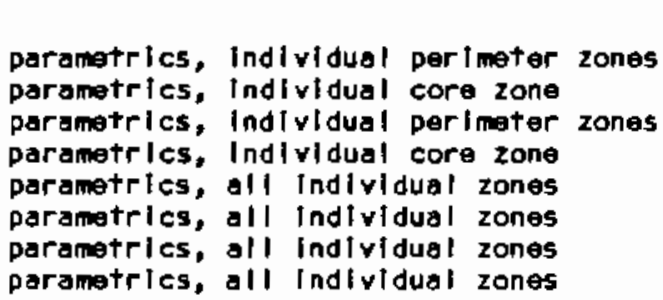 \\
\hline
\end{tabular}

\begin{tabular}{|c|c|}
\hline $\begin{array}{l}\text { Number of Zones } \\
\text { Systems, Plants } \\
\text { Paranetrles }\end{array}$ & $\begin{array}{c}\text { Weather } \\
\text { Dato (WYEC) }\end{array}$ \\
\hline $\begin{array}{l}5,0,0,3 \\
5,0,0,3\end{array}$ & $\begin{array}{l}\text { Ft. Worth, } T X \\
\text { Madison, wil }\end{array}$ \\
\hline $\begin{array}{l}5,1,1,3 \\
5,1,1,3 \\
5,1,1,3 \\
5,1,1,3 \\
5,5,1,3 \\
5,5,1,3\end{array}$ & $\begin{array}{l}\text { Ft. Worth, TX } \\
\text { Madison, wi I } \\
\text { Ft. Worth, TX } \\
\text { Madison, i I } \\
\text { Ft. Worth, TX } \\
\text { Madison, wi }\end{array}$ \\
\hline $\begin{array}{l}4,4,4,2 \\
1,1,1,2 \\
4,4,4,2 \\
1,1,1,2 \\
5,5,1,2 \\
5,5,1,2 \\
5,5,1,2 \\
5,5,1,2\end{array}$ & $\begin{array}{l}\text { Ft. Worth, TX } \\
\text { Ft. Worth, TX } \\
\text { Madison, WI } \\
\text { Madison, WI } \\
\text { Ft. Worth, TX } \\
\text { MadI son, II } \\
\text { Ft. Worth, TX } \\
\text { Madison, II }\end{array}$ \\
\hline
\end{tabular}


Number of Zones

Systams, Plants

Fl Iename

Simulation Description

Paranetrics

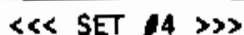

FVAVPS

FVAVCS

MVAYPS

VAV schedule mod, Individual perlmeter zones:

Var schedule mod. Individual cores zone

VAV schedule mod, individual perimeter zones:

MYAYCSI

FPSZAS I

YAY schedule mod, individual core zone

PSZ schedule mod, all individual zones

MPSZASI

PSZ schedule mod, all Individual zones

PTAC schedule mod, all indlvidual zones

$4,4,4,1$

$1,1,1,1$

$4,4,4,1$

$1,1,1,1$

$5,5,1,1$

$5,5,1,1$

$5,5,1,1$

PTNC schedule mod, oll individual zones

$5,5,1,1$

Weather Data (WYEC)

Ft. worth, TX $F+$. Worth, $T X$ Modison, il Mad Ison, il

Ft. worth, TX Madison, W

Ft. Worth, $T X$

Mad Ison, il

NOTE: The first four tlies in set 3 were nodifled to Include reverse octing thermostats and minimum stop positlons set at ventilation requlrements. The corresponding files in set in (five-zone simulations) and set 4 (schedule modiflcations) were not modtf led. 
The following is the DOE-2.1C input data for the loads portion of the Phase 1 simulations. The loads input data were identical for all runs except for title line changes and two minor data modifications in the PTAC system simulations. These modifications are discussed below. Parametrics loads input (used to vary the level of sensible load) is included at the end of the file.

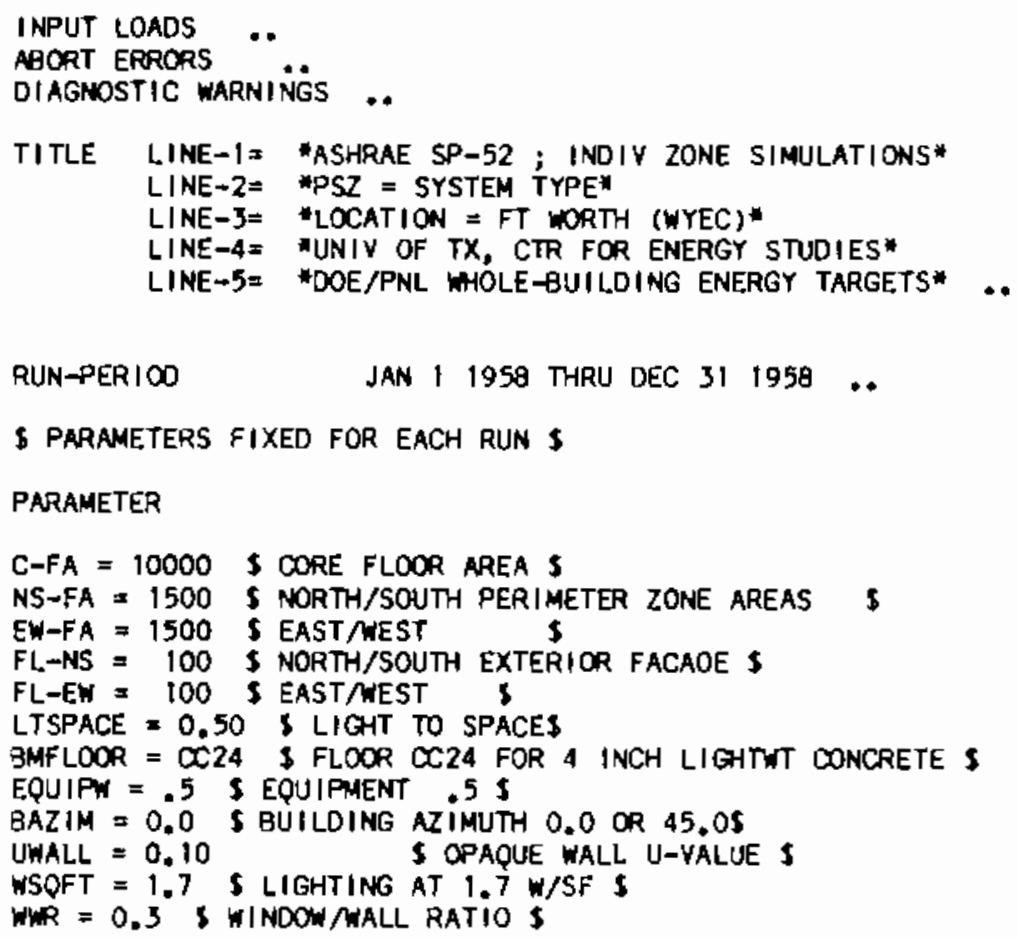

\$ PARAMETERS VARIED FOR EACH RUN \$

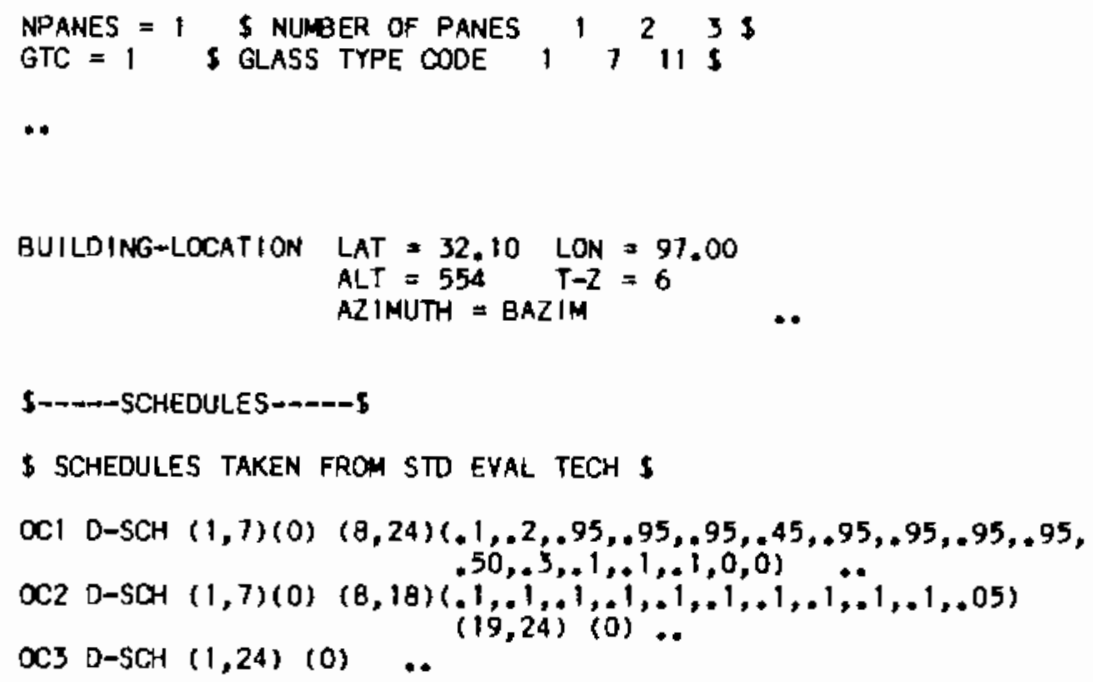




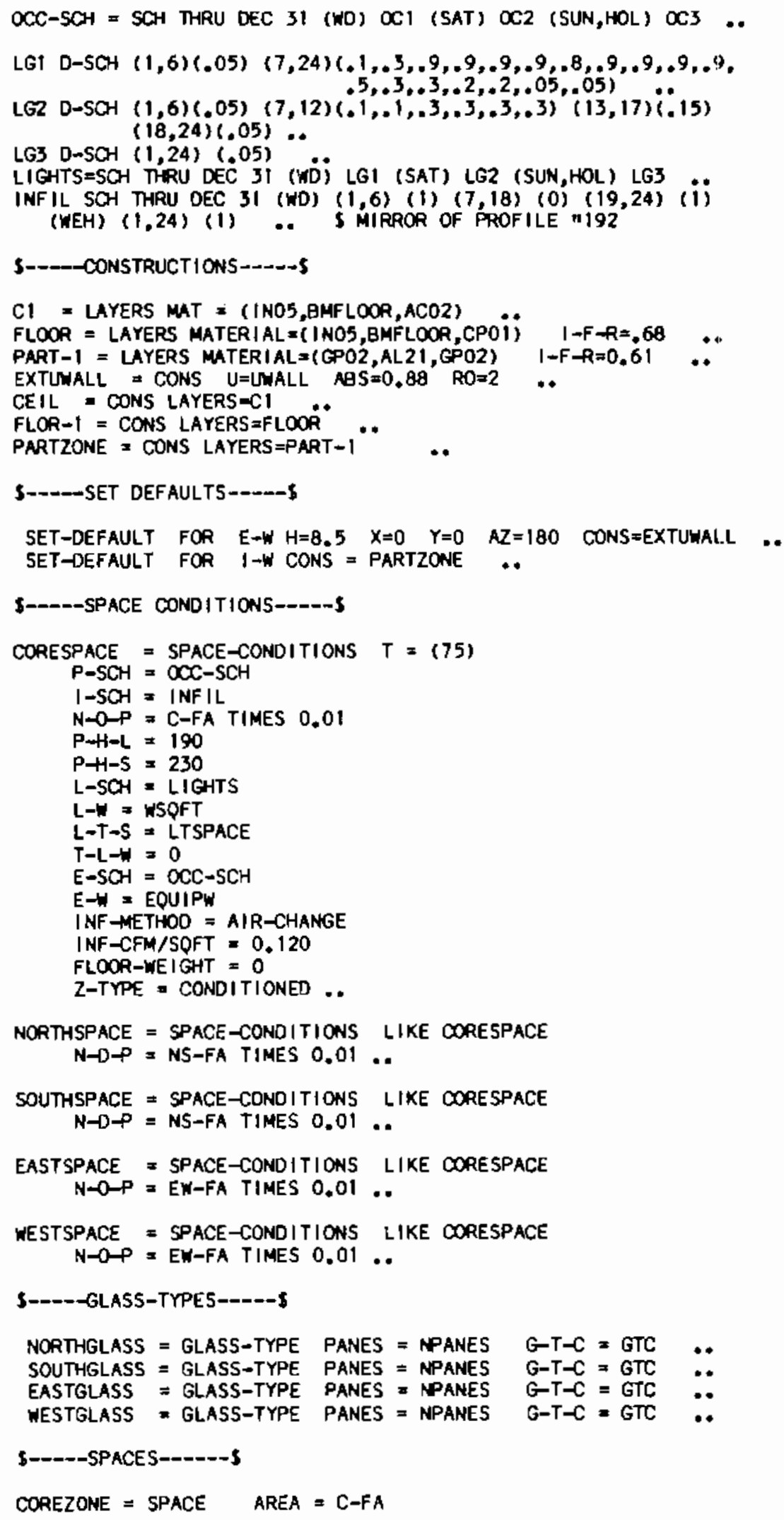




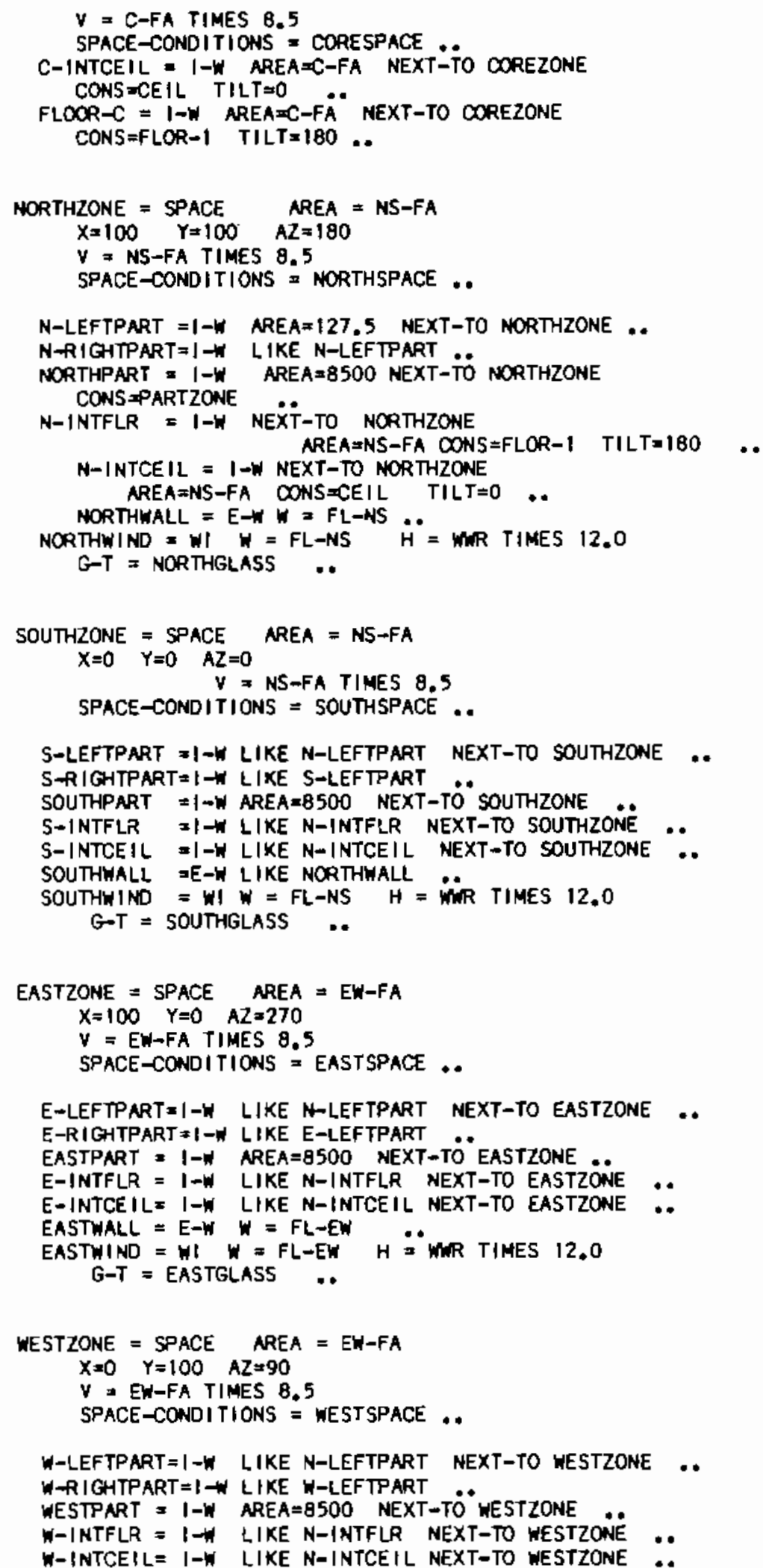




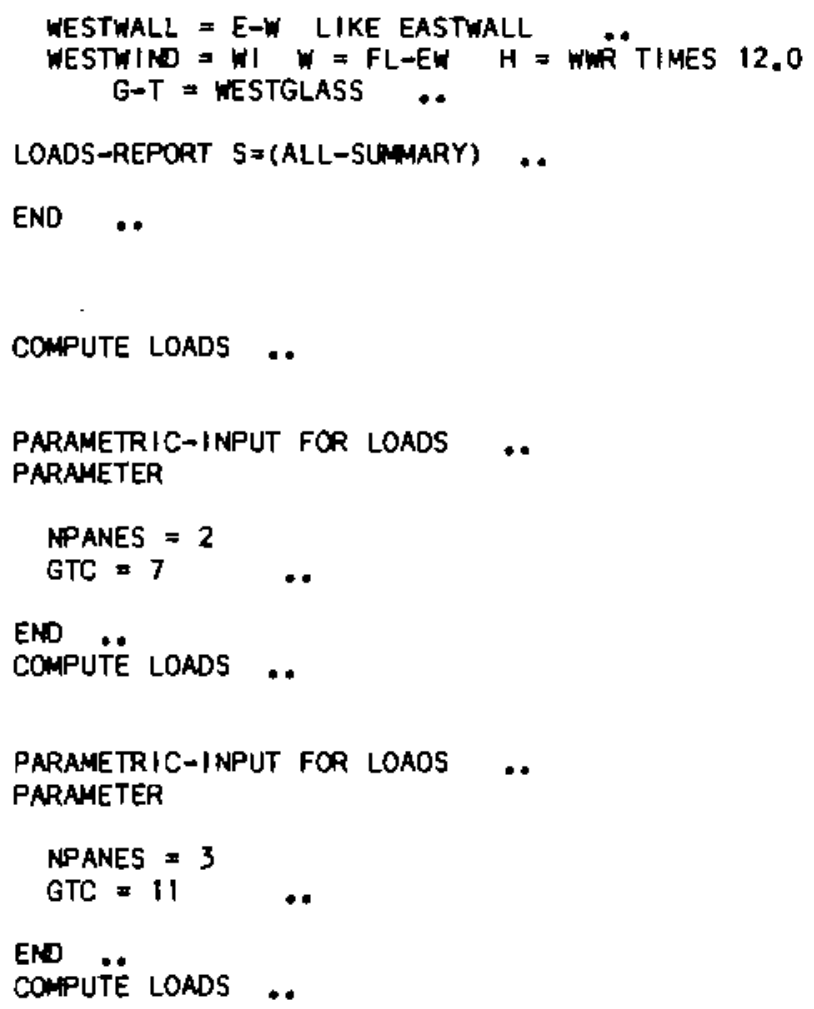


The following data lines indicate the changes made to the LOADS input for the PTAC simulations. The keyword LTSPACE represents the fraction of lighting heat gain that is a sensible load on the space. For PTAC systems, this value is 1.0 (or 100\%) since there are no return air ducts to capture the light heat.

The infiltration schedule and amount reflect a constant level of infiltration set equal to the ventilation levels present in the other system types. This reflects the fact that the PTAC system does not include forced ventilation, with a net result of the same outdoor air load being imposed on the space.

9 LINE-2 = SYSTEM TYPE = PTAC*

26 LTSPACE $=1.0 \$$ LIGHT TO SPACE $\$$ $\$$ INFILTRATION EQUIVALENT OF 12 CFM/PERSON

65 INFIL SCH THRU OEC 31 (ALL) $(1,24)$ (1) .. 
The following is the DOE-2.1C input data for the systems portion of the Phase 1 simulations. The system and plant descriptions for the Variable Air Volume (VAV) system type is shown. The input is separated into two sections, one for the core zone and one for the four perimeter zones; these were run separately because of the DOE-2 maximum of four central plants. Parametric systems input is included at the end of both files; these parametrics were necessary to correct a bug in the DOE-2 code that incorrectly sizes volumetric air flow rates for VAV systems.

System and plant input for core zones

Variable Air Volume (VAV) System

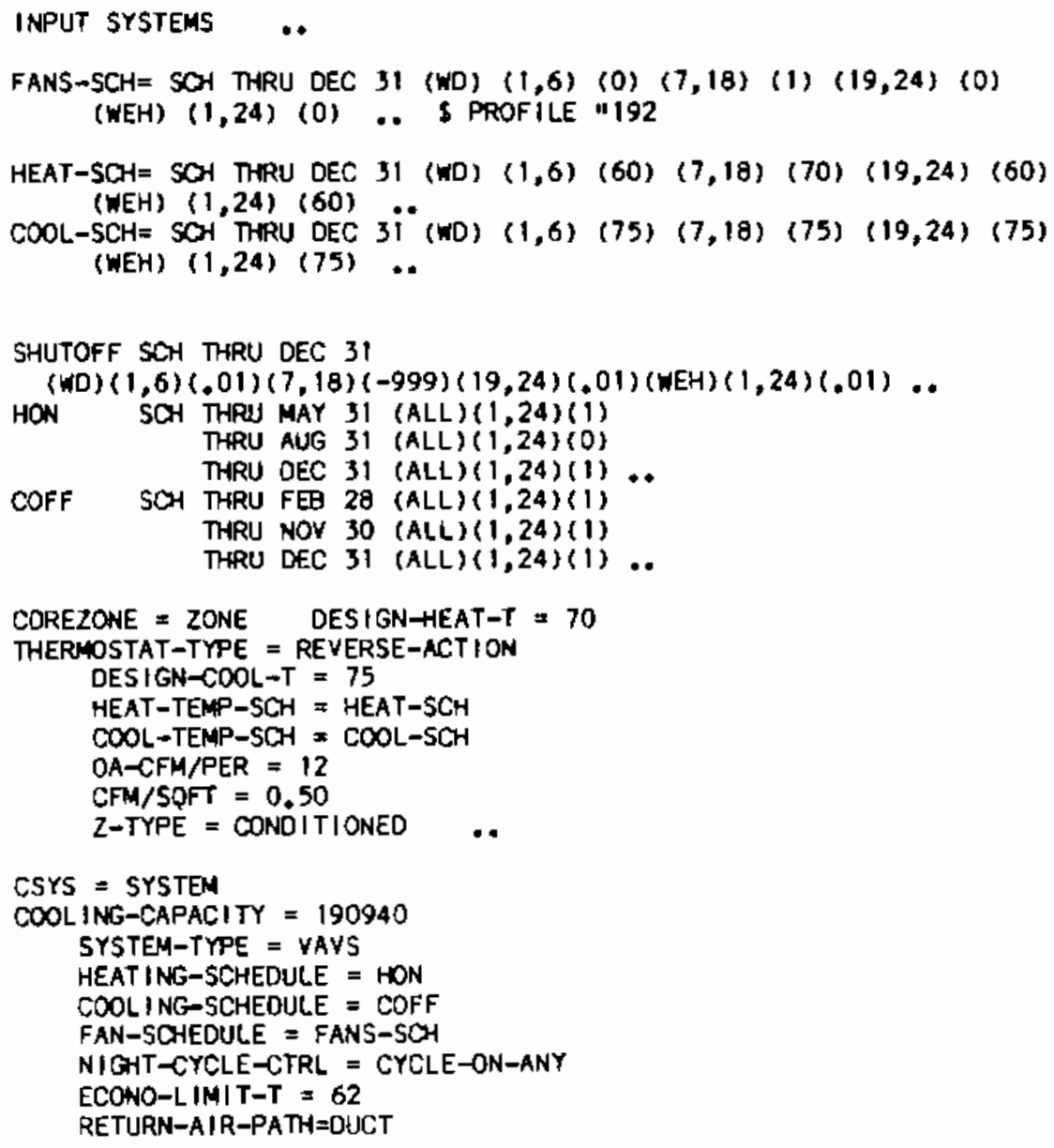




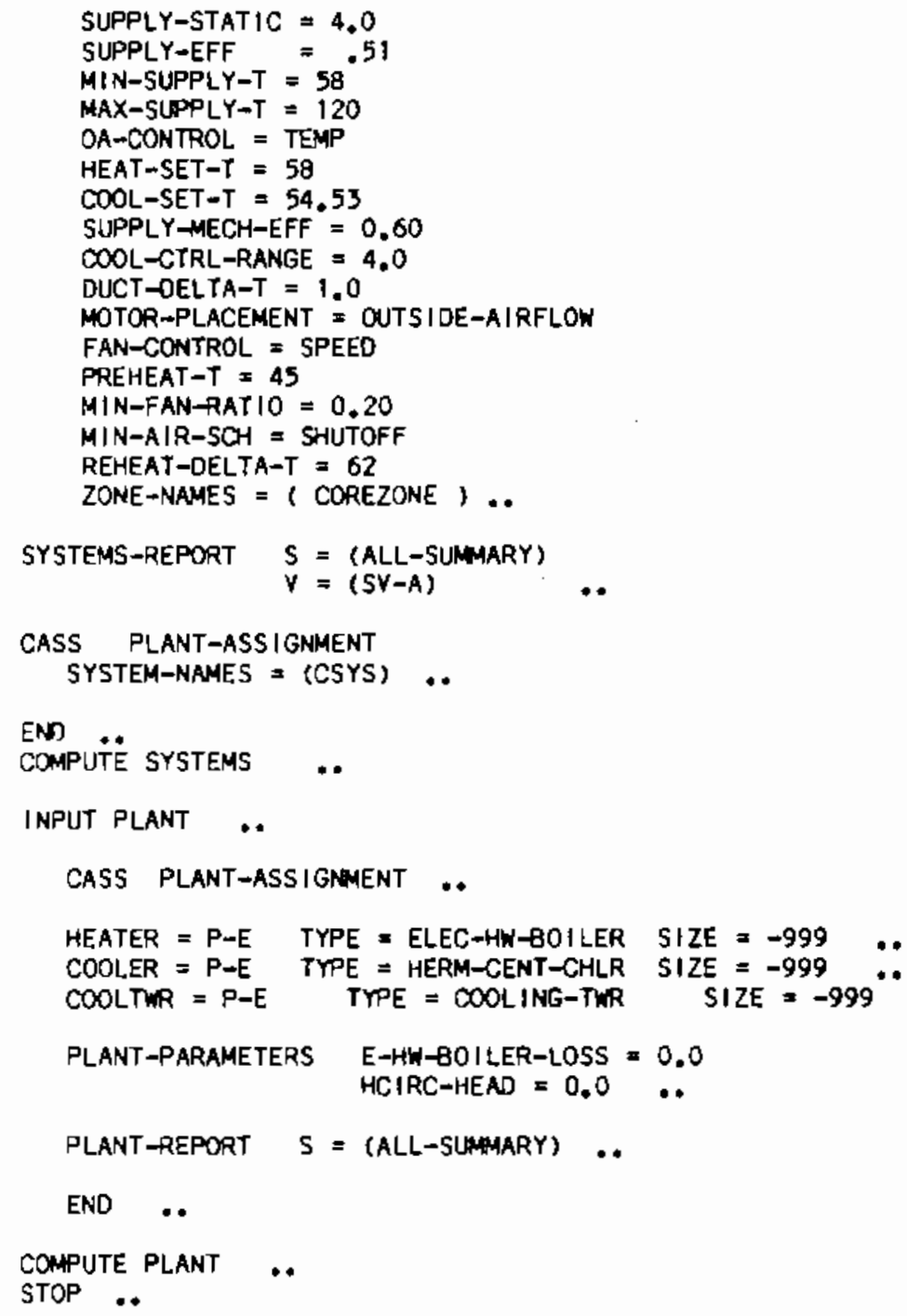


System and plant input for perimeter zones Variable Air Volume (VAV) System

INPUT SYSTEMS

FANS-SCH= SCH THRU DEC 31 (WD) $(1,6)(0)(7,18)(1)$ $(19,24)(0)$

(WEH) $(1,24)(0) \ldots$

HEAT-SCH= SOH THRU DEC 31 (WD) $(1,6)(60)(7,18)(70)$ $(19,24)(60)$

(WEH) $(1,24)(60) \ldots$

COOL-SCH $=$ SCH THRU DEC 31 (WD) $(1,6)(75)(7,1 \ddot{B})(75)$ $(19,24)(75)$

(WEH) $(1,24)(75) \ldots$

SHUTOFF SOH THRU DEC 31

(WD) $(1,6)(.01)(7,18)(-999)(19,24)(.01)(W E H)(1,24)(.01) \ldots$

HON SCH THRU MAY 31 (ALL) $(1,24)(1)$

THRU AUG 31 (ALL) $(1,24)(0)$

THRU DEC $31(A L L)(1,24)(1)$..

COFF SCH THRU FEB 28 (ALL) $(1,24)(1)$

THRU NOV $30(A L L)(1,24)(1)$

THRU DEC 31 (ALL) $(1,24)(1) \ldots$

NORTHZONE $=$ ZONE DESIGN-HEAT-T $=70$

THERMOSTAT-TYPE = REVERSE-ACTION

DESIGN-COOL-T $=75$

HEAT-TEMP-SCH = HEAT-SCH

COOL-TEMP-SCH $=\mathrm{COOL}-\mathrm{SCH}$

$O A-C F M / P E R=12$

$Z-T Y P E=$ CONDITIONED

SOUTHZONE = ZONE LIKE NORTHZONE ..

EASTZONE $=$ ZONE LIKE NORTHZONE ..

WESTZONE = ZONE LIKE NORTHZONE ...

$\$$ SUPPLY-CFM and MIN-CFM-RATIO varled parametrically for esch \$ system to overrlde automatic sizing

PARAMETER

NSUP $=2440$

SSUP $=4160$

ESUP $=3960$

WSUP $=\mathbf{4 2 0 0}$

NSTOP $=0.0738$

SSTOP $=0.0433$

ESTOP $=0.0455$

WSTOP $=0.0429$

NSYS = SYSTEM

SYSTEM-TYPE = VAVS

SUPPLY-CFM = NSUP

MIN-CFM-RATIO = NSTOP

HEATING-SCHEDULE = HON

COOL ING-SCHEDULE = COFF

FAN-SCHEDULE = FANS-SCH

NIGHT-CYCLE-CTRL = CYCLE-ON-ANY 


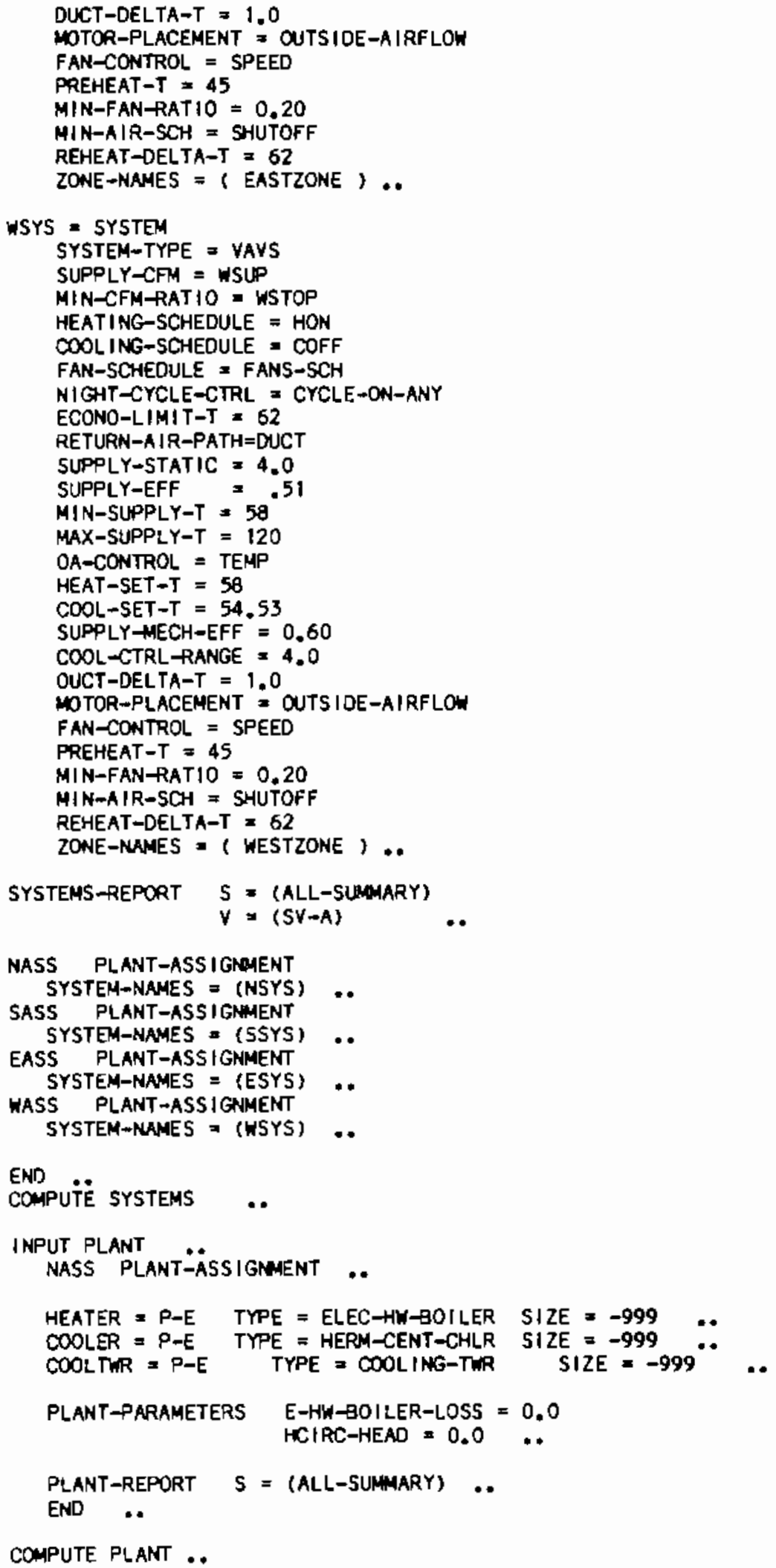




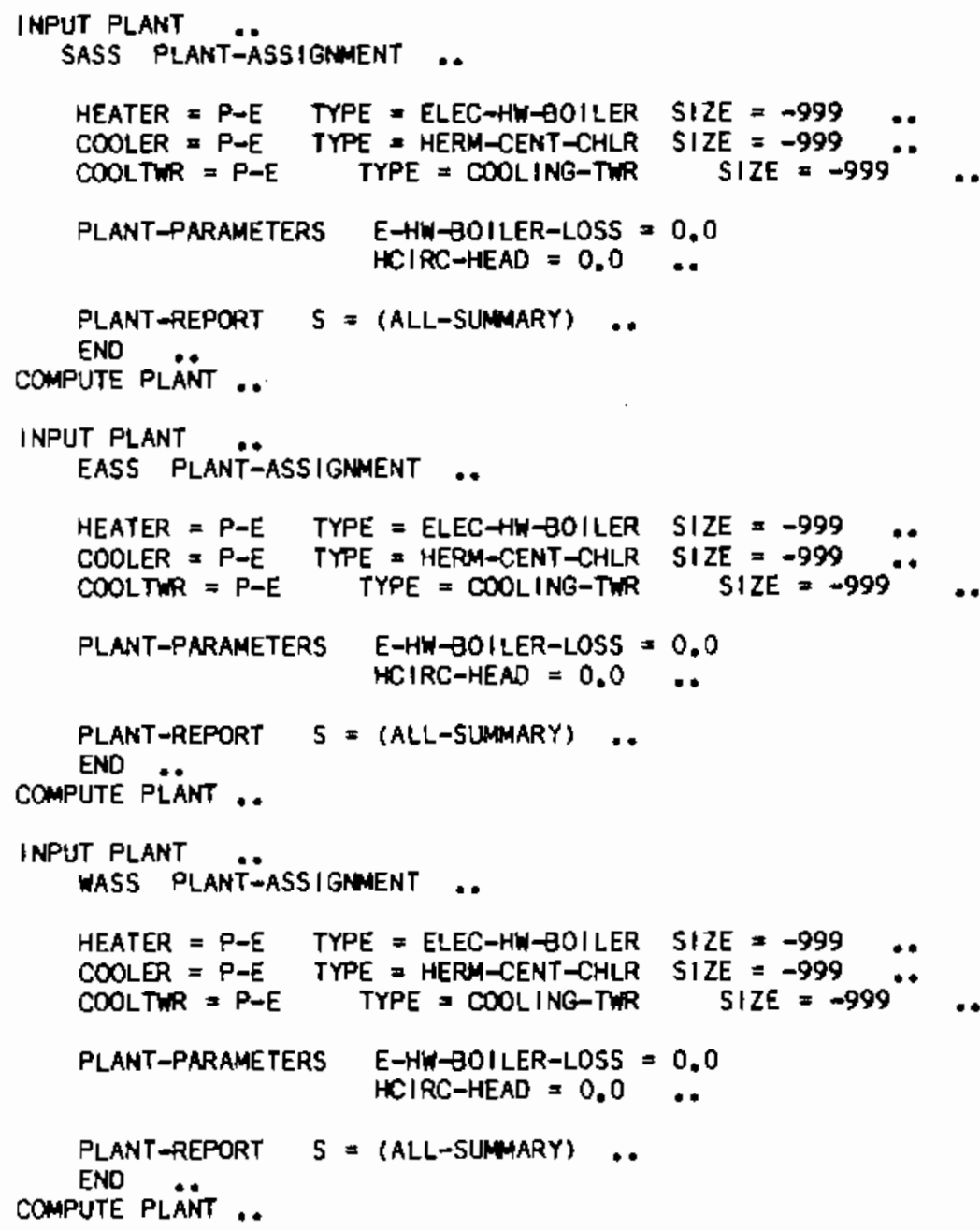




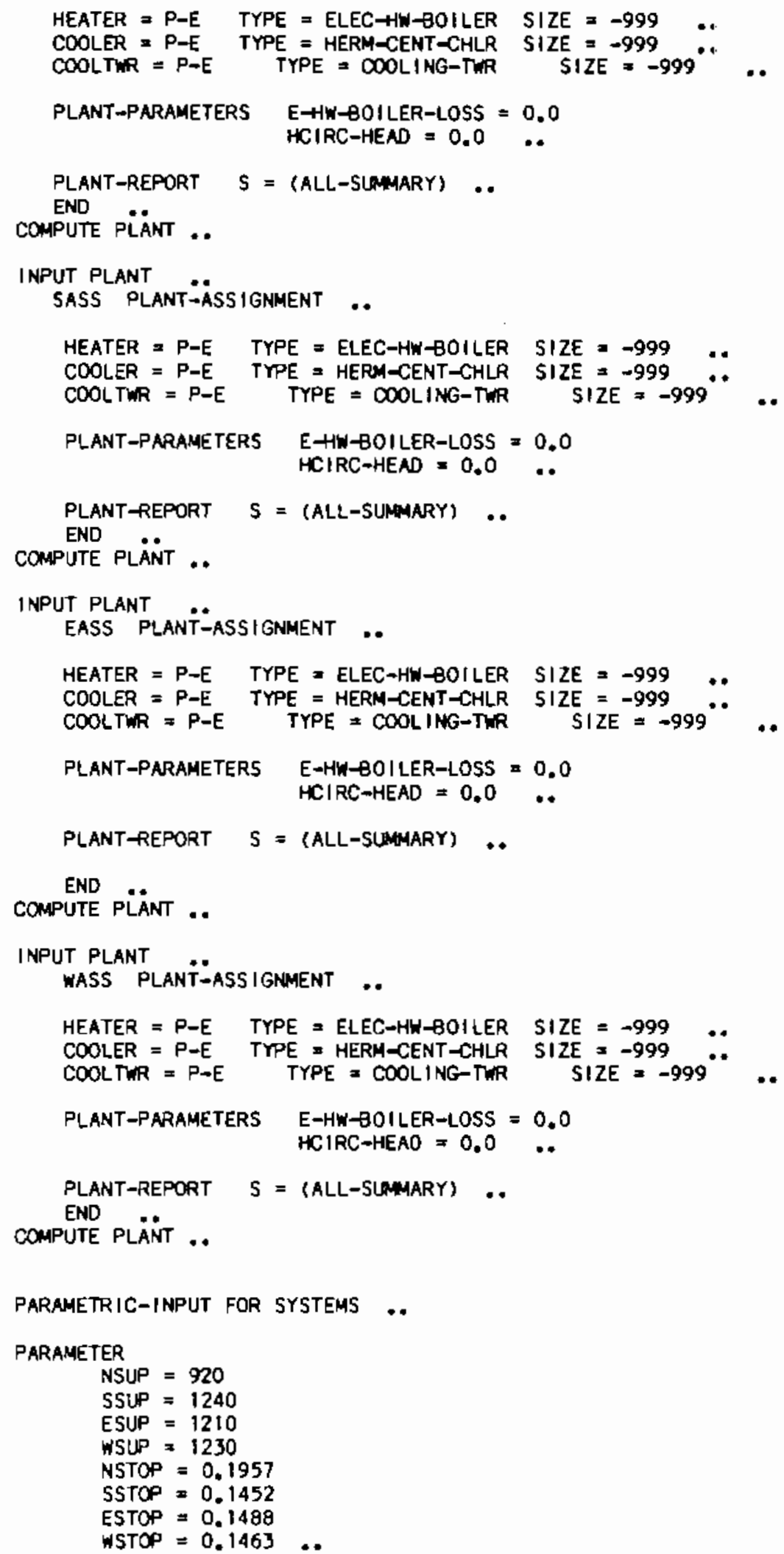




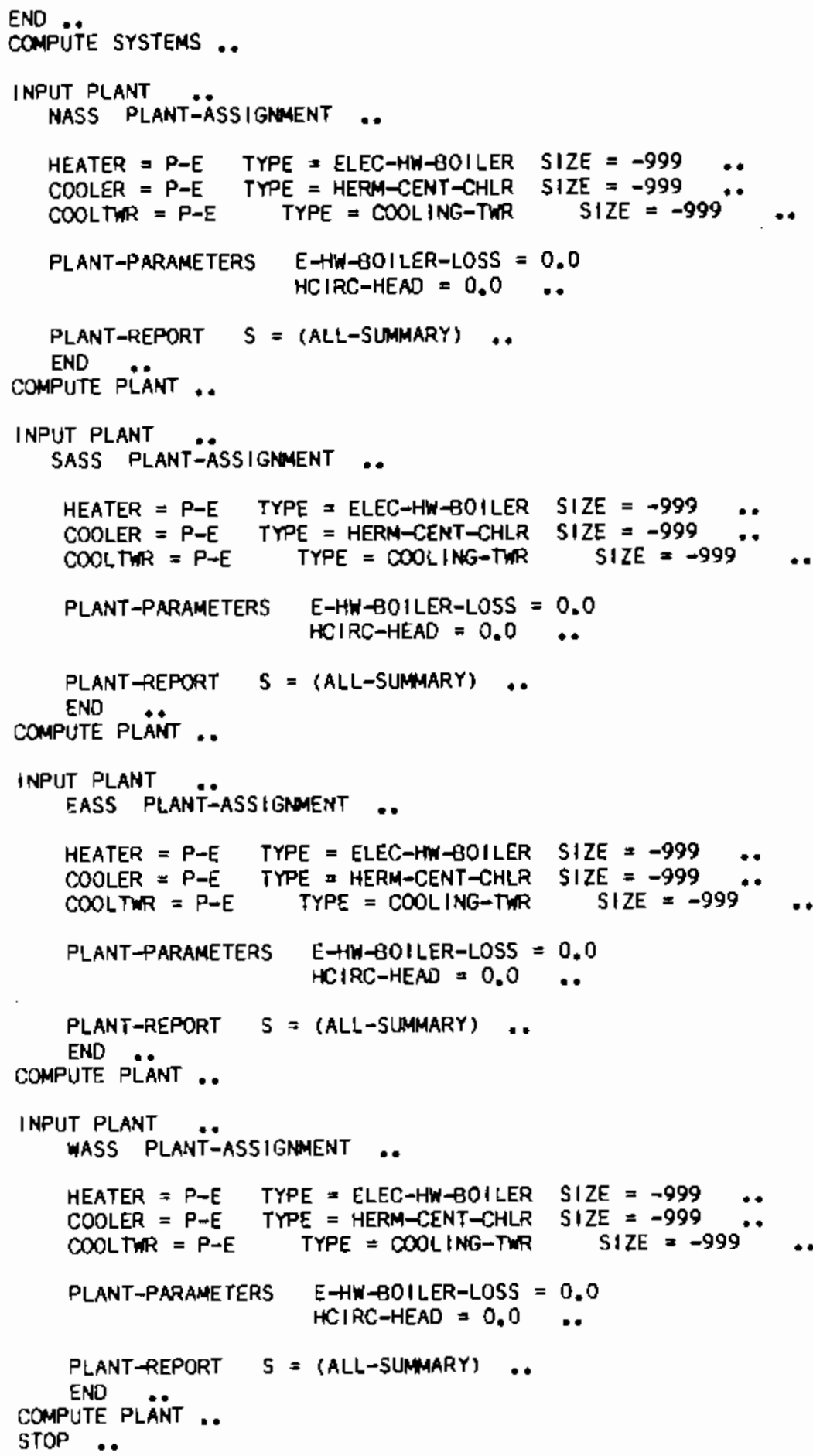


System and plant input

Packaged Single Zone (PSZ) System

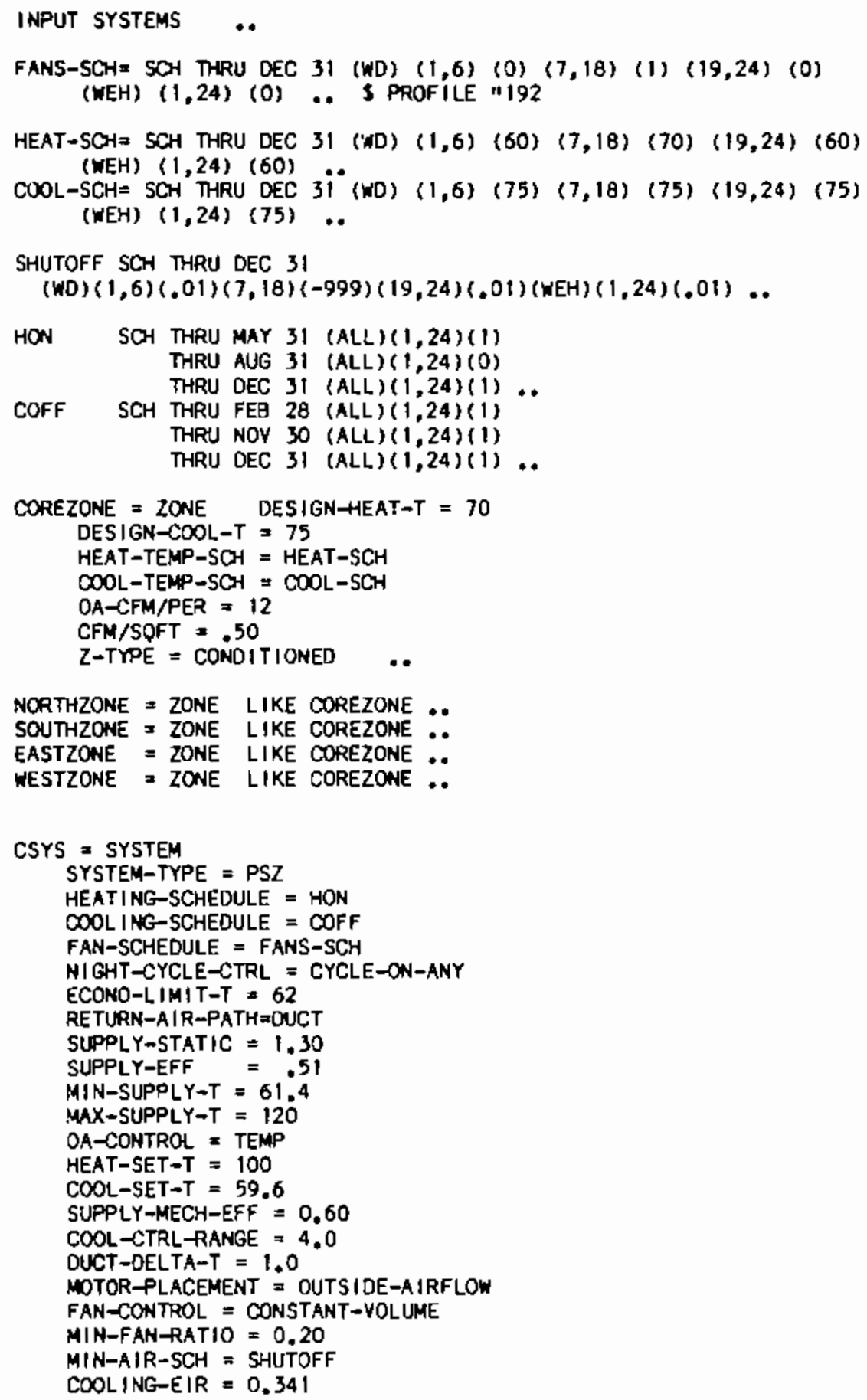


SIZING-OPTION = NON-COINCIDENT

REHEAT-DELTA- $T=60.4$

HEAT-SOURCE = ELECTRIC

ZONE-NAMES $=($ COREZONE ) ..

NSYS = SYSTEM

SYSTEM-TYPE = PSZ

HEATING-SCHEDULE $=$ HON

COOLING-SCHEDULE = COFF

FAN-SCHEDULE $=$ FANS-SCH

NIGHT-CYCLE-CTRL = CYCLE-ON-ANY

ECONO-LIMIT-T $=62$

RETURN-AIR-PATH=DUCT

SUPPLY-STATIC $=1.30$

SUPPLY-EFF $\quad 3.51$

MIN-SUPPLY-T $=61.4$

MAX-SUPPLY-T $=120$

$O A-C O N T R O L=T E M P$

HEAT-SET-T $=100$

COOL-SET-T $=59.6$

SUPPLY-MECH-EFF $=0.60$

COOL-CTRL-RANGE $=4.0$

DUCT-OELTA-T $=1.0$

MOTOR-PLACEMENT = OUTSIDE-AIRFLOW

FAN-CONTROL = CONSTANT-VOLUME

MIN-FAN-RATIO $=0,20$

MIN-AIR-SCH = SHUTOFF

COOLING-EIR $=0.341$

$S I Z I N \mid G \rightarrow O P T I O N=$ NON-COINCIDENT

REHEAT-DELTA-T $=60.4$

HEAT-SOURCE = ELECTRIC

ZONE-NAMES $=($ NORTHZONE $) \ldots$

SSYS = SYSTEM

SYSTEM-TYPE = PSZ

HEATING-SCHEDULE $=$ HON

COOL ING-SCHEDULE = COFF

FAN-SCHEDULE = FANS-SCH

NIGHT-CYCLE-CTRL = CYCLE-ON-ANY

ECONO-LIMIT-T $=62$

RETURN-AIR-PATH=DUCT

SUPPLY-STATIC $=1.30$

SUPPLY-EFF $=.51$

$M ! N-S U P P L Y-T=61.4$

MAX-SUPPLY-T $=120$

OA-CONTROL = TEMP

HEAT-SET-T $=100$

COOL-SET-T $=59.6$

SUPPLY Y MECH-EFF $=0.60$

COOL $-C T R L-R A N G E=4.0$

OUCT-DELTA-T $=1.0$

MOTOR-PLACEMENT = OUTSIOE-AIRFLOW

FAN-CONTROL = CONSTANT-VOLLME

MIN-FAN-RAT $10=0.20$

MIN-AIR-SCH $=$ SHUTOFF

COOL ING-EIR $=0.341$

SIZING-OPTION = NON-COINCIDENT

REHEAT-DELTA-T $=60.4$

HEAT-SOURCE = ELECTRIC

ZONE-NAMES $=($ SOUTHZONE $) \ldots$

ESYS = SYSTEM

SYSTEM-TYPE = PSZ

HEATING-SCHEDULE = HON

COOL ING-SCHEDULE = COFF

FAN-SCHEDIJLE $=$ FANS-SCH

NIGHT-CYCLE-CTRL = CYCLE-ON-ANY 
ECONO-LIHIT-T $=62$

RETURN-AIR-PATH $=$ DUCT

SUPPLY-STATIC $=1.30$

SUPPLY-EFF $=.51$

MIN-SUPPLY-T $=61.4$

MAX-SUPPLY-T $=120$

OA-CONTROL = TEMP

HEAT-SET-T $=100$

COOL-SET-T $=59.6$

SUPPLY-MECH-EFF $=0.60$

COOL-CTRL-RANGE $=4.0$

DUCT-DELTA-T $=1.0$

MOTOR-PLACEMENT = OUTSIOE-AIRFLOW

FAN-CONTROL = CONSTANT-VOLUME

MIN-FAN-RATIO $=0.20$

MIN-AIR-SCH = SHUTOFF

COOLING-EIR $=0.341$

SIZING-OPTION = NON-COINCIDENT

REHEAT-DELTA-T $=60.4$

HEAT-SOURCE $=$ ELECTRIC

ZONE-NAMES $=$ (EASTZONE,$\ldots$

WSYS = SYSTEM

SYSTEM-TYPE $=$ PSZ

HEATING-SCHEOULE $=$ HON

COOL ING-SCHEOULE = COFF

FAN-SCHEDULE $=$ FANS-SCH

NIGHT-CYCLE-CTRL = CYCLE-ON-ANY

ECONO-LIMIT-T $=62$

RETURN-AIR-PATH=DUCT

SUPPLY-STATIC $=1.30$

SUPPLY-EFF $=.51$

$M I N-S U P P L Y-T=61.4$

MAX-SUPPLY-T $=120$

$O A-C O N T R O L=T E M P$

HEAT-SET-T $=100$

COOL-SET-T $=59.6$

SUPPLY $=$ NECH-EFF $=0.60$

COOL-CTRL-RAMGE $=4.0$

DUCT-DELTA-T $=1.0$

MOTOR-PLACEMENT = OUTSIDE-A JRFLOW

FAN-CONTROL = CONSTANT-VOLUME

MIN-FAN-RATIO $=0.20$

$M I N-A \mid R-S C H=$ SHUTOFF

COOL ING-EIR $=0.341$

SIZING-OPTION = NON-COINCIOENT

REHEAT-OELTA-T $=60.4$

HEAT-SOURCE = ELECTRIC

ZONE-NAMES $=($ WESTZONE $) \ldots$

$\begin{array}{ll}\text { SYSTEMS-REPORT } & \begin{array}{l}S=(A L L-S(A N A R Y) \\ V\end{array}=(S V-A)\end{array}$

CONVENTIONAL PLANT-ASSIGNMENT

SYSTEM-NAMES $=($ CSYS, NSYS, SSYS, ESYS,WSYS $) \ldots$

END

COMPUTE SYSTEMS $\quad \cdots$

INPUT PLANT

CONYENTIONAL PLANT-ASSIGMENT \#

COOLER $=$ P-E $\quad$ TYPE $=$ HERM-CENT-CHLR $\quad$ SIZE $=1$

COOLTWR = P-E TYPE $=$ COOL ING-TWR

$S I Z E=1^{\circ}$

PLANT-REPORT $S=$ (ALL-SUMMARY) ..

COMPUTE

STOP

UTE

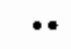


System and plant input

Packaged Terminal Air Conditioning (PTAC) System

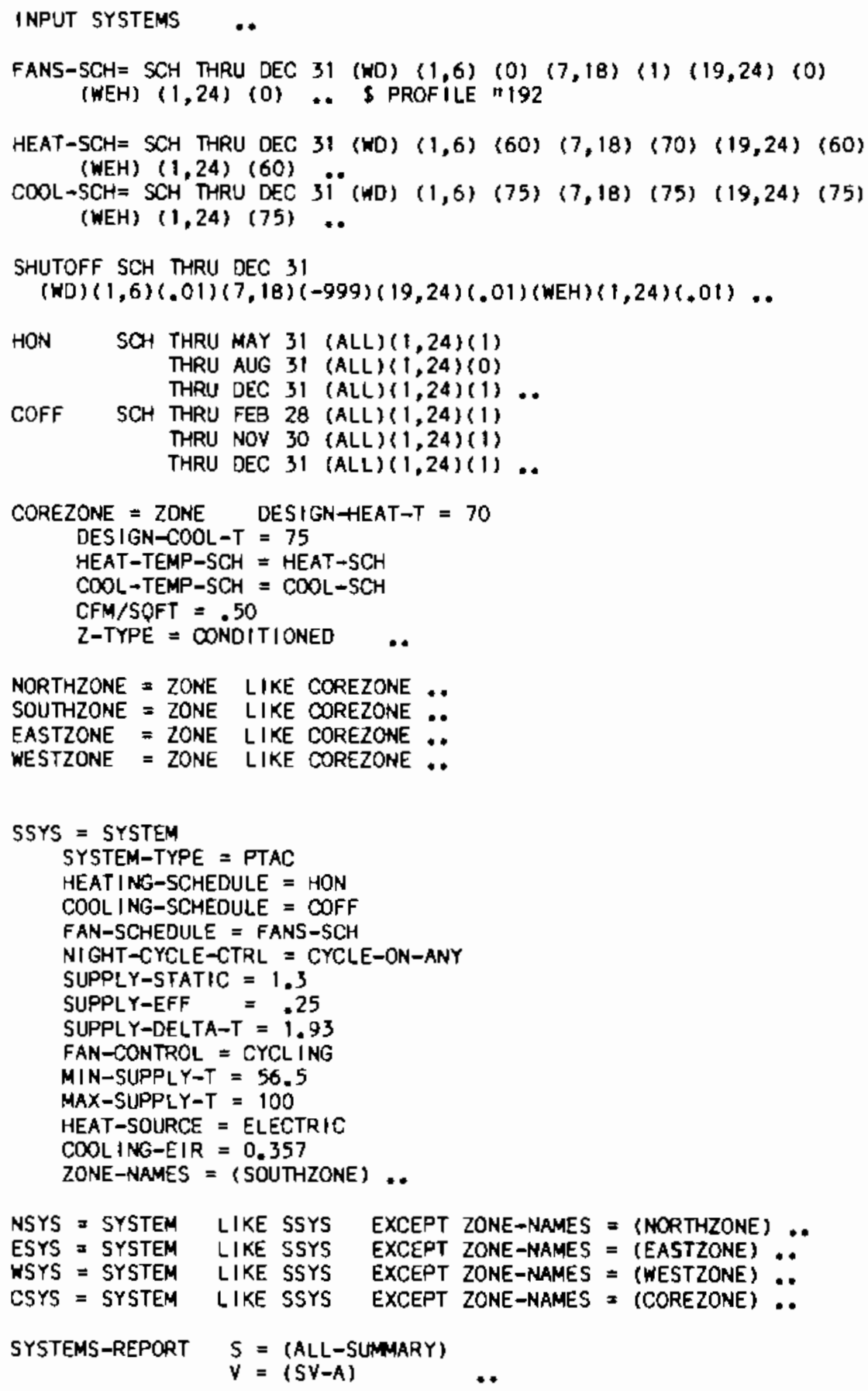




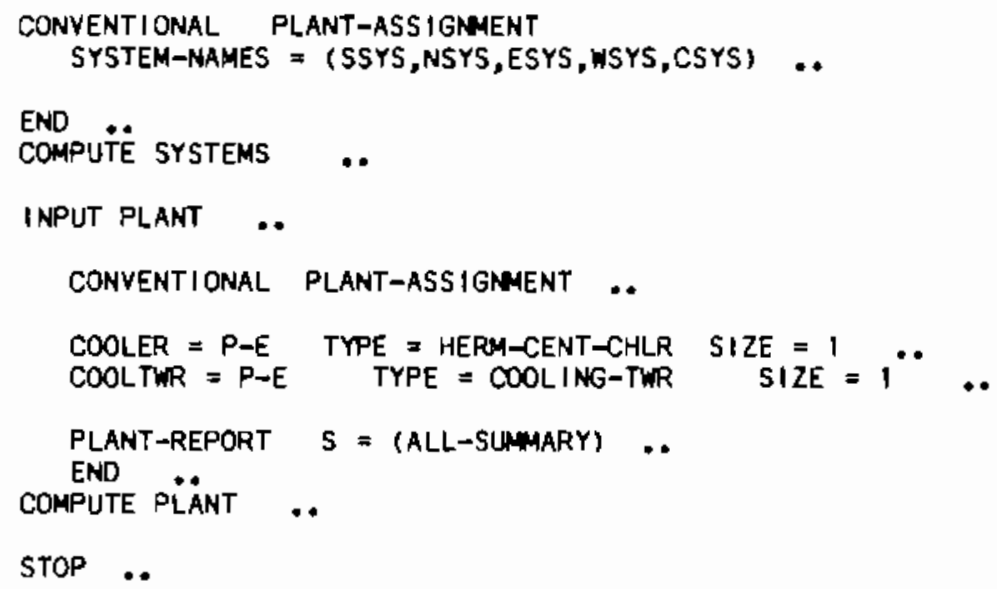


For Madison, WI simulations, several input parameters were modified: year of weather data, latitude, longitude, time zone, and altitude. In addition, space temperatures were allowed to drift up to $85^{\circ} \mathrm{F}$ during unoccupied hours with the HVAC system cycling on and of $f$.

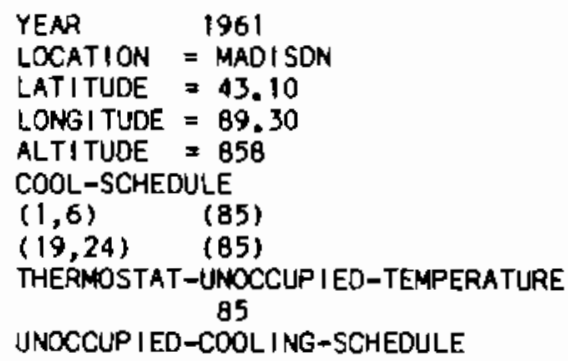

(O) 
The modifications made to the operation profiles of all scheduled parameters were shown below. The schedules that were varied are: Occupancy (OCC-SCH), Lighting (LIGHTS), Inf $j$ lt ration (INFIL), HVAC Fans (FANS-SCH), Heating and Cooling Thermostat (HEAT-SCH, COOL-SCH), and HVAC operating schedules (SHUTOFF, HON, COFF). These schedules reflect addition of Saturday building operation.

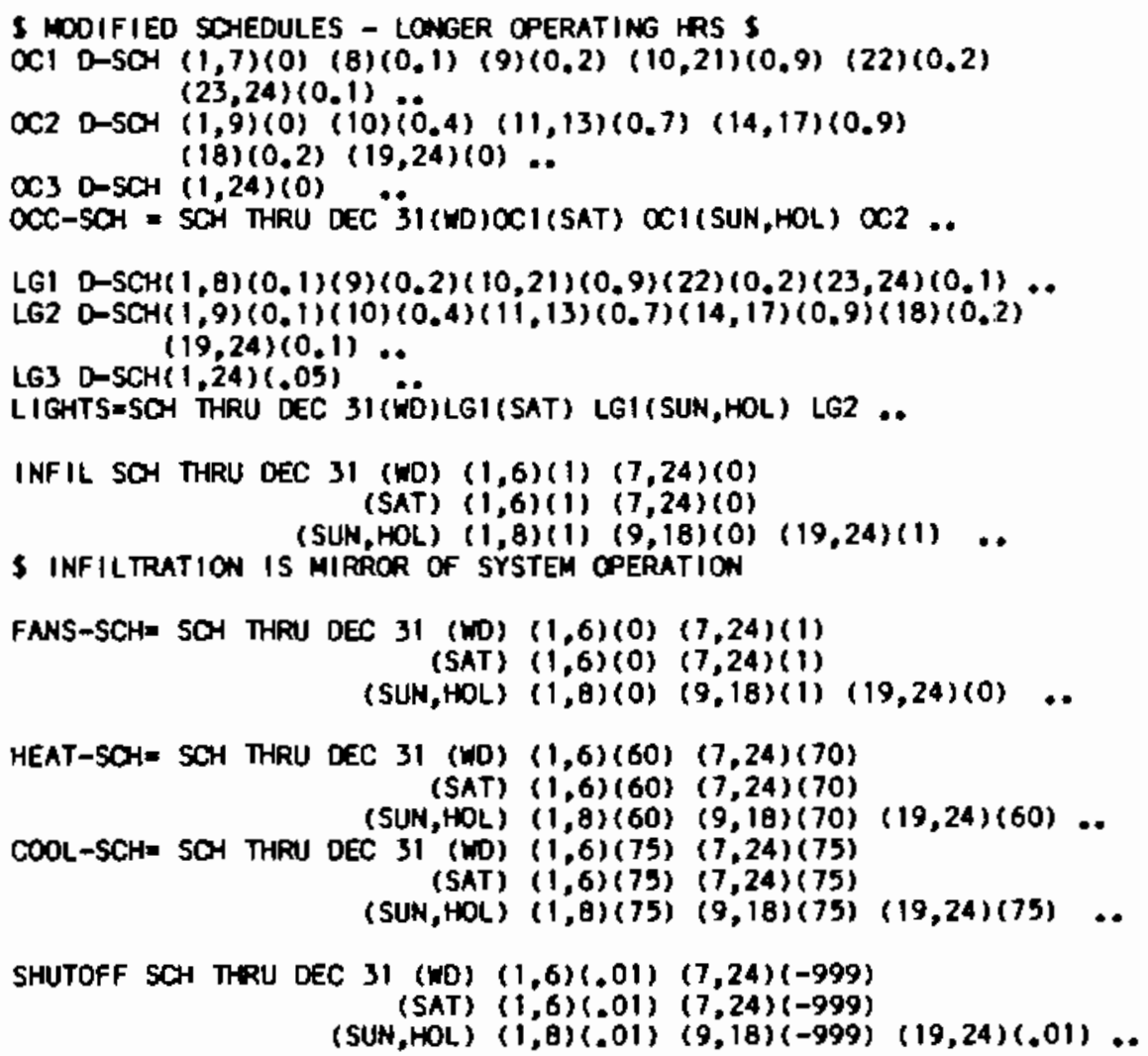


The following are the directives for the DOE-2 weather packer program used in packing the Madison, WI weather data. The Fort Worth directives are the same as for Madison with one exception: the sixth line contains instructions for shifting solar radiation data required for days when the solar time does agree with the local standard time (10:55 local time versus 11:01 solar time. A 1-hour data shift was required for the months Apri1-June and August-December. The exact dates for the shifts were confirmed by Fred Buehl, Energy Simulation Group, Lawrence Berkeley Laboratory.

Following the input directives is the output generated by the weather packer; summary statistics generated include temperatures, degree days, wind information, and solar information. The directives and output for Fort Worth follow those for Madison. 
DOE-2, TC WEATHER UTILITY FROGRAM INPUT VERIFICATION

RUN TYPE PACK

\begin{tabular}{|c|c|c|}
\hline 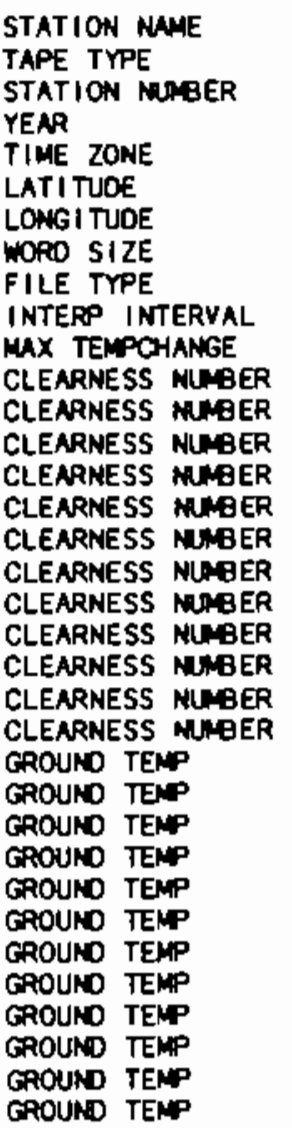 & $\begin{array}{l}(1) \\
(2) \\
(3) \\
(4) \\
(5) \\
(5) \\
(7) \\
(9) \\
(9) \\
(10) \\
(11) \\
(12) \\
(1) \\
(2) \\
(3) \\
(4) \\
(5) \\
(6) \\
(7) \\
(2) \\
(9) \\
(10) \\
(11) \\
(12)\end{array}$ & $\begin{array}{l}\text { MDISON WI WEC } \\
\text { WYEC } \\
14837 \\
1961 \\
5 \\
43.100 \\
\text { B9.300 } \\
30.81 T \\
\text { SOLAP } \\
4 \\
20.000 \\
0.950 \\
0.950 \\
0.950 \\
0.950 \\
0.950 \\
0.950 \\
0.950 \\
0.950 \\
0.950 \\
0.950 \\
0.950 \\
0.950 \\
41.000 \\
38.000 \\
39.000 \\
43.000 \\
49.000 \\
56.000 \\
61.000 \\
63.000 \\
62.000 \\
59.000 \\
52.000 \\
46.000\end{array}$ \\
\hline
\end{tabular}

DATES ANO OIRECTION OF SOLAR BIN SHIFTS FOR WYEC TAPES

$\begin{array}{lrr}\text { JAN } & 1 & 1 \\ \text { NPR } & 0 & -1 \\ \text { JUN } & 24 & 1 \\ \text { AUG } & 26 & -1 \\ \text { OEC } & 30 & 1\end{array}$


RUN TYPE STAT

MADISON WI WYEC MONTHLY WEATHER DATA SUMUARY LATITUDE $=43.10$

AVG. TEMP. (F) (DRYBULE)

AVG. TEMP. (F) (WETBULB)

AVG. DAILY MAX. TEMP.

AVG. DAILY MIN. TEP.

HEATING DEG, DAYS (BASE 65) (BASE 60)

(BASE 55)

(BASE 50)

COOLING DEG. DAYS (BASE 80)

(BASE 75)

(BASE 70)

in

1016.0

025.5

0.0

0.0
0.0
0.0

$$
0.0
$$

$$
0.0
$$$$
0.0
$$

LONGITUOE $=89.30$

JAN FEB MAR APR MAY JUN

$\begin{array}{lll}17.2 & 21.2 & 30.7 \\ 15.3 & 19.7 & 28.6\end{array}$

45.2
39.6

56.4

$\begin{array}{rrr}26.7 & 27.3 & 37.3 \\ 7.8 & 13.7 & 23.4\end{array}$

54.6

$1481.0 \quad 1245.5 \quad 1075.5$

$1326.0 \quad 1105.5 \quad 920.5$

$1171.0 \quad 965.5 \quad 767.5$

$$
\begin{aligned}
& 0.0 \\
& 0.0 \\
& 0.0 \\
& 0.0
\end{aligned}
$$

$1482.9 \quad 1226.6$

$\begin{array}{rr}1327.9 & 1086.6 \\ 1172.9 & 946.6\end{array}$

1172.9

946.6
806.6

064.5

910.8

758.3
607.1 (BASE S5) (BASE 50)

\section{0}

$$
\begin{aligned}
& 0.0 \\
& 0.0
\end{aligned}
$$

(BASE 80)

(BASE 70)

(BASE 65)

0.0
0.0
0.0

$$
0.0
$$

0.0

0.0

0.0
0.0

\section{5}

$597.5 \quad 303.5$

$\begin{array}{rr}449.0 & 175.5 \\ 310.5 & 86.0\end{array}$

183.0

30.0

$$
\begin{aligned}
& 0.0 \\
& 0.0 \\
& 0.0 \\
& 0.0
\end{aligned}
$$

0.0

0.0
14.5

597.3

455.5

325.3

312.3
202.8
116.3
56.1

0.0
0.0
0.4
3.9

1.2
6.4
18.5
45.3

\begin{tabular}{|c|c|c|c|c|c|c|c|c|c|c|c|c|}
\hline $\begin{array}{r}53 \\
-11\end{array}$ & $\begin{array}{l}43 \\
-7\end{array}$ & $\begin{array}{l}70 \\
-9\end{array}$ & $\begin{array}{l}73 \\
26\end{array}$ & $\begin{array}{l}84 \\
27\end{array}$ & $\begin{array}{l}90 \\
43\end{array}$ & $\begin{array}{l}88 \\
46\end{array}$ & $\begin{array}{l}90 \\
43\end{array}$ & $\begin{array}{l}85 \\
32\end{array}$ & $\begin{array}{l}78 \\
20\end{array}$ & $\begin{array}{l}59 \\
17\end{array}$ & $\begin{array}{r}61 \\
-21\end{array}$ & $\begin{array}{r}90 \\
-21\end{array}$ \\
\hline $\begin{array}{r}0 \\
22\end{array}$ & $\begin{array}{r}0 \\
23\end{array}$ & $\begin{array}{l}0 \\
8\end{array}$ & $\begin{array}{l}0 \\
0\end{array}$ & $\begin{array}{l}0 \\
0\end{array}$ & $\begin{array}{l}t \\
0\end{array}$ & $\begin{array}{l}0 \\
0\end{array}$ & $\begin{array}{l}1 \\
0\end{array}$ & $\begin{array}{l}0 \\
0\end{array}$ & $\begin{array}{l}0 \\
0\end{array}$ & $\begin{array}{l}0 \\
1\end{array}$ & $\begin{array}{r}0 \\
20\end{array}$ & $\begin{array}{r}2 \\
74\end{array}$ \\
\hline $\begin{array}{l}31 \\
10\end{array}$ & $\begin{array}{r}28 \\
3\end{array}$ & $\begin{array}{r}28 \\
2\end{array}$ & $\begin{array}{r}10 \\
0\end{array}$ & $\begin{array}{l}3 \\
0\end{array}$ & $\begin{array}{l}0 \\
0\end{array}$ & $\begin{array}{l}0 \\
0\end{array}$ & $\begin{array}{l}0 \\
0\end{array}$ & $\begin{array}{l}1 \\
0\end{array}$ & $\begin{array}{l}6 \\
0\end{array}$ & $\begin{array}{r}27 \\
0\end{array}$ & 28 & $\begin{array}{r}162 \\
19\end{array}$ \\
\hline 9.4 & 11.1 & 9.8 & 11.3 & 9.6 & B. 6 & 7.7 & 8.3 & 7.4 & 8.1 & 7.7 & 9.6 & 9.0 \\
\hline $\begin{array}{r}11.6 \\
8.5\end{array}$ & $\begin{array}{l}12.4 \\
10.5\end{array}$ & $\begin{array}{r}11.0 \\
9.0\end{array}$ & $\begin{array}{r}14.2 \\
8.8\end{array}$ & $\begin{array}{r}12.1 \\
6.9\end{array}$ & $\begin{array}{r}10.6 \\
6.3\end{array}$ & $\begin{array}{l}9.3 \\
6.0\end{array}$ & $\begin{array}{r}10.0 \\
6.7\end{array}$ & $\begin{array}{l}9.8 \\
5.5\end{array}$ & $\begin{array}{r}10.3 \\
6.7\end{array}$ & $\begin{array}{l}9.3 \\
6.8\end{array}$ & $\begin{array}{r}11.2 \\
8.9\end{array}$ & $\begin{array}{r}10.9 \\
7.7\end{array}$ \\
\hline
\end{tabular}

MAXIMLA TEMP.

NO. DAYS MAX. 9O MD MBOVE HO. DAYS MAX. 32 ND BELOW

NO. DAYS MIN. 32 ANO BELO HO: DAYS MIN. O ND BELOH

AVG. WINO SPEED (MPH)

AVG. WIND SPEED (DAY)

AVG. WINO SPEED (NIGHT)
DOE-2.1C ZONE $=5$

SEP OCT NOV DEC YEAR

$\begin{array}{llllllll}66.3 & 70.4 & 69.3 & 59.6 & 50.2 & 34.6 & 22.3 & 45.4 \\ 60.0 & 64.8 & 65.3 & 55.6 & 45.7 & 32.3 & 21.1 & 41.7\end{array}$

$\begin{array}{llllllll}77.1 & 80.4 & 78.9 & 71.6 & 61.5 & 43.7 & 29.2 & 54.8 \\ 54.5 & 59.2 & 58.7 & 47.7 & 38.5 & 26.0 & 14.7 & 35.4\end{array}$

$\begin{array}{llllllll}66.0 & 13.0 & 27.5 & 194.5 & 468.0 & 904.5 & 1333.5 & 7710.0\end{array}$

$\begin{array}{llllllll}21.5 & 0.0 & 5.5 & 105.5 & 329.5 & 754.5 & 1178.5 & 6371.5\end{array}$

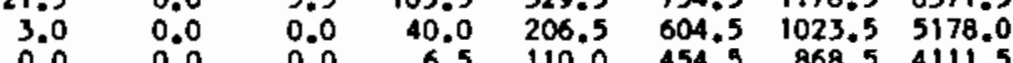

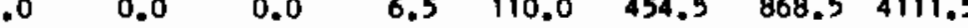

$\begin{array}{llllllll}0.0 & 0.0 & 0.0 & 0.0 & 0.0 & 0.0 & 0.0 & 0.0\end{array}$

$\begin{array}{rrrrrrrr}5.0 & 6.5 & 9.0 & 0.0 & 0.0 & 0.0 & 0.0 & 20.5 \\ 31.0 & 49.0 & 43.0 & 8.0 & 0.0 & 0.0 & 0.0 & 134.0\end{array}$

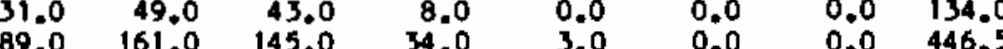

$\begin{array}{lllllllll}105.5 & 44.4 & 51.4 & 228.2 & 476.5 & 912.9 & 1322.9 & 7825.4\end{array}$

$\begin{array}{llllllll}50.8 & 15.3 & 19.0 & 142.6 & 348.0 & 762.9 & 1167.9 & 6490.3\end{array}$

$\begin{array}{llllllll}19.6 & 4.5 & 6.7 & 80.1 & 236.4 & 613.9 & 1013.9 & 5294.5\end{array}$

$\begin{array}{llllllll}5.5 & 0.8 & 1.8 & 40.2 & 145.4 & 467.0 & 862.0 & 4222.0\end{array}$

$\begin{array}{llllllll}10.0 & 13.0 & 8.1 & 1.7 & 0.0 & 0.0 & 0.0 & 33.8\end{array}$

$\begin{array}{llllllll}32.8 & 49.5 & 36.5 & 8.5 & 1.0 & 0.0 & 0.0 & 34.8\end{array}$

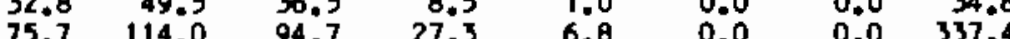

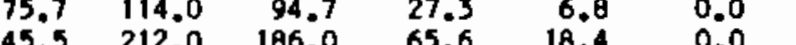

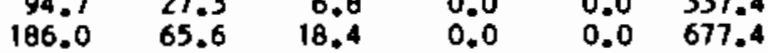


RUN TYPE STAT

MAOISON WI WYEC MONTHLY WEATHER DATA SUMANRY LATITUDE $=43.10$
DOE-2, $1 \mathrm{C}$

$$
\text { TIME ZONE }=5
$$

AVG. TEMP. (DAY)

AVG. TERP. (NIGHT)

AVG, SKY COVER (DAY)

AVG. REL. HUM. AT 4NM

$4 N M$
$10 \mathrm{NMM}$
$10 \mathrm{PM}$

APR MY JUN

JUL NUG SEP

$\propto \mathbf{C T}$

MOV

DEC YENR

$\begin{array}{lll}22.9 & 24.5 & 34.7 \\ 14.7 & 19.5 & 28.1\end{array}$

$\begin{array}{lll}7.0 & 7.2 \quad 7.5\end{array}$

$49.8 \quad 61$.

$\begin{array}{lll}71.6 & 75.6 & 74.3\end{array}$

56.2

56.7
46.0

30.6

6.97 .0

6.5

6.5

3.6

6.5

5.8

7.6

26.154 .0

$75.4 \quad 88.7 \quad 88.8$

61.7

$\begin{array}{ll}05.4 & 85.5 \\ 63.1 & 66.3\end{array}$

95.9
69.6

$69.6 \quad 77.5$

93.2

82.5
69.6

80.5

$85.0 \quad 87.2$

$\begin{array}{rrr}60.7 & 73.7 & 71.3 \\ 74.4 & 81.2 & 84.9\end{array}$

$\begin{array}{lll}50.2 & 56.5 & 56.4 \\ 69.9 & 75.6 & 79.9\end{array}$

58.2
84.9

67.2
89.6

63,3

58.3
77.0

70.7

$87.2-73.5$

AVG. DAILY DIRECT NORMAL SOLAR

622.5
518.3

866.8 1095.8

$1231.1 \quad 1433.1 \quad 1673.7$

$1704.7 \quad 1561.7 \quad 1149.0$

1019.8

$483.3 \quad 371.6 \quad 1102.7$ AVG. OAILY TOTAL HORIZNTL SOLAR

MAX. DAILY DIRECT NORMAL SOLNR 1678.0 $2386.0 \quad 2603.0$ $\begin{array}{lllllll}1404.4 & 1757.0 & 1931.3 & 1949.7 & 1725.5 & 1290.2 & 914.1\end{array}$

MAX. DAILY TOTAL HORIZNTL SOLAR

2827.0

$\begin{array}{rr}2827.0 & 3314.0 \\ 2426.0 & 2803.0\end{array}$

3183.0

$\begin{array}{lll}2746.0 & 2187.0 & 2229.0 \\ 2351.0 & 1785.0 & 1542.0\end{array}$

504.1

$393.8 \quad 1195.7$

MIN. DAHLY DIRECT NORMAL SOLAR

MIN. DAILY TOTAL HORIZNTL SOLAR

5.0
143.0

0.01725 .0

2261.0

2699.0

$1430.0 \quad 1016.0 \quad 3314.0$

MAX. HRLY DIRECT NOPMAL SOLNR

$262.0269 .0 \quad 208.0$

$398.0 \quad 743.0 \quad 016.0$

12.0
542.0

20.0

24.0

3.0
142.0

$901.0 \quad 672.0 \quad 2603.0$

MAX. HRLY TOTAL HORIZNTL SOLAR

AVG. MAX. HRLY DIRECT NORML

SOLAR

$\begin{array}{llll}46.0 & 204.0 & 308.0 & 273.0\end{array}$

269.0305 .0

309.0

321.0

258.

268.0

149.0

$\begin{array}{rr}672.0 & 2603.0 \\ 0.0 & 0.0\end{array}$

SOLAR

$96.9 \quad 137.6 \quad 174.1$

197.7227

222.9

$228.0 \quad 226.9 \quad 179.8$

165.3

92.4

88.7

168.8

AVG. DAILY TOTAL VERTICAL SOLAR AZ IMUTH

E

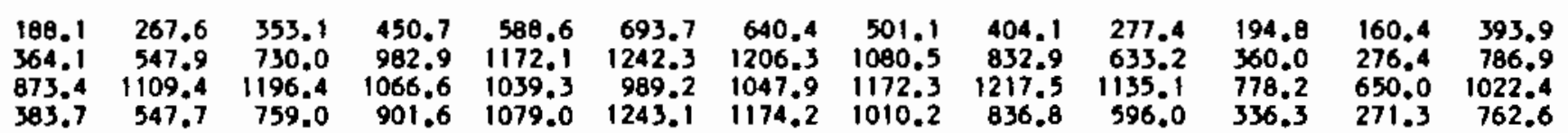

MAX. DAILY TOTAL VERTICAL SOLAR

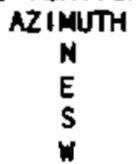

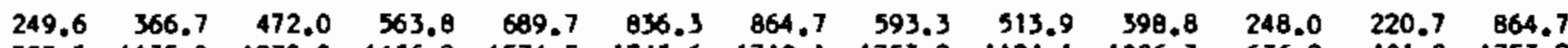

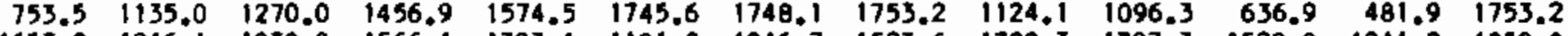

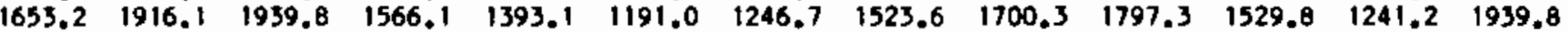

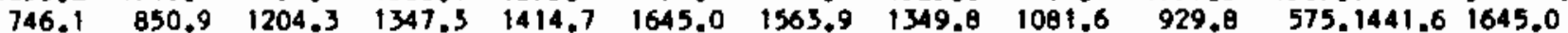


RUN TYPE STAT

MADISON WI WYEC MONTHLY WEATHER DATA SUMMRY

LATITUDE $=43.10$

LONGITUDE $=89.30$

DOE-2.IC TIME ZONE $=5$

JAN FEB MAR NPR MAY JUN JUL AUG SEP OCT NOV DEC YEAR

MAX. HRLY TOTAL VERTICAL SOLAR AZIMUTH

\begin{tabular}{|c|c|c|c|c|c|c|c|c|c|c|c|c|c|}
\hline $\begin{array}{l}\mathbf{M} \\
E \\
S \\
W\end{array}$ & $\begin{array}{r}43.8 \\
190.1 \\
282.1 \\
186.6\end{array}$ & $\begin{array}{r}54.1 \\
227.9 \\
275.8 \\
203.6\end{array}$ & $\begin{array}{r}64.9 \\
245.2 \\
275.6 \\
245.8\end{array}$ & $\begin{array}{r}73.5 \\
252.2 \\
223.8 \\
247.4\end{array}$ & $\begin{array}{r}77.9 \\
252.8 \\
197.9 \\
248.1\end{array}$ & $\begin{array}{r}96.0 \\
278.7 \\
174.1 \\
273.6\end{array}$ & $\begin{array}{r}83.5 \\
256.8 \\
191.5 \\
287.2\end{array}$ & $\begin{array}{r}73.8 \\
288.2 \\
230.1 \\
258.8\end{array}$ & $\begin{array}{r}64.1 \\
223.7 \\
250.1 \\
214.5\end{array}$ & $\begin{array}{r}57.1 \\
227.3 \\
261.3 \\
205.0\end{array}$ & $\begin{array}{r}43.6 \\
143.5 \\
251.6 \\
138.1\end{array}$ & $\begin{array}{r}38.4 \\
113.3 \\
227.7 \\
102.8\end{array}$ & $\begin{array}{r}96.0 \\
288.2 \\
282.1 \\
287.2\end{array}$ \\
\hline
\end{tabular}


MADISON WI WYEC

MONTHLY WEATHER DATA SUMMRYY

DOE-2. $1 \mathrm{C}$

DESIGN TEIPERATURES

SUMAER

- WINTER

$\begin{array}{crrr}\text { PER CENT } & \text { T(DRY) } & \text { T(WET) } & \text { T(DRY) } \\ 1.0 & 86 & 76 & -9 \\ 2.5 & 84 & 74 & -6 \\ 5.0 & 82 & 73 & \end{array}$

MONTHLY AVERAGE TEMPERATURES AS A FUnCTION OF hOLR OF THE DAY

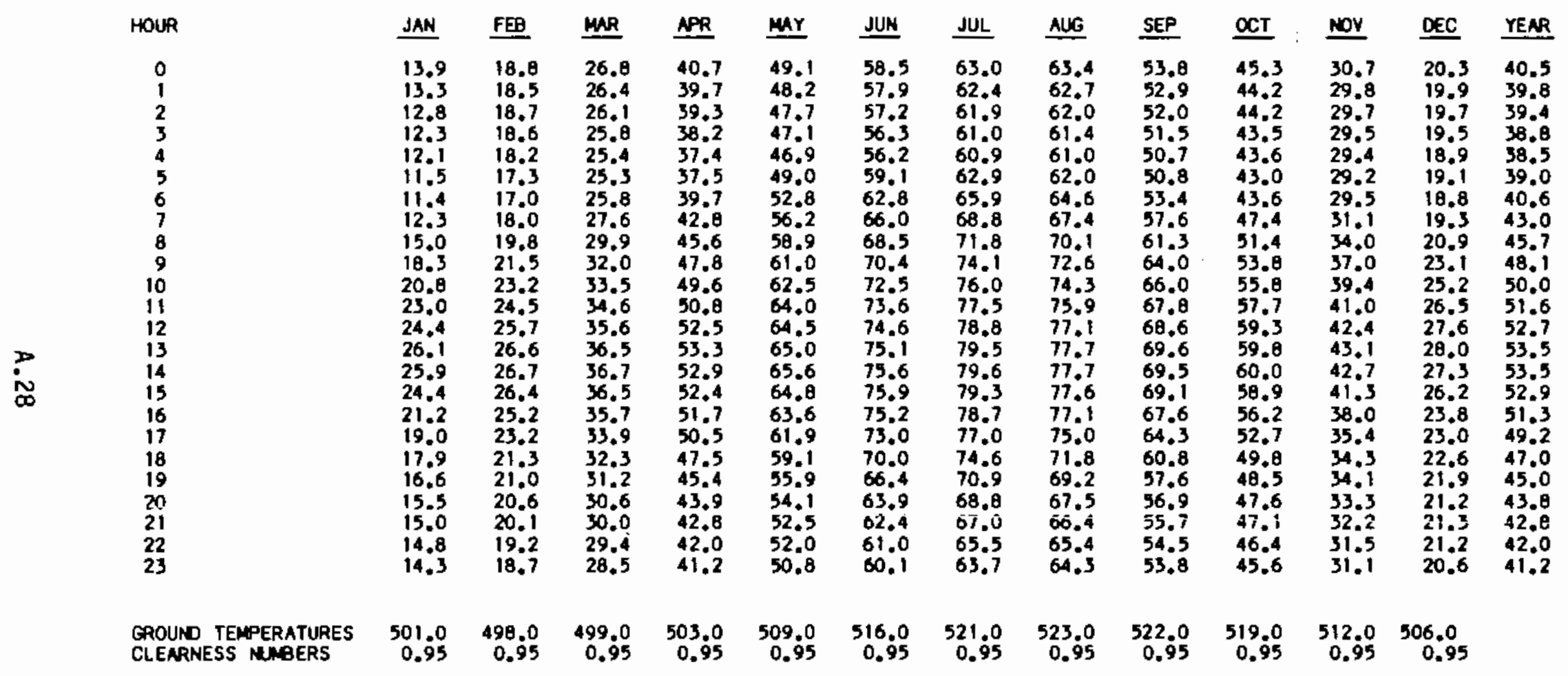


DOE-2. IC WEATHER UTILITY PROGRAM INPUT VERIFICATION

RUN TYPE PACK

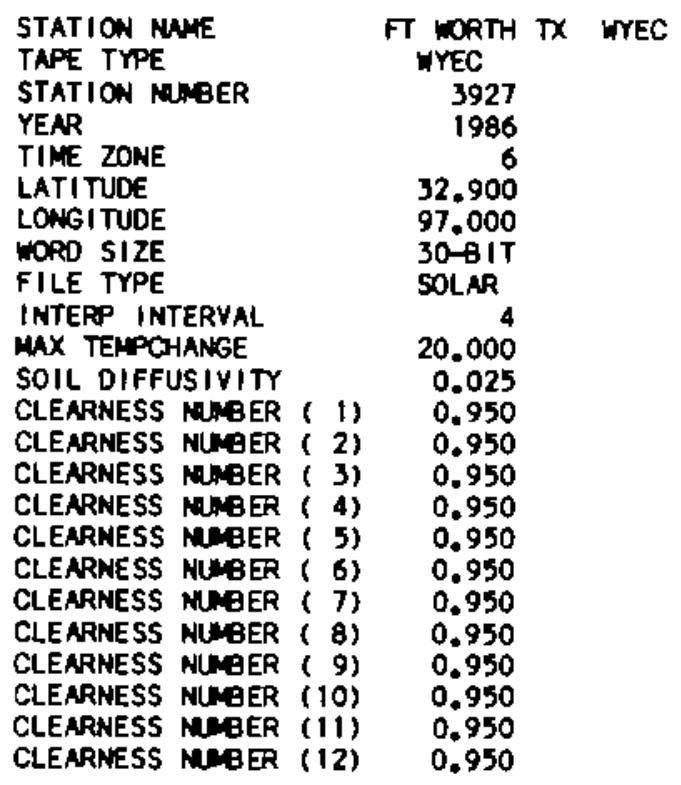

DATES AND DIRECTION OF SOLAR BIN SHIFTS FOR WYEC TAPES

JAN 11 
DOE-2. 1C WEATHER UTILITY PROGRNM

INPUT VERIFICATION

RUN TYPE STAT

FT WORTH IX WYEC MONTHLY WEATHER DATA SLMAARY

LATITUDE $=32.90$

AVG. TEMP. (F) (DRYBUL)

AYG. TEMP: (F) (WETBULB)

AVG. DAILY MAX. TEMP.

AVG. DAILY MIN. TEMP.

HEATING DEG. DAYS (BASE 65) (BASE 60)

(BASE 55)

COOLING DEG. DAYS (BASE 80)

(BASE 75)

(BASE 70)

(BASE 65)

>

.

\begin{tabular}{|c|c|c|c|c|c|c|c|c|c|c|c|c|}
\hline JAN & FEA & $M R R$ & APR & MAY & JUN & JUL & ALG & SEP & $\alpha C T$ & NoY & DEC & YEAR \\
\hline $\begin{array}{l}44.3 \\
40.0\end{array}$ & $\begin{array}{l}48.2 \\
43.7\end{array}$ & $\begin{array}{l}54.8 \\
47.1\end{array}$ & $\begin{array}{l}65.3 \\
57.8\end{array}$ & $\begin{array}{l}72.5 \\
64.5\end{array}$ & $\begin{array}{l}00.3 \\
71.9\end{array}$ & $\begin{array}{l}03.9 \\
74.0\end{array}$ & $\begin{array}{l}84.4 \\
73.1\end{array}$ & $\begin{array}{l}77.3 \\
68.1\end{array}$ & $\begin{array}{l}67.1 \\
60.1\end{array}$ & $\begin{array}{l}35.5 \\
50.1\end{array}$ & $\begin{array}{r}46.8 \\
42.9\end{array}$ & $\begin{array}{l}65.1 \\
57.8\end{array}$ \\
\hline $\begin{array}{l}54.6 \\
35.2\end{array}$ & $\begin{array}{l}59.0 \\
38.4\end{array}$ & $\begin{array}{l}65.4 \\
44.4\end{array}$ & $\begin{array}{l}74.8 \\
55.4\end{array}$ & $\begin{array}{l}82.1 \\
63.2\end{array}$ & $\begin{array}{l}89.6 \\
71.3\end{array}$ & $\begin{array}{l}93.8 \\
74.9\end{array}$ & $\begin{array}{l}94.9 \\
74.9\end{array}$ & $\begin{array}{l}87.1 \\
67.9\end{array}$ & $\begin{array}{l}77.1 \\
57.7\end{array}$ & $\begin{array}{l}65.0 \\
46.8\end{array}$ & $\begin{array}{l}57.0 \\
30.1\end{array}$ & $\begin{array}{l}75.1 \\
55.8\end{array}$ \\
\hline $\begin{array}{l}623.0 \\
468.0 \\
313.0 \\
165.5\end{array}$ & $\begin{array}{l}459.5 \\
341.5 \\
243.0 \\
156.5\end{array}$ & $\begin{array}{r}325.5 \\
204.5 \\
113.0 \\
51.5\end{array}$ & $\begin{array}{r}99.0 \\
43.0 \\
14.5 \\
4.0\end{array}$ & $\begin{array}{r}10.0 \\
0.0 \\
0.0 \\
0.0\end{array}$ & $\begin{array}{l}0.0 \\
0.0 \\
0.0 \\
0.0\end{array}$ & $\begin{array}{l}0.0 \\
0.0 \\
0.0 \\
0.0\end{array}$ & $\begin{array}{l}0.0 \\
0.0 \\
0.0 \\
0.0\end{array}$ & $\begin{array}{l}1.0 \\
0.0 \\
0.0 \\
0.0\end{array}$ & $\begin{array}{r}52.5 \\
12.0 \\
0.0 \\
0.0\end{array}$ & $\begin{array}{r}276.0 \\
153.0 \\
62.0 \\
27.0\end{array}$ & $\begin{array}{l}540.0 \\
387.5 \\
253.5 \\
153.5\end{array}$ & $\begin{array}{r}2376.5 \\
1609.5 \\
999.0 \\
558.0\end{array}$ \\
\hline $\begin{array}{l}0.0 \\
0.0 \\
0.0 \\
0.0\end{array}$ & $\begin{array}{l}0.0 \\
0.0 \\
0.0 \\
4.0\end{array}$ & $\begin{array}{r}0.0 \\
0.0 \\
1.5 \\
11.5\end{array}$ & $\begin{array}{r}0.0 \\
1.0 \\
23.5 \\
93.0\end{array}$ & $\begin{array}{r}5.0 \\
52.5 \\
128.5 \\
247.5\end{array}$ & $\begin{array}{r}58.5 \\
166.5 \\
313.0 \\
463.0\end{array}$ & $\begin{array}{l}142.5 \\
290.5 \\
445.5 \\
600.5\end{array}$ & $\begin{array}{l}158.5 \\
307.0 \\
462.0 \\
617.0\end{array}$ & $\begin{array}{r}52.5 \\
139.0 \\
247.0 \\
376.0\end{array}$ & $\begin{array}{r}0.0 \\
5.0 \\
50.0 \\
127.0\end{array}$ & $\begin{array}{l}0.0 \\
0.0 \\
0.0 \\
3.5\end{array}$ & $\begin{array}{l}0.0 \\
0.0 \\
0.0 \\
0.0\end{array}$ & $\begin{array}{r}417.0 \\
961.5 \\
1671.0 \\
2543.0\end{array}$ \\
\hline $\begin{array}{l}641.8 \\
488.4 \\
344.5 \\
217.7\end{array}$ & $\begin{array}{l}490.5 \\
374.7 \\
272.8 \\
185.2\end{array}$ & $\begin{array}{r}348.9 \\
236.3 \\
145.8 \\
79.7\end{array}$ & $\begin{array}{r}114.0 \\
55.8 \\
25.7 \\
10.9\end{array}$ & $\begin{array}{r}29.3 \\
9.6 \\
1.8 \\
0.0\end{array}$ & $\begin{array}{l}0.2 \\
0.0 \\
0.0 \\
0.0\end{array}$ & $\begin{array}{l}0.0 \\
0.0 \\
0.0 \\
0.0\end{array}$ & $\begin{array}{l}0.0 \\
0.0 \\
0.0 \\
0.0\end{array}$ & $\begin{array}{r}17.3 \\
3.8 \\
0.0 \\
0.0\end{array}$ & $\begin{array}{r}88.8 \\
40.7 \\
12.4 \\
2.1\end{array}$ & $\begin{array}{r}307.2 \\
192.8 \\
109.2 \\
51.5\end{array}$ & $\begin{array}{l}565.0 \\
421.0 \\
299.0 \\
198.3\end{array}$ & $\begin{array}{r}2603.2 \\
1823.9 \\
1211.0 \\
743.4\end{array}$ \\
\hline $\begin{array}{l}0.0 \\
0.0 \\
0.0 \\
0.0\end{array}$ & $\begin{array}{r}0.0 \\
0.9 \\
6.5 \\
20.3\end{array}$ & $\begin{array}{r}0.4 \\
3.6 \\
12.0 \\
33.1\end{array}$ & $\begin{array}{r}7.3 \\
25.6 \\
62.2 \\
122.8\end{array}$ & $\begin{array}{r}29.5 \\
75.6 \\
154.0 \\
261.2\end{array}$ & $\begin{array}{r}95.1 \\
186.3 \\
313.2 \\
457.8\end{array}$ & $\begin{array}{l}164.2 \\
281.7 \\
431.5 \\
586.5\end{array}$ & $\begin{array}{l}176.3 \\
298.2 \\
448.1 \\
602.0\end{array}$ & $\begin{array}{r}80.1 \\
190.2 \\
258.0 \\
384.8\end{array}$ & $\begin{array}{r}2.6 \\
21.1 \\
70.3 \\
155.1\end{array}$ & $\begin{array}{r}0.2 \\
1.5 \\
7.5 \\
23.5\end{array}$ & $\begin{array}{l}0.0 \\
0.0 \\
0.0 \\
2.0\end{array}$ & $\begin{array}{r}556.7 \\
1044.7 \\
1763.2 \\
2649.2\end{array}$ \\
\hline $\begin{array}{l}66 \\
22\end{array}$ & $\begin{array}{l}79 \\
22\end{array}$ & $\begin{array}{l}82 \\
27\end{array}$ & $\begin{array}{l}86 \\
35\end{array}$ & $\begin{array}{l}93 \\
50\end{array}$ & $\begin{array}{r}101 \\
64\end{array}$ & $\begin{array}{r}102 \\
70\end{array}$ & $\begin{array}{r}103 \\
64\end{array}$ & $\begin{array}{l}98 \\
55\end{array}$ & $\begin{array}{l}85 \\
43\end{array}$ & $\begin{array}{l}83 \\
36\end{array}$ & $\begin{array}{l}71 \\
20\end{array}$ & $\begin{array}{r}103 \\
20\end{array}$ \\
\hline $\begin{array}{l}0 \\
0\end{array}$ & $\begin{array}{l}0 \\
0\end{array}$ & $\begin{array}{l}0 \\
0\end{array}$ & $\begin{array}{l}0 \\
0\end{array}$ & $\begin{array}{l}5 \\
0\end{array}$ & $\begin{array}{r}16 \\
0\end{array}$ & $\begin{array}{r}26 \\
0\end{array}$ & $\begin{array}{r}24 \\
0\end{array}$ & $\begin{array}{r}16 \\
0\end{array}$ & $\begin{array}{l}0 \\
0\end{array}$ & $\begin{array}{l}0 \\
0\end{array}$ & $\begin{array}{l}0 \\
1\end{array}$ & $\begin{array}{r}87 \\
1\end{array}$ \\
\hline $\begin{array}{r}11 \\
0\end{array}$ & $\begin{array}{r}11 \\
0\end{array}$ & $\begin{array}{l}4 \\
0\end{array}$ & $\begin{array}{l}0 \\
0\end{array}$ & $\begin{array}{l}0 \\
0\end{array}$ & $\begin{array}{l}0 \\
0\end{array}$ & $\begin{array}{l}0 \\
0\end{array}$ & $\begin{array}{l}0 \\
0\end{array}$ & $\begin{array}{l}0 \\
0\end{array}$ & $\begin{array}{l}0 \\
0\end{array}$ & $\begin{array}{l}0 \\
0\end{array}$ & $\begin{array}{l}9 \\
0\end{array}$ & $\begin{array}{r}35 \\
0\end{array}$ \\
\hline 11.8 & 12.6 & 14.6 & 13.9 & 13.9 & 11.9 & 11.8 & 10.2 & 15.3 & 12.7 & 10.9 & 11.4 & 12.6 \\
\hline $\begin{array}{l}13.4 \\
10.9\end{array}$ & $\begin{array}{l}14.0 \\
11.7\end{array}$ & $\begin{array}{l}16.5 \\
13.1\end{array}$ & $\begin{array}{l}15,5 \\
12,3\end{array}$ & $\begin{array}{l}14.7 \\
12.9\end{array}$ & $\begin{array}{l}12.8 \\
10.7\end{array}$ & $\begin{array}{l}12.5 \\
11.0\end{array}$ & $\begin{array}{r}10.9 \\
9.5\end{array}$ & $\begin{array}{l}16.6 \\
14.2\end{array}$ & $\begin{array}{l}14.0 \\
11.6\end{array}$ & $\begin{array}{l}11.9 \\
10.1\end{array}$ & $\begin{array}{l}12.9 \\
10.5\end{array}$ & 13.8 \\
\hline
\end{tabular}


FT WORTH TX WEC MONTHLY WEATHER DATA SLMMARY LATITUDE $=32,90$

LONGITUDE $=97.00$

JAN FEB WR APR MAY JUH JUL AUG SEP OCT NOV DEC YEAR

AVG. TEMP. (DAY)

AVG. TEMP. (NIGHT)

$48.7 \quad 52.3 \quad 59.2$

69.4

69.4

AVG. SKY COVER (DAY)

AVG. REL. HN. AT 4NH

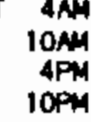

AVG. DAILY OIRECT MORMAL SOLAR

$$
5.8
$$

5.9

AVG. DAILY TOTAL HORIZNTL SOLAR

MAX. OAILY DIRECT MORMAL SOLAR 1810.0

$\begin{array}{lll}80.8 & 85.1 & 72.4 \\ 72.8 & 77.4 & 62.6 \\ 52.9 & 54.4 & 42.7 \\ 73.4 & 76.7 & 59.0\end{array}$

6.0

78.9

64.3
49.8
68.0

1205.5

$1140.1 \$ 313.9$

MIN. DAILY DIRECT MORMAL SOLAR

MIN. DAILY TOTAL HORIZNTL SOLAR

MAX. HRLY DIRECT MORMAL SOLAR MAX. HRLY TOTAL HORIZNTL SOLAR AYG, MAX. HRLY DIRECT MORML SOLNR SOLAR

$\begin{array}{rrr}1310.0 & 1721.0 & 2088.0 \\ 0.0 & 0.0 & 6.0 \\ 01.0 & 101.0 & 361.0\end{array}$

2563.0 2360.0

6.0
345.0

262.0

210.0

282.0

292.0

282.0

310.0

197.0

143.2

177.8

193.4

245.0 $\begin{array}{lll}75.9 & 83.7 & 87.6 \\ 68.6 & 76.2 & 79.6\end{array}$

$5.9 \quad 4.0 \quad 4.8$

$65.8 \quad 66.6 \quad 63.5$

$\begin{array}{ll}51.6 & 50.3 \\ 69.7 & 72.6\end{array}$

1619.5

1887.3

$\begin{array}{ll}49.8 & 43.6 \\ 68.5 & 64.4\end{array}$

2004.6

1829.2

10.0231 .0

231.0
669.0

3068.0

o 2827.0

73.0

22.0

$280.0 \quad 292.0$

292.0

318.0

277.6

268.1
203.0

DOE-2. $1 C$

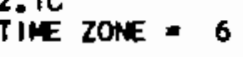

$41.7 \quad 45.5 \quad 51$.

80.9 $\quad 05.0 \quad 01.7$

$321.0 \quad 317.0$

$\begin{array}{lllll}1.5 & 71.0 & 59.9 & 51.0 & 70.6\end{array}$

$\begin{array}{lllll}7.4 & 63.4 & 52.5 & 44.2 & 60.2\end{array}$

$\begin{array}{llllll}.5 & 4.5 & 4.4 & 5.5 & 5.1 & 5.2\end{array}$

$\begin{array}{lllll}82.0 & 81.9 & 81.9 & 84.9 & 80.9\end{array}$

$\begin{array}{lllll}64.3 & 66.6 & 70.7 & 76.9 & 67.6\end{array}$

$\begin{array}{lllll}46.3 & 49.2 & 55.5 & 58.0 & 50.3 \\ 67.5 & 71.9 & 75.4 & 77.9 & 70.4\end{array}$

AVG. DAILY TOTAL YERTICAL SOLAR
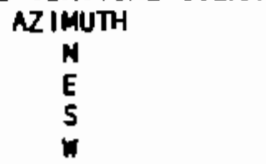

$\begin{array}{rrr}267.0 & 300.6 & 382.5 \\ 510.1 & 642.2 & 815.2 \\ 1098.3 & 1211.3 & 1166.7 \\ 519.3 & 661.4 & 841.6\end{array}$

$\begin{array}{rrrrrrrrrr}474.0 & 599.8 & 717.0 & 685.0 & 550.5 & 446.7 & 353.4 & 290.5 & 245.4 & 443.4\end{array}$ $1092.51181 .2 \quad 1276.0 \quad 1160.6 \quad 938.7 \quad 745.7 \quad 583.7 \quad 456.9062 .5$ $\begin{array}{rrrrrrrrrr}985.2 & 818.6 & 805.6 & 834.5 & 1011.9 & 1192.5 & 1307.0 & 1190.0 & 1089.1 & 1058.1 \\ 925.1 & 1146.2 & 1309.1 & 1252.7 & 1150.0 & 1009.0 & 804.8 & 593.0 & 496.5 & 893.6\end{array}$

MAX. DAILY TOTAL VERTICAL SOLAR

N
S
H

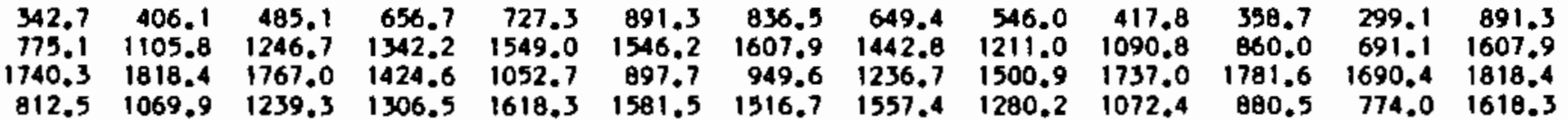

MAX. HRLY TOTAL VERTICAL SOLAR AZIMUTH

E
S

$\begin{array}{rrrrrrr}54.6 & 63.7 & 75.2 & 79.5 & 81.3 & 83.9 & 82.0 \\ 175.9 & 227.9 & 247.3 & 252.4 & 274.9 & 264.2 & 263.0 \\ 270.9 & 263.1 & 244.6 & 201.9 & 151.3 & 124.6 & 136.0 \\ 101.8 & 220.9 & 241.7 & 246.0 & 283.1 & 272.7 & 268.8\end{array}$
80.1
256.6
177.5

177.5

273.4 $\begin{array}{rrrrr}73.6 & 66.9 & 57.7 & 52.7 & 03.9 \\ 234.8 & 219.7 & 193.2 & 160.9 & 274.9\end{array}$

$216.7 \quad 267.9 \quad 262.8 \quad 275.6 \quad 275.6$

$\begin{array}{lllll}247.4 & 233.4 & 203.8 & 183.0 & 283.1\end{array}$ 
FT WORTH TX WYEC

WONTHLY WEATHER DATA SUMWARY

DESIGN TEMPERATURES

$\begin{array}{crrrr} & & & \\ \text { PER CENT } & \text { T(DRY) } & \text { T(MET) } & \text { T(DRY) } \\ 1.0 & 99 & 78 & 23 \\ 2.5 & 98 & 77 & 27 \\ 3.0 & 96 & 77 & \end{array}$

MONTHLY AVERAGE TEMPERATURES AS A FUNCTION OF HOUR OF THE DAY

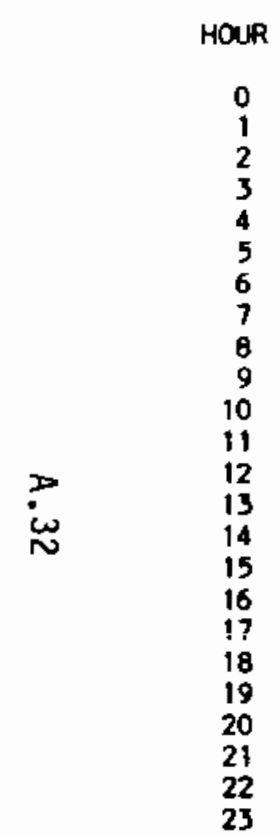

$61.6-72.1$

\begin{tabular}{c} 
JUN \\
\hline 75.9 \\
74.9 \\
73.5 \\
73.1 \\
72.4 \\
71.9 \\
73.9 \\
76.2 \\
79.1 \\
81.5 \\
83.5 \\
84.9 \\
86.3 \\
87.3 \\
88.4 \\
89.1 \\
88.1 \\
86.5 \\
84.3 \\
81.9 \\
80.2 \\
78.8 \\
77.7 \\
76.6 \\
527.4 \\
0.95
\end{tabular}

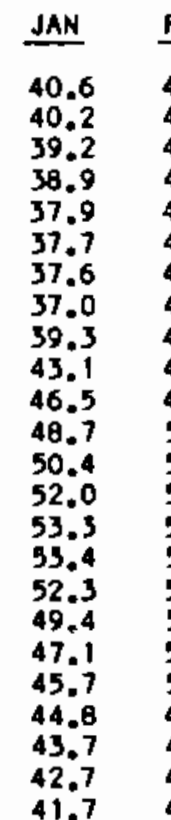

\begin{tabular}{l}
$F E B$ \\
\hline 44.5 \\
44.0 \\
43.3 \\
42.3 \\
41.5 \\
40.6 \\
40.3 \\
41.1 \\
43.0 \\
46.4 \\
49.4 \\
52.1 \\
54.1 \\
55.9 \\
57.1 \\
57.7 \\
57.0 \\
54.9 \\
52.3 \\
50.0 \\
48.9 \\
47.9 \\
46.8 \\
45.6
\end{tabular}

MAR

50.1

49.2

48.5

$47.2 \quad 58.0$

$46.6 \quad 58.1$

$48.4 \quad 60.6$

51.2

63.6

54.2

56.8
59.2

$\begin{array}{lll}63.0 & 73.1 & 80.1\end{array}$

$64.0 \quad 73.7 \quad 81.0$

$64.2 \quad 74.2 \quad 81.1$

$\begin{array}{lll}63.6 & 73.2 & 60.4 \\ 62.0 & 71.9 & 79.2\end{array}$

$\begin{array}{lll}62.0 & 71.9 & 79.2 \\ 59.1 & 68.6 & 76.5\end{array}$

$\begin{array}{lll}59.1 & 68.6 & 76.5 \\ 57.0 & 66.5 & 74.5\end{array}$

55.7

$64.7 \quad 72.5$

$\begin{array}{lll}53.3 & 63.5 & 71.4 \\ 53.1 & 63.0 & 70.6\end{array}$

514,3

515.7

69.4

0.95

0.95
0.95

\begin{tabular}{l} 
JUL \\
\hline 79.2 \\
78.1 \\
77.6 \\
76.8 \\
76.1 \\
75.6 \\
76.6 \\
79.6 \\
82.7 \\
85.2 \\
87.6 \\
89.4 \\
90.6 \\
91.4 \\
92.5 \\
91.6 \\
91.5 \\
90.7 \\
88.4 \\
85.4 \\
83.4 \\
82.1 \\
81.5 \\
80.4 \\
532.4 \\
0.95
\end{tabular}

\begin{tabular}{l} 
NUG \\
\hline 79.6 \\
78.6 \\
77.6 \\
77.1 \\
76.3 \\
75.7 \\
76.3 \\
79.1 \\
92.6 \\
85.8 \\
88.6 \\
90.3 \\
92.2 \\
93.4 \\
94.2 \\
93.2 \\
92.4 \\
91.0 \\
88.6 \\
85.7 \\
83.9 \\
82.5 \\
81.2 \\
80.2 \\
535.6 \\
0.95
\end{tabular}

SEP

72.8
71.7
71.2

71.2

70.2

69.7

69.8

75.0

75.0

77.8
80.7
82.6
84.4

$82.6 \quad 73.0$

$84.4 \quad 74.5$

$85.6 \quad 75.7$

$86.8 \quad 76.5$

85.3

85.3

83.072 .5

$78.6 \quad 68.2$

$77.1 \quad 66.7$

$\begin{array}{ll}75.5 & 65.4 \\ 74.7 & 64.4\end{array}$

$2.5 \quad 52.0$

52.0

$61.1 \quad 50.8$

59.9

48.8

48.5

49.7

$\begin{array}{lll}55.6 & 45.9 & 65.4\end{array}$

$38.4 \quad 49.0 \quad 68.0$

$\begin{array}{lll}60.8 & 51.3 & 70.0\end{array}$

$62.5 \quad 53.0 \quad 71.8$

$63.4 \quad 54.2 \quad 73.0$

$64.3 \quad 55.3 \quad 74.0$

$64.0 \quad 55.1 \quad 74.0$

$\begin{array}{lll}62.4 & 53.9 & 73.0\end{array}$

$\begin{array}{lll}59.8 & 51.3 & 71.1\end{array}$

$\begin{array}{lll}57.7 & 49.3 & 68.6 \\ 56.2 & 47.9 & 66.5\end{array}$

$\begin{array}{lll}55.4 & 46.5 & 65.1\end{array}$

$54.1 \quad 45.5 \quad 63.8$

$33.2 \quad 44.5 \quad 62.9$

GROUAO TEMPERATURES
CLEARNESS NUEERS

$0.95 \quad 0.95$

535.9

$\begin{array}{rrrr}5.9 & 533.3 & 528.4 & 522.8 \\ .95 & 0.95 & 0.95 & 0.95\end{array}$

528.4

43.861 .8 
APPENDIX B

ENERGY-COST AND BUILDING-COST MODEL AND SELECTION PROCEDURE, DOCUMENTATION OF PROOF-OF-CONCEPT SPREADSHEET 
APPENDIX B

ENERGY-COST AND BUILDING-COST MODEL AND SELECTION PROCEDURE, DOCUMENTATION OF PROOF-OF-CONCEPT SPREADSHEET

\section{B.1 PURPOSE OF THE SPREADSHEET}

A spreadsheet program was developed as a proof-of-concept test of the proposed approach for treating economics in the project. The approach makes economics an integral part of the whole-building energy targets methodology. The spreadsheet contains a set of keyboard macros that, when invoked, identify a set of space-function characteristics for consideration on the basis of economic criteria and convert these space-function characteristics into a set of measures of annual energy performance.

Because this proof-of-concept test has been developed prior to the completion of the space-function energy model, on which it ultimately will be based, a rough building energy-use model was installed in the procedure simply to give the selection procedure something with which to work. For this reason, the specific numbers generated by the spreadsheet should not be taken seriously. The energy-use model in the spreadsheet is based on formulas and coefficients from Standard $90.1 \mathrm{P}$ and on a number of rules of thumb and best estimates. An effort has been made to give the model many of the characteristics that the final functional approach model will have. However, it is the viability of the approach and not the accuracy of the resulting numbers that the spreadsheet is designed to demonstrate.

\subsection{DESCRIPTION OF THE SPREADSHEET}

Briefly, the organization of the spreadsheet is as follows: Input assumptions, calculation results, and all tables that the procedure draws from while conducting the calculations are located in a vertical column at the extreme left-hand side of the spreadsheet. The actual calculations are performed in a column one screen to the right of the left-hand edge of the spreadsheet, and the macros are located in a series of columns starting at the top of the 
spreadsheet and extending to the right from the third column (or screen) out to the twelfth. A table entitled Macro Optimization Table, where decisions made by the procedure are logged, is located at cell N79. Three tables or logs that record many of the internediate calculations are adjacent to this table; one extends downward as the procedure progresses and two others extend horizontally to the right, one above the other. Finally, a table designed for recording the results of a number of optimizations performed as a batch is located diagonally to the right and down from the Macro Optimization Table.

\section{B.2.1 Basis for Selection}

The basis for space-function characteristic selection is the minimization of the total of first costs and the present value of energy costs over the selected time horizon. This is done by multiplying annual energy costs by the present worth factor corresponding with the economic perspective that has been selected, adding the first cost of a set of energy related features, and selecting the least expensive option. Parameters that are treated as continuous variables are modified until the simple payback ratio resulting from an incremental change to their value matches the target present worth factor. Simply stated, once the selection procedure has been run, there will be no combination of characteristics that can potentially be selected that will result in lower total costs than the values displayed.

\section{B.2.2 Modular Nature of the Spreadsheet}

The selection routine uses multiple recalculations of the spreadsheet to guide the alterations to the space-function characteristics selected. As a result, the routine is generic and largely independent of the energy model in the spreadsheet. This approach has made the spreadsheet easy to alter but has resulted in slower execution than if the routines had been tailored to the specific energy and cost model. Building-cost and performance data are located in tables where values can easily be changed.

\section{B.2.3 Sumary of the Selection Procedure}

Several of the space-function characteristics that are optimized by the procedure are treated as continuous variables, in contrast to other characteristics that are treated as discreet variables. This assumption of 
continuousness has been used for electric lighting systems, glass shading coefficients, and wall insulation values. Figure B.1 illustrates the iterative search process that is used to find the value for these parameters that result in the lowest owning and operating costs. The procedure searches for the value of each parameter at which the energy savings resulting from an incremental change exactly equals the additional cost. This iterative search routine is used repeatedly throughout the procedure.

There are three principal steps that the selection procedure employs as it executes. First, it attempts to eliminate options from further consideration by testing them under conditions that are as favorable as possible for costjustifying their retention. For example, a space with automatic daylighting controls is compared to a space without automatic daylighting controls, assuming a high electric lighting power level, a high shading coefficient for the glazing, an efficient heating system, and an inefficient cooling system. If the cost of the controls can not be justified under these very favorable conditions, the controls are eliminated from further consideration as an option during the remainder of the optimization. If the above test does not result in

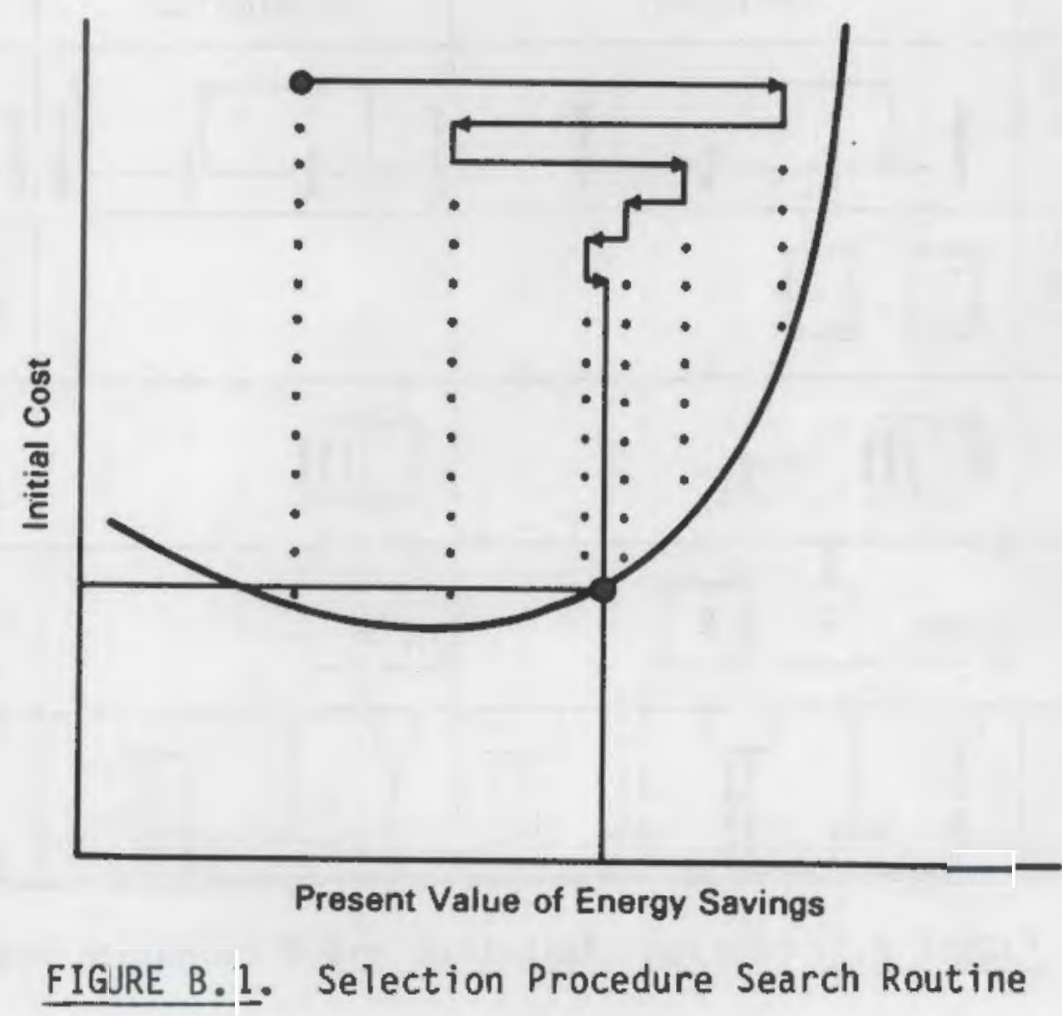


the elimination of the option, a similar test is conducted to establish whether the alternative of not providing automatic daylighting can be eliminated from further consideration. Similar tests are conducted in attempt to narrow the options for heating system, cooling system, and glazing type. The results of this procedure are shown graphically in Figure B.2, and a sample calculation $\log$ from the spreadsheet is shown in Figure B.3.

Where options are assumed to be available over a continuous range of values, the search routine attempts to narrow the range under consideration, by looking at extreme conditions that are either highly favorable or highly unfavorable to the parameter. This approach is used for electric lighting power level and wall insulation. The procedure uses the following order in considering the possibility of limiting or eliminating options: electric lighting, daylighting controls, cooling system type, heating system type, glazing type, shading coefficient, wall insulation level. The procedure works from what are assumed to be the most important parameters to the least important,

\begin{tabular}{|l|l|l|l|l|l||}
\hline & \multicolumn{2}{|c|}{$\begin{array}{c}\text { OPTIONS } \\
\text { AVAILABLE }\end{array}$} & \multicolumn{1}{c|}{$\begin{array}{c}\text { OPTIONS } \\
\text { ELIMINATED }\end{array}$} & \\
\hline $\begin{array}{l}\text { ELECTRIC } \\
\text { LIGHTING }\end{array}$ & OPTIONS \\
RETAINED
\end{tabular}

FIGURE B.2. Option Limitation and Elimination Procedure 


\begin{tabular}{lcccccccccccc}
\hline & 1 & 2 & 3 & 4 & 3 & 6 & 7 & 8 & 9 & 10 & 11 & 12 \\
\hline E Ltg & 2.00 & 2.00 & 3.00 & 3.00 & 3.00 & 3.00 & 2.00 & 2.00 & 2.00 & 2.00 & 2.00 & 3.00 \\
D Ltg & 1 & 2 & 1 & 2 & 1 & 1 & 2 & 2 & 2 & 2 & 2 & 1 \\
C Sys & 1 & 1 & 2 & 2 & 1 & 2 & 1 & 2 & 2 & 2 & 2 & 2 \\
H Sys & 5 & 5 & 4 & 4 & 4 & 4 & 5 & 5 & 3 & 4 & 5 & 3 \\
G Typ & 4 & 4 & 3 & 3 & 3 & 3 & 4 & 4 & 4 & 4 & 4 & 5 \\
Shd C & 0.25 & 0.25 & 0.83 & 0.83 & 0.83 & 0.83 & 0.25 & 0.25 & 0.25 & 0.25 & 0.25 & 0.67 \\
R $\rightarrow$ all & 7.2 & 7.2 & 14.8 & 14.8 & 14.8 & 14.8 & 7.2 & 7.2 & 7.2 & 7.2 & 7.2 & 14.8 \\
\hline To.080 & 20.98 & 21.72 & 21.14 & 19.65 & 22.47 & 21.14 & 21.72 & 20.90 & 20.38 & 20.08 & 20.90 & 22.16 \\
\hline
\end{tabular}

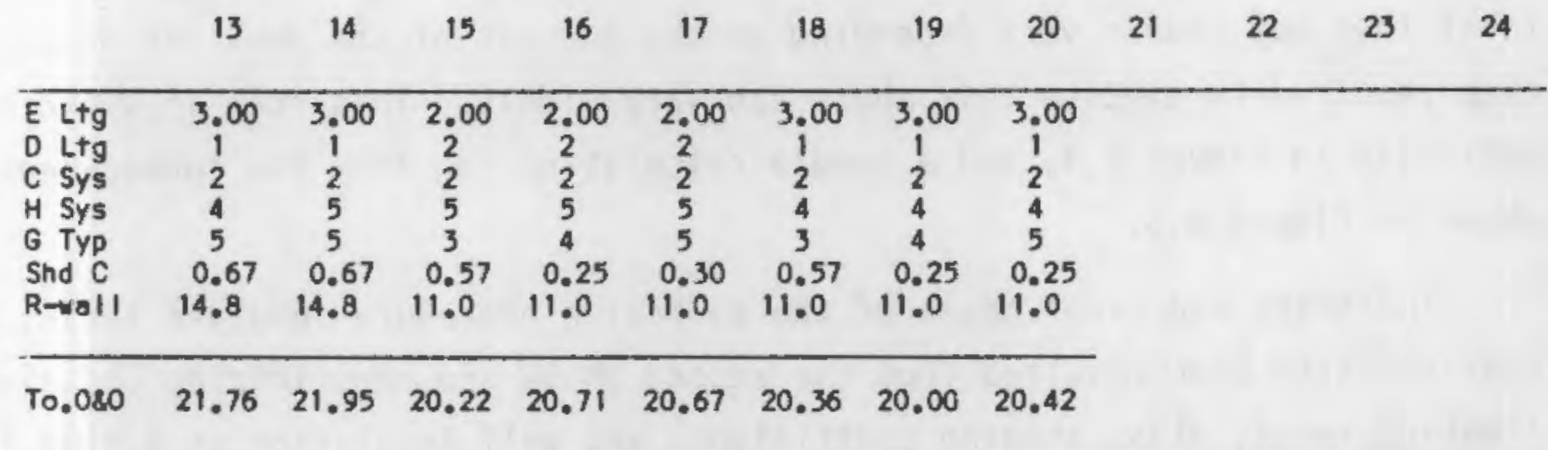

FIGURE B.3. Example Option Elimination Table from the Spreadsheet

and with each parameter that is limited or eliminated, the variability affecting the testing of the remaining options is diminished. Where there is variability or uncertainty in what constitutes the most or least favorable conditions for an option, a margin for uncertainty has been provided. For example, for heating, cooling, and glazing systems, an option must be significantly outperformed before it will be abandoned.

This procedure simplifies the problem in a manner that is similar to the way in which an energy analyst might proceed, initially considering a wide range of strategies but rapidly eliminating from further consideration those options that could not possibly be cost-effective. Because a large number of combinations of options result even when only a few options are available, it is highly efficient to attempt to eliminate unpromising options before they are considered in combination with other options. If, for example, the option of not providing daylighting controls can be eliminated initially, half the 
possible combinations of options need not be considered. Eliminating two of three possible heating systems would reduce the remaining combinations by a factor of three, and so on.

The second phase of the optimization begins after the initial attempt to eliminate options has been completed. This step is by-passed if a single set of characteristics has emerged. This phase takes all possible combinations of the remaining options, optimizes electric lighting, shading coefficient, and wall insulation for each configuration at a moderate level of precision, and selects the most cost-effective configuration. Because the number of combinations that may remain vary depending on the success of the previous phase, the time required to execute this phase can vary widely. This step is shown schematically in Figure $\mathbf{B . 4}$, and a sample calculation log from the spreadsheet is shown in Figure B.5.

The third and final phase of the selection procedure involves taking the configuration that resulted from the second phase and reoptimizing the electric lighting level, glass shading coefficient, and wall insulation at a high level of precision. This seemingly redundant step ensures that, even where options are highly interactive, the interactions will be reflected in the final selection because each parameter is reoptimized based on adjusted values for the other parameters. Significant levels of interaction have been observed, for example, between electric lighting levels and shading coefficients in spaces with automatic daylighting controls.

The calculation procedure described here represents one approach to the problem of generating economically balanced configurations from which targets can be generated. While it appears to work satisfactorily, it is certainly not the only way to design such a procedure and may well not be the best way. The logic will be reexamined during Phase 2 and an entirely new program will be written at that time.

\section{B.2.4 Uses for the Spreadsheet}

The spreadsheet is capable of defining appropriate levels of energy performance for a wide range of spaces, based on a balance of energy and economic criteria. The procedure enables a designer to generate the estimate based on 


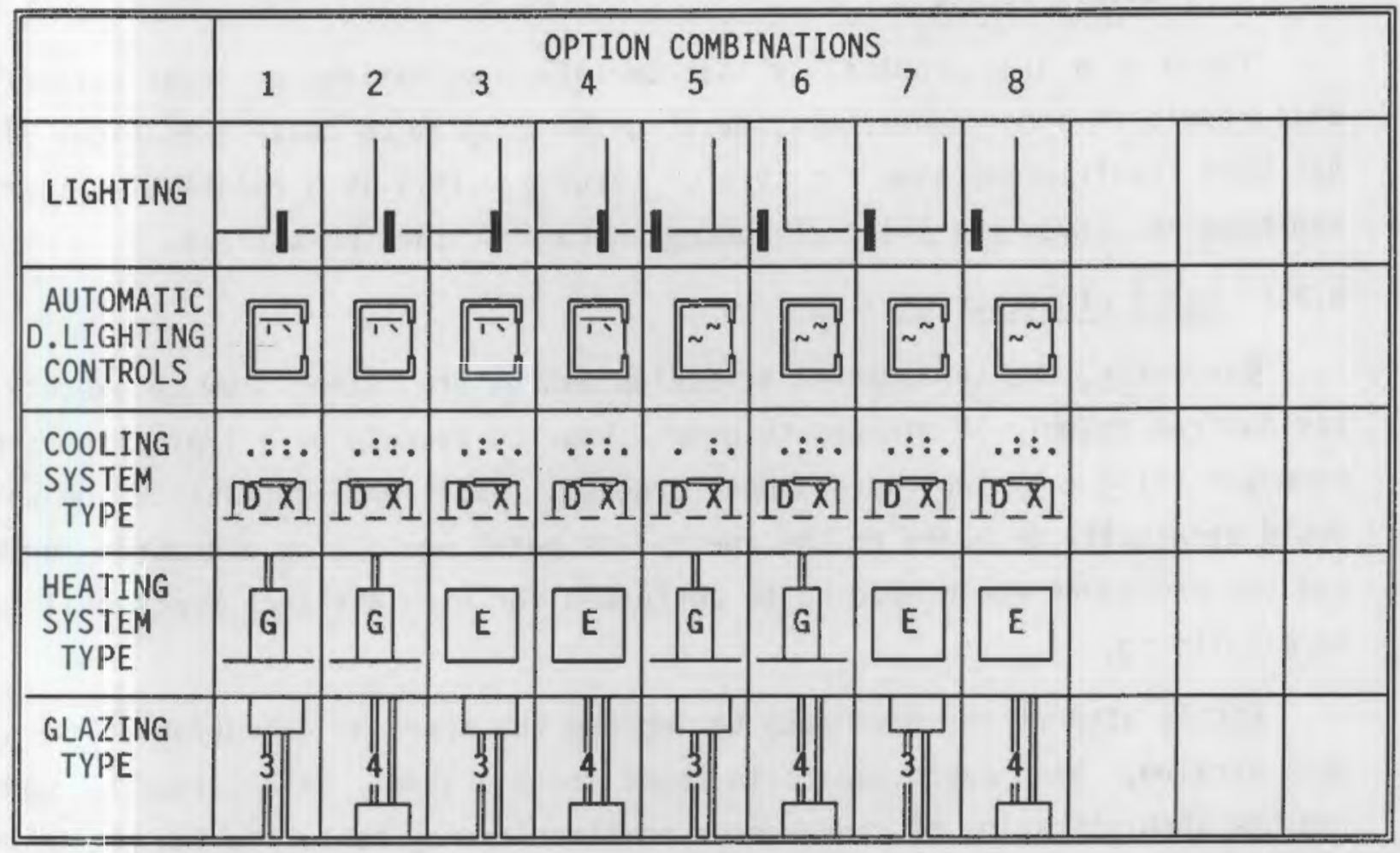

FIGURE B.4. Option Comparison Procedure

\begin{tabular}{|c|c|c|c|c|c|c|c|c|c|}
\hline & 1 & 2 & 3 & 4 & 5 & 8 & 7 & 8 & 9 \\
\hline $\begin{array}{l}\text { E Ltg } \\
\text { D Ltg } \\
\text { C Sys } \\
\text { H Sys } \\
\text { C Typ } \\
\text { Shd C } \\
\text { R-wall } \\
======= \\
\text { To.080 }\end{array}$ & $\begin{array}{r}2.80 \\
1 \\
2 \\
4 \\
3 \\
6.57 \\
16.2 \\
====== \\
19.75\end{array}$ & $\begin{array}{r}2.60 \\
1 \\
2 \\
4 \\
4 \\
6.25 \\
19.3 \\
19.36\end{array}$ & $\begin{array}{r}2.07 \\
1 \\
2 \\
5 \\
3 \\
0.57 \\
12.7 \\
====1= \\
26.36\end{array}$ & $\begin{array}{r}2.05 \\
1 \\
2 \\
5 \\
4 \\
4.25 \\
12.7 \\
19.98\end{array}$ & $\begin{array}{r}2.64 \\
2 \\
2 \\
4 \\
3 \\
3 \\
.57 \\
10.2 \\
=19.25\end{array}$ & $\begin{array}{r}2.13 \\
2 \\
2 \\
4 \\
4 \\
0.29 \\
16.3 \\
==== \\
19.99\end{array}$ & $\begin{array}{r}2.78 \\
2 \\
2 \\
5 \\
3 \\
3 \\
1.57 \\
12.6 \\
====1 \\
19.97\end{array}$ & $\begin{array}{r}2.26 \\
2 \\
2 \\
5 \\
4 \\
4.25 \\
12.7 \\
===== \\
20.66\end{array}$ & \\
\hline
\end{tabular}

FIGURE B.5. Example Option Comparison Table from the Spreadsheet

the particular factors that characterize his project and, in most cases, to evaluate the performance of his design using the same procedure. The calculation procedure may also be useful in providing direct guidance on appropriate building features during the early phases of a design project. Where certain design decisions have already been made, optimizations reflecting those decisions can be performed on the remaining elements. 


\section{B.2.5 Potential for Bugs}

There is a high probability that certain combinations of input parameters will result in error conditions, causing the program to cease execution. There has been insufficient time for careful testing. This is a relatively minor shortcoming, given the proof-of-concept nature of the spreadsheet.

\section{B.2.6 Speed of Execution}

Currently, the spreadsheet selection macros are rather slow to execute, taking from roughly 15 minutes to over 1 hour to execute on a typical personal computer using a typical spreadsheet program. Additional sophistication which would eventually be added to the energy-use model would slow execution further, and the procedure would need to be performed for each distinct functional space in a building.

Little attempt has been made to improve the speed of execution of the current version. Vast improvements in speed could probably be obtained by improving the sophistication of convergence routines and by tailoring the procedure to the behavior of the energy and cost model. These steps might reduce execution time by a factor of 2 to 5 . According to some sources, execution times for spreadsheets can be reduced by up to an order of magnitude by using a more powerful personal computer with coprocessor and a more recent spreadsheet version. Dramatic reductions in execution time could also be achieved by writing the selection routines in a compiled language such as $C$. Alternatively, regression coefficients could be developed that might produce satisfactory approximations of the values generated using the selection procedure itself.

While the current version is so slow as to hamper some potential uses for the spreadsheet, a number of options that would minimize the problem are available.

\section{B.2.7 Generalized Cost Expressions}

The proposed whole-building energy targets procedure will be based on generalizations about the costs of energy-related features. It would be 
impossible to determine the cost of every available material or piece of equipment. This would aiso be unnecessary, since target levels should not be based on the most or least expensive material but rather on representative, intermediately priced products. The approach to developing generalized cost expressions will be to base them on a sample of appropriate building costs and to use statistical methods to convert these costs into mathematical expressions.

The current spreadsheet makes use of some building cost expressions that treat building parameters as continuous functions of cost rather than as discreet data points. Although most actual building materials and systems are available only in discreet sizes, the large number of suppliers, constantly changing costs and product lines, and the variety of ways that many elements can be combined make the assumption that certain parameter are continuous reasonable for the purposes to which this data will be put. The continuous cost expressions are intended to describe the underlying relationships that drive building system costs rather than the specific sample of costs that was observed. While a procedure based on the actual data would at first appear to be more accurate, as products disappeared over time and new ones were introduced, such a procedure would be tied permanently to noise in the initial sample.

In order for a simplified energy cost model to account for mechanical system first cost reductions resulting from design load reductions, the relationship between mechanical system costs and system capacity has been treated as a continuous relationship, as is done in DOE-2. Again, the relationship in reality is more nearly a stair-step function. Yet, the assumption of continuousness is appropriate because, if a large sample were considered, the expected consequence of a design load reduction would be described by a continuous function. Basing the procedure on the most probable outcome, even though it is uncertain, is appropriate both for establishing targets and for the uses to which a designer might put the procedure early in the design process. The alternative to this approach would be to build stair steps into the target values to account for available equipment sizes or to ignore the substantial first cost savings that can result from design load reductions. 


\section{B.2.8 Treatment of Glazing Transmission Characteristics}

Figures B.6 and B.7 illustrate the approach that was used in developing generalized expressions to describe glazing performance. Least-squares regres- . sions were performed on glass transmission data from two manufacturers. These. data have been plotted along with the regression lines that were developed for each type of glass. The selection procedure then used glass type and shading coefficients, within the appropriate range, as independent variables, while glass conductance and visible transmittance were treated as dependent variables based on the regression equations. Review of data from other manufacturers suggests that their products exhibit similar characteristics: generally wellconfined scatter around the regression lines and a variety of available shading coefficients, which support the assumption of continuousness for this variable.

These graphs have been presented to illustrate the general approach that will be taken to describe the cost and performance characteristics of systems and building components.

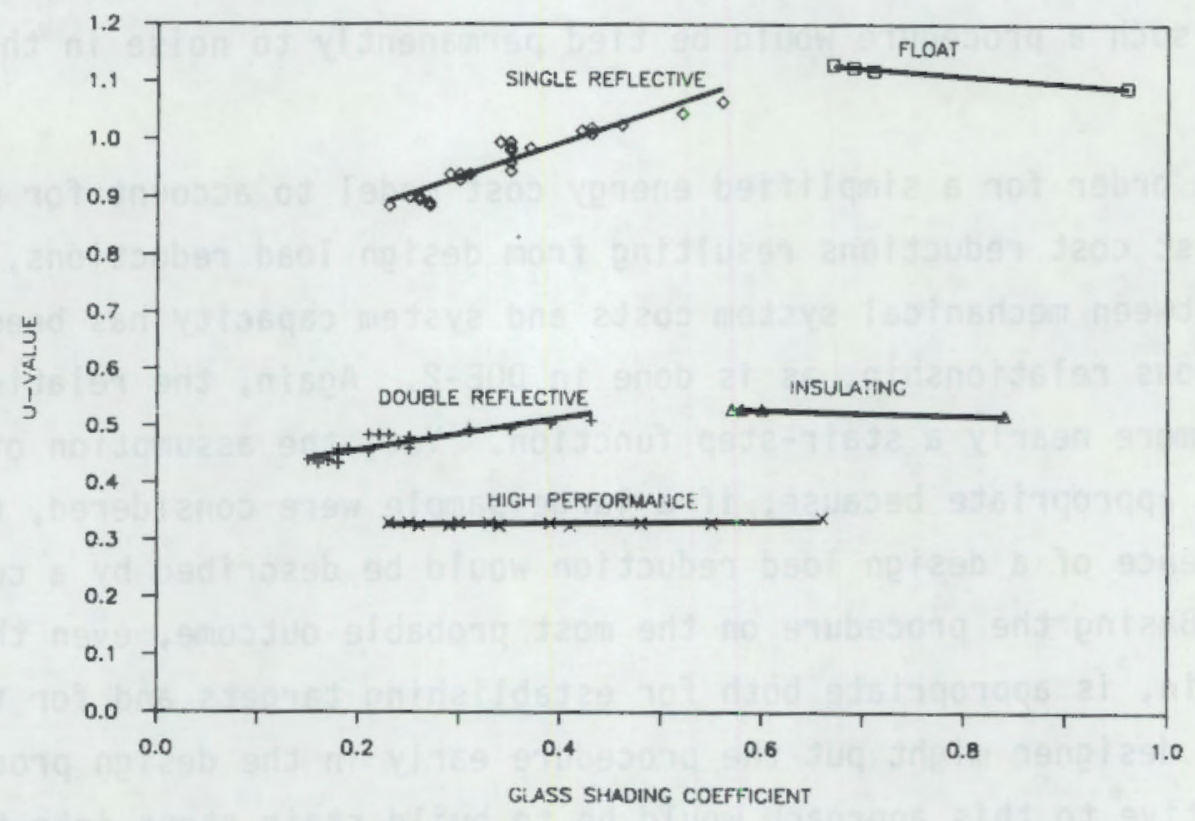

FIGURE B.6. Conductance of Glass Types 


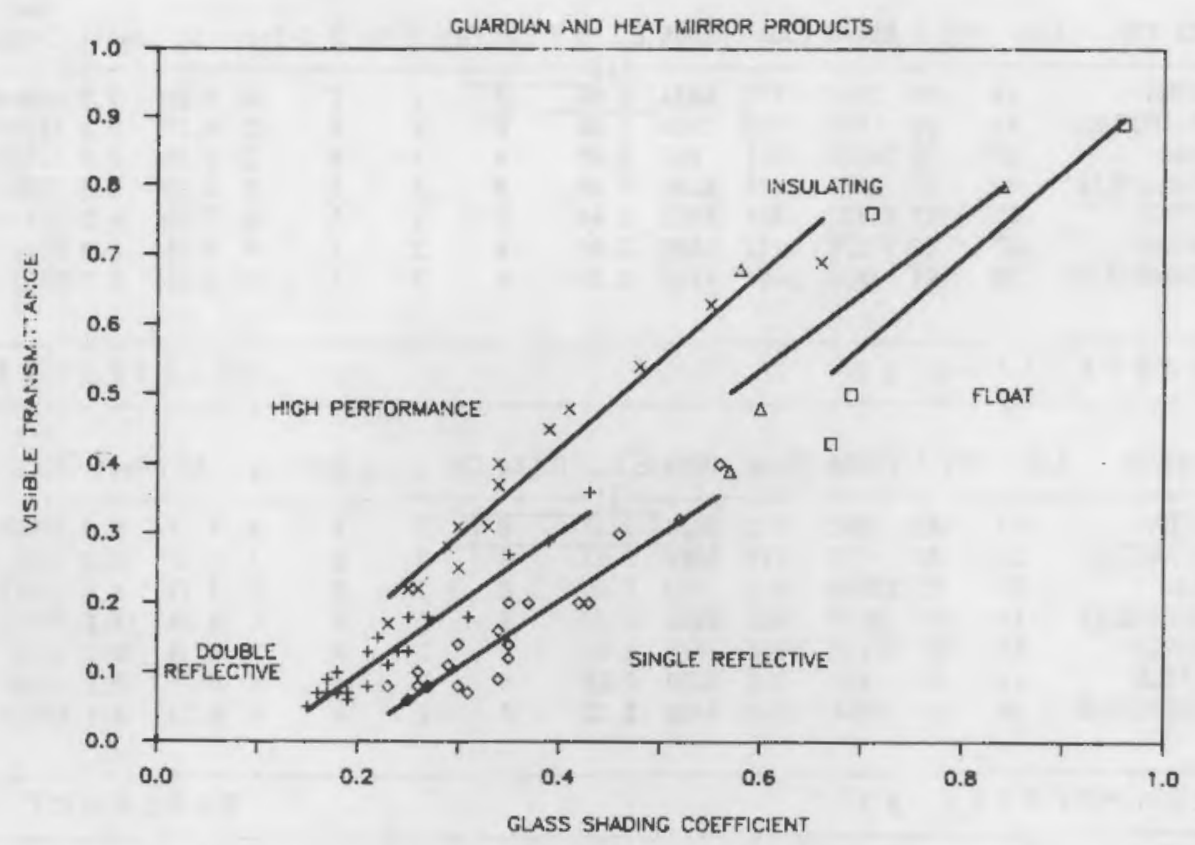

FIGURE B.7. Visible Transmittance of Glass Types

\section{B.3 EXAMPLE SPREADSHEET RESULTS AND ANAL YSIS}

Figure $B .8$ shows the building configuration, energy consumption, and energy and incremental building costs that resulted from running the spreadsheet program for five economic perspectives in seven locations. The economic perspect ives that were used were intended to represent the widest possible range of assumptions that might be reasonable. The perspectives shown correspond with the following assumptions:

1. Minimize first cost regardless of energy costs. Limiting simple payback ratio 0 .

2. Minimize initial cash flow with 10-year financing. Limiting simple payback ratio 4.66 .

3. Minimize short-term (8-year) owning and operating costs. Limiting simple payback ratio 7.08 .

4. Minimize life-cycle costs for long-term owner. Limiting simple payback ratio 13.09 .

5. Minimize total societal costs (with allowance for external costs). Limiting simple payback ratio 30.19 . 


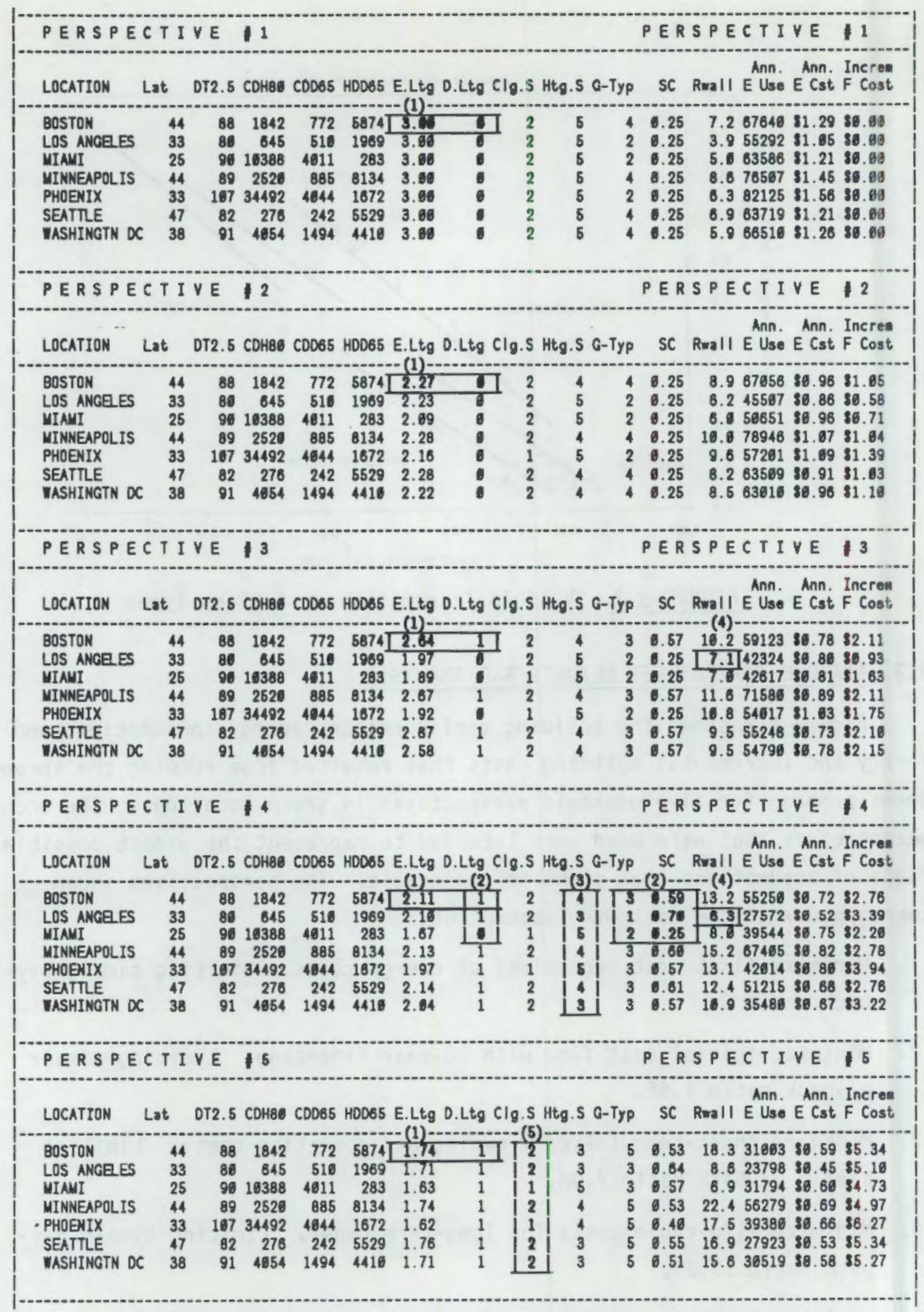

FIGURE B.8. Summary Table Generated Using Characteristics Shown in Figure B.17. 
The space-function characteristic assumptions were for a typical exterior, north-facing office zone. The specific assumptions that were used are listed in the "TARGET GENERATION" column of Figure B.17. Boxes have been drawn around certain values in Figure B. 8 in order to key the discussions that follow to the figure.

1. In general, the electric lighting power level (E.Ltg) drops as the economic perspective becomes more favorable to long-term investment, the examples lower down on the page. The boxes labelled \#1 illustrate that this trend is reversed when automatic daylighting controls are added ( $D . \operatorname{Ltg}=1$ ), since more efficient and expensive lighting fixtures are not cost-justified in the model when their hours of operation are reduced by automatic controls. The selections of space-function characteristics made by the procedure reflect the fact that many energy conserving features compete with one another for potential cost savings.

2. The set of boxes labelled \#2 illustrate that the selection of glass type (G.Typ) and shading coefficient (SC) are interdependent with the decision to employ automatic daylighting controls. Glass types 1 through 5 are single-tinted, single-reflective, double-tinted, double-reflective, and high-performance glazing, respectively. The configurations with automatic daylighting controls use relatively high shading coefficients, while low shading coefficients are selected for the configurations without. The procedure evaluates sets of strategies in a way that recognizes the synergistic relationships between certain building features.

3. The box labelled \#3 illustrates the climate dependency that is inherent in the selection of heating system types (Htg.S). Heating system types 3,4 , and 5 represent electric heat pumps, gas furnaces, and electric furnaces, respectively. Varying first costs, heating loads, and the performance of mechanical equipment under different climatic conditions are accounted for in this selection.

4. In general, the more favorable the economic perspective is to longterm investment the higher the wall insulation level (Rwall) will 
be. The box labelled \#4 illustrates that this trend is temporarily reversed when a heating system that delivers heat less expensively has been added. This illustrates the economic balancing of buildingenvelope and mechanical-system that are inherent in the operation of the model.

5. The box labelled \#5 illustrates the climate dependencies inherent in the selection of cooling system types (Clg.S). As in the selection of heating systems, initial cost, load, cooling system performance, and lighting and envelope design are all traded off in the selection of the most cost-effective set of space-function characteristics.

\section{B.3.1 Summary Graphs}

Tables B.1 and B.2 and Figures B.9 through B. 15 sumarize 230 executions of the procedure that were performed using 5 economic perspectives and 46 U.S. climates. The space-function characteristics that were used to generate the graphs were intended to represent a typical exterior south-facing office zone. The specific assumptions that were used are listed in Table B.1. Table B.2 lists the locations and the climatic parameters that were used and serves as a key for the graphs. The locations were sorted on the basis of ascending annual energy use (ignoring onsite conversion losses) for perspective \#5. The economic perspectives were the same as those used for the previous table.

A detailed interpretation of the results would be inappropriate, since the data from which the graphs were generated are based on rules of thumb and best estimates, which were intended to demonstrate that the approach was workable rather than produce accurate results. However, the graphs do illustrate the type of data that can be generated from the procedure and also the types of relationships between indices of space-function energy performance that are likely to result from the final targets model.

Figure B.9 shows annual energy use for the south-facing office space for the five economic perspectives and 46 U.S. locations having WYEC (Weather Year for Energy Calculations) data. Annual energy use varies by nearly a factor of 
TABLE B.1. Conditions Used to Generate Summary Graphs

Defining

Characteristics:

Location $1-46$
Orientation (N1,E2,
Cost of Electricity
(\$/MBTU)
Cost of Natural Gas
(\$/MBTU)
Econ. Perspctv PWF 5
(1-5)

Space Function:

Operation

(HRS/WK)

Occ. Density

(SF/PERS)

OSA Vent Rate

(CFM/PERS)

Infiltration -Unocc. (AC/HR)

Daylighting (N01, YES2, MAYBE3)

Receptacle Load (Ep)

Window-Wall

Ratio

Minimum Shading

Coefficient

Econ. Perspctv PWF 5

$(1-5)$
Target Generation

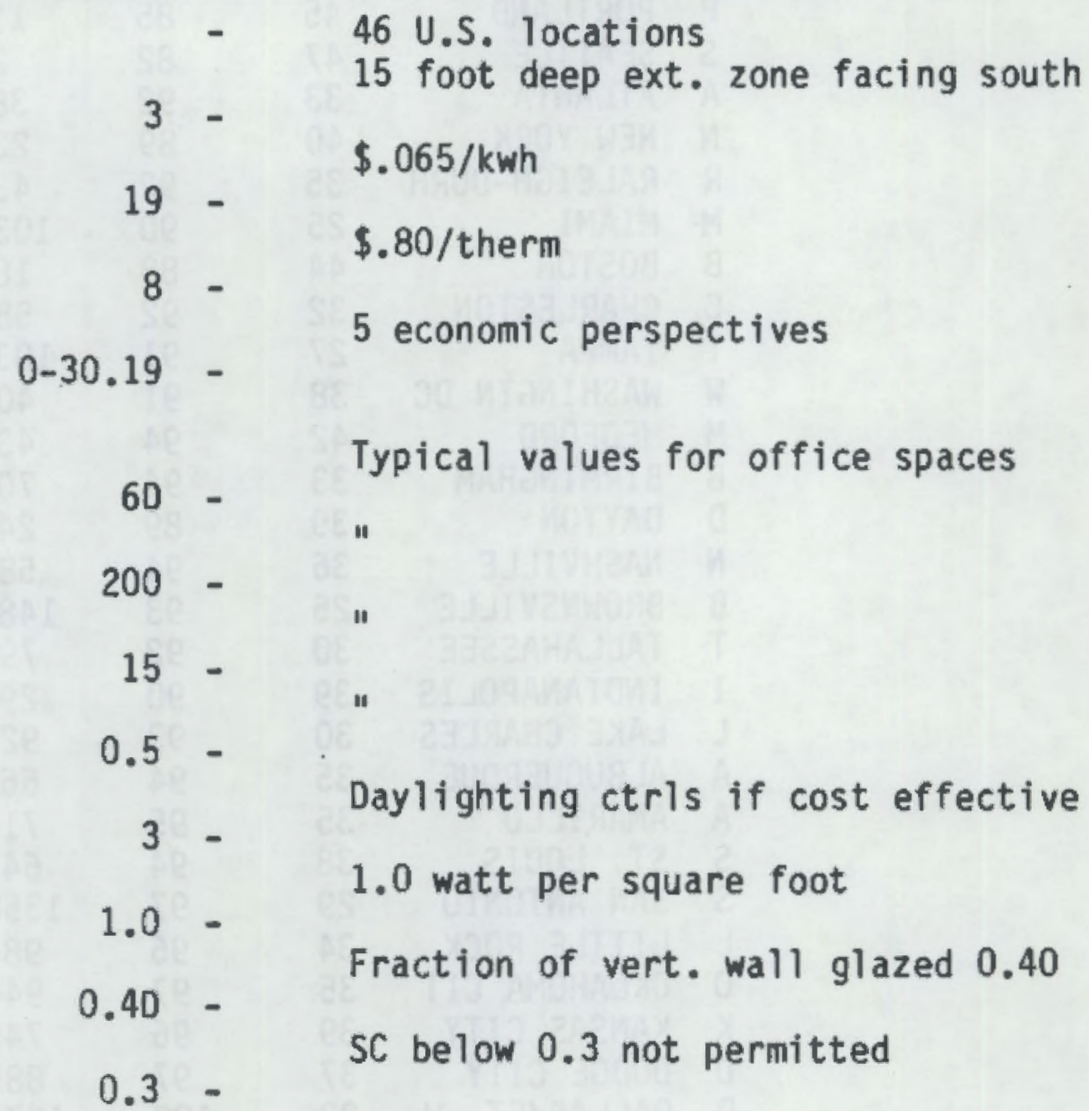

Explanation

\section{(1)}

Cost of Natural Gas

Coefficient

3 depending on economic perspective and climate. The reason for the crossing of lines in several cases is the switching from electric to gas heat.

Figure B.10 shows annual energy use (ignoring onsite conversion losses for natural gas) for the same south-facing office space. Ignoring onsite conversion losses for fossil fuels is one of the approaches that has been investigated for use in dealing with different energy sources. The bottom line of this graph, annual energy use ignoring conversion losses for the societal optimum configurations, is the basis that was used in sorting the locations for Figures B.9 through B.15, which explains the smoothness of the line. The variability in energy use between climates is somewhat reduced when energy use is measured downstream of the onsite fossil fuel conversion losses. 
TABLE B.2. Location Key for Summary Graphs

\begin{tabular}{|c|c|c|c|c|c|c|}
\hline & EV.LOCATION & Lat & DT2.5 & $\mathrm{CDH} 80$ & $\operatorname{CDD} 65$ & HDD65 \\
\hline L & LOS ANGELES & 33 & 80 & 645 & 510 & 1969 \\
\hline$p$ & PORTLAND & 45 & 85 & 1164 & 452 & 4879 \\
\hline$S$ & SEATTLE & 47 & 82 & 276 & 242 & 5529 \\
\hline A & ATLANTA & 33 & 92 & 3868 & 1601 & 3215 \\
\hline N & NEW YORK & 40 & 89 & 2337 & 1076 & 5029 \\
\hline R & RALEIGH-DURH & 35 & 92 & 4393 & 1507 & 3778 \\
\hline M & MIAMI & 25 & 90 & 10388 & 4011 & 283 \\
\hline 3 & BOSTON & 44 & 88 & 1842 & 772 & 5874 \\
\hline c & CHARLESTON & 32 & 92 & 5830 & 2075 & 2414 \\
\hline $\mathrm{T}$ & TAMPA & 27 & 91 & 10301 & 3145 & 884 \\
\hline W & WASHINGTN DC & 38 & 91 & 4054 & 1494 & 4410 \\
\hline M & MEDFORD & 42 & 94 & 4389 & 918 & 5523 \\
\hline 8 & BIRMINGHAM & 33 & 94 & 7064 & 1950 & 2941 \\
\hline D & DAYTON & 39 & 89 & 2458 & 1073 & 5803 \\
\hline N & NASHV ILLE & 36 & 94 & 5848 & 1729 & 3858 \\
\hline 8 & BROWNSVILLE & 25 & 93 & 14812 & 3687 & 728 \\
\hline $\mathrm{T}$ & TALLAHASSEE & 30 & 92 & 7984 & 2506 & 1760 \\
\hline I & INDIANAPOL IS & 39 & 90 & 2957 & 1133 & 5831 \\
\hline L & LAKE CHARLES & 30 & 93 & 9272 & 2686 & 1718 \\
\hline A & ALBUQUERQUE & 35 & 94 & 6690 & 1546 & 4618 \\
\hline A & AMARILLO & 35 & 95 & 7108 & 1611 & 4648 \\
\hline s & ST. LOUIS & 38 & 94 & 6438 & 1544 & 5090 \\
\hline S & SAN ANTONIO & 29 & 97 & 13585 & 2913 & 1805 \\
\hline L & LITTLE ROCK & 34 & 96 & 9855 & 2165 & 3420 \\
\hline 0 & OKLAHOMA CIT & 35 & 97 & 9449 & 2019 & 4036 \\
\hline $\mathrm{k}$ & KANSAS CITY & 39 & 96 & 7455 & 1775 & 5007 \\
\hline 0 & DODGE CITY & 37 & 97 & 8857 & 1616 & 5484 \\
\hline & DALLAS/FT. W & 32 & 100 & 13743 & 2649 & 2604 \\
\hline E & EL PASO & 31 & 98 & 12590 & 2429 & 2867 \\
\hline & PHOENIX & 33 & 107 & 34492 & 4044 & 1672 \\
\hline & PITTSBURGH & 40 & 86 & 1547 & 782 & 6174 \\
\hline & LAS VEGAS & 36 & 106 & 25725 & 3192 & 2795 \\
\hline & CLEVELAND & 41 & 88 & 1.873 & 822 & 6312 \\
\hline & DETROIT & 42 & 88 & 1.278 & 743 & 6730 \\
\hline P & PORTLAND MN & 43 & 84 & 773 & 468 & 7540 \\
\hline B & BOISE & 43 & 94 & 4742 & 1009 & 6185 \\
\hline & DENVER & 39 & 91 & 3808 & 972 & 6411 \\
\hline c & CHICAGO & 41 & 91 & 3442 & 1104 & 6331 \\
\hline c & CHEYENNE & 41 & 86 & 1498 & 574 & 7612 \\
\hline j & DES MOINES & 41 & 91 & 3140 & 1078 & 6724 \\
\hline & OMAHA & 41 & 91 & 4911 & 1310 & 6276 \\
\hline$S$ & SALT LAKE CT & 40 & 95 & 7048 & 1293 & 6137 \\
\hline & MADISON & 43 & 88 & 985 & 677 & 7826 \\
\hline & GREAT FALLS & 47 & 88 & 1486 & 578 & 7989 \\
\hline & MINNEAPOL IS & 44 & 89 & 2520 & 885 & 8134 \\
\hline & BISMARK & 46 & 91 & 2718 & 751 & 9283 \\
\hline
\end{tabular}




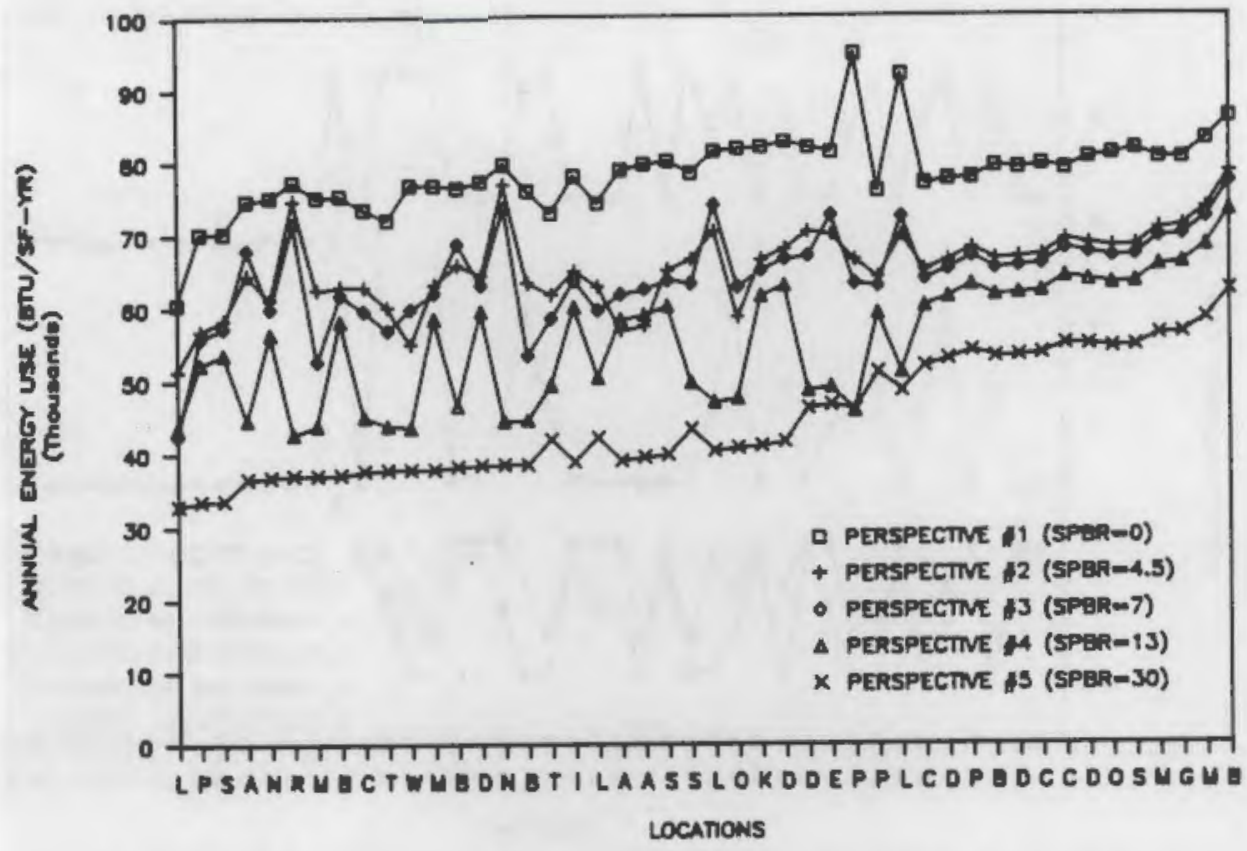

FIGURE B.9. Annual Energy Use at 46 WYEC Locations

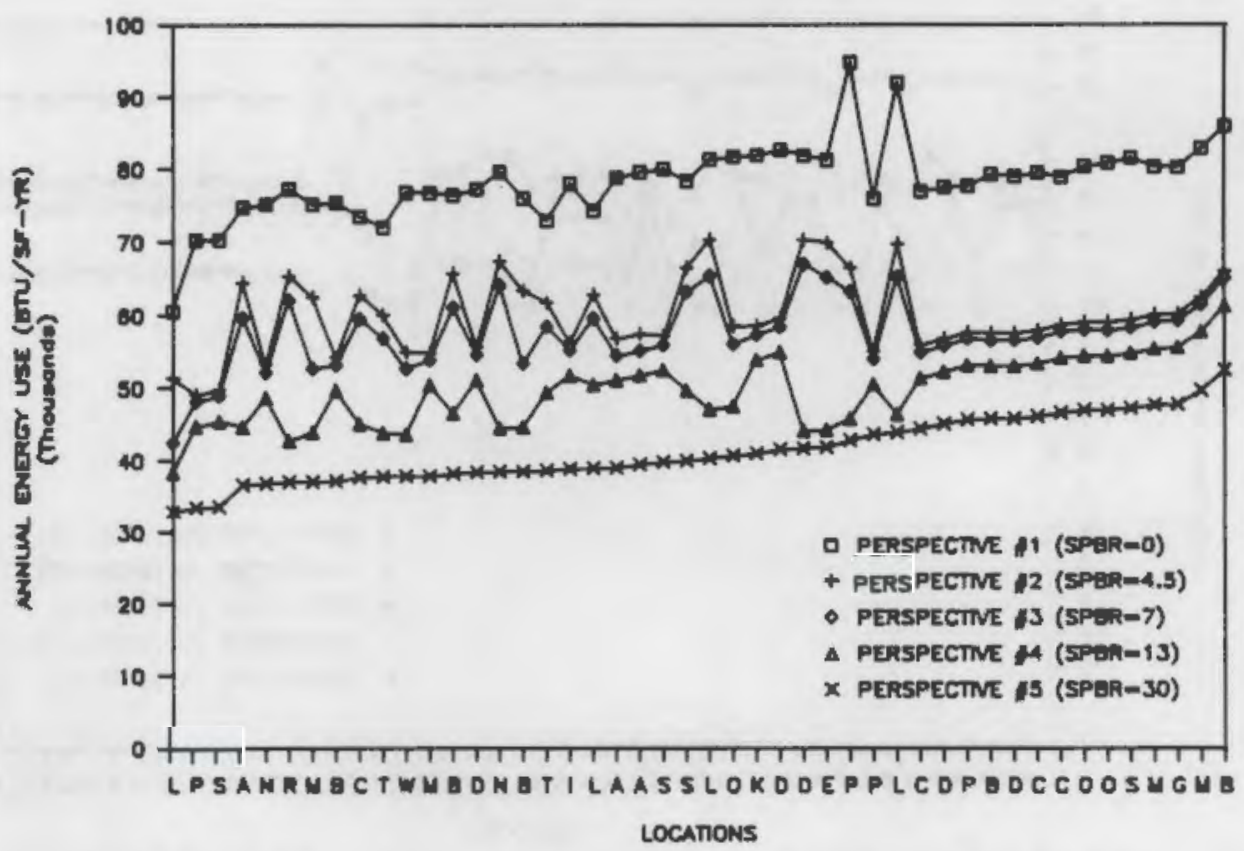

FIGURE B.10. Annual Energy Use Ignoring Conversion Losses at 46 WYEC Locations 


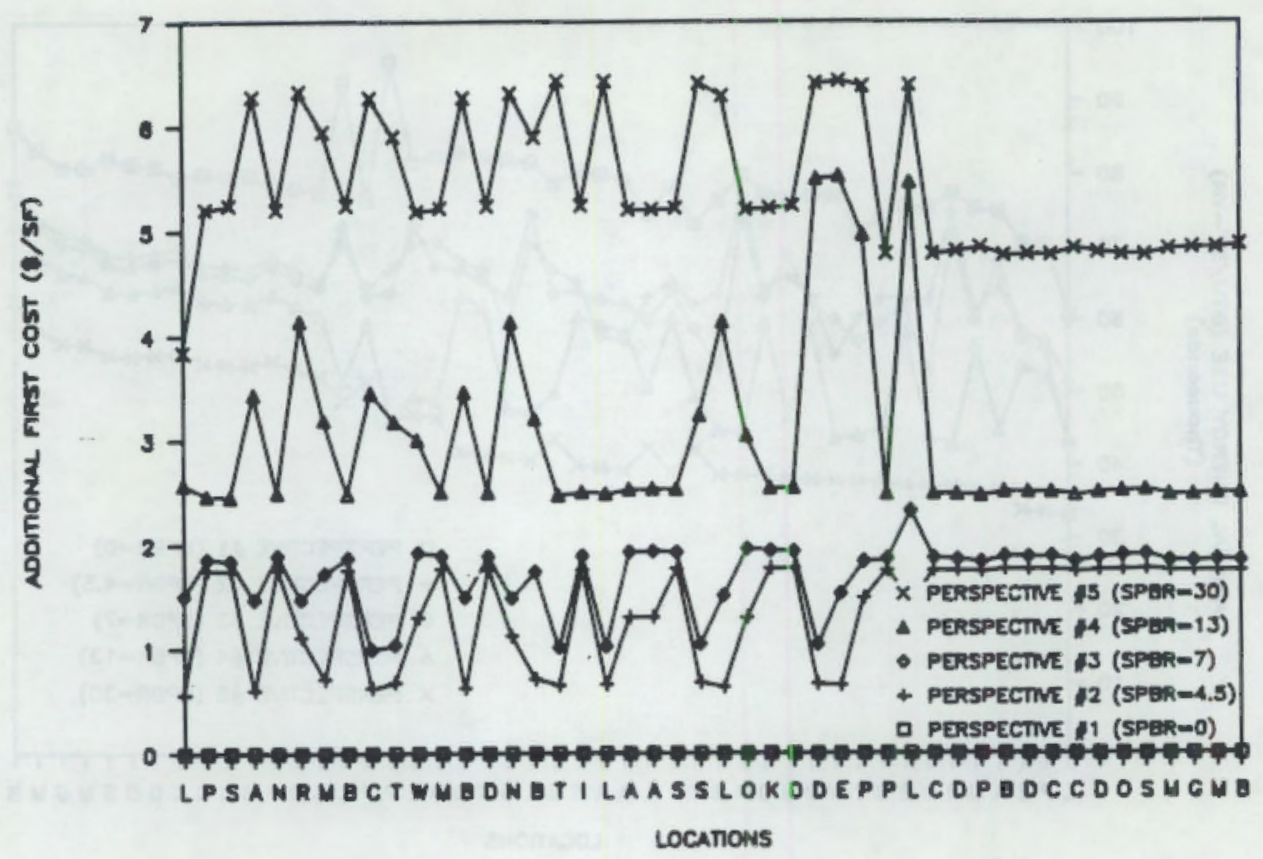

FIGURE B.11. Additional First Cost at 46 WYEC Locations

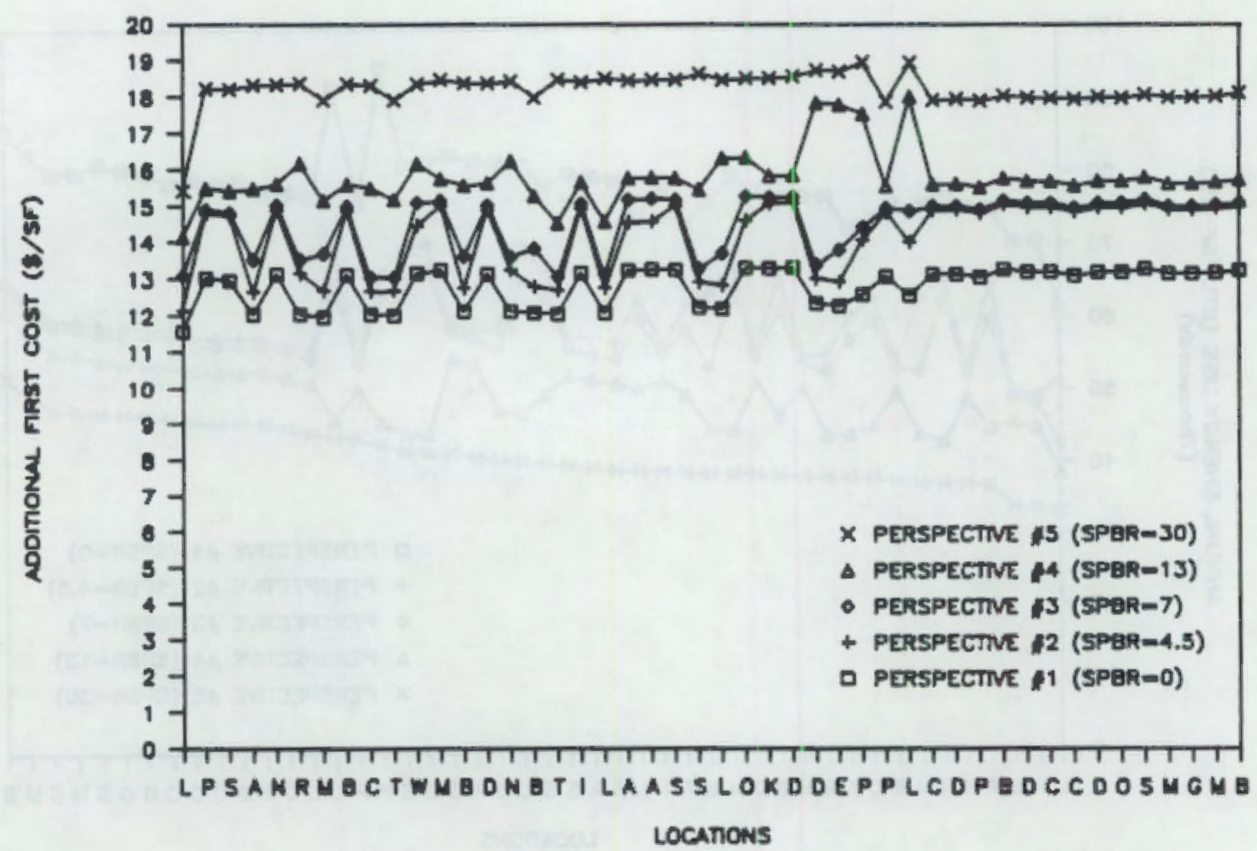

FIGURE B.12. First Cost of Energy-Related Features at 46 WYEC Locations 


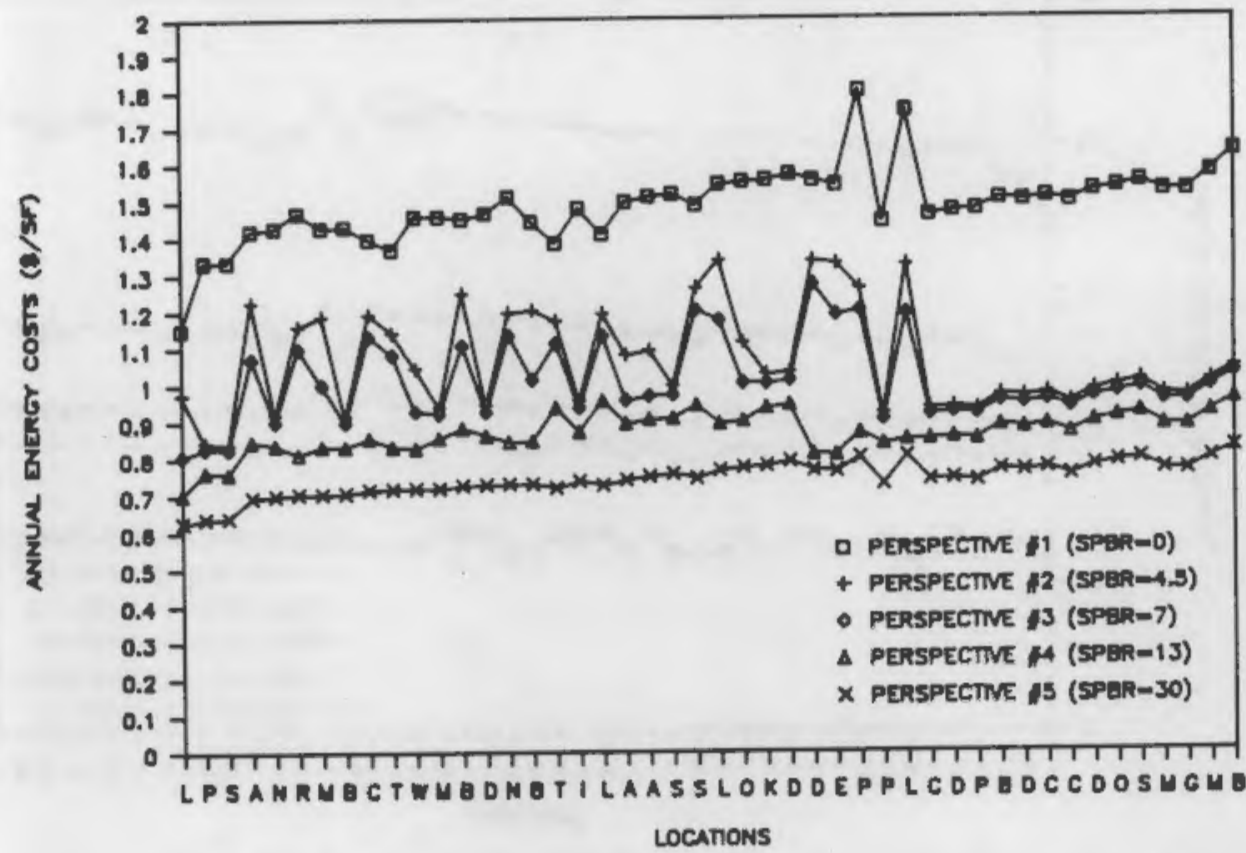

FIGURE B.13. Annual Enery Costs at 46 WYEC Locations

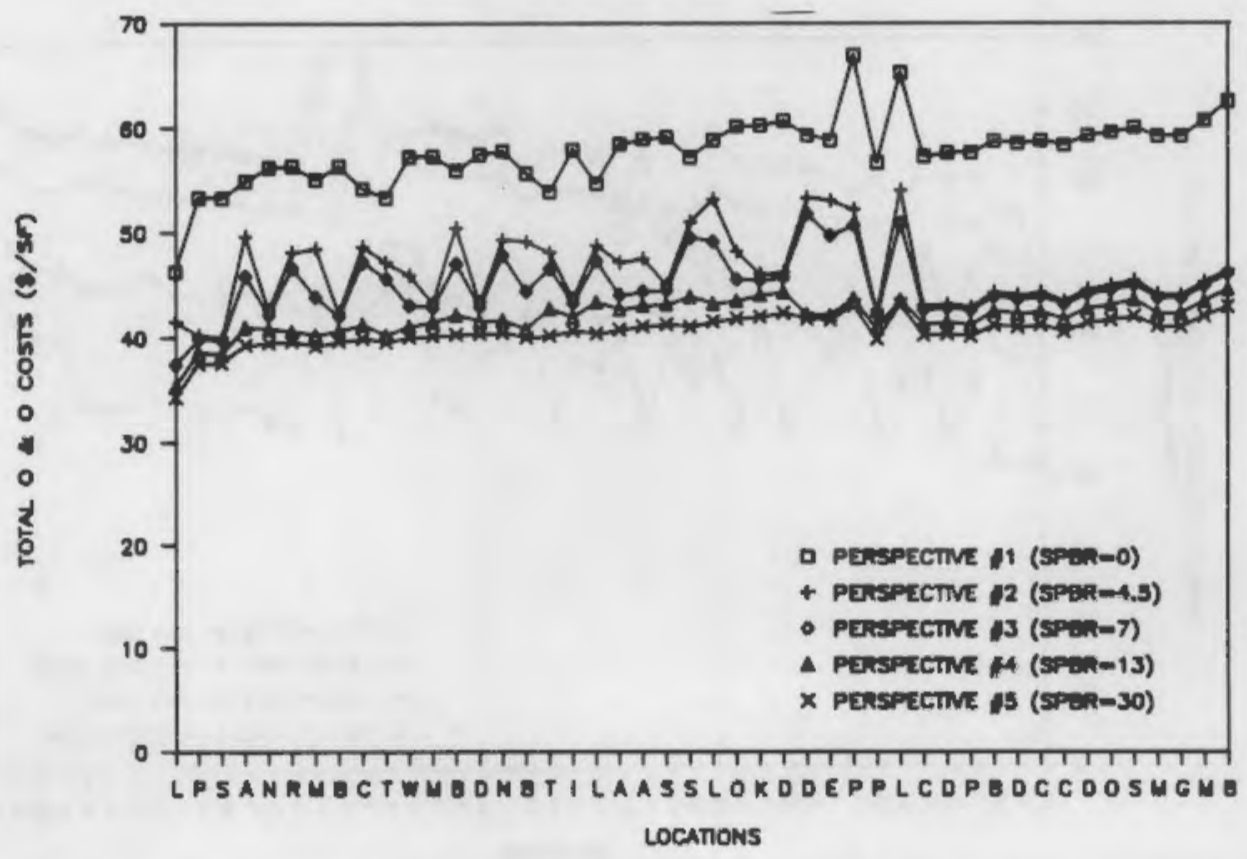

FIGURE B.14. Total Owning and Operating Costs (Societal) at 46 WYEC Locations 


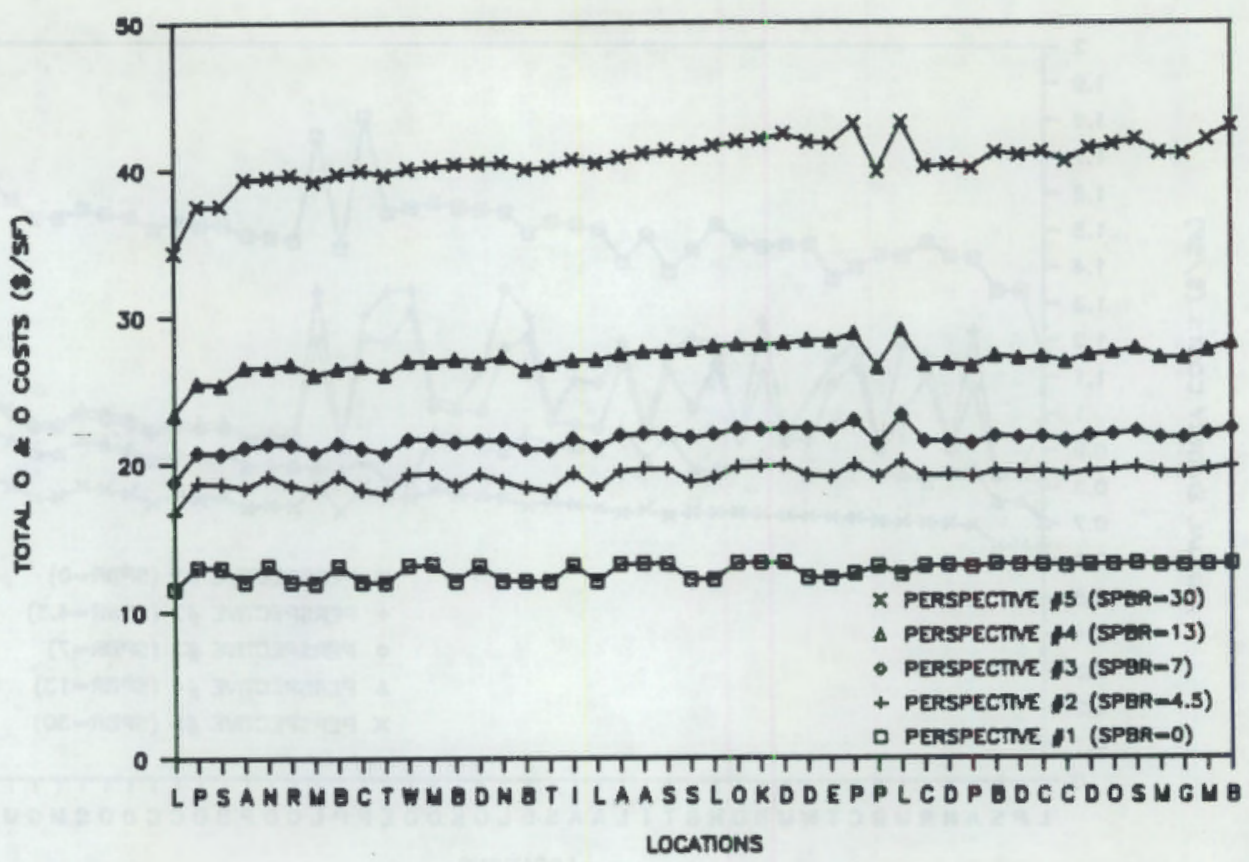

FIGURE B.15. Total 0wning and 0perating Costs (Perspectives 1 through 5) at 46 WYEC Locations

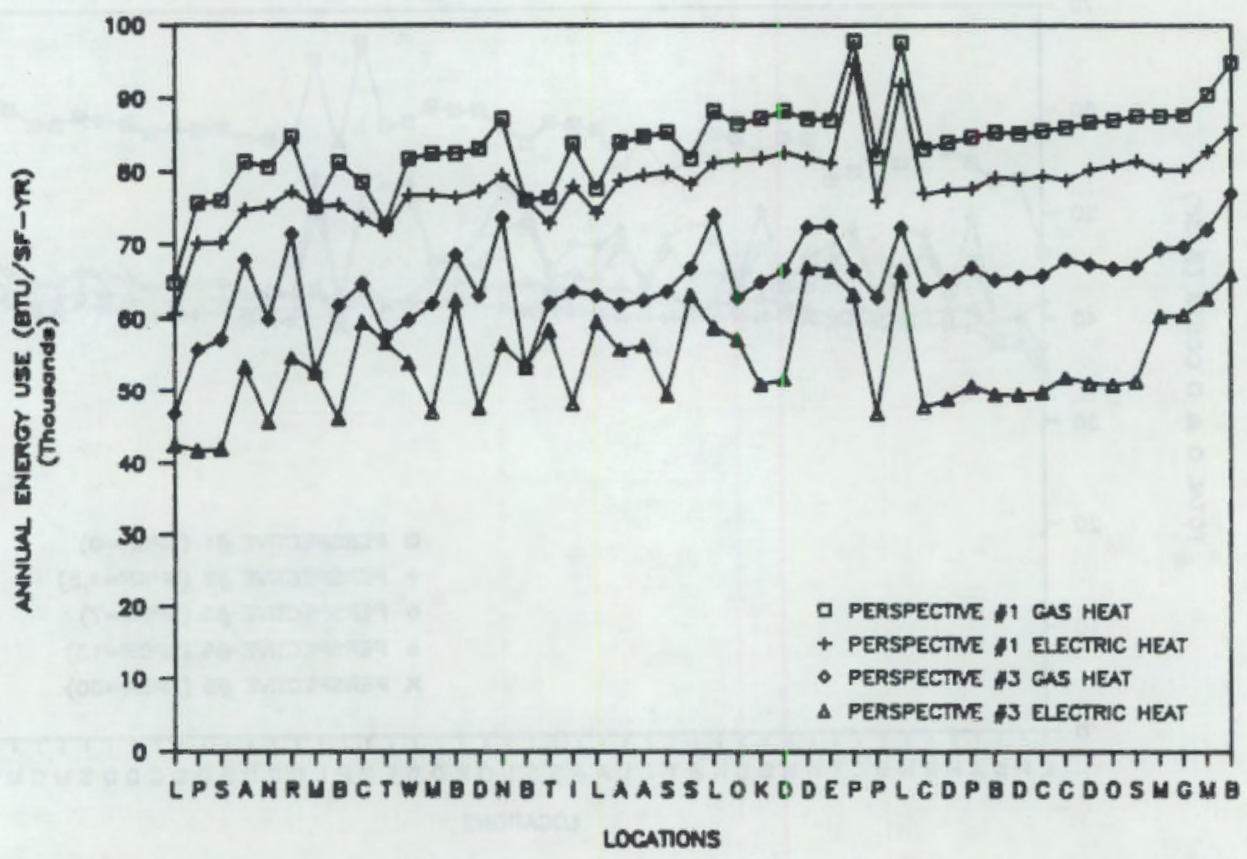

FIGURE B.16. Annual Energy Use at 46 WYEC Locations 
Figure B.11 shows the additional first costs for energy-related features which were necessary to achieve the energy performance levels that are shown in the previous two graphs. The additional first cost is defined as the firstcost increment above the first cost for Perspective \#1 for that particular location. Perspective "1 minimizes the first cost of the space function and incorporates any energy-conserving measures that reduce space function first costs resulting from mechanical system down sizing.

The variability in additional first cost for the different locations reflects the fact that different space-function features are adopted at different points in different locations. Minimum total owning and operating costs (TOOC) are the criteria that the procedure uses to select features. The procedure freely trades first costs against energy cost savings, and this fact accounts for some of the variation between locations that is observed for both energy use and first costs. For example, the peak that occurs in the Perspective \#4 line in Figure 8.11 , additional first cost for Dallas/Fort Worth, El Paso, and Phoenix, corresponds with a trough in Figures B.9, B.1D, and B.13, annual energy use and costs, for the same perspective and locations. This feature of trading first costs against energy costs has significant implications for the design of the Targets Model and for the selection of a suitable metric of energy performance to be used for the project. Targets defined on the basis of TOOC but expressed in terms of an energy use metric $\left[\mathrm{Btu} /\left(\mathrm{yr} \cdot \mathrm{ft}^{2}\right)\right]$, for example, would exhibit undesirable discontinuities.

Figure B.12 shows the first cost for energy-related features for the 46 WYEC locations and the 5 economic perspectives. This graph differs only slightly from the previous one in that it reflects the costs of energy-related features and not just the added costs. The absolute value of the costs are not particularly meaningful, given the complexity and subjectiveness of the definition of building costs that are energy-related. Vertical variations in the lowest line (Perspective $\# 1$ ) reflect energy code requirements. The relative uniformity of the top line (Perspective reflects. that under the societal optimum many of the most costly options (e.g. high-performance glazing) have been implemented in almost all locations. Vertical variations for intermediate 
perspectives reflect the different points at which measures become cost effective in different locations. In virtually all cases, Los Angeles (located on the $y$-axis) shows significantly lower costs than other locations, reflecting the effect of that temperate climate.

Figure B.13 shows the annual energy costs for the south-facing office space. This graph is similar in appearance to the annual energy-use graphs, although the percentage reductions between perspectives for annual energy costs are generally larger than those for annual energy use.

Figure B.14 shows the TOOC from a societal perspective for the southfacing office when configured optimally based on each of the 5 different economic perspectives for the 46 locations. Absolute values of the numbers are not particularly meaningful because of the subjective definition of the energyrelated first cost component for the proof-of-concept model. The graph does illustrate that beyond a certain point significant diminishing returns may be encountered in investments in energy efficiency even when viewed form a societal perspective.

Figure B.15 shows the TOOC for each of the five levels of performance when each is based on its respective perspective. This is the parameter that the spreadsheet is designed to minimize as it executes.

From a macroeconomic perspective, this parameter would constitute the ideal metric to use for the targets. By using TOOC as the decision criterion and as the compliance metric, the targets would be defined at levels achievable when all energy-related technologies are implemented in all buildings and in all locations using the same economic criteria. The sets of building features used to define target levels would be equally productive at the margin for all buildings. This would mean that no rearrangement or reallocation of how money was spent on energy conservation could produce more energy savings, or similarly that the resulting conservation could not be achieved at lower cost. Such a solution would minimize the total collective burden of the target guidelines on those who would use them and would give the targets a strong claim to neutrality and even-handedness in their treatment of different segments of the buildings industry. 
The lines in Figure B.15 are among the most uniform of the graphs that have been displayed. This lack of range and variation reflects the fact that this parameter is a smooth and continuous function of all of the defining space characteristics that are continuous. The variation that does exist reflects the fact that when available building technologies are optimally applied to the same space in a variety of climates, some variation in TOOC will result. Consistent and predictable results would be the expected consequence of using this parameter as the targets metric.

A comparison of Figures B.9 and B.10 illustrate certain facets of the important issue of treatment of different energy sources. The portions of the bottom line in Figure B.9 that are higher than the bottom line in Figure B.10 reflect onsite conversion losses, which are necessarily higher for fossil fuels than for electricity. A higher target is needed where natural gas is used as the heating source. Using the same target for different fuel types while measuring compliance downstream of the conversion losses (similar to Figure B.10) would lessen the inefficiency and inequity. Yet such an approach would still create distortions and inefficiency from an economic perspective because it would ignore the changes that an efficient design solution would undergo as a result of the change in energy source. The common use of higher insulation levels in electrically heated buildings is an example of this type of change. Establishing a target conversion factor based on energy costs would create a similar problem.

From an economic point of view, a desirable solution would be to generate custom targets that were intended for use with specific heating fuels. Figure B.16 illustrates the annual energy use results that were generated from the model when natural gas or electricity were specified as the mandatory heating fuels for Perspectives \#1 and \#3 for the 46 WYEC locations. The two pairs of lines reflect the kind of relationships that would be expected if an energy use metric and energy-source-specific targets were used. Note that the targets would be almost identical in hot climates where almost no heating is required. 


\section{B.4 USING THE SPREADSHEET}

The proof-of-concept model uses Lotus 1-2-3, Release 1A. The spreadsheet has been developed on an IBM-PC with 512K of RAM. It is not known whether it will work on computers having less memory than this. To use the software:

Load Lotus 1-2-3. (123 Return).

Load the spreadsheet (/FR Return).

The help screen can be accessed by typing: Goto(F5) H Return. Calc(F9) will recalculate the spreadsheet based on the values in the highlighted cells. To view the screens containing the highlighted, user-input cells type Home, PgDn, and GoTo(F5) T Return. Some users may wish to alter certain cells containing building system costs, equipment performance coefficients, and economic assumptions. These cells are located in the tables on the left-hand side of the spreadsheet. Cells that will likely accept user input without dire consequences have been highlighted.

Figure B.17 shows the Home screen of the spreadsheet. The values in the highlighted cells, here shown underlined, can be changed by the user. In the proof-of-concept model, the cells that a user will normal alter are divided into two groups called defining characteristics and generated characteristics. The first group includes those characteristics that are either defined by the nature of the building project or that have such important design implications that they can not reasonably be defined on an economic basis. The generated characteristics are characteristics that, within limits, can be defined on an economic basis either because they are transparent to the user or because all possible solutions within the allowable range are assumed to be equally acceptable to the user.

The column entitled TARGET GENERATION contains the active cells whose values are actually used in the calculations. The column entitled STORED VALUES stores the input values and results of calculations for purposes of comparison. Cells containing dashes are currently not used and have been reserved for additional defining characteristics that could be added in later versions. 


\section{Defining Characteristics(a) TARGET GENERATION STORED VALUES}

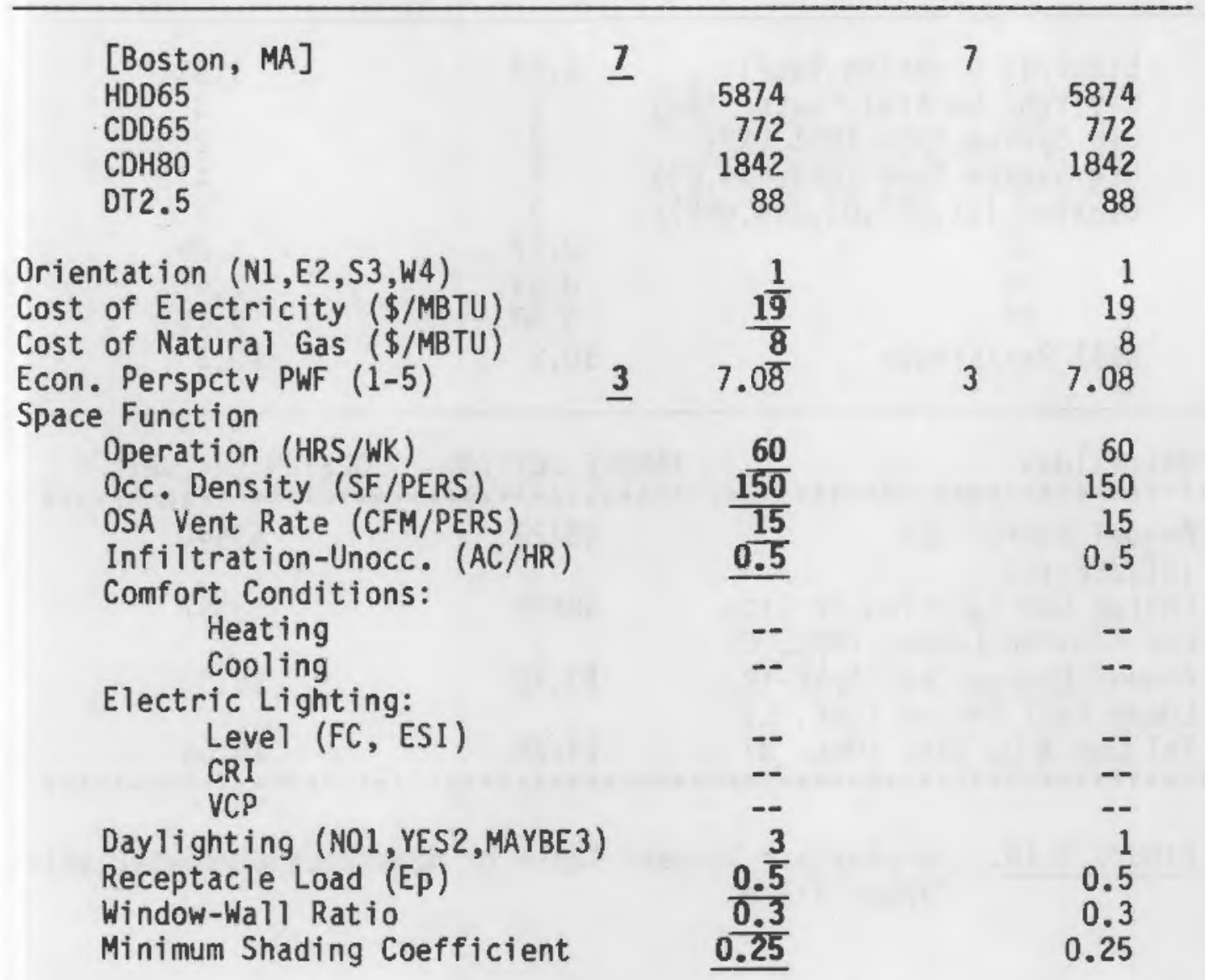

(a) Characteristics followed by a dash were not used as input in the proof-of-concept model but are proposed as input for the final procedure.

FIGURE B.17. Home Screen of the Proof-of-Concept Spreadsheet

Figure B.18 shows the spreadsheet screen that reports the results of the optimizations and recalculations. Generated characteristics and the energy use and costs associated with them are displayed. This screen is accessed by entering GoTo (F5) 0 .

Figure B.19 shows the screen where values for generated characteristics can be entered in order to calculate the performance of a user defined configuration. Values may be entered into the highlighted cells (here underlined). 
GENERATED CHARACTER I S T I C S

$\begin{array}{ccc}\text { Electric Lighting (WSF): } & 2.64 & 1.99 \\ \text { Daylight Control Factor (Rc) } & 1 & 0 \\ \text { Clg System Type (CH1, DX2) } & 2 & 2 \\ \text { Htg System Type (HP3,GB4,E5) } & 4 & 4 \\ \text { Glazing (S1,SR2, D3,DR4,HP5): } & 3 & 4 \\ \text { SC } & 0.57 & 0.25 \\ \text { UG } & 0.53 & 0.47 \\ \text { VT } & 0.50 & 0.15 \\ \text { Wall Resistance } & 10.2 & 10.3\end{array}$

Target Values

TARGET SETTING DESIGN EVALUATION

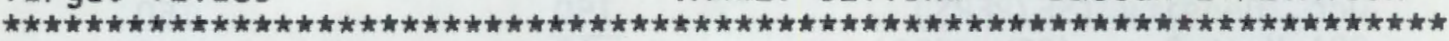

- Annual Energy Use

59123

63640

(BTU/SF-YR)

- Energy Use Ignoring On Site

Fos Convrsn Losses (Opt. C)

48580

53957

- Annual Energy Cost (\$/SF-YR)

Local Fuel Prices (Opt. L)

- Ttl Own \& Op Csts (Opt. N)

$\$ 0.78 \quad \$ 0.90$

FIGURE B.1B. Spreadsheet Screen: Table of Generated Characteristics and Target Values

This screen is accessed by entering GoTo (F5) T. Note that for automatic daylighting controls $2=Y e s$ and $1=$ No, whereas in the Generated Characteristics Table $1=$ Yes and $0=\mathrm{NO}$.

Figure B.20 shows the help screen that is available on the spreadsheet for user reference. Press the Goto (F9), $\mathbf{H}$, and Return keys to access this Help screen. 


\section{SEED:}

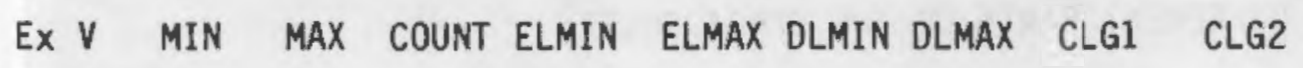

\begin{tabular}{llccccccccc}
\hline E Ltg & 2.64 & 2.64 & 3.00 & & 3.00 & 3.00 & 2.64 & 3.00 & 3.00 & 2.64 \\
D Ltg & 2 & 1 & 22 & 1 & 2 & 1 & 1 & 1 & 2 & \\
C Sys & 2 & 2 & 12 & 2 & 2 & 2 & 2 & 2 & 2 & \\
H Sys & 4 & 4 & 25 & 5 & 5 & 5 & 5 & 5 & 5 & \\
G Typ & 3 & 3 & 24 & 4 & 4 & 4 & 4 & 4 & 4 & \\
Shd C & 0.57 & 0.57 & 0.83 & & 0.57 & 0.83 & 0.57 & 0.83 & 0.83 & 0.57 \\
R-wa1110.2 & 10.2 & 12.7 & & 12.7 & 10.2 & 10.2 & 12.7 & 12.7 & 10.2
\end{tabular}

T.080 19.25

19.25

FIGURE B.19. Screen: Macro Optimization Table

HELP SCREEN

["GOTO H" WILL ACCESS THIS HELP SCREEN

ANY TIME THE READY PROMPT IS DISPLAYED]

TO USE SPREADSHEET:

F9 (Calc) Recalculates spreadsheet based on the values that have been entered in cells E8, E17, G14 thru G16, G19 thru G33, and 085 thru 091.

Alt M Performs an optimization on the parameters in cells 085 thru 091. Allow 15 minutes to an hour for completion.

Ctrl Break, Esc Interrupts macro execution.

Alt L.

Alt Z

Saves the values currently in Column $\mathrm{G}$ in Column $\mathrm{J}$. Generates a summary table of annual values based on the economic perspectives specified in AB146..AB150 and the locations in AC146..AC200. The location having the highest number must be listed last. The macro will clear values currently in the table. FIGURE B.20. Help Screen from Spreadsheet Program 
TO VIEW DIFFERENT PARTS OF THE SPREADSHEET:

These screens are used to define which options the optimization will consider and to trace the decisions made by the program. These screens are erased whenever an Alt M or Alt $Z$ is issued.

Home

GoTo H

GoTo 0

GoTo W

GoTo $N$

GoTo P

GoTo Q

GoTo R

GoTo T

GoTo X
List of Defining Characteristics or assumptions used. This is the Help Screen.

Table of Generated Characteristics and Target Values. List of available climates.

Option availability table.

Convergence macro calculation $10 \mathrm{~g}$.

Option elimination table

Option comparison Table.

Macro Optimization Table.

Table of target values.

TO VIEW OR RUN OPTIMIZATION MACRO SUBROUTINES:

Subroutines can be run individually in order to observe specific calculations. Execution will end with a "return without call" error after which an "Esc" must be issued.

TO VIEW: TO RUN: RANGE NAME: DESCRIPTION OF. RDUTINE OR SUBROUTINE:

\begin{tabular}{|c|c|c|c|}
\hline $\begin{array}{ll}\text { GoTo } & \text { A } \\
\text { GoTo B } \\
\text { GoTo } \\
\text { GoTo } \\
\text { GoTo } \\
\text { GoTo } \\
\text { GoTo } \\
\text { GoTo } \\
\text { GoTo J } \\
\text { GoTo } & \text { K } \\
\text { GoTo } & \text { L } \\
\text { GoTo } & M \\
\text { GOTo } & \text { S } \\
\text { GoTo U } \\
\text { GoTo } & Z\end{array}$ & 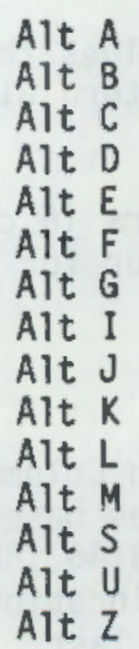 & $\begin{array}{l}\text { READOUT1 } \\
\text { READOUT2 } \\
\text { CLGE } \\
\text { DLTGE } \\
\text { ELTGO } \\
\text { ELTGL } \\
\text { GTE } \\
\text { WIO } \\
\text { WIL } \\
\text { HTGE } \\
\quad- \\
\text { SCO } \\
\text { RNOF } \\
-\end{array}$ & $\begin{array}{l}\text { Records calc. result in table } Q Q . \\
\text { Records calc. result in table } Q \text { R. } \\
\text { Attempts to eliminate clg systems. } \\
\text { Attempts to eliminate daylighting. } \\
\text { Optimizes electric lighting power. } \\
\text { Limits electric lighting power. } \\
\text { Attempts to eliminate glass types. } \\
\text { Optimizes wall insulation. } \\
\text { Limits wall insulation. } \\
\text { Attempts to eliminate htg systems. } \\
\text { Saves current values. } \\
\text { Main optimization macro. } \\
\text { Optimizes shading coefficient } \\
\text { Conducts runoff of remaining options. } \\
\text { Generates summary table. }\end{array}$ \\
\hline
\end{tabular}

FIGURE B.20. (contd) 
APPENDIX C

CASE STUDY: HOTEL ENERGY USE 


\section{APPENDIX C}

\section{CASE STUDY: HOTEL ENERGY USE}

The following conclusions have been drawn from the data presented in Figures C.1 through C.12 and are based on the preliminary analysis of 1984 energy data for over 300 hotels nationwide collected from the American Hotel and Motel Association.

- Energy use in hotels has decreased almost $30 \%$ since 1977 . The reduction from 1983 to 1984 was $8.3 \%$.

- Energy use does not differ substantially among the various regions of the country.

- The national average for hotels of all sizes is $115,000 \mathrm{Btu} /\left(\mathrm{yr} \cdot \mathrm{ft}^{2}\right)$. This number closely approximates hotels of 300 to 500 rooms. This total average is within 10\% of the averages for hotels with 150 to 300 rooms and over 500 rooms. However, the average for all hotels is over 25\% higher than the average for hotels with under 150 rooms.

- A correlation exists between total square feet and total energy use. Average energy use within $10,000-\mathrm{ft}^{2}$ intervals results in an average of $90,000 \mathrm{Btu} /\left(\mathrm{yr} \cdot \mathrm{ft}^{2}\right)$ for hotels having a total area of less than $60,000 \mathrm{ft}^{2}$ and $137,000 \mathrm{Btu} /\left(\mathrm{yr} \cdot \mathrm{ft}^{2}\right)$ for hotels having a total area of over $60,000 \mathrm{ft}^{2}$.

- The average maximum energy use for hotels is approximately 170,000 $B t u /\left(y r \cdot f t^{2}\right)$, while the average minimum energy use is approximately $80,000 \mathrm{Btu} /\left(\mathrm{yr} \cdot \mathrm{ft}^{2}\right)$.

- A correlation exists between total number of rooms and total energy use. Average energy use within 10-room intervals results in an average of $90,000 \mathrm{Btu} /\left(\mathrm{yr} \cdot \mathrm{ft}^{2}\right)$ for hotels with under 150 total rooms and $137,000 \mathrm{Btu} /\left(\mathrm{yr} \cdot \mathrm{ft}^{2}\right)$ for hotels over 150 rooms.

- A direct correlation exists between hotel total area and number of rooms. 


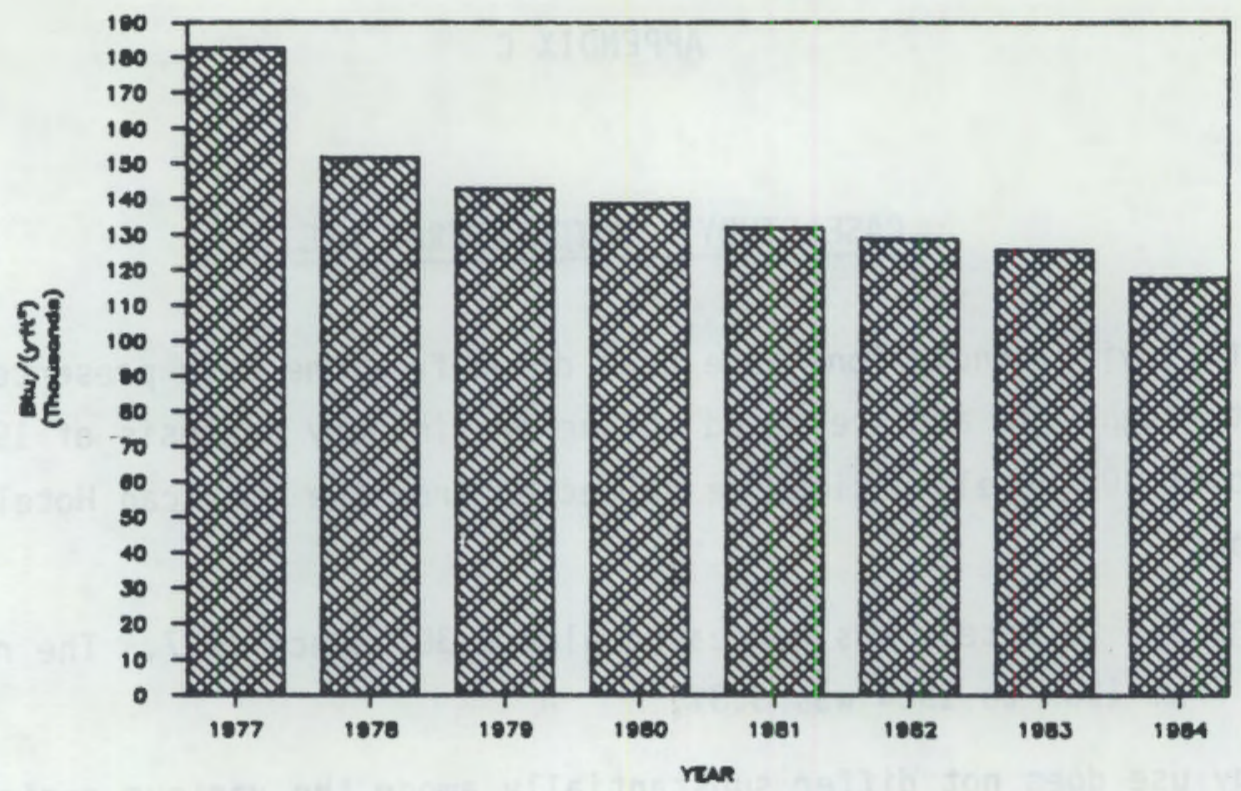

FIGURE C.1. Hotel Energy Use by Year

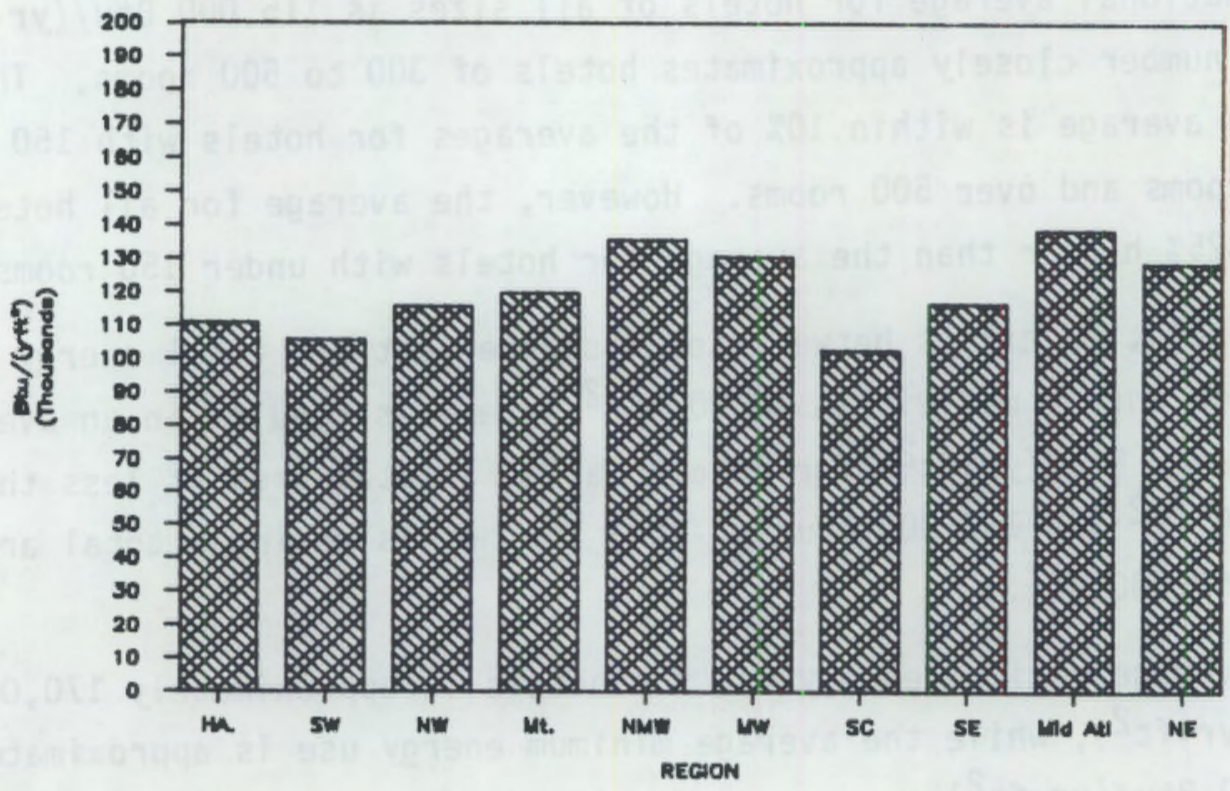

FIGURE C.2. Hotel Energy Use by Region in 1984 


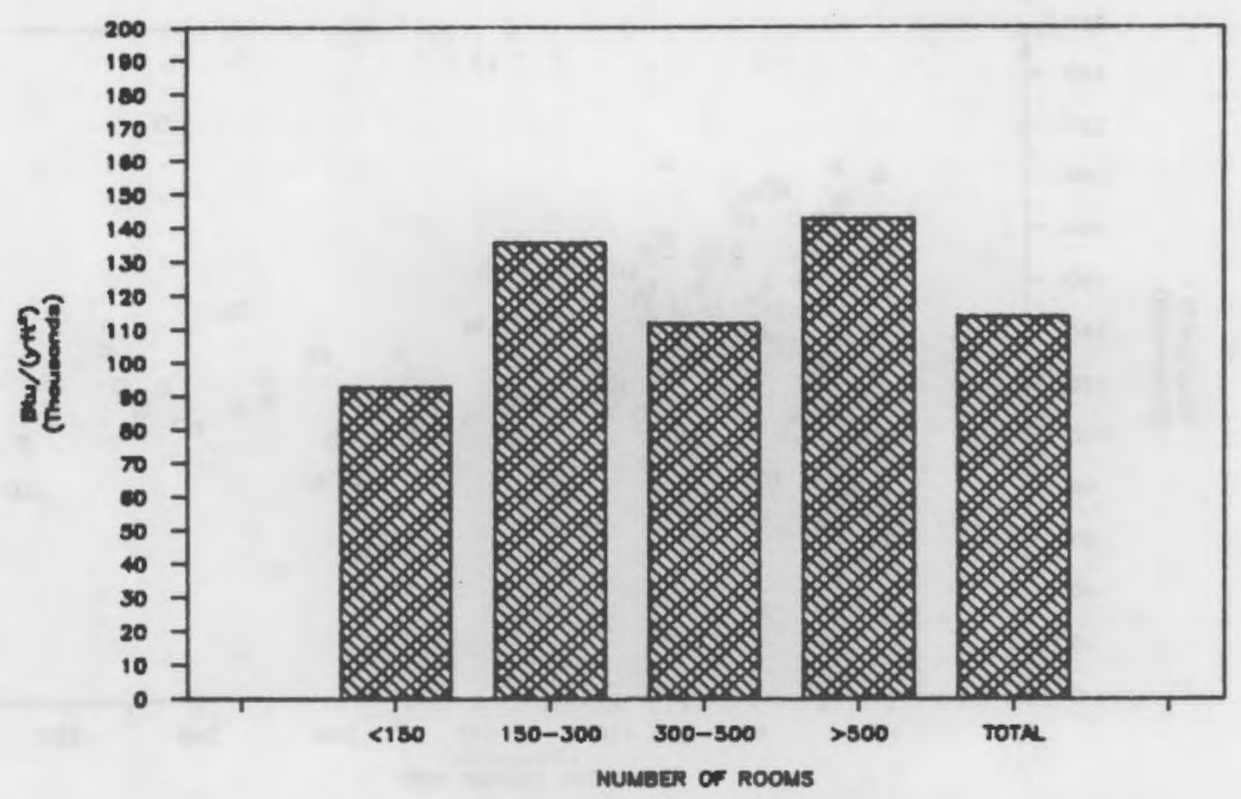

FIGURE C.3. Hotel Energy Use Versus Number of Rooms

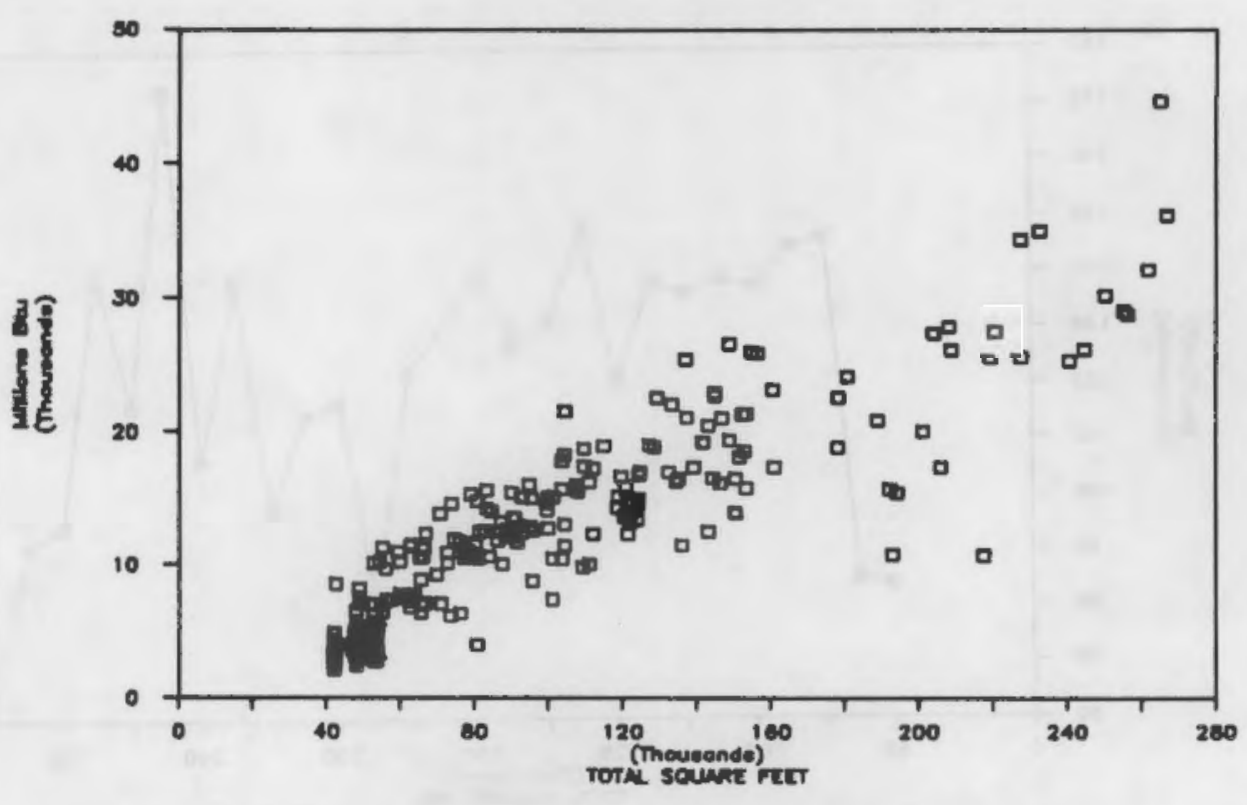

FIGURE C.4. Total Square Feet Versus Energy Use 


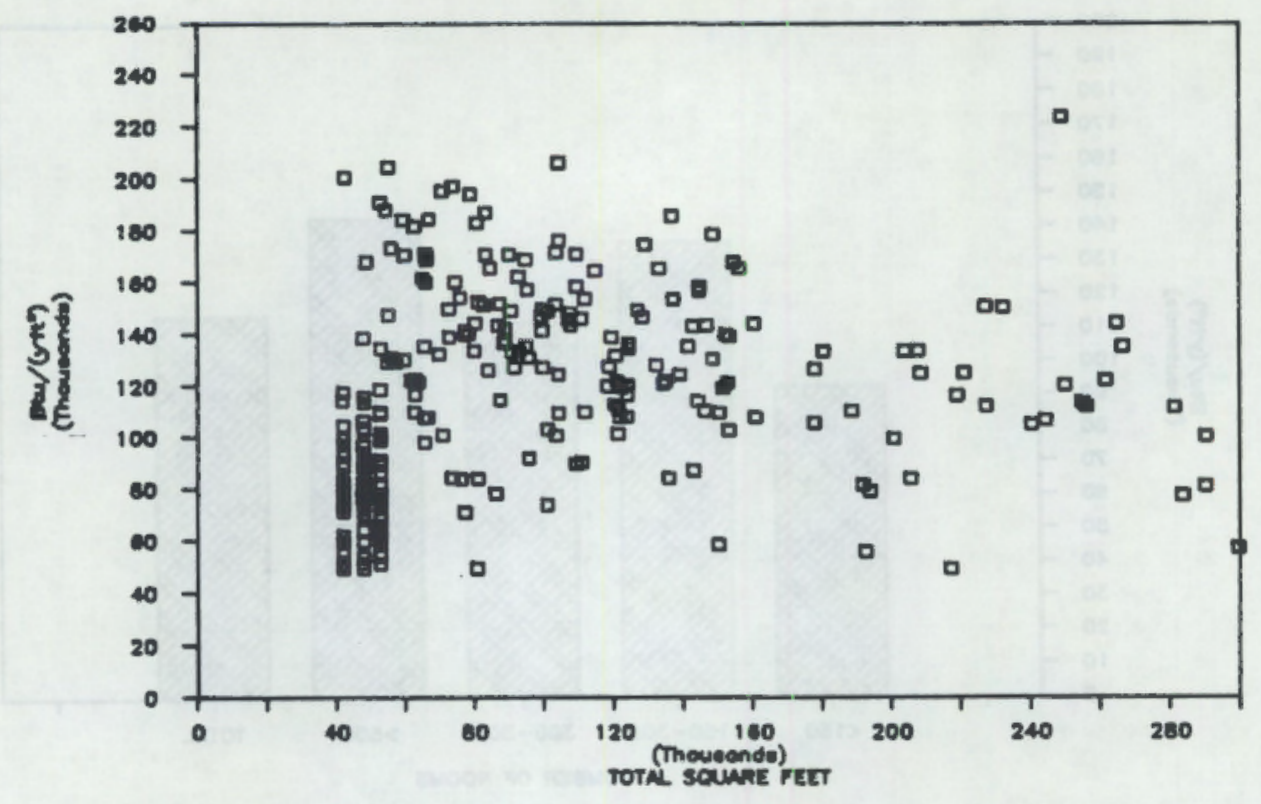

FIGURE C.5. Total Energy Use Versus Area

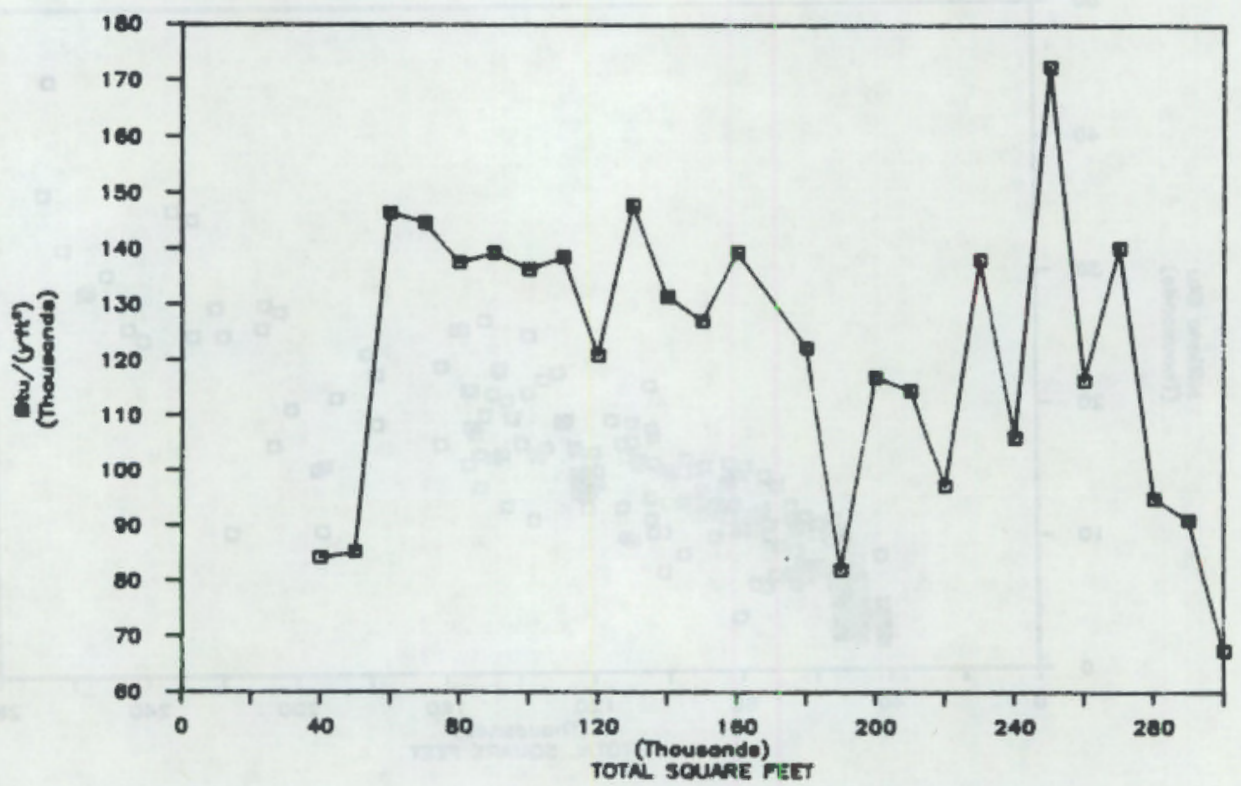

FIGURE C.6. Average Energy Use at $10,000-\mathrm{ft}^{2}$ Intervals 


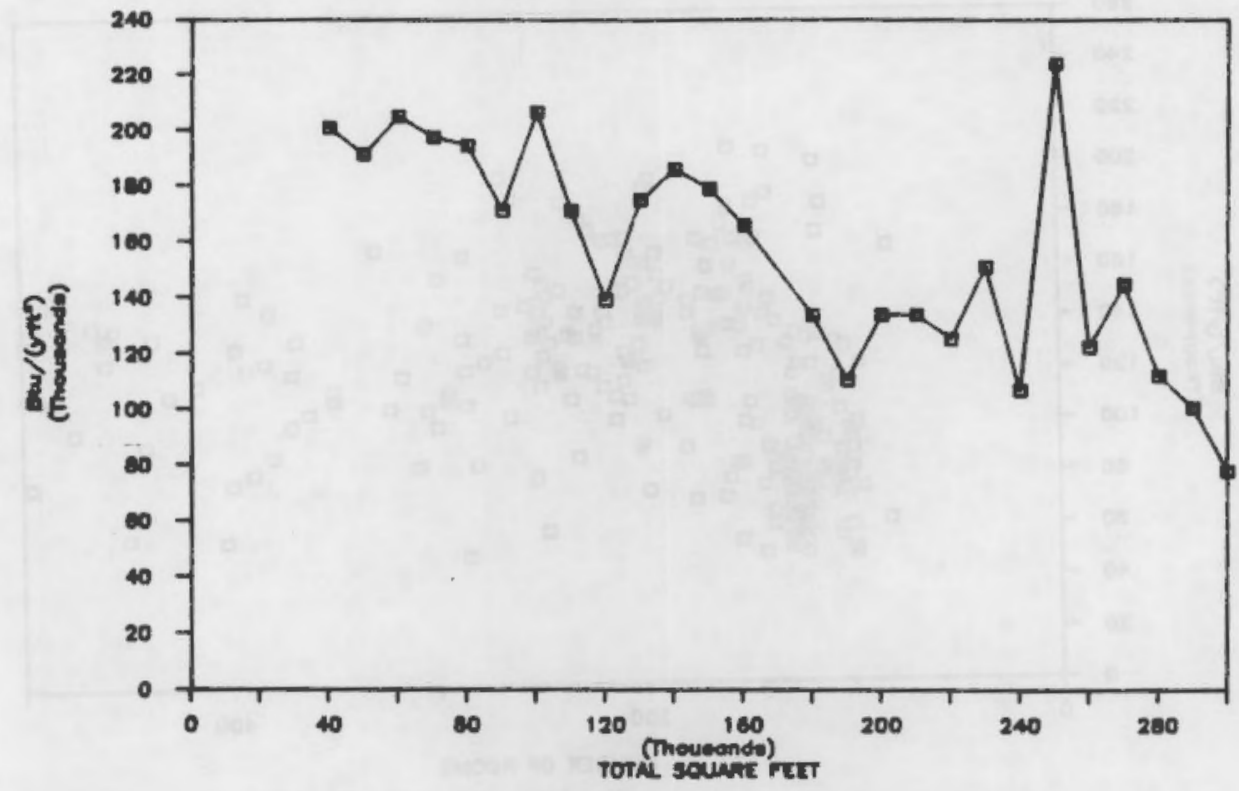

FIGURE C.7. Maximum Energy Use in Hotels

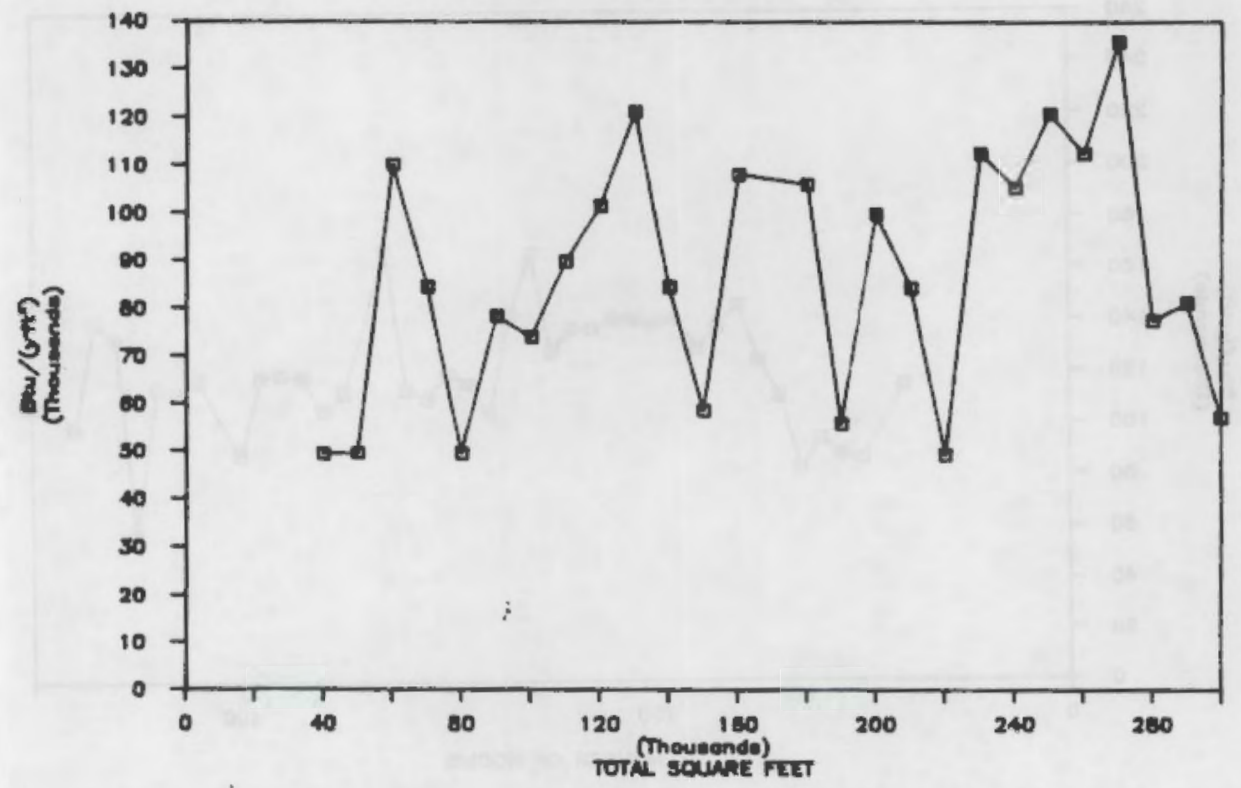

FIGURE C.8. Minimum Energy Use for Hotels 


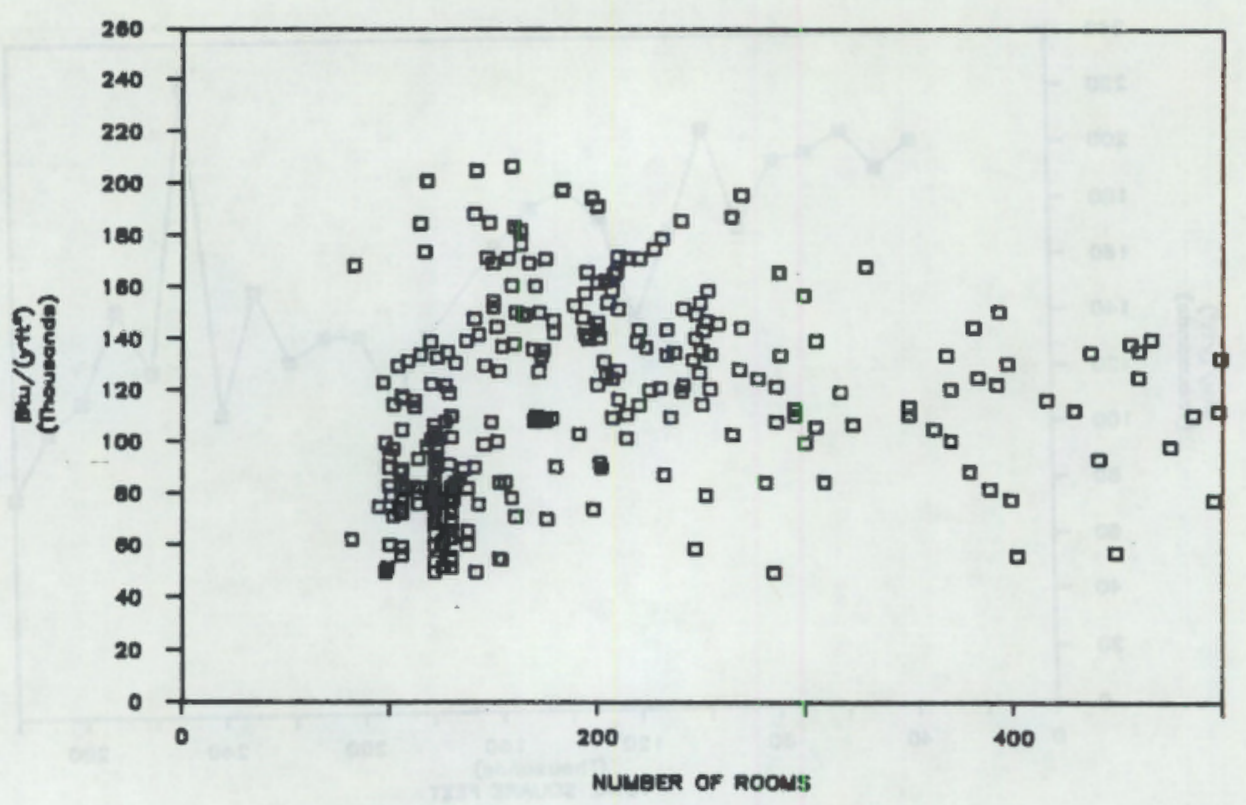

FIGURE C.9. Number of Rooms Versus Energy Use

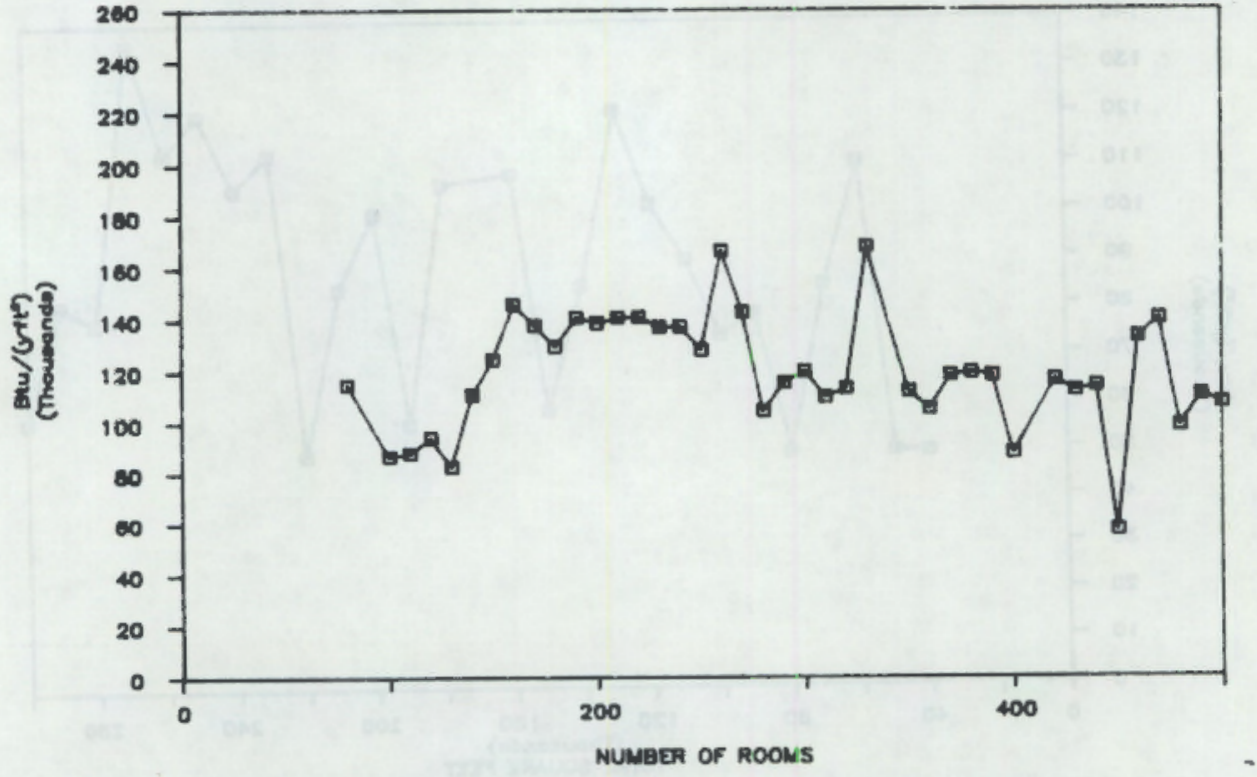

FIGURE C.10. Average Energy Use at 10-Room Intervals 


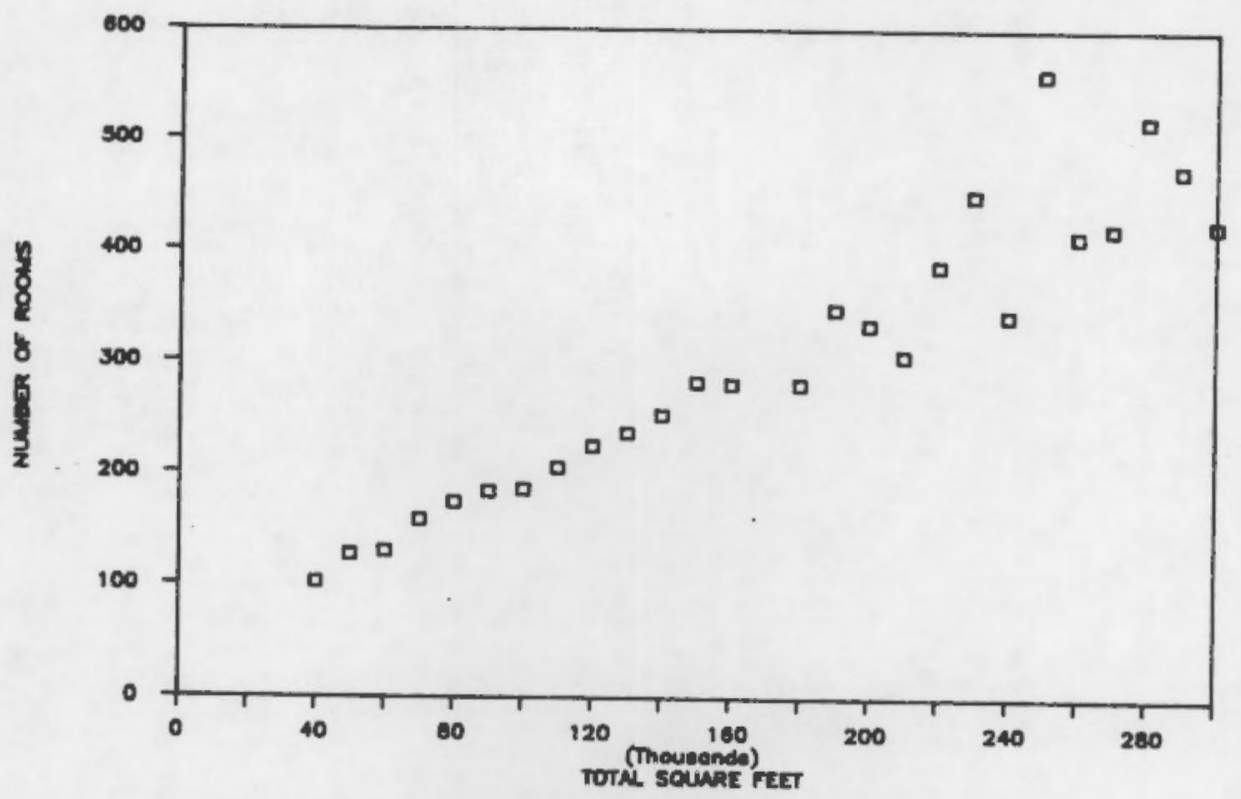

FIGURE C.11. Number of Rooms Versus Area

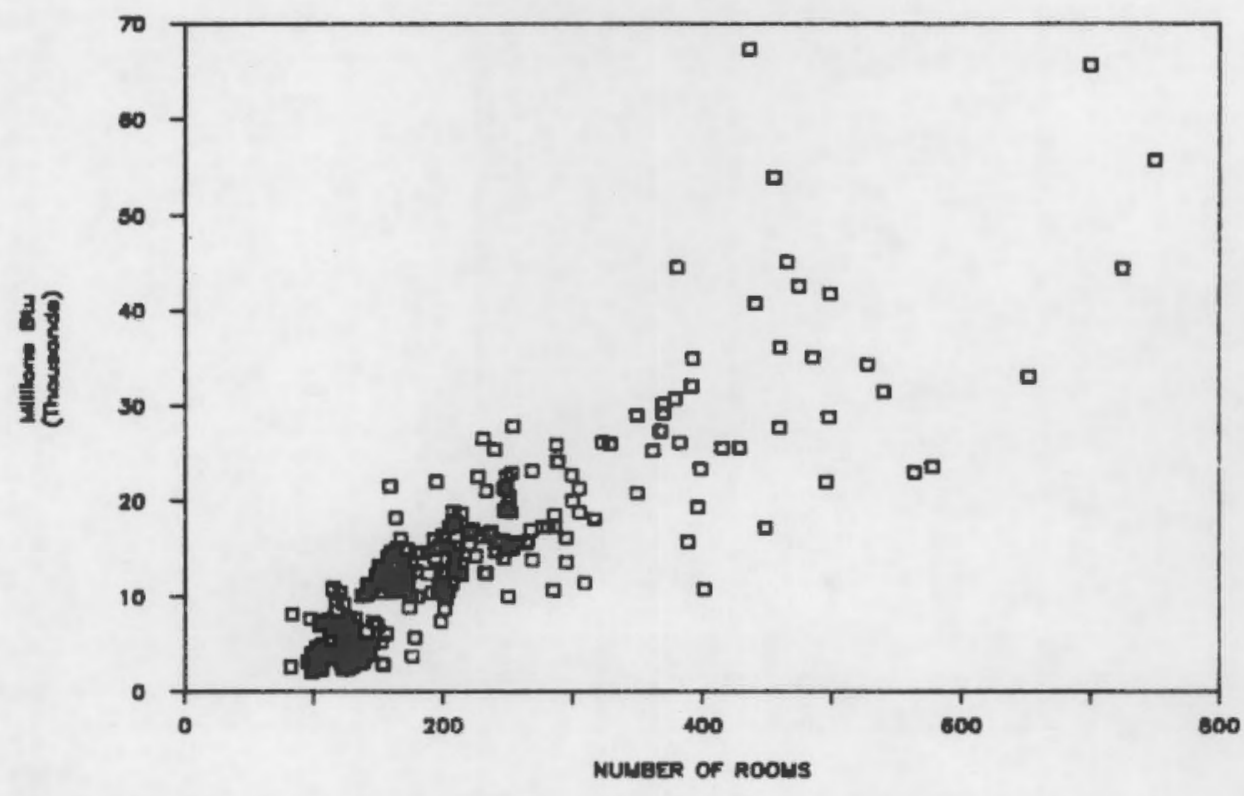

FIGURE C.12. Number of Rooms Versus Energy Use 


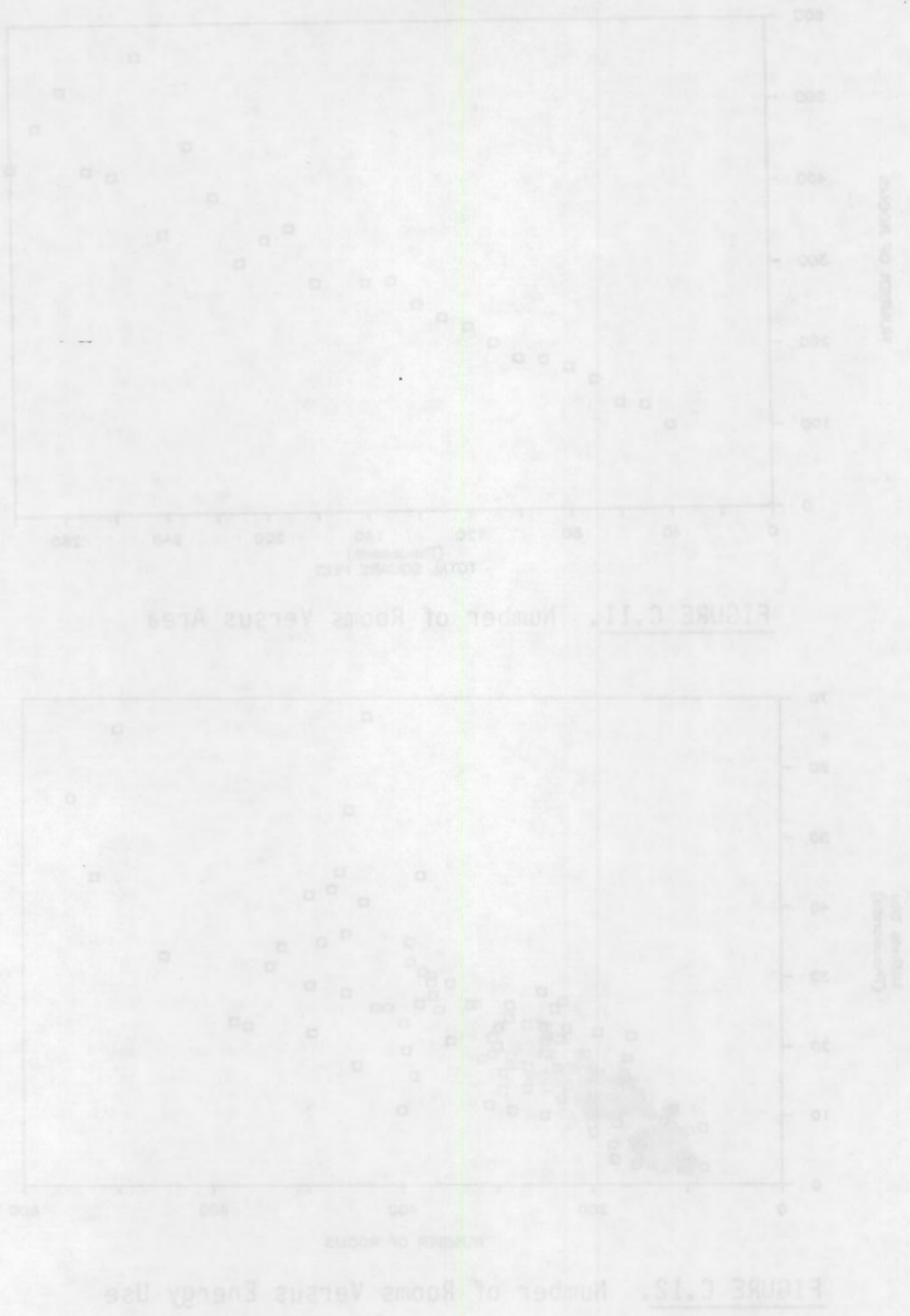


APPENDIX D

SURVEY OF ENERGY EXPERTS--SUPPORTING INFORMATION 
APPENDIX D

\section{SURVEY OF ENERGY EXPERTS--SUPPORTING INFORMATION}

This appendix contains sets of supporting data and information obtained from the survey of energy experts. The data include:

- a table of energy estimates obtained from respondents

- list of survey respondents

- letters from respondents expressing concerns about the survey in lieu of providing estimates.

\section{D.1 FULL TABLE OF ENERGY ESTIMATES OBTAINED}

Table 0.1 contains the full set of numerical results obtained from the respondents to the survey. Each row in the table consists of a separate set of estimates for a building type or subtype for a particular location or set of locations. The estimates have been arranged by major building category.

The respondents' names are not associated with specific responses. Most respondents provided from one to three estimates; however, a few respondents provided up to 10 sets of estimates for different building types.

Only data from the Energy Estimates page of the questionnaire are contained in Table D.1. The column furthest right in Table 0.1 contains numbers of notes that describe any special assumptions, supporting information, or special features that may influence interpretation of the estimates.

\subsection{LIST OF SURVEY RESPONDENTS}

Table $D .2$ contains the names of those survey respondents who did not request anonymity. 
TABLE D.1. Energy Estimates Obtained From Respondents

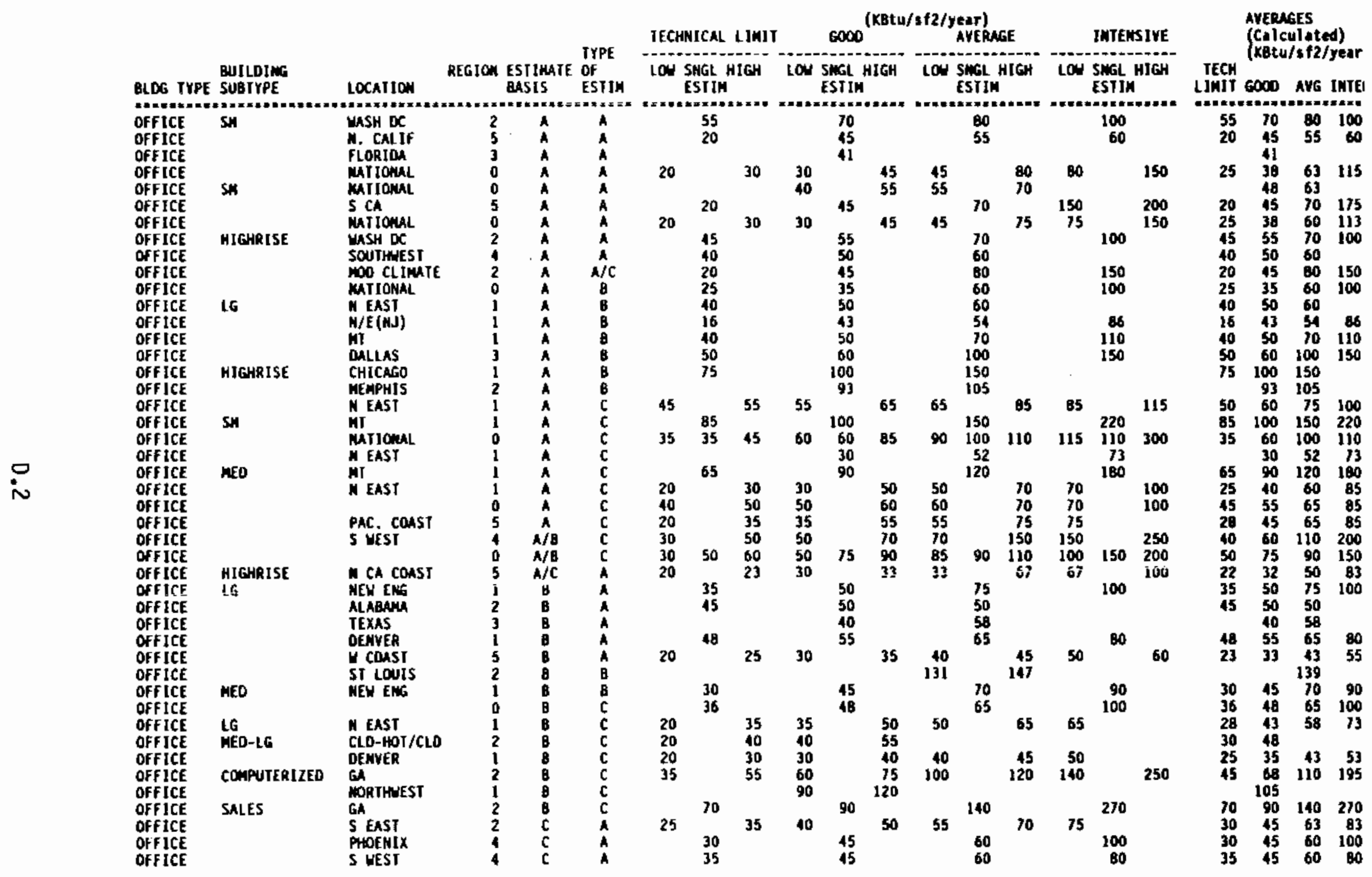


TABLE 0.1. (Contd)

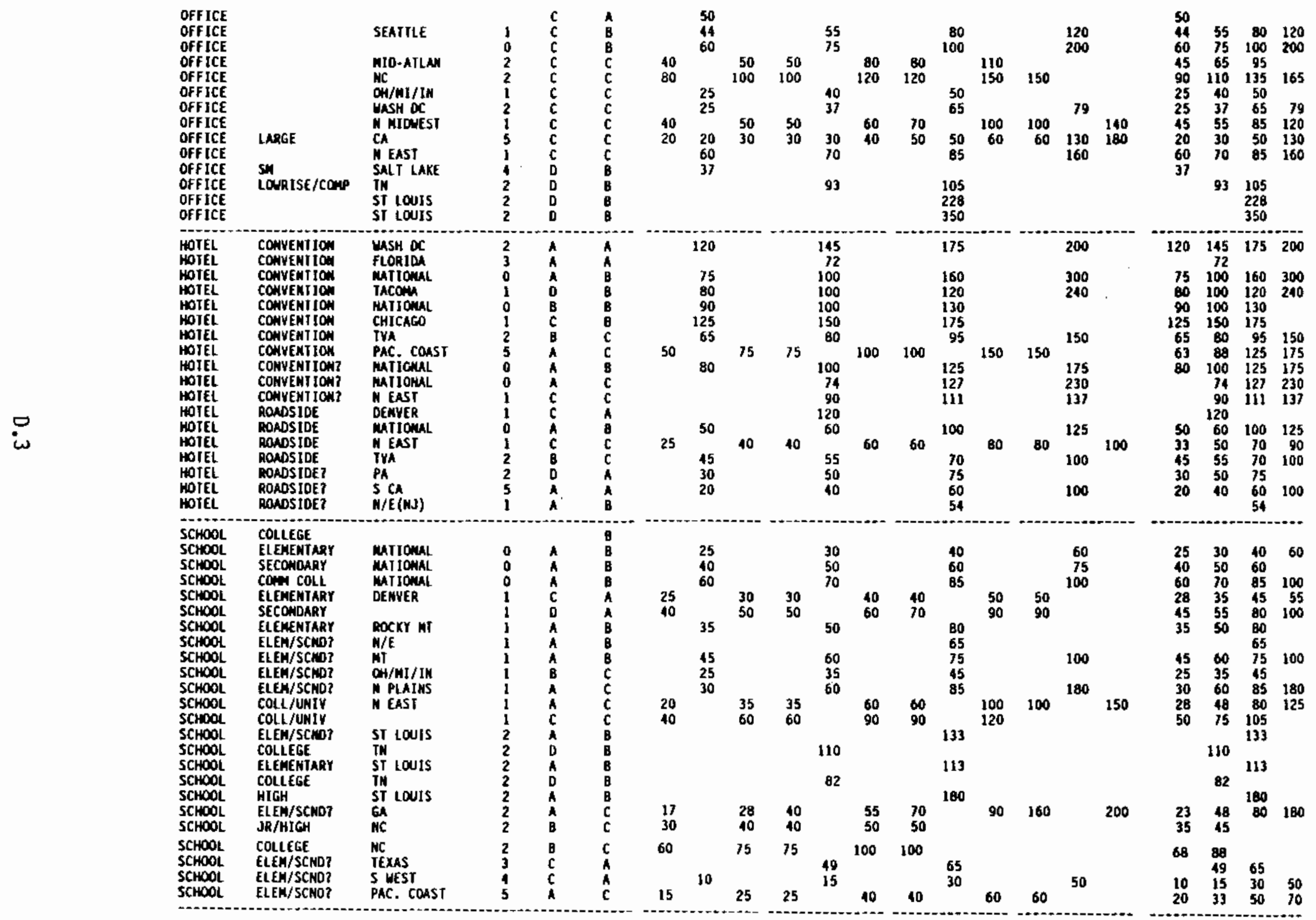


TABLE 0.1. (Contd)

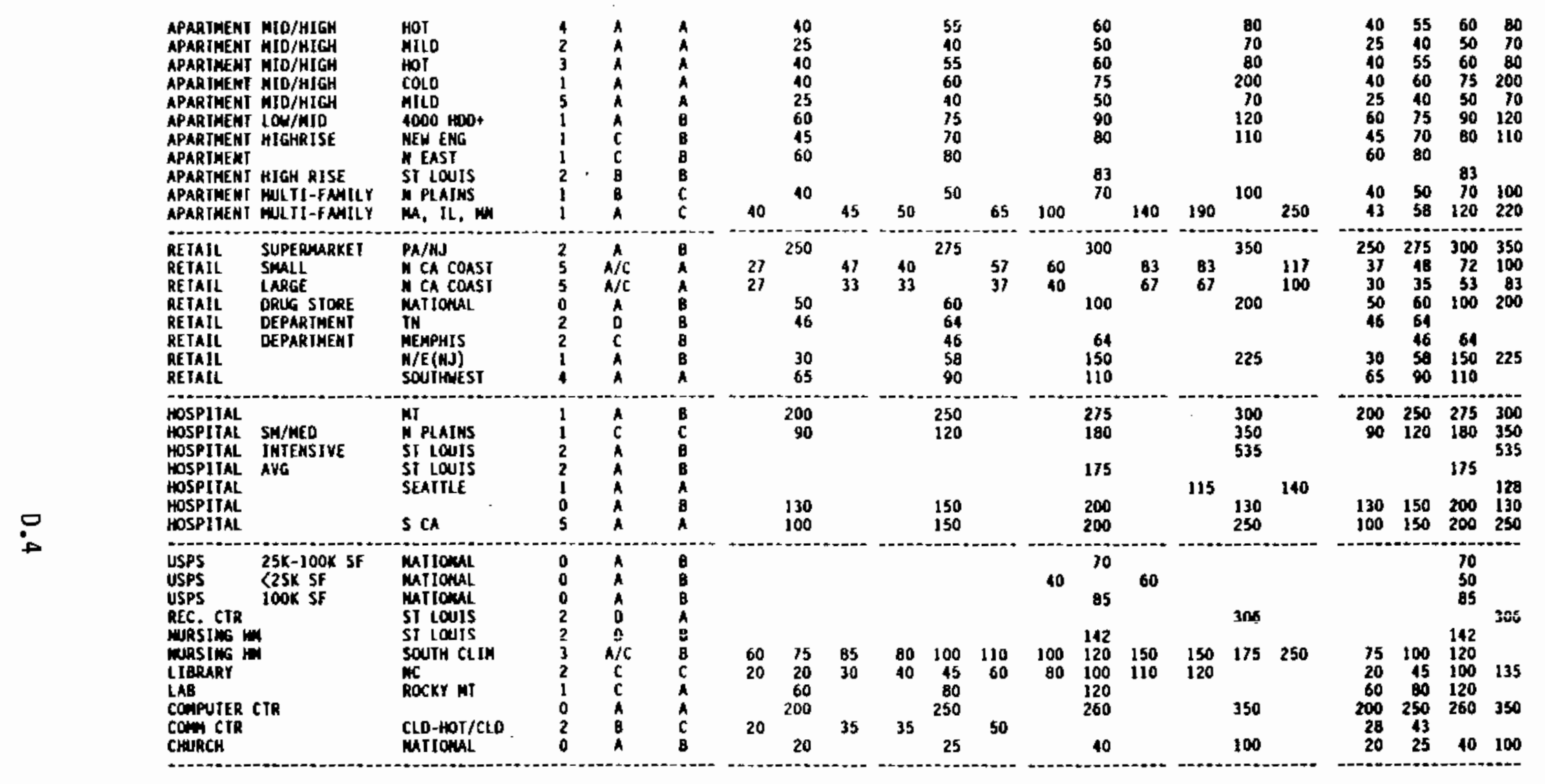


TABLE D.2. List of Survey Respondents

$\begin{array}{ll}\text { Anderson, John } & \text { Holton, John } \\ \text { Arnold, George } & \text { Holtz, Michael } \\ \text { Bickle, Larry } & \text { Hughes, Gene } \\ \text { Bobenhausen, Bill } & \text { Kalas, Jan AlA } \\ \text { Brandle, Kurt } & \text { Keb, Phil } \\ \text { Briggs, Robert } & \text { Kelbaugh, Doug } \\ \text { Brown, Peter } & \text { Knipe, Edward } \\ \text { Bruning, Steven F. } & \text { Levitt, Bruce } \\ \text { Bryan, Harvey } & \text { Mathews, Scott } \\ \text { Buehrer, Huber } & \text { Maybaum, Mike } \\ \text { Burr, Griffith C. } & \text { Mazria, Edward } \\ \text { Busch, Robert } & \text { Mehta, Laheri } \\ \text { Butkus, A. S. Jr. } & \text { Moore, Jim } \\ \text { Calthorpe, Peter } & \text { Murphy, Girard } \\ \text { Cook, Jeffrey } & \text { Nall, Dan } \\ \text { Crawley, Drury } & \text { Nelson, Norman } \\ \text { Cunnings, Richard } & \text { Nichiaides, Manny } \\ \text { Curtis, Alan } & \text { Pfister, Peter } \\ \text { Deringer, Joe } & \text { Prowler, Don } \\ \text { Diserens, Steve } & \text { Sayre, Tom } \\ \text { Eley, Charles } & \text { Sizemore, Mike } \\ \text { Felts, Don } & \text { Spielvogel, Lawrence G. } \\ \text { Ferreira, Francis } & \text { Tao, William } \\ \text { Franta, Greg } & \text { Thumann, Albert } \\ \text { Friberg, Emil } & \text { Watson, Donald } \\ \text { Grisson, Bill } & \text { Wilcox, Bruce } \\ \text { Hirsh, Jeff } & \text { Willman, Alex } \\ \text { Holder, Mac } & \end{array}$

\section{D.2 LETTERS FROM RESPONDENTS AND NON-RESPONDENTS}

The following three letters are from individuals who expressed concerns about the survey, potential use of survey results, or the development of whole building energy targets in general. The proposed approach for developing an energy targets procedure includes innovative features specifically intended to resolve a number of the long-standing issues facing whole-building energy performance standards, including the issues mentioned in the following letters.

In keeping with the survey approach, the letters are reproduced without the names of the originators. Also, a short selection of one letter that contained references to specific individuals has been deleted. 


\author{
REFLECTION \\ ON \\ REQUEST FOR JUDGMENT ABOUT BUILDING ENERGY PERFORMANCE LEVELS
}

The following are some of $\mathrm{my}$ thoughts in response to the survey request generated by the ASHRAE/AIA/IES joint research project to determine energy performance targets for new comercial building designs.

The cover letter of the survey asked the participants to: 1) Reflect on the request, 2) Answer the questionnaire, and 3) Review the survey results. Since I have nothing to offer in answering the questionnafre point by point, I can only reflect on the survey requests at this time.

As a professional engineer, I am committed to design, to the best of my knowledge and capability, energy efficient service systems for buildings. I am not, however, a believer in the need to develop energy performance targets.

The foremost reason against having performarce targets is that $I$ think of a building as a living thing. It is comprised of an innumerable amount of interacting influencing factors which make the energy performance of one building unique and the applicability of its energy target to another building purely incidental.

It is easy to develop tables and charts to establish performance targets, but it is virtually impossible to define all the influencing factors associated with such target numbers. To illustrate the point, I noticed that the questionnaire did not address the HVAC system type and lighting levels, which play vital roles in determining the energy target of a building. Without this information, the target loses its meaning. Surely we are not trying to compete in energy use with a poorly lit building without air conditioning!

The performance targets remind me of the answers to the exercise problems in the back of a textbook. The student does the problem, finds that the answer is wrong, and goes back to try to find out where he made the mistake. With the energy target, when the engineer finds that the building cannot meet the target performance, he goes back trying to modify the design so that the building will perform within the target number. There is a small difference between the two cases, however. With the answers in the textbook, the student is asked to find out what he did do wrong. With the target number, the engineer is asked to "beat" the number. The emphasis is shifted from how to design an energy efficient building to how to lower the budget number. The design process then becomes a numbers game.

Today, there are a number of computer programs available for an engineer to calculate an air conditioning load or to estimate the energy consumption of a building. It is quite easy for a young engineer to input a bunch of numbers, push a few buttons in front of the computer, and out comes a one number answer. Whether or not the young engineer is capable of judging the reasonableness of the answer is seldom questioned. One of the original goals for these computer 
programs, i.e., trying to relieve the engineers" mind from tedious manual calculations so that he can be free to analyze the results and be more creative in the engineering design, is lost. The performance target concept further emphasizes the "final" answer approach which I think is wrong.

For a given purpose of a building, it is the responsibility of the architects and engineers to design an energy efficient building for their client. So long as the engineer has designed the most energy efficient system for the building, he does not have to justify that the building meet or not meet a broad range performance target. An office building in which every occupant has a word processor and/or a computer terminal is bound to use more energy than another office building which has an ordinary occupancy. How many target are we going to set? How do we expect an engineer to justify his design and comply with which target number?

I have seen research papers comprised of nothing more than a housekeeping job of numerous computer runs. I have seen grants given to research on subjects that the practicing engineers understood for years in their daily practice. I have seen buildings with sophisticated automation control systems discarded in favor of time clock and/or manual control. I have seen buildings equipped with heat recovery systems abandoned because the maintenance personnel have no confidence to operate the system as designed. Performance targets will not help al leviate these problems. To the contrary, it will create more paper work for the engineers to play the numbers game and increase the opportunity for misunderstanding between architects-engineers and their clients.

I feel that instead of gathering information to formulate design targets, ASHRAE should spent a greater effort on basic research, to better the understanding between the academic community who conducts the research and the practicing engineers who understand the need for research. ASHRAE, together with AIA and IES, should also make an effort to communicate and educate the general public so that they understand the functions of the service systems in their building and the importance of energy conservation. Thus, they will know how to operate a building designed to run efficiently and will seek better qualified engineers to design their buildings, instead of demanding that the engineer come up with a design which meets a target number! 
January 29, 1986

Subject: Whole-Building Design Targets Project

I am responding to your letter of December 11, 1986 concerning the above survey, in the interest of making a statement on the issues as well as tying up loose ends. I think the issues are of major significance, and only hope a more reasoned approach may be established before irreparable harm occurs.

When I first got your letter, I considered it and the questionnaire in some depth. It was quickly apparent that to provide meaningful responses to the numerous questions would require significant effort and no little time. Since ASHRAE had apparently comitted itself formally to the venture I felt some pressure to proceed as requested, but then decided to evaluate things a little further and to discuss them with you when you called in mid-December. Having somehow missed connections on the call however, leaves me in the present situation.

In the meanwhile, I have continued to review the various ramifications of this project, and the more I think about it the more convinced I am that ASHRAE needs to withdraw completely from any association with it. The problem is that, in my considered judgment, the kind of data being sought does not and cannot realistically exist except for each and every individual building as it happens to exist and to be utilized. It is a rare case when data available to the designer concerning projected building usage, population, and operating schedules turn out to be accurate after the fact, and only the most random coincidence when his best estimate of actual building construction details, equipment full-load and part-load operating characteristics, and operator efficacy bear much resemblance to subsequent actuality.

Since the latter items have more influence on the actual energy consumption of the building in being than the more readily identifiable design decisions, any relationship between predicted and actual BTU per square foot per year is pure happenstance. To compound the felony, while the architectural profession has established a procedure for determining the "square foot area" of a building, no two individual practitioners in my experience ever do it exactly the same way, and all are tempted to inflate the numbers slightly to bring down their cost per square foot values. Intellectually this should be a solvable problem, but from practical experience I wonder if it actually is.

What we are left with then is the hope of being able to use certain "standard" building performance "data" expressed in BTU per year, divided by architectural "square feet", to produce a quantity against which various types of building designs could be measured and/or adapted to conform with. This is a very attractive theoretical idea in an energy-conscious society, and of course is that which prompted and supported the ill-fated BEPS adventure through the expenditure of quite a few millions of DOE dollars, but which fortunately died 
of its own weight a couple of years ago. Reliable numbers simply could not be generated in the design phase of a project which bore any resemblance to building performance after construction, once all of the actual variables of the building process, operational, and maintenance factors could finally be known.

This precise situation is of course the deadiy dangerous element which must at all costs be avoided. Everyone in the building profession is (or should be) painfully aware of the increasingly litigatious attitudes of the general population, and the corresponding virtual disappearance of liability protection for design professionals. Any building designer, particularly those with major influence over energy consuming systems and elements, will be totally dead in the water sooner or later as a result of being forced to "certify" maximum building energy consumption before the fact, which usage ends up being grossly exceeded by building owner/operators who are deviating tremendously from the original design concepts but are completely unaware (and uncaring) of that fact.

The disclaimer in the instructions you sent (or a hundred like it) to the effect that "The targets are not intended to dictate the levels of energy use which are required" wouldn't even be a finger in the dyke in today's courtrooms, where such wild inanities as "lost inheritance rights" are now being considered fair game for creative attorneys in "wrongful death" law suits.

I truly hate to be negative or obstructive in matters concerning ASHRAE, or society in general, particularly when I know that the individuals sponsoring this cause are dedicated and sincere. Unfortunately they are also badly misjudging reality, and ASHRAE needs to extricate itself from such a potential disaster area as quickly as possible.

Best regards, 
Date: December 30,1985

\section{SUBJECT: REQUEST FOR JUDGMENT CONCERNING ENERGY PERFORMANCE LEVELS}

Thank you for the opportunity to provide input to your project. While I have not answered the questions as specifically stated on your form, I have enclosed information concerning the building stock in Austin that may be formatted to produce data that I believe will be of interest to you.

We are currently engaged in a study, different from, yet analogous to yours, directed specifically at the area served by the City of Austin Public Utility. The Department that $I$ work in manages a broad range of demand-side programs targeted at comercial and residential customers of the Utility. Our specific objective is to obtain demand savings for the city in as cost-effective a manner as possible.

I would like to outline several practical problems that I foresee with creating energy-performance standards. These are stated in consideration of the information available to us, and what we feel are the needs of both the City and the owners of the comnercial buildings within the utility service area:

1. General Energy Design or Performance Standards (EDS) may not be we11suited to the interests of either a utility or a building owner, because they are not clearly related to total or component energy costs, or to the performance of conservation measures in specific buildings. It is not clear that they are a valid substitute for building-specific evaluation, in terms of providing realistic or cost-effective design goals for new buildings, or, if used as a regulatory or statutory device, that they will ensure that new buildings are designed in as energy-efficient a manner as possible;

2. Selection of a reasonable sample of representative buildings of adequate size ("a jury of peers") to determine average levels of energy use for a particular category of buildings (such that these will be meaningful when applied to new bujldings in the same category) is at best made on the basis of arbitrary criteria. The selection methodology must also take the effect of multiple occupancy, or uses, for single buildings and variations in fuel types and site conditions into account, to avoid categorizing buildings (envelopes) inappropriately. The sample will also require regular updating to reflect advances in building practices and conservation technology to remain valid over time. This greatly limits the usefulness of any standard based on simplified data selection and management, and suggests that the frame of reference for preparing such a standard should be local--city- or SMSA-specific--and that significant effort on a continuing basis would be required to establish and maintain a valid standard;

3. EOS may not be clearly related to the architectural or engineering design processes involved in building design, if the assumptions used 
to generate the standard are: a) overly general ("the average building of this type"); b) unavailable to the practicing designer, or expressed in a manner unrelated to the design professions "frame of reference; and c) not subject to manfpulation to reflect real design considerations involved in specific buildings, e.g., changes in hours of occupancy, or orientation and the shading effects of surrounding buildings, that can have significant effects on energy use, and result in variances between predicted performance and the standard. As with the Passive Solar Load Ratio procedure for residences, the accuracy and value of the procedure decreases as one departs from the assumptions upon which the procedure is based.

The Commercial Data Base (COB) project currently underway in my Department is intended to characterize the building stock in Austin, in a manner that facilitates the targeting of different segments of the commercial sector for Programs aimed at demand reduction. Each Program has its own analytical procedures for verifying the effectiveness of specific strategies at reducing peak demand, on a building-by-building basis.

The first attachment sumarizes the first phase of this research. Componentspecific energy-use and demand data will be determined through a combination of end-use metering and computer simulation. Information collated by the Planing and Growth Management Department of the City of Austin (summary attached) may be used to determine average sizes for different building types. The results of our investigation will eventualiy be published by the Resource Management Department, with appropriate caveats, to serve as a frame of reference for local design professionals ("Am I doing better or worse that average?"), but we do not anticipate that it will supplant the energy-related portions of the current municipal energy code.

Please let me know if I may be of further assistance. Thank you for your attention. 

APPENDIX E

ENERGY SOURCES 
APPENDIX E

ENERGY SOURCES

This appendix contains information on energy sources that is supplemental to Section 5 of this report. The 14 alternative energy source methods that were identified in Section 5 are divided in four groups and discussed in greater detail in the following sections.

\section{E.1 CONVERT TO THERMAL ENERGY AT SITE BOUNDARY}

The two methods described under this grouping use scientific heating values of energy forms to convert onsite quantities to energy units.

\section{E.1.1 Site Boundary Conversion to Thermal Energy Method}

With this widely used method, the annual quantity of each energy source used is converted to a common energy unit ( $\mathrm{Bt} u, k W h$, or $j$ ) and is summed. Only energy consumed within the site boundaries is considered, and conversion values are scientific, onsite heating values of each energy source (higher heating value for fossit fuels and $3413 \mathrm{Btu} / \mathrm{kWh}$ for electricity).

The strengths of this method are its quick development, ease of use, inexpensive maintenance, and familiar units. Very little new information is required to apply this method.

The method's weaknesses are the consideration of energy consumption, not demand; the favoring of electricity; and the bias against fossil fuels. This method does not directly reflect market forces.

\section{E.1.2 ASHRAE/IES Standard 90B-1975 (Section 10) Method}

This method was intended to be used to compare overall energy use of two building designs, a reference design complying with the prescriptive part of Standard 90, and a desired design. Since each design would be for same building project, the comparison could be in terms of $\mathrm{kj}$ or Btu rather than $\mathrm{kj} / \mathrm{m}^{2}$ or $\mathrm{Btu} / \mathrm{ft}^{2}$, i.e., floor area unitization is not needed. The conversion of each onsite energy source to energy units would be presumably involve the use of the 
method described in Section E.1.1 (onsite conversion losses included for fossil fuels, $3413 \mathrm{Btu} / \mathrm{kWh}$ for electricity). By using this method however, a designer is required to use the same energy forms for similar functions in both the reference and the desired design; therefore, it is not possible to meet a target simply by switching energy forms.

This method was originally developed and included in Section 10 of ASHRAE Standard 90 in 1975. This is the current method in effect for Standard 90 . It is used in the Model Code for Energy Conservation administered by code groups. As such, this code is applicable in well over 40 states. Section 10 was developed in response to those who desired a more flexible way to comply with Standard 90, versus following the prescriptive path. Section 10 prescribed an alternative path of comparing the energy use of a desired design to a design complying with the prescriptive requirements of Standard 90 .

Like the method described in Section E.1.1, this method can be developed quickly; it is easy to use, inexpensive to maintain, and the units are familiar to the buildings industry. As with the previous method, it considers energy consumption, not demand, and it does not directly reflect the market forces. However, this method however does prevent the bias against fossil fuels.

\section{E.2 CONVERT TO THERMAL ENERGY AT SITE BOUNDARY, BUT IGNORE FOSSIL FUEL CONVERSION LOSSES}

The two methods described in this section omit onsite combustion conversion losses after employing the methods described in Section E.1.

\section{E.2.1 Onsite Postconverion Adjustment Factor}

This method takes the energy units of the fossil fuel quantity required, applies a predefined adjustment factor; and adds the result to the onsite energy equivalent of annual electrical usage, using $3413 \mathrm{Btu} / \mathrm{kWh}$. The adjustment factor is intended to modify the fossil fuel energy to exclude fossil fuel-to-heat (i.e., combustion) conversion losses, that occur onsite. With electricity, conversion from raw resource to k.Wh occurs offsite at the power plant. Results are expressed in Btu/yr.ft ${ }^{2}$. The intent of this method is to put all energy forms on a "postconversion" basis. 
For the user, this method is relatively easy to understand and apply (e.g., $70 \% \times$ fossil fuel energy subject to conversion $x$ heating value). Targets that onit onsite fossil fuel conversion losses are also easy to develop using this method. This method also has the capability of comparing onsite fossil fuels and electricity, but only for heat-generating end uses. The method achieves neutrality among fuels by excluding onsite conversion losses for fossil fuels; in effect, the conversion losses for both fossil fuels and electricity are excluded.

This method does have some disadvantages: the target does not include complete onsite energy use, it takes an unfamiliar approach, and demand and social and environmental factors are not considered. The choice of the seasonal efficiency conversion factor is subjective and prone to differences of opinion; thus, the procedure is not necessarily repeatable. The targets do not consider conversion efficiency of onsite fossil fuel equipment. Conversion efficiency criteria would need to be addressed separately from the whole building energy targets (e.g., via ASHRAE Standard 90 component criteria).

\section{E.2.2 Omit Onsite Conversion Energy Losses Method}

This method is similar to the method described in Section E.2.1 except in cases where calculated or projected data are available. However, this method uses annual energy requirements destined to be provided by fossil fuel after conversion (i.e., combustion) equipment (e.g., the annual heating energy load requirements imposed on a heating boiler and/or a domestic water heater). Such load data are most likely available for a new building design on which an energy analysis is performed. As with previous method, the result is expressed in Btu/yr.ft ${ }^{2}$.

This method is relative simple to use, if an annual energy analysis providing the annual heating energy load on the conversion equipment has been performed. Targets that omit onsite fossil fuel conversion losses are easy to develop. This method can compare onsite fossil fuels and electricity only for heat-generating end uses. Because it uses actual computed loads as a basis for the conversion factor, the method is repeatable and more precise and accurate, than the Section E.2.1 method. By excluding onsite conversion losses for fossil fuels, the method attempts to achieve neutrality among fuels. 
The method has disadvantages that include: a somewhat unfamiliar approach; no complete onsite energy use; and no consideration of the conversion efficiency of onsite fossil fuel equipment, demand, and social and environmental factors. The method also requires the use of an annual energy analysis with specific output for annual energy loads on fossil fuel conversion equipment.

\section{E.3 CONVERT ENERGY RESOURCES TO THERMAL ENERGY AT THE RESOURCES LEVEL}

These three methods use scientific heat values to convert energy resource quantities to energy units.

\section{E.3.1 The U.S. Department of Energy's Institutional Grant Program Factor Method}

This method takes site boundary energy sources and converts them to common energy units (Btu) using $11,600 \mathrm{Btu} / \mathrm{kWh}$ for electricity instead of $3413 \mathrm{Btu} / \mathrm{kWh}$ to reflect offsite electricity conversion losses. The products are summed and the total is expressed in Btu/yr.ft ${ }^{2}$.

This method is similar others being used, but it has a value assigned to the electricity conversion factor. The purpose is to express both energy forms on a preconversion basis; fossil fuel would be left as is and electrical energy (in $\mathrm{kWh}$ ) would be converted to its raw (or resource) energy equivalent (Btu) before conversion at a power plant.

The method is simple to apply; the user multiplies all onsite electricity energy uses by $11,600 \mathrm{Btu} / \mathrm{kWh}$. Targets are easily developed with the offsite electricity conversion factor included. The method works toward neutrality by including an estimated average factor to account for the of fsite electricity conversion losses.

This method considers only energy, not demand, social, or environmental factors. The selection of the offsite electricity conversion factor reflects annual average electricity-generating efficiency, but it does not reflect variation in electricity-generating efficiency with respect to region, plant efficiency, or energy source. This selection may result in erroneous signals about 
electricity conversion efficiencies for specific regions, fuel sources and plants. The method favors fossil fuels as an energy source for building heating.

\section{E.3.2 QW Index}

Developed in the early years of the energy crisis, this method was published in a national technical magazine as a proposed way of comparing the energy performance of different types of buildings in different locations.

Although it normalizes targets for building operating hours and climate, the additional data required for the calculations are readily avajlable, and it attempts neutrality by including an estimated average factor to account for offsite electricity conversion losses, this method was never extensively used.

This method has a number of disadvantages for the user. The computations are much more complex than in the previous methods; the format (Btu/yr.ft ${ }^{2} \cdot \mathrm{DDh}$ ) for the targets would be unfamiliar to many users; and data on air-conditioned square footage would not be as readily available as gross square footage.

The disadvantages concerning the technical aspects are also numerous. Fan system operating hours only approximately indicate building operating hours. Cooling degree days can be a misleading normalizing factor for cooling energy; other parameters are needed as well. Some building energy use is not influenced by climate; therefore, dividing all energy by $D D$ is not always correct. Sumer heating and cooling DD often do not assume equal weight. This method considers only energy; demand, social, or environmental factors are not considered.

Like the method described in Section E.3.1, the selection of the offsite electricity conversion factor reflects annual average electricity generating efficiency, but it does not reflect variation in electricity generating efficiency with respect to region, plant efficiency or energy source. This selection may result in erroneous signals about electricity conversion efficiencies for specific regions, fuel sources and plants. The method favors fossil fuels as an energy source for building heating. 


\section{E.3.3 ASHRAE 90C-1977R--Resource Utilization Factors/Resource Impact Factors Method}

Unlike the current Section 12 that it was intended to replace, this method could be used to establish equivalence (compare buildings on the basis of energy use to each other or to a target). This method takes the quantity of each energy source in units of occurrence and, applying a Resource Utilization Factor (RUF), determines the equivalent quantity of raw energy resource (again, in units of occurrence) required to produce the site energy needed. This value is multiplied by 1--a Resource. Impact Factor (RIF). The RIF is determined for each energy resource as a Resource Energy Impact (REI), a dimensionless number which can be derived for any energy resource. Summing REIs yields Total Resource Energy Impact (TREI), which is the basis for comparison between energy resource options (thus establishing equivalence). A RUF is a multiplier applied to a quantity of onsite energy source units to determine the quantity or quantities of energy resource units needed to produce and deliver that energy source quantity to the site. The RUF is applied to each onsite energy source being considered. A RIF is a multiplier applied to a quantity of energy resource units expressing the relative impact of that energy resource, with respect to other energy resources, on the nation's well-being as affected by availability, social impact, economics, environmental acceptability and national interest issues.

The rationale is to account, not only for the physical energy characteristics of alternative energy sources and resources, but also the various societal effects.

This method provides the means to derive RUF numbers on a regional (or even a local utility company) basis. Actual numbers for RuFs are provided on a regional basis; they cover two sets of electricity supply regions as well as projections of RUFs for future years. This method represents the only known attempt to explicitiy and rigorously define societal impacts as part of comparisons among energy sources. The method, if applied properly, has no biases toward energy sources.

The weaknesses of this method, from the user's standpoint are its complexity, and the fact that it did not achieve ASHRAE consensus in public review as 
revision to Part $C$ or Section 12 of Standard 90 . The development of the RUF numbers is moderately complex; the development of the RIF numbers is quite subjective and hampered by technical and political difficulties; and the task of keeping the RUF and RIF data would be difficult. Regional values for RUFs and RIFs often ignore significant variations within regions at local utility levels.

\section{E.4 CONVERT TO DOLLARS, OR USE COST AS BASIS OF COMMONALITY}

The seven methods described in this section use cost instead of heating value as the basis for relating different onsite energy quantities. The following cost methods assume that cost reflects a reasonable common denominator among energy sources.

However well or poorly such considerations are reflected in energy costs, these factors are part of a cost approach. Therefore, cost-based approaches are significantly different from any of the methods that only use a form of Btu conversion factor for relating different energy sources. The use of dollars rather than energy units to relate different energy sources has a number of additional ramifications (information required, calculation methods, potential complexity, etc.). Some of the ramifications can be seen in the lists of pros and cons for the cost methods discussed below.

\section{E.4.1 Building Energy Performance Standards (BEPS)--Weighting Factors}

This method has similarities to method discussed in Section E.4.2, National Average Unit Cost. The BEPS energy budgets took the form of mandatory design energy budgets for different regions of the country and different building types. The energy performance for the proposed building was determined by multiplying the building's estimated energy use for each energy source by a weighting factor peculiar to that energy source, and then summing result to arrive at that building's design energy consumption. Building design complies with the design energy budget only if the design energy consumption is less than or equal to the design energy budget. Weighting factors were presented on national average basis and differed depending on energy source (e.g., 1.0 for gas, 1.2 for oil, and 3.08 for electricity). The intent for using weighting factors was to account for differences in market prices. 
This description relates only to the weighting factor method and does not address other aspects of BEPS. A detailed description of the weighting factor method is contained in Technical Support Document No. 4 (Weighting Factors) to BEPS (DOE 1979).

This method is relatively simple to apply, the user multiplies each onsite energy source by the appropriate weighting factor and sums the results. Once the weighting factors are determined, the targets are relatively simple to develop. The method also estimates complete of fsite inefficiencies for each energy sources.

The weaknesses of the method include the somewhat unfamiliar approach and the association of the method with the adverse public response to the BEPS program. The weighting factors are difficult to develop and would need to be updated regularly. The method considers only energy, not demand or time of day, and no explicit mechanism exists for considering societal impact.

The method is only neutral from a national perspective, not at the local application level. National averages lead to wide discrepancies for local or regional offsite inefficiencies, Large local biases would result which would give the wrong signal to owners and designers.

\section{E.4.2 National Average Unit Cost Per Energy Source Method}

A national average unit energy cost, applied to establish a basis of commonality among different energy forms on a given building, would be derived and promulgated for each of the the three or four major energy sources used in buildings. Unit energy source costs would be applied to convert one (or more) energy source quantities into the units of the other (Tike $\mathrm{Mft}^{3}$ to $\mathrm{kWh}$ ) or into common units ( 1 ike Btu), using the ratio of the relative unit costs to modify the normal conversion process:

$$
k W h_{\text {equivalent }}=k W_{\text {actual }}+M \mathrm{ft}^{3}{ }_{\text {actual }}\left(\frac{U E C_{\text {gas }}}{\text { DEC electricity }}\right)
$$

where UEC = unit energy cost 
As with any cost-based methodology, the rationale is to let actual cost of an energy form be the common denominator for relating that form to other forms or to a target. The BEPS weighting factor proposal was similar in using the national average price base.

This method is simple to use and fairly easy to develop and maintain. The method to arrive at a national average cost is probably technically unassailable. The weaknesses of the method include the necessity of periodic updating, and the lack of consideration for demand or the time of day. National average costs can produce very strong local and even regional biases that send incorrect signals to owners and designers.

\section{E.4.3 Regional Average Unit Energy Source Cost}

The rationale is similar to that of method described in Section E.4.1, but regional costs have the benefit of reflecting regional attributes of energy cost, and so are more likely to be applicable to any given building.

This method can be easily understood, there is a single regional average cost per energy source. The method is also fairly easy to update, it provides some differentiation among costs from region to region, and it less biased than the National Average Unit Cost Method.

The weaknesses of the method include the periodic updating of the data base. The data base for this method contains 8 to 190 times more data than the method described in E.4.1. This method does not address demand, only energy. Significant biases would still exist within regions causing incorrect signals to owners and designers.

\section{E.4.4 ASHRAE/IES Standard 908-1975R (Local Cost) Method}

The strengths of using this method are related to local energy costs, because they are very familiar to owners and to the buildings industry, and they influence most energy decisions. Local utilities may find market advantage in providing assistance to building owners and designers in calculating impacts of local costs in meeting targets. Energy targets are easily developed using local costs. Updating the data base is virtualiy automatic as changes in local energy costs constitute updates. This method considers social and environmental factors, demand, and time-of-day as well as all energy sources and 
regional differences. This method contains no biases for fuels other than differences in local costs, and it reflects market forces.

A weakness of the method is that the computation can get very complex, if for example, monthly demand charges and/or time-of-day charges are part of the local cost structure. Information requirements can also be complex. An ASHRAE consensus was attempted but not achieved because of differences about what items would be included in local costs. This method may also not yield a single energy cost per energy source unit.

An early attempt to did not spell out precisely how local costs were to be calculated and applied to specific building situations. Future energy costs could vary substantially from those in effect during the building design and biases may be introduced if all provisions of local cost rate schedules for each energy source are not included.

\section{E.4.5 Local Energy Source Cost (per Published Rate Schedule) Method}

Rate schedules from local utility companies would be the basis for obtaining cost information. This method includes all energy costs related to each energy source, including demand charges and time-of-day rates. Unless the rate schedule is very simple, an overall single cost-per-energy unit could not be taken from the schedule unless the building energy-use pattern were known.

A similar method was proposed for ASHRAE Standard 90B (Section E.4.4) but was not accepted. A modification of this method is being proposed in Section 9 of proposed ASHRAE Standard 90.1P. The method proposed here is stated in more detail than the $90 \mathrm{~B}$ revised version and to addresses the objections raised to that version.

As with the method described in Section E.4.4, the strengths of using this method are related to local energy costs, because they are very familiar to owners and to the buildings industry, and they influence most energy decisions. Local utilities may find market advantage in providing assistance to building owners and designers in calculating impacts of local costs in meeting targets. Energy targets are easily developed using local costs. Updating the data base is virtually automatic as changes in local energy costs constitute updates. This method considers social and environmental factors, demand, and 
time-of-day as well as all energy sources and regional differences. This method contains no biases for fuels other than differences in local costs and it also reflects market forces.

A weakness of the method is that the computation can get very complex, if for example, monthly demand charges and/or time-of-day charges are part of the local cost structure. Information requirements can also be complex. An ASHRAE consensus was attempted but not achieved because of differences about what items would be included in "local costs." This method may also not yield a single energy cost per energy source unit. Future energy costs could vary substantially from those in effect during the building design.

\section{E.4.6 Marginal Cost Method}

One strength of the marginal cost method is that it can be selfupdating. This method also portrays the true utility cost of additional energy supply more accurately than actual prices. The method is quite sensitive to local situations; for example, utilities needing generating capacity tend to have higher marginal costs, while excess capacity utilities have very low marginal costs.

Marginal cost forecasts are extremely complex and variable, and may not always be publicly available. Marginal costs may also be dramatically higher or lower than actual rates, which leads to user confusion. There are no standardized or established methods of estimating marginal costs, and it could be difficult and expensive to develop procedures and data bases.

\section{E.4.7 Tota] Owning and Operating Cost Method}

Since energy costs can frequently be profitably offset by increased first costs, TOOC methods can automatically yield (based upon input assumptions) optimum cost-effective energy design by specifically addressing the tradeoffs between first costs and ongoing energy and operations costs. Total owning and operating cost methods, by their nature, present cost-effective design solutions. In addition, TOOC methods can best represent owner needs since the methods are based upon owner's financial outlook. These methods assume that overall owning and operating costs are true common denominator of commonality between energy sources and conservation. 
The use of TOOC calculations benefit the user by giving building owners a more reliable cash flow projection, which may justify more favorable financing; encouraging a long-range view of building design by placing first-cost considerations in the proper context; and having the capability to be customized to meet highly specialized owner needs. The T00: method can be the most flexible of all design approaches, by permitting the simultaneous evaluation of all building decisions, including non-energy items.

While TOOC methodologies are straightforward, their data inputs are sometimes variable and difficult to obtain. Users unfamiliar with TOOC methods may regard them as complex. Design targets developed with TOOC methods are highly dependent on nonenergy-related cost factors, such as interest rates. 


\section{DISTRIBUTION}

No. of

Copies

OFFSITE

30 DOE Technical Information Center

L. G. Bellenger

Donald McGeddy, P.E., P.C. 890 Westfall Road

Rochester, NY 14618

D. A. Beranek

U.S. Army Corps of Engineers

P.D. Box 103, Downtown Station Omaha, NE 6B1D1

B. Birdsall

Lawrence Berkeley Laboratory

1 Cyclotron Road, Bldg. 90

Berkeley, CA 94720

B. Bobenhausen

Energy Design Collaborative

529 Central Avenue

Scarsdale, NY 10583

5 J. Boulin

Office of Buildings and

Comonunity Systems

U.S. Department of Energy

1000 Independence Ave., SW

Washington, DC 20585

J. R. Brodrick

Gas Research Institute

8600 West Bryn Mawr

Chicago, IL 60631

H. J. Bryan

Harvard University

48 Quincy Street

Cambridge, MA 02138
No, of

Copies

F. 8ueh1

Lawrence Berkeley Laboratory

1 Cyclotron Road, 81dg. 90

Berkeley, CA 94720

H. H. Buehrer

Buehrer Group

122 East Dudley

Maumee, $\mathrm{OH} 43537$

R. Busch

AREA, Inc.

7428 El Morro Road, NE

Albuquerque, NM 87109

M. E. Carr

Office of the Secretary of

Defense

DASD (L\&MN), The Pentagon

Washington, DC 20301

C. Claar

Pennsylvania State University 104 Engineering "A" Building

University Park, PA 16802

D. Claridge

Texas A\&M University

Department of Architecture

College Station, TX 77843

J. Clarke

ABACUS

Department of Architecture

University of Strathclyde

131 Rottenrow

Glasgow G4 ONG

SCOTLAND

D. R. Conover

NCSBCS

481 Carlisle Drive

Herndon, VA 22070 
No. of

Copies

B. J. Davids

Southwall Technologies

1029 Corporation Way

Palo Alto, CA 94303

L. 0. Degelman

Texas A\&M University

Department of Architecture

College Station, TX 77843

$3 \mathrm{~J}$. Deringer

The Deringer Group

335 Cove Road

Riva, MD 21140

H. K. Diemer

Flack and Kurtz

$475 \mathrm{Fifth}$ Avenue

New York, NY 10017

D. L. DiLaura

Lighting Technologies

3060 Walnut Street, $\$ 209$

Boulder, CO B030l

8. Donaldson

Tishman Research Corporation

666 Fifth Avenue

New York, NY 10103

C. Eley

Charles Eley Associates

142 Minna Street

San Francisco, CA 94105

S. Ellinwood

Scott Ellinwood and Associates 3639 Harbor B1vd.

Ventura, CA 93001

M. Fagerson

University of Minnesota

110 Architecture

Minneapolis, MN 55455
No. of

Copies

D. Felts

Don Felts and Assocjates

1 Loop One

Albuquerque, NM 87120

C. Fernandez

Hi) USAF/LEEEU B1dg. 516

Bolling Air Force Base

Washington, DC 20332

W. S. Fisher

General Electric Company

Nela Park

Cleveland, $\mathrm{OH} \quad 44112$

$H$, S. Fraker

University of Minnesota

School of Architecture

Minneapolis, MN 55455

G. Franta

ENSAR Group

$2820 \mathrm{E}$. Fifth Avenue

Oenver, CO 80206-4306

C. Gardner

Office of Buildings and Community Systems

U.S. Department of Energy

1000 Independence Ave., SW

Washington, DC 20585

D. B. Goldstein

Natural Resources Defense Council

25 Kearny Street, Suite 200

San Francisco, CA 94108

H. Gordon

Burt, Hill, Kosar, Rittelmann Associates

440 lst St. NW, Suite 500

Washington, DC 20001

G. C. Groff

P.0. Box 556

Cazenovia, NY 13035 
No. of

Copies

D. L. Grumman

Grumman/Butkus Associates

500 Davis Street

Evanston, IL 60201

J. P. Harris

Buldings Energy Data Group

Applied Science Division

Building, 90-H

Lawrence Berkeley Laboratory

University of California

Berkeley, CA 94720

J. E. Hill

National Bureau of Standards Building 226, Room B306

Gaithersburg, MD 20899

A. V. Hinge

New York State Energy Office

Two Rockefeller Plaza

Albany, NY 12223

J. Hogan

City of Seattle

400 Municipal Building

Seattle, WA 9B104

J. Holton

Burt, Hill, Kosar, Rittelmann Associates

440 First Street, NW, $\$ 500$

Washington, DC 20001

B. Hunn

University of Texas at Austin 10100 Burnet Road

Austin, TX 7875B

$3 \mathrm{~J}$. Jones

University of Texas at Austin Engineering Teaching Center

Austin, TX 78712
No, of

Copies

J. E. Kaufman

Illuminatfng Engineering Society

345 East 47 th Street

New York, NY 10017

R. M. Kelso

University of Tennessee

School of Architecture

Knoxville, TN 37916

E. Kennett

AIA Foundation

1735 New York Avenue, NW

Washington, DC 20006

S. Kimsey

Heery Energy Consultants, Inc. B80 West Peachtree St., NW Atlanta, GA 30367

T. Kurkowski

U.S. Department of Energy 1000 Independence Ave., SW

Washington, DC 20585

R. A. Kutina

American Gas Association

1515 Wilson Bivd.

Arlington, VA 22209

L. Lawrie

U.S. Corps of Engineers

P.0. Box 4005

Champaign, IL 61B20

M. Lee

Marlene Lee Lighting Design

153 Kearny Street

San Francisco, CA 94108

R. C. LeVere

Manville Prod. Corp.

P.0. Box 51098

Denver, CO 80217 
No. of

Copies

H. Lobdell

Lithonia Lighting

Post Box "A"

Conyers, GA 30207

v. Loftness

Carnegie-Mellon University

Department of Architecture

Pittsburg, PA 15213

B. T. Maeda

California Energy Comission

1516 9th Street, MS-25

Sacramento, CA 95814

S. Mathews

334 E. 91st Street \#5E

New York, NY 10128-5340

M. Maybaun

Cosentini

2 Pen Plaza

Suite 2750

New York, NY 10121

M. McBride

Owens Corning Fiberglas

Technical Center

Granville, $\mathrm{OH} 43023$

J. A. McCarty

U.S. Army Corps of Engineers, $\mathrm{HQ}$

20 Mass Avenue, NW

Washington, DC 20314

M. McCloskey

Lighting Technologies

1568 S. Bradley Drive

Boulder, CO 80303

K. M. McGrath

Edison Electric Institute

1111 Nineteenth Street, NW

Washinton, DC 20036
No. of

Copies.

3 H. N. Mckay

Howard Brandston Lighting

Design

141 West 24th Street

New York, NY 10011

L. Meht a

Syska and Hennesey, Inc.

11 W. 42nd Street

New York, NY 10036

J. Millhone

Office of Buildings and

Community Systems

U.S. Department of Energy

1000 Independence Ave., SW

Washington, DC 20585

H. P. Misuriello

HS. Fleming and Associates, Inc.

P.0. Box 15442

Wastington, DC 20003

N. R. Patterson

The Trane Company

3600 Panmel Creek Road

La Crosse, WI 54601

J. Peterson

University of Texas at Austin

10100 Burnet Road

Austin, TX 78758

G. H. Reiling

General Electric Company

Nelan Park

Cleveland, $\mathrm{OH} 44112$

R. Rittelmann

Burt, Hill, Kosar, Rittelmann Associates

400 Morgan Center

Butler, PA 16001 
No. of

Copies

S. J. Rohr

John Weidt Associates

$110 \mathrm{~W}$. Second Street

Chaska, MN 55318

W. W. Seaton

ASHRAE, Inc.

1791 Tullie Circle

Atlanta, GA 30329

S. Silver

University of Texas at Austin 10100 Burnet Road

Austin, TX 78758

J. A. Smith

U.S. Department of Energy

1000 Independence Ave., SW CE-131

Washington, DC 20585

R. H. Socolow

Princeton University

Center for Energy and Environ. Study

Princeton, NJ 08544

$R$. Sonderegger

Morgan Systems Corporation

1654 Solano Avenue

Berkeley, CA 94707

L. G. Spielvogel

Lawrence G. Spielvogel, Inc. Wyncote House

Wyncote, PA 19095

W. K. Tao

William K. Tao and Associates 2357 - 59th Street

St. Louis, MO 63110

S. T. Taylor

Linford Engineering Company

P.0. Box 449

0akland, CA 94604
No. of

Copies

K. Teichman

U.S. Department of Energy

1000 Independence Ave., SW

Washington, DC 20585

T. Todd

Engineering Sciences, Inc.

2701 Union Ave., Extd, Suite 200

Memphis, TN 38112

A. J. Van den Berg

Edison Electric Institute

1111 Nineteenth Street, NW

Washington, DC 20036

T. Vonier

Thomas Vonier Associates, Inc.

3741 W. Street, NW, Suite 200

Washington, DC 20007

E. Watkins

U.S. Navy - EP03A

200 Stovall Street

Alexandria, VA 22332

D. Watson

P.0. Box 401

Guilford, CT 06437

J. W. White

Engineering Consultants, Inc.

409 Cook Road \#300

Fort Wayne, IN 46825-3650

B. Wilcox

Berkeley Solar Group

3140 Martin Luther King Jr. Way

Berkeley, CA 94703

A. Willman

ACEC/Research and Management

Foundation

1015 15th Street, NW, Suite 802

Washington, DC 20005 
ONSITE

DOE Richland Operations Office

J. J. Sutey/O. R. Segna

38 Pacific Northwest Laboratory

P. K. Alley

R. S. Briggs

D. B. Crawley (25)

E. S. Edin

R. W. Reilly

T. J. Secrest

K. R. Taylor

Publishing Coordination MH (2)

Technical Report Files (5) 